A Multidisciplinary Palaeoenvironmental Reconstruction of the Campanian Foremost Formation of Southern Alberta

\author{
by \\ Michael Glen Wenstob Thompson
}

A thesis submitted to the Faculty of Graduate and Postdoctoral Affairs in partial fulfillment of the requirements for the degree of

\author{
Master of Science \\ in \\ Earth Sciences
}

Carleton University

Ottawa, Ontario

(C) 2018, Michael Glen Wenstob Thompson 


\begin{abstract}
The Foremost Formation of southern Alberta, Canada, is the basal member of the Cretaceous (Campanian) Belly River Group, and has been understudied relative to the overlying Oldman and Dinosaur Park formations of this group. Examined outcrop of the upper Foremost Formation preserves coastal estuarine or barrier island/lagoonal environments that transition upward into more inland coastal/ fluvial plain environments during the Claggett marine regression of the Western Interior Seaway. A low abundance, low diversity agglutinated benthic foraminiferal fauna, together with whole rock geochemical proxies, suggests commonly stressed oxygen and salinity conditions in marginal marine environments. Vertebrate microsite faunas display a primarily brackish water environmental influence, with an increase in diversity upsection in conjunction with increased terrestrial deposition. Hadrosaur remains suggest the previously unknown presence of kritosaurs and potentially a basal hadrosauroid, suggesting that the Foremost Formation dinosaur fauna was similarly diverse compared to faunas of well-characterized Campanian formations in North America.
\end{abstract}




\section{Acknowledgments}

My genuine thanks go out to Dr. Claudia Schröder-Adams and Dr. Michael Ryan for giving me the opportunity to work on such an exciting, multidisciplinary project and for their knowledge, advice, and encouragement throughout my time at Carleton University. I'd like to thank Kieran Shepherd and Margaret Currie at the Canadian Museum of Nature and Brandon Strilisky at the Royal Tyrrell Museum for allowing access to their institution's vertebrate fossil collections and for the assistance they gave me during my research. I thank Dr. David Eberth and Dr. Don Brinkman for doing preliminary sample preparation for my microvertebrate material. I thank the graduate students of Carleton University for their friendship and comradery and the staff and faculty of the Earth Sciences Department for their constant support and hard work. Greg Froude is thanked for always being up for a friendly conversation about our work, birding and everything in between. Thanks goes to Dr. Hillary Maddin and her students, who invited me to many lab meetings, shared insightful advice and information and made me feel very welcome in their group. Special thanks to the Southern Alberta Dinosaur Project 2016 and 2017 field crews for their accommodations and assistance in the field and for making my field experiences some of the best memories I will ever have. Thank you to my committee members, Dr. Jordan Mallon and Dr. Quentin Gall, for their input regarding this thesis and its defense, and thanks to my defense chair Dr. Hanika Rizo for overseeing. My most heartfelt thanks are reserved for my parents, Linda and Murray, my brother Adam, my dog Lexi and the rest of my family and friends for their constant support regarding this degree and everything else I've ever wanted to do. 
This research was supporting by an NSERC Discovery Grant awarded to Dr. Schröder-Adams. Field work and conference travel was supported by a Paleontological Society Student Grant and a Dinosaur Research Institute student grant. Accommodations in the field were provided by Dr. Michael Ryan and Dr. David Evans and their funding form the Cleveland Museum of Natural History and the Royal Ontario Museum, respectively, for the Southern Alberta Dinosaur Project. 


\section{Table of Contents}

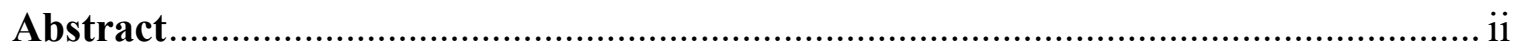

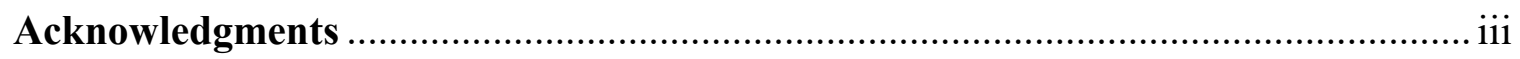

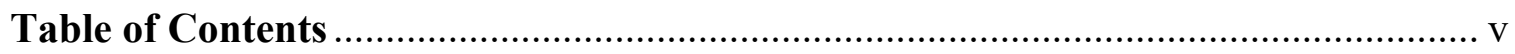

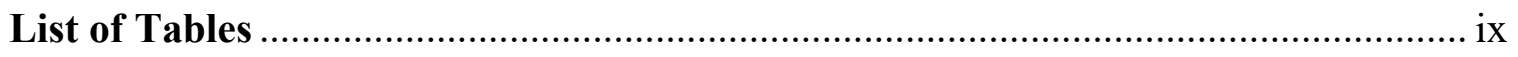

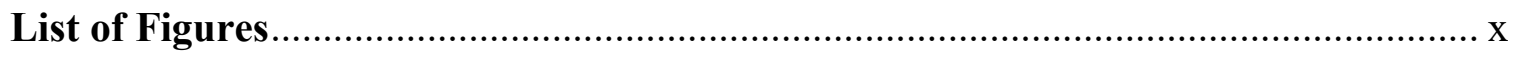

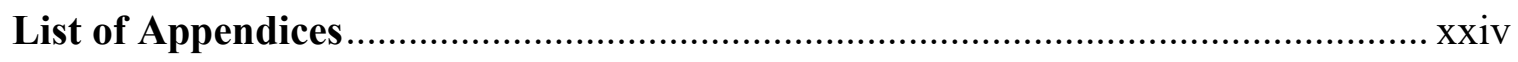

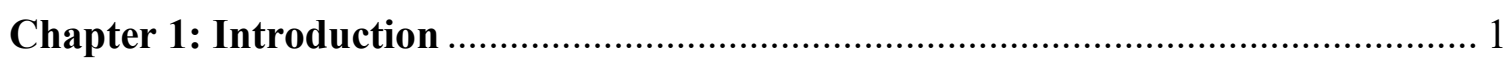

1.1: Geology and Stratigraphy of the Belly River Group and the Foremost

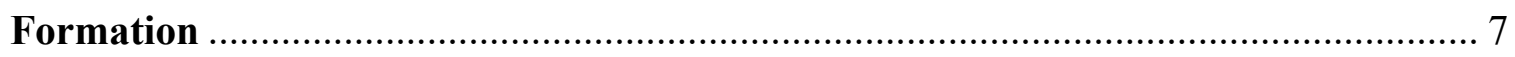

1.2: Foraminiferal Studies of the Foremost Formation........................................ 10

1.3: Geochemical Studies of the Belly River Group.......................................... 11

1.4: Vertebrate Microsite Analyses from the Belly River Group ........................... 12

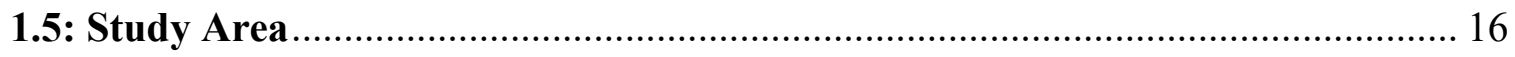

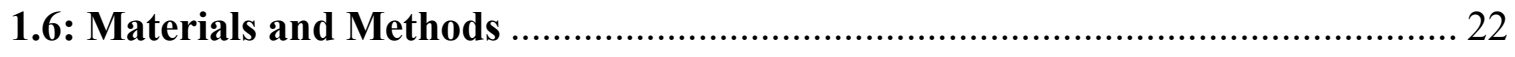

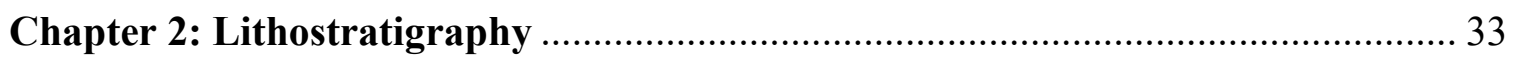

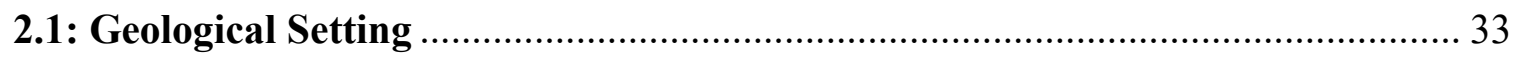

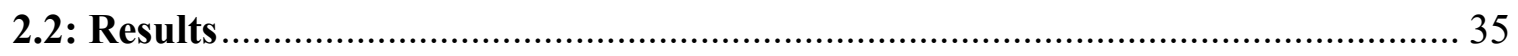

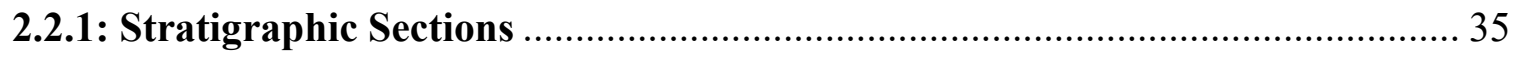

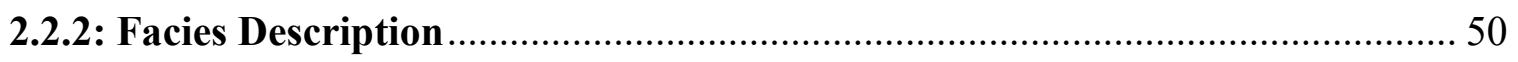


Chapter 3: Foraminiferal Assemblages of the Foremost Formation ....................... 70

3.1: Foraminiferal Zonation of the Foremost Formation..................................... 70

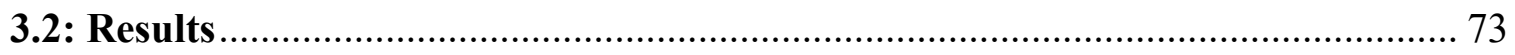

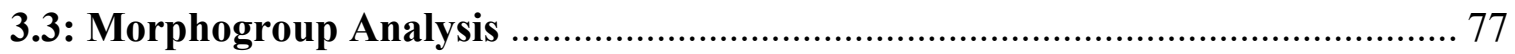

3.4: Morphogroups and Palaeoenvironmental Significance of Assemblages ........... 79

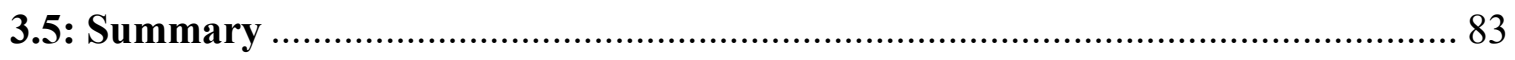

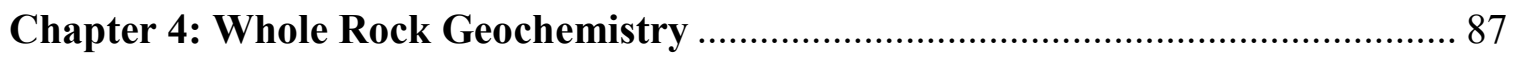

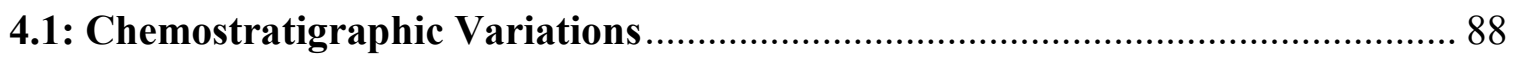

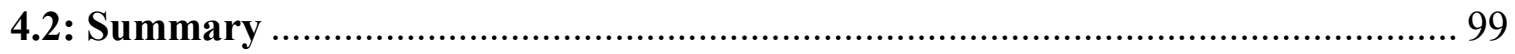

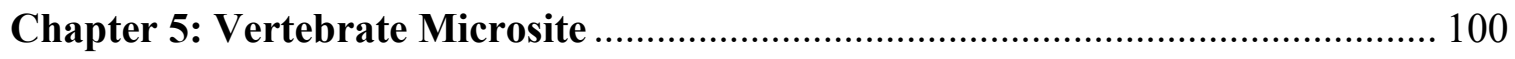

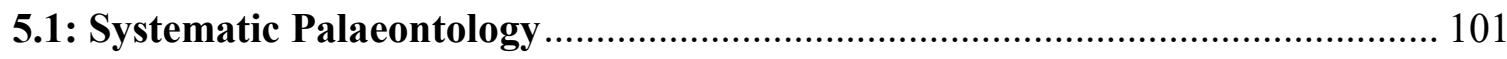

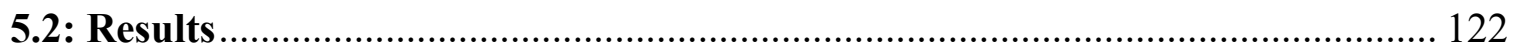

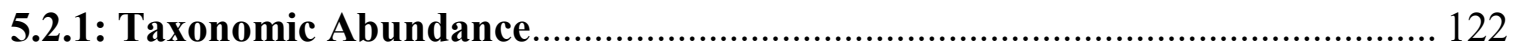

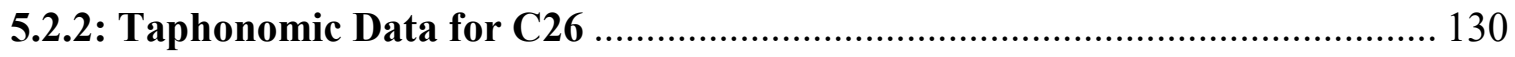

5.3: Comparison of Vertebrate Microsites from the Foremost Formation with C26

5.4: Belly River Group Microsite Assemblage Comparisons............................... 141

5.5: Dinosaur Abundances of the Belly River Group based on Microsite Data..... 155 
5.6: Dinosaur Assemblages of the Foremost Formation Based on Macrofossils..... 164

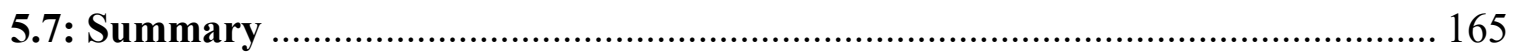

Chapter 6: Hadrosaurs of the Foremost Formation.......................................... 167

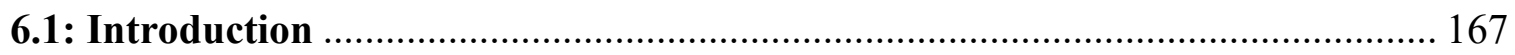

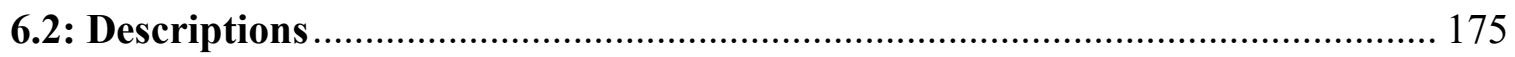

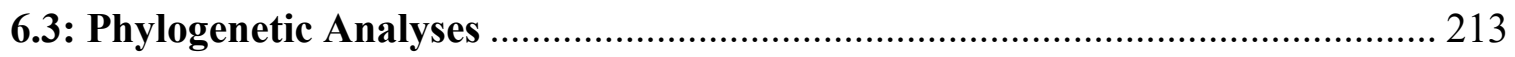

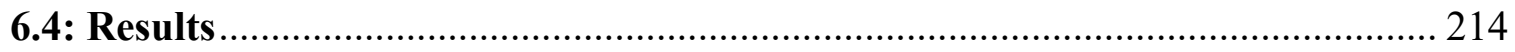

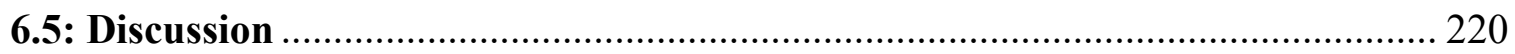

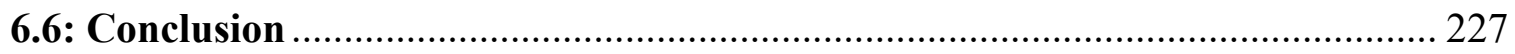

Chapter 7: Interpretations and Discussion...................................................... 230

7.1: Sequence Stratigraphy of the Foremost Formation in the Pinhorn Ranch Area

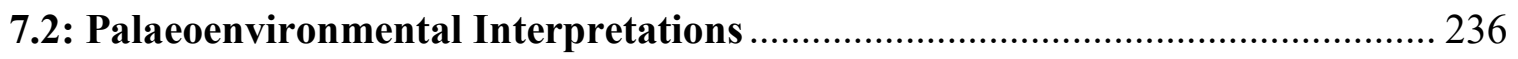

7.3: Foraminiferal Assemblages of the Foremost Formation and their

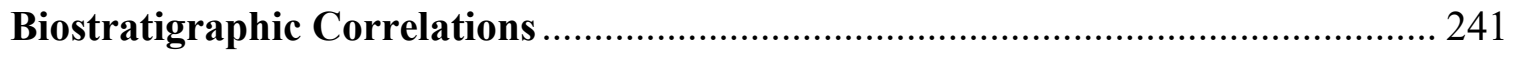

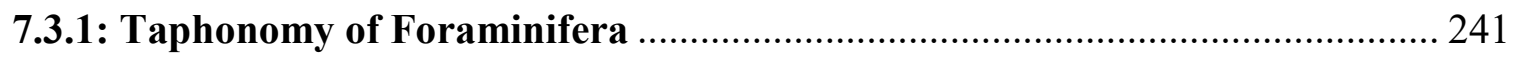

7.3.2: Foraminifera Biostratigraphic Zonation and Faunal Comparison of the

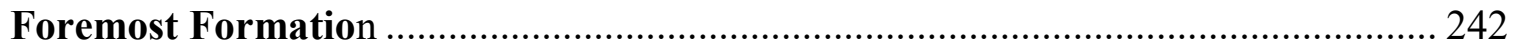

7.4: Microvertebrate Faunas of the Foremost Formation and the Belly River Group 
7.5: Dinosaur Palaeoecology of the Foremost and Comparisons to the Belly River Group based on Vertebrate Microsite Localities .................................................. 245

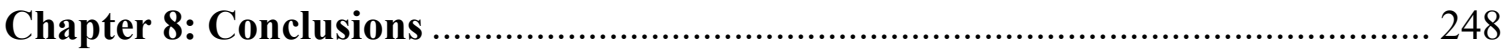

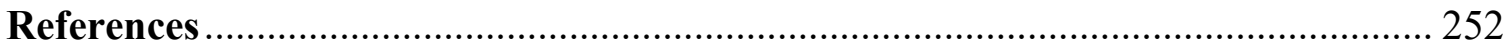

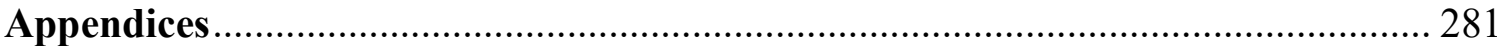




\section{List of Tables}

Table 1.1: List of examined hadrosaur macrofossil material in this study

30

Table 2.1: Table outlining a summary of facies names and interpretations as identified within Chapter 2 of this study

Table 5.1: Stages of fossil material abrasion collected from vertebrate microsite C26 based on Fiorillo (1988), Cook (1995) and Phillips (2009)....

Table 5.2: Table showing the vertebrate taxa included within the 11 categories used in the relative abundance pie charts in this study (Fig. 5.2; Fig. 5.5.13; Fig. 5.19; Fig.

Table 6.1: Age class assignments of examined hadrosaur specimens based on the criteria of Horner et al., (2000)

Table 6.2: Measurements of individual elements of CMN 9951. Length=Proximodistal measurement, width= mediolateral (top row) and craniocaudal (bottom row) measurements. Only mediolateral was taken for Digit II as it was too damaged to handle outside of its jacket. .209

Table 6.3: Individual element measurements for $\mathrm{CMN}$ 9951. Height= Proximodistal measurement, width=mediolateral measurement and length $=$ craniocaudal measurement. 


\section{List of Figures}

Figure 1.1: (see page 18): Locality map of study area modified from Cullen et al., (2016). A: Map of Alberta relative to Canada, and area of study, relative to Alberta, as represented by the grey rectangle. B: Aerial view of study area, including locations of nearby settlements and rivers. Red rectangle indicates area containing my section (marked by C26) and the locations of adjacent vertebrate microsites discussed in this study. C: Aerial view of Pinhorn Ranch site along the Milk River in southeast Alberta. Sections measured in the field are marked by letters A through E corresponding to their names (Map data (C2017 Google Earth).

Figure 1.2: Simplified stratigraphic relationships of the Belly River Group with approximate ages (from Renne et al., 2010) compared to equivalent formations of

Northern Montana.

Figure 1.3: Simplified general zonation of the Foremost Formation and lower Oldman Formation in the Milk River area compared to informally named units of Ogunyomi and Hills (1977) and Kwasniowski and Eberth (1993) and their previous palaeoenvironmental interpretations. 20

Figure 1.4: Santonian to Maastrichtian lithostratigraphic correlations within the Southern Canadian Western Interior Seaway from the Alberta Foothills to Southern Manitoba based on Dawson et al. (1994) and Catuneanu et al. (2000). Foraminifera biostratigraphic zonations are based on Caldwell et al. (1978).

Figure 2.1: Legend for the Stratigraphic Section illustrations presented in this study... 36 
Figure 2.2: Stratigraphic $\log$ of Section A with facies on the left and outcrop photos on the right. A: Facies 1 outcropping as a dark grey to black, organic rich bed within lighter coloured siltstone and sandstone. B: Top of section C displaying Facies 4 barrier sandstone changing into a siderite cemented shoreface sandstone unit with undulatory

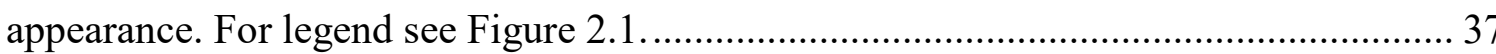

Figure 2.3: Section B with assigned facies and outcrop photo. A: Top of estuarine Crassostrea conglomerate. B: Flaser bedded sandstones. TCZ= Taber Coal Zone, not measured due to partially covered. Human scale $=1.75 \mathrm{~m}$. For legend see Figure 2.1. .. 38

Figure 2.4: (see page 41): Section $C$ with assigned facies and outcrop photos. A: Offshore siderite cemented firmground in outcrop. Note the concretionary appearance. Breakage is secondary due to weathering. B: Barrier Island Sideritic mud rip-up intraclasts in sandy matrix. C: Outcrop appearance of vertebrate microsite C26 showing surface exposed vertebrate fossil material D: Crassostrea shell conglomerate displaying shell orientation and size. E: Outcrop appearance of unionid bivalve shell bed featuring

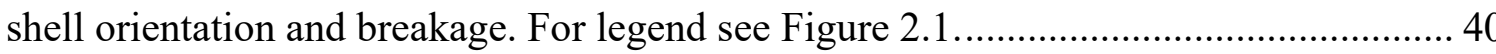

Figure 2.5: (see page 43): Measured Section $C$ and photograph of surrounding slope face. Black dotted lines show laterally correlative surfaces compared between illustration and outcrop. The red dot is located just to the left of the C26 microsite. Vertical white dotted lines indicate sections measured in outcrop. Scale bar $=5 \mathrm{~m}$ vertical................. 42

Figure 2.6: Outcrop profiles and relative positions of Section D (left box) and Section E (right box). Vertical dotted lines indicate position of composite sections measured for Section E. Scale bar $=5 \mathrm{~m}$ vertical 
Figure 2.7: Section D with assigned facies on left and outcrop photos on right. A: Basal Crassostrea shoreface shell bed. Note the difference in colour of unit as well as sorting and preservation of shell material in relation to estuarine shell conglomerate in Section B and Section C. B: Facies 1 in outcrop at Section D. Note the preserved channel bed displaying a sharply erosional lower contact located just above the Jacob's staff $(1.5 \mathrm{~m})$.

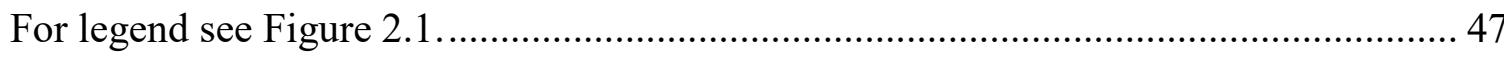

Figure 2.8: Section E with assigned facies on left and outcrop photos on right. A: Sharp, discontinuity between underlying lagoonal siltstones and barrier island sandstones. B: Barrier island sandstone outcrop with siderite cement. C: Highly organic, fossil-rich basal unit of the Taber Coal Zone. D: Heavily bioturbated, siderite rich estuarine sandstone located at the top of Section E. Burrows are assignable to Ophiomorpha. For legend, see

Figure 2.1. 48

Figure 2.9: Lithostratigraphic correlations of proposed depositional units between the outcrop sections observed in this study. For location of sections see Figure 1.1.C..... 67

Figure 2.10: Depositional units of Foremost Formation as measured in Section $\mathrm{C}$ and their respective palaeoenvironmental and sea level change interpretations. $\mathrm{R}=$ regressive, $\mathrm{T}=$ transgressive. Blue dotted lines $=$ discontinuities. For legend see Figure 2.1. 68

Figure 2.11: Proposed depositional units of the Foremost Formation as measured in Section C compared to those proposed by Ogunyomi and Hills (1977) and Kwaniowski and Eberth (1993), who also measured their sections in the Pinhorn Ranch area near Section D and E in this study and in several other localities in the valley. The right hand column displays sea-level transgressive $(\mathrm{T})$ and regressive $(\mathrm{R})$ trends. 69 
Figure 3.1: Foraminifera biostratigraphic zonation of the Santonian to Maastrichtian within the Western Interior Seaway based on Caldwell et al., (1978). Dark grey zones indicate areas that remain unsampled or have no marine deposits. Sizes of each province are not to scale.

Figure 3.2: Biostratigraphic ranges (middle) and number of specimens per sample (right) taken of Foraminifera in sections of the Foremost Formation. Each Assemblage was identified by the presence of absence of infaunal morphotypes (see Chapter 3.3; Fig. 3.3). Samples D4 to D6 and A9 are considered equivalent to Sample C3 (all samples within Facies 1) in terms of species richness and faunal composition of Foraminifera and are therefore combined with data from Section C.

Figure 3.3: (see page 81): Distribution of foraminiferal morphogroups as expressed in percentage of each morphogroup in the total assemblage within each sample in Section C. Not pictured are Section A and Section D as they are equivalent to Section C. Also shown is the ratio of infaunal to epifaunal Foraminifera morphogroups per sample. Morphogroup C individuals are considered infaunal; Morphogroup D individuals were considered epifaunal sensu Nagy et al. (2009).

Figure 3.4: Plate 1 (see page 86): Photographs of Foraminiferal taxa of the Foremost Formation from the Pinhorn Ranch, Southern Alberta, Canada. Scale Bar $=0.5 \mathrm{~mm} \ldots . .84$ Figure 4.1: Chemostratigraphic profiles of the variation of $\mathrm{Fe}, \mathrm{Zn}, \mathrm{V}, \mathrm{Mo}$, and $\mathrm{Mn}$ concentrations within Sections A and C of the Foremost Formation plotted together to display potential correlations to redox conditions at time of deposition (Brumsack, 2006). 
Figure 4.2: Chemostratigraphic profiles of $\mathrm{Al}, \mathrm{Na}, \mathrm{K}$, and $\mathrm{Ca}$ within sections $\mathrm{A}$ and $\mathrm{C}$ of the Foremost Formation. These elements were plotted together to display information regarding to clay mineral makeup and their associations to terrestrial sediment input (Al). Ca was included to compare bivalve fossil concentration in sediment samples to terrestrial sediment input (Al)

Figure 4.3: Chemostratigraphic profiles of $B$ and $S$ within Sections $A$ and $C$ from this study of the Foremost Formation. B and S were plotted together to display palaeosalinity trends. 93

Figure 4.4: Discrimination plots for $\mathrm{Fe}, \mathrm{Mn}$ and $\mathrm{Ca}$ versus $\mathrm{Al}$ in order to determine association of these elements to terrestrial sediment input (represented by Al concentrations). Fe and Mn show strong positive correlation to terrestrial input, whereas $\mathrm{Ca}$ is shown to be negatively correlated to it, suggesting a relatively marine origin. 94

Figure 4.5: Discrimination plots for $\mathrm{Zn}, \mathrm{V}$ and Mo versus $\mathrm{Al}$ in order to determine association of these elements to terrestrial sediment input (Al used as a proxy). Zn and V are strongly linked to terrestrial sediment input, while Mo is weakly negatively corelated and suggested to have little relationship to terrestrial sediment amounts. 95

Figure 4.6: Discrimination plots for $\mathrm{Na}$ and $\mathrm{K}$ versus $\mathrm{Al}$ to determine association of these elements to terrestrial sediment input (Al used as a proxy) as well as $\mathrm{Na} / \mathrm{Al}$ vs $\mathrm{K} / \mathrm{Al}$ to determine the smectitie:illite ratio. $\mathrm{K}$ is strongly positively correlated to $\mathrm{Al}$, whereas $\mathrm{Na}$ is weakly positively correlated, suggesting a mix of fluvial introduction and other sources for the origin of $\mathrm{Na} . \mathrm{Na} / \mathrm{Al}$ ratios are greater than $\mathrm{K} / \mathrm{Al}$ ratios, suggesting a greater smectite mineral content is present in the samples of the Foremost Formation... 96 
Figure 4.7: Discrimination plots for B and $\mathrm{S}$ versus Al. Both B and $\mathrm{S}$ are shown to have negative correlations to $\mathrm{Al}$ (terrestrial indicator), supporting their marine origins.... 97

Figure 5.1: Outcrop profile of site C26 outlined in white. See Figs. 2.4 and 2.5 for stratigraphic position. Scale bar $=1 \mathrm{~m}$

Figure 5.2: (Microvetebrate Plate 1)

Figure 5.3: (Microvetebrate Plate 2) 118

Figure 5.4: (Microvetebrate Plate 3)

Figure 5.5: (Microvetebrate Plate 4)

Figure 5.6: (Microvetebrate Plate 5)

Figure 5.7: (Microvetebrate Plate 6)

Figure 5.8: Pie chart of taxonomic relative abundance of identified fossil elements from the C26 microsite $(n=179)$. Refer to Table 5.2 for category descriptions. 126

Figure 5.9: Size class distribution of microsite material based on Brinkman et al. (2004) for unidentified material from the $\mathrm{C} 26$ microsite. $\mathrm{A}=$ all material (Total Sample $=843$ ); $\mathrm{B}=$ material from screen washed samples only (Total Sample $=788)$. Material $5 \mathrm{~mm}$ or less in size dominates in both samples, though larger material is more common for material that was both screen washed and surface collected (A). 127

Figure 5.10: Size class distribution of microsite material based on Brinkman et al. (2004) for identified material from the $\mathrm{C} 26$ microsite. $\mathrm{A}=$ all material (Total Sample $=179)$; $\mathrm{B}=$ material from screen washed samples only (Total Sample $=156)$. The majority of 
material in both is $10 \mathrm{~mm}$ or less in size, with material larger that this decreasing in samples that were of screenwashed material only.

Figure 5.11: Abrasion stages based on Fiorillo (1988), Cook (1995) and Phillips (2009) for material sampled from microsite C26. (Total Sample \# = 1022). Material from C26 is mostly Stage 0 or Stage 1, unabraded to slightly abraded.

Figure 5.12: Palaeocommunity distribution of $\mathrm{C} 26$ based on the palaeoenvironemental categories and designations of Cullen et al. (2016). 130

Figure 5.13: Relative abundance pie charts of taxa for the PHRN site of Frampton (2006), the C26 site of this study the PHR-1 and PHR-2 sites of Peng et al. (2001), the PK site of Cullen et al. (2016) $(n=280)$ and the SPS site of Peng et al. (2001). The stratigraphic positioning of each site relative to eachother within the context of units proposed in this thesis is displayed on the left hand column. An increase in freshwater and terrestrial taxa is encountered upsection. Refer to Table 5.2 for category descriptions.

Figure 5.14: Palaeocommunity relative distribution (based on Cullen et al., 2016) for the Foremost Formation microsites and their approximate relative stratigraphic placement to the depositional units described in this study. Stratigraphic positioning of each site relative to eachother within the context of units proposed in this thesis is displayed on the left hand column. Dominance of brackish species and an increase in freshwater and terrestrial species is encountered upsection following the Claggett marine regression...136

Figure 5.15: (see page 138): Rarefaction curves plotting number of taxa versus number of fossil speciemns calculated for each microsite from the Foremost Formation examined 
in this study. Top and bottom lines of each curve represent upper and lower standard deviations respectively. C26 and PK are noted to be below sampling threshold............137

Figure 5.16: (see page 144): Relative abundance of taxa from Dinosaur Park Formation and Oldman Formation (Comrey Unit) microsites within the Dinosaur Provincial Park (DPP) area compared with all Foremost Formation microsite data (data from Cullen and Evans, 2016). LCZ= Lethbridge Coal Zone. The enivornmental change up section shifts from marginal marine in the Foremost ( 6 sites; $\mathrm{n}=24742$ ) to fully terrestrial in the Oldman Formation ( 7 sites; $\mathrm{n}=7685$ ) and majority of the Dinsoaur Park Formation (18 sites Pre LCZ; $n=24797$ ) with a marine transgression occuring at the top of the Dinosaur Park Formation (2 sites; Post LCZ; n=3354) 143

Figure 5.17: (see page 146): Relative abundance of taxa from the Oldman Formation (upper, Comrey (11 sites; $\mathrm{n}=8674$ ) and lower Oldman Formation Units ( 5 sites; $\mathrm{n}=$ 6038)) and Foremost Formation (6 sites; $\mathrm{n}=24742$ ) microsites (data from Cullen and Evans, 2016). upper and Comrey Units of the Oldman Formation were considered one unit based on faunal similarity as in Brinkman et al. (2004) and Cullen et al. (2016). A transition from marginal marine deposition in the Foremost Formation to fluvial plain deposition in the oldman Formation is displayed and reflected by the faunal assemblages presented here.

Figure 5.18: (see page 148): Palaeocommunity distributions for the Dinosaur Park Formation and Oldman Formation (Dinosaur Provincial Park area) microsites based on Cullen et al. (2016). LCZ= Lethbridge Coal Zone. The enivornmental change up section shifts from marginal marine in the Foremost ( 6 sites; $n=24742)$ to fully terrestrial in the Oldman Formation (7 sites; $\mathrm{n}=7685)$ and majority of the Dinsoaur Park Formation (18 
sites Pre LCZ; $\mathrm{n}=24797$ ) with a marine transgression occuring at the top of the Dinosaur Park Formation (2 sites Post LCZ; $\mathrm{n}=3354$ ).

Figure 5.19: (see page 150): Palaeocommunity distributions for the Foremost Formation and Oldman Formation (Milk River area) microsites based on Cullen et al. (2016). An environmental shift from a marginal marine to fluvial plain is experienced between the Foremost Formation and the Oldman Formation. (upper an Comrey Units = 11 sites; $\mathrm{n}=8674$, lower lnit $=5$ sites; $\mathrm{n}=6038$, Foremost Formation $=6$ sites; $\mathrm{n}=24797$ ) Figure 5.20: (see page 152): Rarefaction curves plotting number of taxa versus number of fossil speciemns calculated for each microsite from the Belly River Group examined in this study. Top and bottom lines of each curve represent upper and lower standard deviations respectively. OM= Oldman Formation, $\mathrm{DPF}=$ Dinosaur Park Formation, $\mathrm{LCZ}=$ Lethbridge Coal Zone, DPP= Dinosaur Provincial Park region. .151

Figure 5.21: (see page 158): Dinosaur relative abundance trends for the Dinosaur Park Formation, Oldman Formation (Dinosaur Provincial Park area), and Foremost Formation microsites based on the data of Cullen et al. (2016) and this study showing differences in relative abundance upsection. The enivornmental change up section shifts from marginal marine in the Foremost (6 sites; $\mathrm{n}=795$ ) to fully terrestrial in the Oldman Formation (7 sites; $\mathrm{n}=1724)$ and majority of the Dinsoaur Park Formation (18 sites; Pre LCZ; $\mathrm{n}=$ 3045) with a marine transgression. All formations are dominated by hadrosaurs, with notable enrichment of ankylosaur material in the Oldman Formation.

Figure 5.22: (see page 160): Dinosaur relative abundance of taxa from the Milk River Area Oldman Formation (upper, Comrey (11 sites; $\mathrm{n}=1941)$ and lower units (5 sites; $\mathrm{n}=490$ ) ) and Foremost Formation (6 sites; $\mathrm{n}=795$ ) microsites (data from Cullen and 
Evans, 2016). upper and Comrey Units of the Oldman Formation were considered one unit based on similarites noted by Brinkman et al. (2004) and Cullen et al. (2016). Hadrosaurs dominate assemblages in the Milk River area Belly River Group, with a notably larger ceratopsian component in these assemblages than found in the Dinosaur Park Area. 159

Figure 5.23: (see page 162): Rarefaction curves plotting number of taxa versus number of dinosaur fossil specimens calculated for each microsite from the Belly River Group examined in this study. Top and bottom lines of each curve represent upper and lower standard deviations respectively. $\mathrm{OM}=$ Oldman Formation, $\mathrm{DPF}=$ Dinosaur Park Formation, DPP $=$ Dinosaur Provincial Park region 161

Figure 5.24: Bar graph of vertebrate macrofossil abundance of the Foremost Formation, showing a dominance of ceratopsian material. Total material $=273$, see Appendix E-9 for further detail. 163

Figure 5.25: Macrofossil abundance of the Foremost Formation with Xenoceratops foremostensis bonebed material excluded to account for sampling issues.Ceratopsian material is still the dominant component, however hadrosaur and pachycephalosaur material contibutes nearly the same amount without the $X$. foremostensis bonebed. Total elements $=209$. See Appendix E-9 for more detail 164

Figure 6.1: Simplified stratigraphic placement of hadrosaurs of similar age from Western and Central Montana to the material represented by CMN 58592 from Southern Alberta. Ages recorded are those specific to the locality of each taxa listed. G. latidens' last 
known appearance placement is shown, is also known from lower Two Medicine Formation approx. 83 Ma. Data adapted from Freedman-Fowler and Horner, 2015)... 173

Figure 6.2: Locality map of Chin Coulee, which contains the sites of CMN 58592, CMN 9951, CMN 9954 and CMN 9955 and TMP 83.180.0001 174

Figure 6.3: Locality map for TMP 2014.012.0019, TMP 2010.120.0002, TMP 2010.120.0008, and TMP 2010.119.0018 in southeastern Alberta. Site locations are marked by rectangles on the maps. Maps altered from Google Maps data $(2017$. 175

Figure 6.4: Central plate (left) and pre-acetabular process of the right ilium of CMN 58592.2. Lateral view (A) and medial view (B). Abbreviations: supra-acetabular process $=\mathrm{Saa}$, sacral ridge $=\mathrm{Sr}$, post-acetabular process $=\mathrm{Poa}$, ischiac peduncle $=\mathrm{I} p$, pubic peduncle $=$ Pp. Lateral view (A) and medial view (B). 178

Figure 6.5: Right pubis of CMN 58592: Abbreviations: Ilp=iliac peduncle, Isp=ischiac peduncle, $\mathrm{Ppr}=$ post pubic process, $\mathrm{Ppn}=$ pre-pubic neck, $\mathrm{Ppb}=$ pre-pubic blade. 181

Figure 6.6: Right ischium CMN 58592.4: Abbreviations: $\mathrm{Ip}=\mathrm{iliac}$ peduncle, $\mathrm{Pp}=$ pubic peduncle, $\mathrm{Of}=$ obturator foramen, $\mathrm{Op}=$ obturator process. 182

Figure 6.7: Left ischium CMN 58592.5. Abbreviation: Ip= Iliac process. 183

Figure 6.8: Left dentary of TMP 83.180.0001. $\mathrm{Cp}=$ Coronoid process. 185

Figure 6.9: Left dentary from TMP $83.180 .0001 . \mathrm{CP}=$ Coronoid process. 186

Figure 6.10: Left scapula of TMP 83.180.0001: Dr=deltoid ridge; Gf=glenoid facet; Psp=Pseudoacromion process; $\mathrm{Cf}=$ coracoid facet 188

Figure 6.11: Ulna of TMP 83.180.0001 189 
Figure 6.12: Metacarpals of TMP 83.180.0001. A= Metacaral IV, B= Metacarpal III. 190

Figure 6.13: Left rib of TMP 83.180.0001 191

Figure 6.14: Left ilium of TMP 83.180.0001 in lateral (A) and medial (B) views.

Pra=Pre-acetabular process; $\mathrm{Sr}=$ Sacral Ridge; $\mathrm{Ip}=$ Ischiac peduncle; Saa=Supra-acetabular

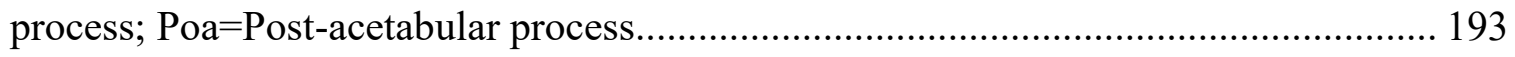

Figure 6.15: Ischium of TMP 83.180.0001. Op=Obturator Process; Pp=Pubic peduncle;

$\mathrm{Ip}=$ Iliac Peduncle 194

Figure 6.16: Left femur of TMP 83.180.0001 196

Figure 6.17: Left tibia of TMP 83.180.0001 197

Figure 6.18: Left Fibula of TMP 83.180.0001. 198

Figure 6.19: Metatarsal III from TMP 83.180.0001 199

Figure 6.20:Left partial quadrate from TMP. 2010.119.0018. 201

Figure 6.21: Disarticulated and heavily weathered vertebrae of CMN 9955 202

Figure 6.22: Left humerus from TMP 2014.012.0019. Dpc=Deltopectoral crest 203

Figure 6.23: Left humerus from TMP 2010.120.002. Dpc=Deltopectoral Crest, $\mathrm{mc}=$ medial condyle, $1 \mathrm{c}=$ lateral condyle. 204

Figure 6.24: Left ilium of TMP 2010.120.0008. Pra=Pre-acetabular Process; Pp=Pubic Peduncle; Saa=Supra-acetabular process. 205

Figure 6.25: Fibular head from TMP 87.064.0003 207 
Figure 6.26: Femoral head from TMP 87.047.0003 208

Figure 6.27: Left hind foot CMN 9951 pedal elements described from CMN 58592. Provided by Bedek 2015. Element 1= Metatarsal II, Element 2= Metatarsal III, Element III= Metatarsal and Proximal Tarsal IV 209

Figure 6.28: Loose podials of CMN 9951 from Digit IV. Bottom left= proximal, top left $=$ sub-proximal, bottom right $=$ sub-distal, top right $=$ distal (pedal ungual).

Figure 6.29: Metatarsal III of CMN 9954. 217

Figure 6.30: Strict Consensus tree of 42 trees from the matrix of Wu and Godefroit, 2012. CMN 58592 is shown to be allied within the clade Hadrosauridae. Bootstrap values are displayed above nodes. This analysis recovered 42 best trees of 191 steps each, a Consistency Index $=0.63$; Retention Index $=0.82$ and Rescaled Consistency Index of 0.51. The blue box encompasses Hadrosauridae.

Figure 6.31: Consensus tree based on 56 most parsimonious trees from the matrix of Prieto- Márquez et al., 2016. CMN 58592 is shown here to ally most closely with Lophorhothon atopus. The analysis returned 56 trees 900 steps, a Consistency Index of 0.42, Retention Index of 0.77 and a Rescaled Consistency Index of 0.33. Red Node= Hadrosauroidea, Blue Node $=$ Hadrosauridae, Yellow Node $=$ Saurolophinae, Green Node $=$ Lambeosaurinae

Figure 6.32: Strict Consensus tree of 6 trees from the matrix of Wu and Godefroit, 2012. TMP 83.120.0001 is shown to be allied within the clade Hadrosauridae. Bootstrap values are displayed above nodes. The strict consensus tree has a Consistency Index of 0.70, a 
Rescaled Consistency Index of 0.61 , and Retention Index of 0.87 . The blue box

encompasses Hadrosauridae

220

Figure 6.33: Consensus tree based on 56 most parsimonious trees from the matrix of Prieto- Márquez et al., 2016. TMP83.180.0001 is shown here grouped with UTEP 37.7, Secernosaurus koeneri and Willinakaqe salitralensis. The analysis yielded 56 best trees of 900 steps, a Consistency Index of 0.420, Retention Index of 0.774, and a Rescaled Consistency Index of 0.327. Red Node $=$ Hadrosauroidea, Blue Node= Hadrosauridae, Yellow Node $=$ Saurolophinae, Green Node $=$ Lambeosaurinae, Purple Node $=$ Brachylophosaurini, Orange Node=Kritosaurini

Figure 7.1: (see page 232): Comparison of palaeoenvironmental proxies within the outcrops of the Foremost Formation observed in this study including facies, depositional units, foraminiferal abundance per sample, infaunal:epifaunal morphogroup ratio (epifaunal=grey, infaunal=white), palaeoenvironmental interpretations, and vertebrate microsites of the Foremost Formation. Note, unlike the other sites, PK and SPS are not located in the Pinhorn Ranch area, therefore their stratigraphic relationships are based solely on the descriptions provided by Cullen et al. (2016) and Peng et al., (2001) respectively and where those horizons may fall within the classification presented in my study. The sea level curve on the far right displays only regressive trends as transgressive events are represented by flooding surfaces (blue dotted line) that created discontinuous surfaces. In general, all proxies presented suggest increased terretrial influence up section and highly variable oxygen and salinity conditions 


\section{List of Appendices}

Appendices

.281

Appendix A: Sample List.

Table A-1: Section A Sample list.

Table A-2: Section B Sample list.

Table A-3: Section C Sample List.

.282

Table A-4: Section D Sample list. .284

Table A-5: Section E Sample list. .284

Appendix B: Foraminifera Taxonomy and Data. .285

Appendix C: Geochemical Data. .289

Table C-1: Geochemical data from Sections A and C in this study of the Foremost

Formation of the Pinhorn Ranch Area. .289

Appendix D: Foraminifera Counts

Table D-1: Counts of Foraminifera from outcrop sections of the Foremost Formation in the Pinhorn Ranch

Appendix E: Microsite Data. .303

Table E-1: Counts of identifiable fossil elements from vertebrate microsites of the Foremost Formation. Left most column contains site names. Data compiled from this study (Site C26) and Cullen and Evans (2016).... .303 
Table E-2: Diversity indices for microsites of the Foremost Formation of Alberta based on data from Diversity indices for microsites of the Foremost Formation of Alberta based on data from Table E-1............................................... 307

Table E-3: Abrasion stages of material from C26. Total number of elements is 1088.

Table E-4: Relative distribution of palaeocommunities of Cullen et al. (2016) within Foremost Formation microsites based on the data from Table E-1 .308

Table E-5: Relative distribution of palaeocommunities of Cullen et al. (2016) in the Belly River Group formations based on the data from Table E-6. .308

Table E-6: Counts of identifiable fossil elements from vertebrate microsites of the Belly River Group. Data compiled from this study (Site C26) and Cullen and Evans (2016)..309

Table E-7: Diversity indices for microsites of the Belly River Group of Alberta based on data from Table E-6.

Table E-8: Diversity indices for dinosaur microsite material of the Belly River Group of Alberta based on data from Table E- 6 . .314

Table E-9: Macrofossil material counts from the Foremost Formation of Alberta based on the databases from the Canadian Museum of Nature, Royal Ontario Museum and Royal Tyrrell Museum .315

Table E-10: Undescribed hadrosaur macrofossil material from the Foremost Formation. Information provided by the Royal Tyrrell Museum of Palaeontology in Drumheller, Alberta, Canada. 
Table E-11: List of Known Campanian Basal Hadrosauroids from North America for age comparisons to the material described in this study................................. 318

Table E-12: List of Known Campanian Saurolophine Hadrosaurid taxa from North America for age comparisons to the material described in this study................. 319

Table E-13: List of Known Campanian Lambeosaurine Hadrosaurid taxa from North America for age comparisons to the material described in this study................ 321 


\section{Chapter 1: Introduction}

The Cretaceous Period had a considerably warmer climate than observed today due to high levels of greenhouse gases (Bice et al., 2006; Hay, 2011). Because of this eustatic sea level was significantly higher than present day in the Albian to the Maastrichtian, leading to flooding of the Cordilleran foreland basin (e.g., Williams and Stelck, 1975; Blakey, 2014). As the foreland basin continued to form, transgressive oceanic phases allowed water to inundate the foreland basin, creating the epeiric Western Interior Sea (WIS) that covered much of inland North America during this time. (Kauffman and Caldwell, 1993; Sageman and Arthur, 1994; Blakey, 2014; SchröderAdams, 2014). The WIS divided North America into two subcontinents; Laramidia to the west and Appalachia to the east (sensu Archibald, 1996; see also Williams and Stelck, 1975; Caldwell, 1975; Miller et al., 2003; Miall et al., 2009). Seventeen global transgressive-regressive mega sea-level cycles have been recorded in the Cretaceous, with seven occurring during the Late Cretaceous (Gradstein et al., 2012). However, in the Cordilleran foreland basin ten major second order transgressive-regressive intervals are recognized within the Late Cretaceous WIS (Kauffman, 1977; Kauffman and Caldwell, 1993) due to regional tectonism of the Cordilleran Orogeny causing periods of uplift and subsidence (Kauffman and Caldwell, 1993; Gale et al., 2008).

The sea-level events spanning the Campanian in the WIS were the regressive portion of the Claggett marine cycle in the early Campanian through to the transgressive portion of the Bearpaw marine cycle in the late Campanian (Caldwell et al., 1993; Rogers, 1998). These two cycles represent the eighth and the ninth transgressiveregressive cycles, respectively, are reflected in the deposits from the Canadian prairie 
provinces and are easily recognized in deposits of the WIS (Caldwell et al., 1993; He et al., 2005). Local depositional patterns were influenced by differing rates of tectonic subsidence, creating third and fourth order sea level events that vary within each formation of the Canadian portion of the WIS (Kauffman and Caldwell, 1993; Caldwell et al., 1993). Additionally, lithostratigraphic boundaries can be diachronous across the WIS based on proximity to the original sediment source (Bhattacharya and Posamentier, 1994).

The middle to late Campanian Belly River Group of Southern Alberta contains some of the best vertebrate fossil assemblages in the world (Brown et al., 2012). The Belly River Group comprises, in ascending order, the Foremost, the Oldman and the Dinosaur Park formations. To date, much of the work in the area has focused on the extraordinarily rich vertebrate assemblages of the Dinosaur Park Formation that has resulted in a well-accepted interpretation of the palaeoenvironment of the formation (e.g., Brinkman, 2003; Currie and Koppelhus, 2005; Mallon et al., 2012). For the past decade, the older Oldman Formation has been the subject of a joint research project by the Cleveland Museum of Natural History (CMNH) and the Royal Ontario Museum (ROM) (e.g., Ryan and Evans 2005; Evans et al., 2009; Ryan et al., 2012). However, to date, the basal Foremost Formation has been relatively understudied compared to the other two formations in the group, due partly to the relatively greater outcrop exposure of the Dinosaur Park and Oldman formations (Eberth, 2005; Cullen et al., 2016). Previous palaeoenvironmental reconstructions utilizing palynomorphs and vertebrate micro- and macro-fossil material have suggested that the Foremost Formation represents a regressional shift from a marine to a terrestrial depositional regime (Ogunyomi and Hills, 
1977; Eberth 1990; Eberth, 2005; Cullen et al., 2016). The Foremost Formation has been recognized to contain alternating units of marine shales and shoreface to terrestrial sands, culminating in the overlying fully terrestrial deposits of the Oldman Formation (Ogunyomi and Hills, 1977; Kwasniowski and Eberth, 1993). Facies present and their stratigraphic relationships has been interpreted as lagoonal deposits, tidal marshes and beach barrier/barrier island complexes (Ogunyomi and Hills, 1977; Gordon, 2000; Frampton, 2006).

\section{My study aims to address the following questions:}

\section{What depositional environments are represented within the Foremost} Formation and how do these environments vary spatially and temporally?

A refined palaeoenvironmental model will be based on a multidisciplinary study of selected outcrop of the Foremost Formation in southeast Alberta that exposes the final major regression of the Cretaceous WIS (Eberth, 2005; Cullen et al., 2016). Data proxies suitable for this reconstruction include observation of stratigraphic and sedimentological structures, identification of the invertebrate microfossil and vertebrate micro and macrofossil communities, and data from geochemical environmental proxies from the Foremost Formation. These proxies allow for the determination of palaeoenvironmental conditions such as reducing or oxidizing potential of the environment, degree of marine or terrestrial influence or palaeosalinity levels. Once a reliable palaeoenvironmental model has been built for the Foremost Formation, it will be compared to the well documented changes noted for the continued regression in the terrestrial Oldman Formation (Brinkman, 2004; Eberth, 2005; Chiba et al., 2015) and those within the 
transgressive Dinosaur Park Formation (Brinkman, 1990; Beavan and Russell 1999; Peng et al., 2001; Mallon et al., 2012).

\section{How do benthic foraminiferal assemblages respond to sea level changes,} salinity changes and nutrient input?

The palaeontological assessment of the Foremost Formation presented here uses invertebrate microfossils, primarily Foraminifera, to assess the assemblage changes from distal marine to proximal terrestrial environments. Foraminifera are single celled marine organisms, either planktic or benthic in nature, that produce an external shell-like structure referred to as a test. Benthic taxa display unique morphologies allowing for the establishment of different morphogroups (Cushman, 1948; Nagy, 1995), which can be related to different benthic habitats (Jones and Charnock, 1985; Nagy et al. 2009). This correlation between morphology and environmental preferences makes fossil Foraminifera an excellent proxy for assessing palaeoenvironmental conditions (e.g., Chamney 1976; Caldwell et al., 1981; Severin 1983; Friedrich, 2010; Schröder-Adams, 2014). Numerous studies have shown that foraminiferal composition relates to specific preferences for oceanic environmental variables such as nutrient source, palaeoredox conditions, salinity etc. which in turn can be partly sea level dependent. Thus, it has been proposed that Foraminifera assemblages within the WIS have undergone turnover events correlating to major shifts related to these environmental variables (Caldwell et al., 1981; Leckie, 1985; Caldwell et al., 1993; Schröder-Adams, 2014). 
3. How do foraminiferal assemblages within the Foremost Formation of this study compare to previous studies? How do those assemblages compare to those seen in the Pakowki/Lea Park formations, the Bearpaw Formation and the established foraminiferal zonation for the Western Interior Seaway as proposed by Caldwell et al. $(1978,1993) ?$

Former studies have suggested that the foraminiferal assemblages from the Foremost Formation most closely resemble those from the underlying Pakowki Formation, but to this date are still poorly resolved (Ogunyomi and Hills, 1977; McNeil, 1995). This study aims to correlate foraminiferal assemblages to the established zonation for the WIS (Caldwell et al., 1978) and looks at linkages between foraminiferal composition and changes in salinity and terrestrial influence within the formation.

4. How do the geochemical signals of various elements correlate to the degree of marine and terrestrial influence in the Foremost Formation? What can we learn from chemostratigraphic profiles of the Foremost Formation in respect to its palaeoenvironments?

Whole rock geochemical data can be practical proxies for determining palaeoenvironmental variables such as palaeosalinity, benthic redox conditions and terrestrial sediment input (Hills and Levinson, 1975; Sageman and Lyons, 2004; Yandoka et al., 2015). Geochemical data from the Foremost Formation will provide new evidence to test current hypotheses related to palaeoenvironment change within the formation. As well, data from these geochemical proxies will be compared to interpretations based on fossil communities. 


\section{How do the microvertebrate fossil community assemblages of the Foremost}

Formation vary stratigraphically and laterally between different study sites? In addition, what difference or similarities in terms of relative abundance and diversity can be detected to those seen in the Oldman and Dinosaur Park formations? How does the dinosaur fossil community assemblages present in vertebrate microsites in the Foremost Formation compare to other Belly River Group assemblages and how do these assemblages change in diversity through time?

Vertebrate microfossils and macrofossils are also useful palaeoenvironmental indicators, with each fossil taxon having their own unique environmental preference (Brinkman et al., 2004; Cullen and Evans, 2016). Aquatic and semi aquatic organisms prefer certain salinity levels in their habitats, and therefore the types of organisms present in a fossil assemblage provide evidence of palaeosalinity changes (Cullen et al., 2016). Evidence to suggest a brackish, marine to terrestrial environment would include observations of a mixed terrestrial and marine vertebrate assemblage.

For terrestrial vertebrate faunas, Horner et al. (1992) proposed that transgressive sea-level cycles of the Late Cretaceous WIS were the major evolutionary force in the region, as fragmentation of geography isolated populations that independently evolved of populations in other regions. Mallon et al. (2012) supported this interpretation by reporting on high turnover rates of large terrestrial fauna in the Oldman and Dinosaur Park formations, but suggested environmental factors do not explain turnover better than a simple time vector. If a change in the structure of microvertebrate palaeocommunities in the Foremost Formation should be observed relative to the decrease in marine influence up section in the Foremost Formation and the Belly River Group as a whole, 
then greater support for the hypothesis that faunal turnover was related to sea-level change would be gained.

6. How do hadrosaurid macrofossil remains described in this study and relative abundance of dinosaur macrofossil material from the Foremost Formation compare to trends in dinosaur diversity derived from the analysis of vertebrate microsites in the Belly River Group?

It has been suggested that the dinosaur communities within the Foremost Formation resemble those seen in the Oldman and Dinosaur Park formations, but are made up of more basal representatives of the major dinosaur families (Ryan et al., 2015). Therefore, any potential classification of hadrosaurid remains could provide greater support for this hypothesis and would shed additional light on overall faunal turnover in the Belly River Group. Understanding the changes in faunal diversity and disparity during the regressive cycle of the Foremost Formation would provide important data that could be used to add to the overall hypothesis relating faunal community change and sealevel shifts.

\section{1: Geology and Stratigraphy of the Belly River Group and the Foremost Formation}

Dawson (1883) first described what is now referred to as the Belly River Group. He divided the strata into two stratigraphic units based on sediment colour, referring to the lower pale beds and upper yellow beds. At the time of Dawson's study, the units now referred to as the Pakowki and Milk River formations were included within the Belly River Group. Dowling (1915) removed these formations from the group and split the 
remaining units into a classification resembling the modern stratigraphic framework of the Belly River Group. He described the lower pale coloured unit of the Belly River Group as Foremost Formation and designated Chin Coulee near the village of Foremost, Alberta as the stratotype locality (Fig 1.2; Fig 1.2). Russell and Landes (1940) maintained the nomenclature of Dowling (1915) and subdivided the Belly River Group into the Foremost and Oldman formations, officially naming the Oldman Formation, previously referred to as the yellow bed unit by Dawson (1883). McLean (1971) described the extension of Belly River Group deposits into Montana and Saskatchewan, but noted a lack of lithological boundaries in those regions that made the distinction between the two formations difficult. This fact, as well as historical usage of the name Judith River Formation in Montana, lead to the preferred usage of the term 'Judith River Formation' (with a lack of subdivisions) in the United States and for the strata that directly correlate to the same units of the Belly River Group in Canada.

Ogunyomi and Hills (1977) conducted a comprehensive palaeoecological analysis of the Foremost Formation, including stratigraphy from data obtained via core and outcrop samples near the Milk River south of Onefour and adjacent to the Pinhorn Ranch Grazing Reserve. Their goal was to use primarily palynology to divide the Foremost into further refined sub units. They split the Foremost Formation into two informal units with a nearly cyclical facies profile, differentiated by specific marker beds and palynological differences. The division of these units was further supported through microfossil proxies, specifically recognition of Foraminifera and pollen species as environmental indicators. Ogunyomi and Hills (1977) argued for retention of the terminology from Russell and Landes (1940) as distinct boundaries between the Foremost and Oldman 
formations were readily visible. Kwasniowski and Eberth (1993) conducted an evaluation of the depositional environment with similar results as Ogunyomi and Hills (1977), but subdivided Foremost strata into three units separated by regional discontinuities recognized by laterally continuous, sharply bounded siderite rich horizons separating underlying sandstones from an overlying mudstone unit. Kwasniowski and Eberth (1993) agreed with the assessment of Ogunyomi and Hills (1977) that the Foremost Formation was a separate, distinguishable formation.

Eberth and Hamblin (1993) agreed with the stratigraphic divisions of the Belly River Group proposed by Russel and Landes (1940) and Ogunyomi and Hills (1977), but subdivided the Oldman Formation into the Oldman (lower subdivision) and Dinosaur Park (upper subdivision) formations. This description was based on an observed disconformity with widespread regional extent within the upper Oldman Formation. However, Eberth and Hamblin (1993) retained 'Judith River' as the stratigraphic group label. Use of Belly River as the group name was again reintroduced by Jerzykiewicz and Norris (1994), who analyzed the stratigraphy of Belly River Group in the foothills of the Rocky Mountains, deposited proximal to the sediment source. The usage of the Belly River Group name was extended by Hamblin and Abrahamson (1996) into southern Alberta, by analyzing the stratigraphic architecture and depositional source of the Foremost and Oldman formations in that region. The use of Belly River Group nomenclature is now established for studies addressing these strata in Alberta (Eberth, 2005; Ryan et al., 2012; Cullen and Evans, 2016).

Traditionally, the Foremost Formation has been split into a tripartite division, with the Mackay Coal Zone at the base, a middle unit dominated by paralic shoreface 
deposits and the Taber Coal Zone at the top, which is overlain by the Herronton Sandstone of the Oldman Formation (Eberth, 2005; Cullen et al., 2016; Fig. 1.3). This nomenclature is retained in this thesis.

\section{2: Foraminiferal Studies of the Foremost Formation.}

Foraminiferal faunas of the Claggett and Bearpaw marine cycles are typically dominated by both calcareous agglutinated genera (North and Caldwell, 1964; 1975; Caldwell et al., 1993). To date, only two studies (Ogunyomi and Hills, 1977; McNeil et al., 1995) have addressed Foraminifera of the Foremost Formation. Ogunyomi and Hills (1977) was the first study in which identification of foraminiferal assemblages within the Foremost Formation was attempted, though primary focus was directed towards the palynological fossil record in order to help bound the stratigraphic subunits that they proposed for the Foremost Formation. The interval from the upper Pakowki Formation through Herronton Sandstone of the Oldman Formation (Fig. 1.1; Fig. 1.2) was sampled in the Pinhorn Ranch region. The Pakowki Formation displays an agglutinated fauna with low species richness in the basal units. Foraminifera last appear in the Taber Coal Zone of the Foremost Formation, represented only by the thin-walled, agglutinated taxon Haplophragmoides and Trochammina. The palaeoenvironment of the Taber Coal Zone was interpreted as lagoonal marsh deposits, where specimens were introduced during periods of sea water influx. Unfortunately, Ogunyomi and Hills (1977) did not identify foraminifera to species level, nor did they provide photographic or illustrated plates, making precise comparisons with other samples and studies problematic.

McNeil et al. (1995) described Foraminifera obtained from outcrops of the Foremost Formation on the Pinhorn Grazing Reserve area, as well as eleven samples 
taken from the paralic mudstone units within the Princess drill core, which was drilled in 1983 approximately $190 \mathrm{~km}$ north of the Pinhorn Grazing Reserve near Dinosaur Provincial Park. These horizons were the only ones sampled as they had the highest potential to preserve Foraminifera when compared to shoreface and barrier island sandstones. Low species richness, combined with primarily agglutinated trochospiral, planispiral, quinqueloculine and elongate morphotypes common to epifaunal to shallow infaunal feeding zones (Wall et al., 1971) indicated a restricted hypersaline lagoonal depositional environments as well as increased proportions of more marine tolerant species during transgressional deposits. Foraminifera also relate to the transgressiveregressive cycling described by Kwasniowski and Eberth (1993), where increased Foraminiferal abundance correlated with their purported transgressive events. The sections of the Foremost Formation described from the Princess Core, displayed hypersaline tolerant Foraminifera exclusively, with more marine forms absent as reported by McNeil et al. (1995).

\section{3: Geochemical Studies of the Belly River Group}

Geochemistry of sedimentary rocks can provide a multitude of palaeoenvironmental information during the time of deposition. The method included in this study is whole rock geochemistry, whereby processed sediment samples taken from measured outcrop sections are exposed to chemical treatments and subsequently analyzed to determine the elemental makeup of the rock (exact methods are outlined later in this chapter). Depending on the abundance of certain elements present in the sediment samples, inferences regarding palaeoenvironmental variables can be made. 
Chemostratigraphic correlations can also be made from stratigraphic horizons that share distinct geochemical signatures.

Goldschmidt and Peters (1932) demonstrated utility of geochemistry as a palaeoenvironmental proxy when they determined that the enrichment of boron in sea water compared to freshwater systems, and its ability to adsorb to clay minerals, could be used as a palaeosalinity marker in marine rocks. Hills and Levinson (1975) conducted the only palaeoenvironmental analysis to date of the Belly River Group using geochemical methods (boron enrichment), but did not include the Foremost Formation in their study.

\section{4: Vertebrate Microsite Analyses from the Belly River Group}

Vertebrate microsites are defined as those localities where $75 \%$ or more of the fossil elements present are $\leq 5 \mathrm{~cm}$ in their longest dimension (Eberth et al., 2007). Vertebrate microsites are sampled both through surface collection of material in the field, but also by post collection screenwashing techniques, allowing for the separation of fine sediment from concentrated vertebrate microfossils. Data from vertebrate microsites can be useful for palaeoenvironmental analysis as they often provide large sample sizes with high species richness compared to macrofossil bone beds (Brinkman, 1990; Brinkman et al., 2004; Cumbaa et al., 2010; Rogers and Brady, 2010; Cullen et al., 2016). These attributes can allow for quantified estimates of species abundance and regional faunal compositions that can then be tested statistically.

The methods used to describe and analyze vertebrate microsites studies were first introduced by Shotwell $(1955 ; 1958)$. Shotwell (1955) proposed the use of vertebrate microsites as a way to quantify palaeocommunities. This allowed for an estimate of the 
relative abundances of each member taxon providing a more accurate representation of the organismal community present in a formation. This data forms important faunal evidence in addition to rarely preserved macrofossil material. As well, this quantification of taxa could then be used to test statistically palaeoecological hypotheses. Shotwell (1958) then applied these techniques to mid-Pliocene mammal assemblages from both Oregon and Texas, thus representing the first attempt at palaeocommunity reconstruction using these methods and the first to compare multiple age equivalent sites to one another.

The methods proposed by Shotwell (1955) were first used within the Cretaceous Period by Estes (1964) and Estes and Berberian (1970) to attempt reconstruction of the palaeocommunity of the Maastrichtian Lance Formation in Wyoming. Brinkman (1990) provided the foundation for modern palaeocommunity reconstructions in the Belly River Group of Alberta based on data from microvertebrate localities. Using data collected from sites in what are now referred to as the Oldman and Dinosaur Park formations in Dinosaur Provincial Park, he established the relative numbers of each fossil taxa within the assemblage. By combining this data with positions (distal or proximal) of the taxa to the palaeoshoreline based on the preferences of living analogs, he recognized four distinct faunal assemblages along the margins of the WIS; these are aquatic and terrestrial proximal, and aquatic and terrestrial distal, assemblages. Eberth (1990) proposed models of deposition for the assemblages in Brinkman (1990), indicating that microfossils were likely deposited in low energy ponds or lakes, then redeposited in channels through floods and bank collapse events.

Beavan (1995) conducted the first study of microvertebrate material from the Foremost Formation. The studied site (Kuehne's site) on the Pinhorn Grazing reserve, 
near the Pinhorn Ranch, within the mudstones of the middle succession of Kwasniowski and Eberth (1993) (Figs. 1.1-1.3). This site displays a strongly marine-influenced assemblage dominated by elasmobranchs typical of those found in other Campanian to Maastrichtian marine microvertebrate assemblages in the WIS. Kuehne's site was interpreted as a single high energy event, such as a storm.

Peng et al. (2001) also examined two Foremost Formation microvertebrate sites (PHR-1 and PHR-2) in the Pinhorn Ranch in addition to several microsites from the Oldman Formation. Their sites were dominated by the brackish water fish genera Myledaphus, Paralbula, and Lepisosteus, suggesting a relatively mixed influence of marine and freshwater. Both sites of the Foremost Formation were interpreted as a shoreface environment directly associated with barrier bar deposits found throughout the valley. Peng et al. (2001) provided evidence to support at least two different vertebrate assemblage types in the Belly River Group; a marine-dominated assemblage in the Foremost Formation and a more terrestrial dominated one in the Oldman Formation. It was noted that the lower Herronton Sandstone of the Oldman Formation displayed a mixture of the assemblages seen in Foremost and middle and upper Oldman Formation microsites.

Brinkman et al. (2004) further refined the examined palaeocommunities of the Foremost and Oldman formations using data collected by Peng et al. (2001), provided the most rigorous and complete statistical analysis of microsites in these formations to date, and delivered supporting evidence for coastal and inland palaeocommunities along the WIS. 
Frampton (2006) investigated both invertebrate and vertebrate microfossils from the Foremost Formation from one microsite (Northern Pinhorn Ranch Site (PHRN)). She used a multidisciplinary approach to identify depositional processes and reconstruct the palaeoenvironment represented by local palaeofauna. This fauna included a new species of rajiform ray Myledaphus, M. psilatus (now nomen dubium referred to Pseudomyledaphus sp. by Kirkland et al., 2013). The PHRN locality was interpreted as preserving a low energy, brackish water locality, probably formed by the slow, continuous accumulation of boney material, based on four criteria: 1) the large lateral extent of the microsite; 2) the large number of fossil elements attributed to brackish water taxa; 3 ) greater relative abundance of taxa attributable to brackish palaeoenvironments; and 4) evidence of predation by Pseudomyledaphus on bivalve taxa present in the site. These lines of evidence and others will be discussed and compared in further detail in Chapter 9 when comparing the PHRN locality to the microsite sampled in this study.

Cullen et al. (2016) published the most recent analysis of a Foremost Formation microvertebrate fossil locality (PK site). Their study primarily utilized chondrichthyans (including the first occurrence of Chimaera in the Campanian WIS) and lissamphibians for their palaeoenvironmental reconstruction, citing their association with specific environments in extant forms, to infer a mixed terrestrial/coastal faunal assemblage. This differs from the findings of Brinkman (1990), Peng et al. (2001), and Brinkman et al., (2004) who suggested a more significant division between coastal and terrestrial faunal zones in the Belly River Group based on the differences seen in their terrestrial (SPS site) and marine (PHR-1 and PHR-2) microvertebrate sites from the Foremost Formation. 
Cullen and Evans (2016) analyzed the data from all published Belly River Group microsites using a variety of statistical methods to determine the palaeoecological drivers behind diversity changes. They concluded that sea-level change was probably the major determining factor for differences in vertebrate community assemblages; however, dinosaur communities were notable for not being significantly related to either coastal or inland terrestrial habitats, suggesting no habitat preference related to coastline proximity based on microvertebrate assemblages.

\section{5: Study Area}

The study area is situated within the Milk River Valley of Southern Alberta, Canada (Fig 1.1). The Milk River is a tributary of the larger Missouri River, and represents the northern most extension of the Mississippi watershed. Outcrops of the Foremost Formation are easily observed due to exposure by glacial valley incision during the last glacial retreat, making the Milk River Valley ideal for outcrop studies of the Foremost Formation. The specific locality on the north side of the river, close to the Pinhorn ranch house on the Pinhorn Grazing Reserve, an Alberta Provincial Grazing Reserve located in Forty Mile County No. 8 approximately $79 \mathrm{~km}$ south of the village of Milk River and bordering the Milk River Natural Area and One Four Research area. The main sections measured are located just east and southeast of Range Road 73A, which runs North/South through the valley and through the Pinhorn Ranch House site (49.131605 N $110.8877254^{\circ} \mathrm{W}$; elevation $858 \mathrm{~m}$ above sea level). Additionally, the Phil's Knob (PK) microsite, described in Cullen et al. (2016), located approximately $40 \mathrm{~km}$ 
Figure 1.1: (see page 18) Locality map of study area modified from Cullen et al., (2016). A: Map of Alberta relative to Canada, and area of study, relative to Alberta, as represented by the grey rectangle. B: Aerial view of study area, including locations of nearby settlements and rivers. Red rectangle indicates area containing my section (marked by C26) and the locations of adjacent vertebrate microsites discussed in this study. C: Aerial view of Pinhorn Ranch site along the Milk River in southeast Alberta. Sections measured in the field are marked by letters A through E corresponding to their names (Map data (2017 Google Earth). 


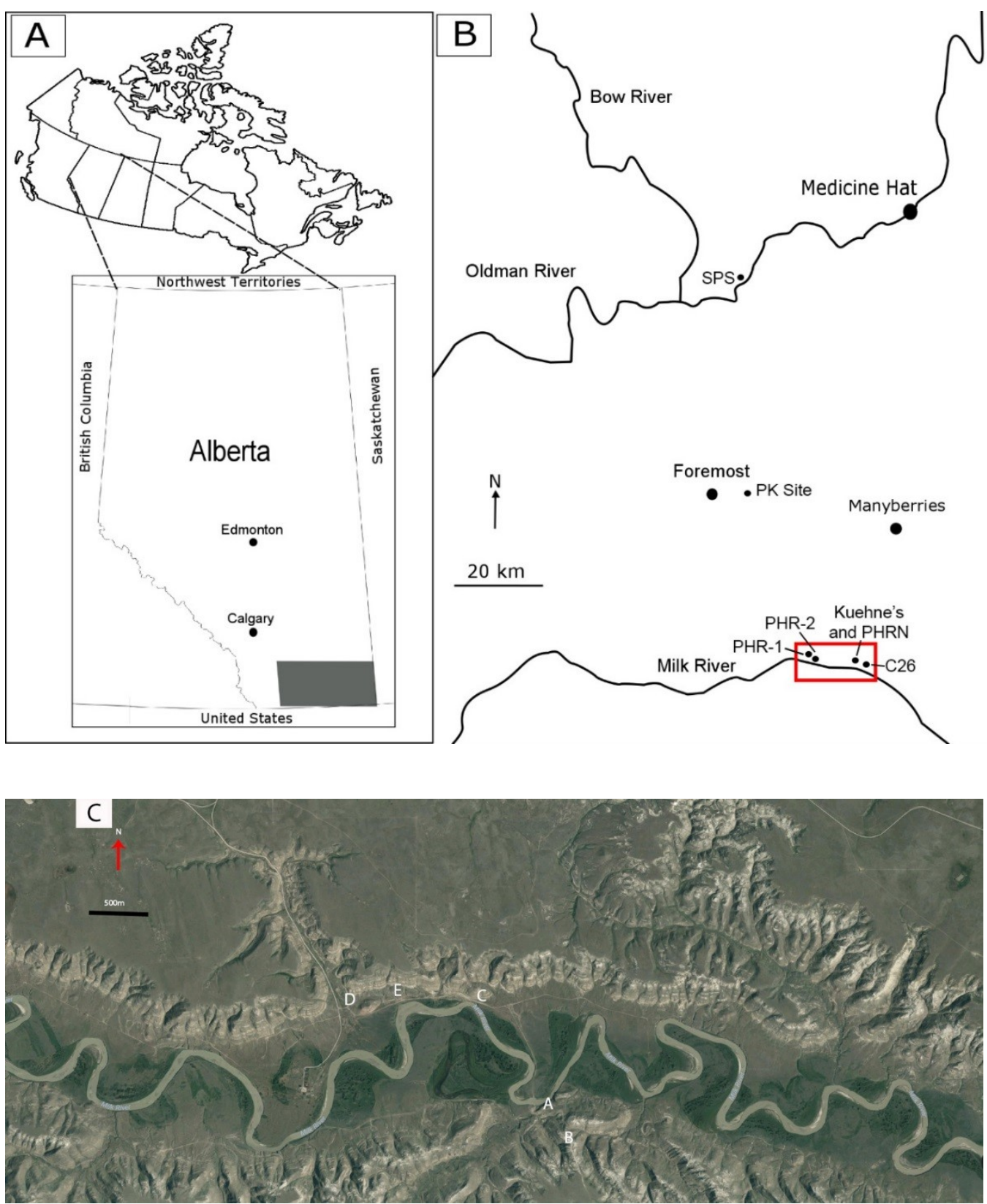




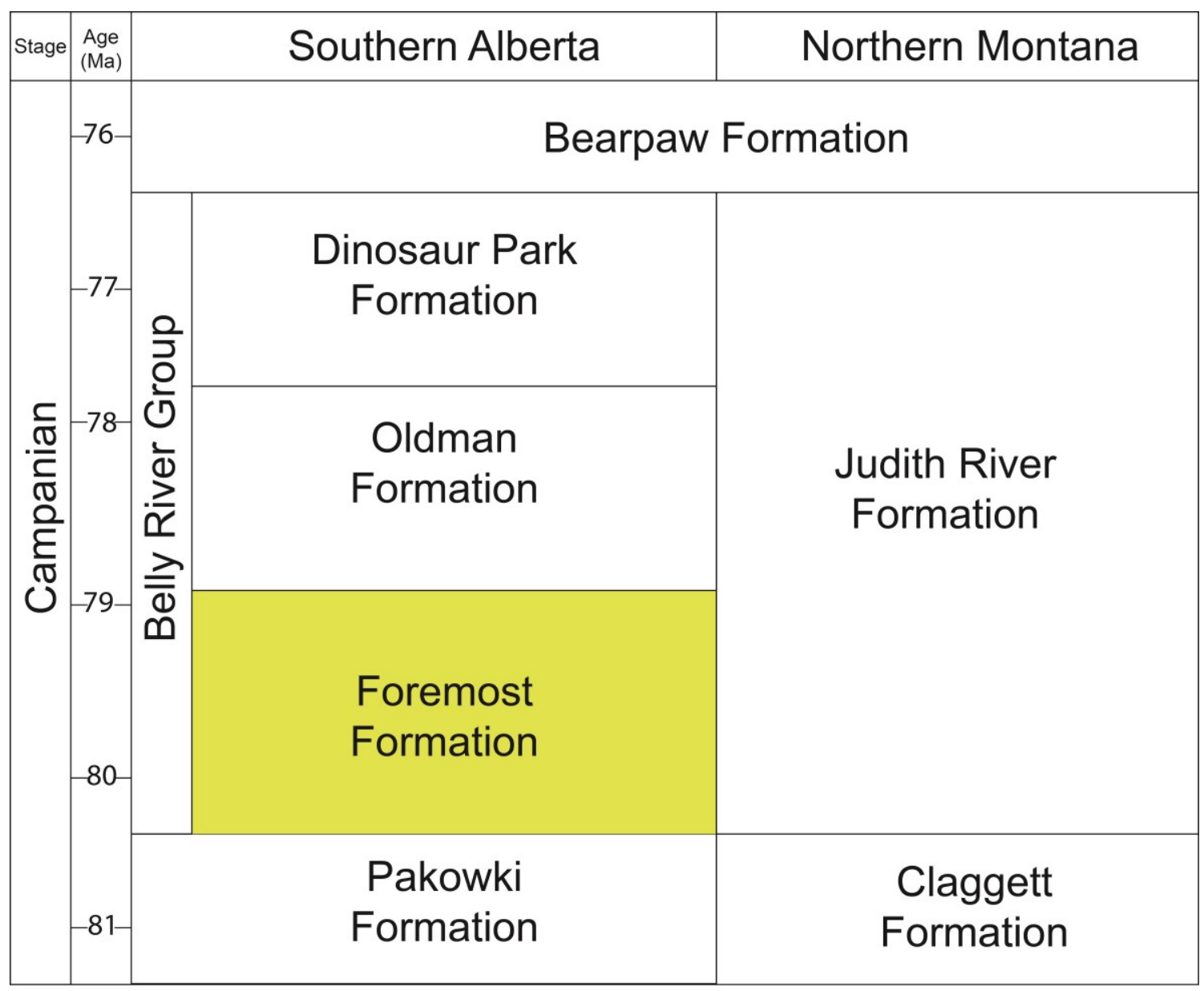

Figure 1.2: Simplified stratigraphic relationships of the Belly River Group with approximate ages (from Renne et al., 2010) compared to equivalent formations of Northern Montana. 


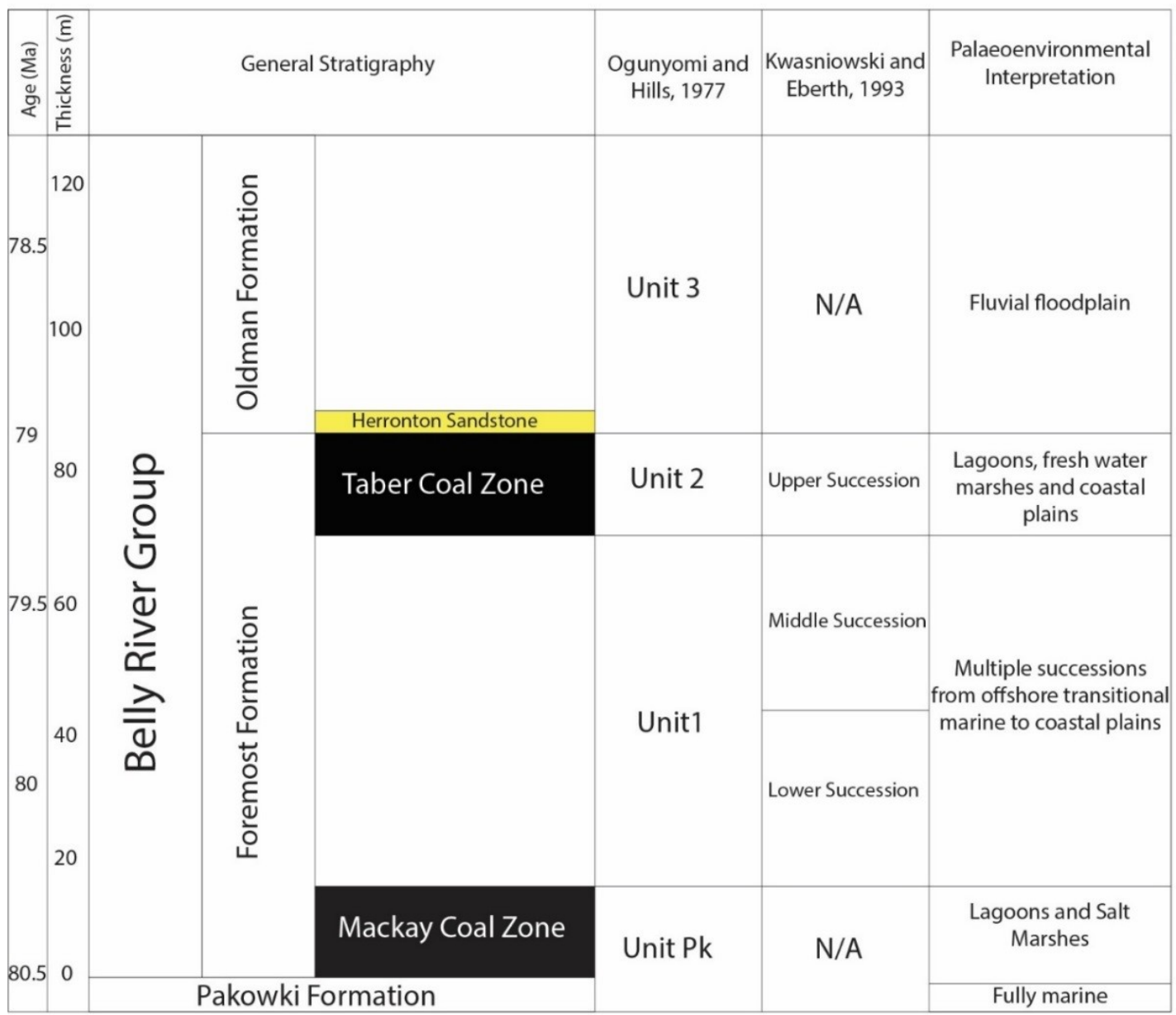

Figure 1.3: Simplified general zonation of the Foremost Formation and lower Oldman

Formation in the Milk River area compared to informally named units of Ogunyomi and Hills (1977) and Kwasniowski and Eberth (1993) and their previous palaeoenvironmental interpretations. 


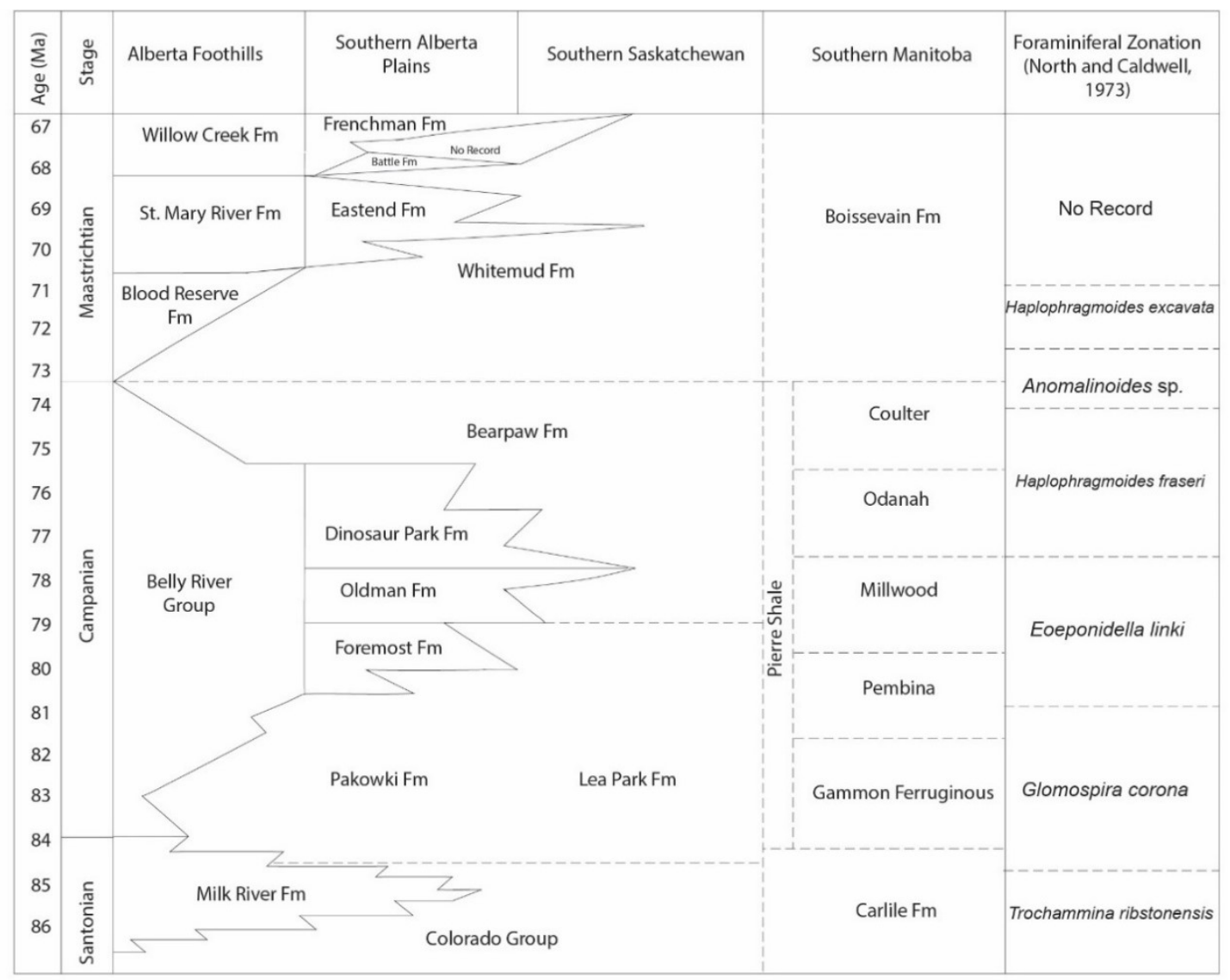

Figure 1.4: Santonian to Maastrichtian lithostratigraphic correlations within the Southern Canadian Western Interior Seaway from the Alberta Foothills to Southern Manitoba based on Dawson et al. (1994) and Catuneanu et al. (2000). Foraminifera biostratigraphic zonations are based on Caldwell et al. (1978). 
north and west $20 \mathrm{~km}$ of the Pinhorn Ranch was also visited for comparison to the Milk River area.

\section{6: Materials and Methods}

Measuring Stratigraphic Sections: Five stratigraphic sections were measured within the Pinhorn locality as part of the data required to assess palaeoenvironmental change in the Foremost Formation (Fig 1.1). These sections are labeled A through E, with section $\mathrm{C}$ offering the thickest stratigraphic section, though none encompass the entirety of the Foremost Formation. Measuring of stratigraphic sections was accomplished using a Jacob's Staff. Lithology and sedimentary structures were observed within each section and recorded. These observations were then further refined through analysis of hand sample material collected from each section and studied via hand lens as well as an Olympus SZX9 dissecting microscope at Carleton University, allowing for observation of more specific relative ratios of grainsize, lithic fragments, organic fragments and fossil remains.

Sediment Sampling: Sediment samples were collected within the section at intervals of 1 to $2 \mathrm{~m}$ stratigraphic thickness depending on the terrain and slope gradient encountered. Units were recorded as "covered" if they were deemed too heavily altered by weathering or plant growth, therefore having limiting potential to yield useful sample information. Locality A was located on the south side of the river along its banks and contained nine samples (A1-A9) over a $17.5 \mathrm{~m}$ thick measured section. Locality B only has one sample (B1) and $8 \mathrm{~m}$ of section measured and is located on the south side of the river stratigraphically above Locality A. The main section of interest, Locality C, contained a total of 50 samples (C1-C50) collected over a $145 \mathrm{~m}$ transect and is located 
approximately $1.3 \mathrm{~km}$ north of Locality A on the north side of the river. Additionally, two supplementary sections correlative to the lower $12.5 \mathrm{~m}$ (Locality D) and $76 \mathrm{~m}$ (Locality E) of Locality C were taken approximately $600 \mathrm{~m}$ west of Locality C near the entrance to the Pinhorn Ranch. Locality D was located less than $100 \mathrm{~m}$ west of Locality E and had 6 (D1-D6) samples taken over its $12.5 \mathrm{~m}$ vertical extent. Locality E was the section equivalent to the lower $76 \mathrm{~m}$ of Locality $\mathrm{C}$, with 3 samples (E1-E3) being taken from this section to facilitate stratigraphic correlation to the main section and highlight specific geological and palaeontological features. (See Figure 1 for exact locations and relative locations of this study to previous ones; See Appendix A for exact section height of each sample).

Foraminiferal Analyses: All samples were separated into smaller subsamples. One portion of each sample initially weighing approximately $150 \mathrm{~g}$ was analyzed for marine microfossils, specifically benthic Foraminifera. Since sediments were not consolidated each subsample was sieved to separate loose fossil material from the matrix using a 62micron sieve. The remaining unbroken material was then further treated with hot $8.75 \%$ hydrogen peroxide to free remaining fossils from the matrix and then sieved again. Sandsized residues were then observed using a dissecting microscope to pick and accurately identify Foraminifera. Foraminifera were removed carefully from residues and adhered using Tragacanth glue to microscope slides for species level identification at higher magnifications. Fossils were then photographed with a Canon Rebel t3i camera mounted to the dissecting microscope at a 40x magnification. Relative abundance of species is herein recorded and compared to their associated sediments to determine degree of marine influence and to distinguish sedimentary facies. The foraminiferal assemblage 
recorded here is compared biostratigraphically to assemblages recorded from other Campanian formations within the WIS with classifications based primarily on North and Caldwell (1964, 1970, 1975), McNeil and Caldwell (1981) and McNeil et al. (1995). Classifications are based on these studies as they specifically focused on the underlying Lea Park (Pakowki) Formation, overlying Bearpaw Formation and the Pierre Shale of Manitoba which spans the Campanian. At least five sample trays of each sample were examined, with samples being deemed barren of fossils if no specimens were found. Any sample containing specimens was then completely picked. Due to fragmentation and poor preservation of most of the examined material not all fossil material could be identified beyond the generic level. Morphogroup analysis was based on the work of Nagy et al., (2009), with each Foraminifera fossil being assigned to a particular morphogroup based on test chamber arrangement.

Geochemical Analyses: Subsamples from each sample in Section C and Section A were sent to ACME Laboratories in Vancouver for whole rock geochemical analysis. These samples were then split into $15 \mathrm{~g}$ portions and processed using an Aqua Regia digest at ACME Laboratories (1:1:1 concentrated $\mathrm{HCl}$, concentrated $\mathrm{HNO}$, deionized $\mathrm{H} 2 \mathrm{O}$ ), with elemental concentrations determined through inductively coupled plasma (ICP) mass spectrometry (MS) and emission spectrometry (ES) methods on $0.5 \mathrm{~g}$ of the $15 \mathrm{~g}$ sample portion. From the ICPMS results, several chemostratigraphic profiles for the Foremost Formation are constructed.

Information related to palaeosalinity and conditions can be determined from the element abundance data gathered from these samples primarily from the element boron (B) (McLennan et al., 1993; Hofer et al., 2013). B is present at higher levels in seawater 
versus freshwater and is adsorbed to clay mineral structures during sediment deposition, leaving B levels stable as these B-bearing minerals are generally immobile once deposited (Hills and Levinson, 1975; Hofer et al., 2013). Sulfur concentrations have also been proposed as a palaeosalinity proxy, and are often complimentary to B concentrations (Bannerjee and Goodarzi, 1990; Hofer et al., 2010). Major (iron and manganese) and trace (zinc, vanadium, molybdenum) metal elements were also analyzed as they are enriched during reducing conditions during the time of sediment deposition, which theoretically provides evidence for benthic palaeoredox conditions (Hofer et al., 2013). Sodium and potassium were analyzed as they are a useful proxy for determining smectite and illite clay mineral content respectively in claystones and mudstones, whereby increased smectite may correlate to wetter and volcanically influenced environments (Hofer et al., 2011; Hofer et al., 2013). Calcium percentages were analyzed in order to compare trends in bivalve concentrations (the primary contributor of calcium in this study) to terrestrial and marine influences. All elements were expressed as ratios to aluminum concentrations to determine effect of sediment source. Aluminum is primarily associated with terrestrial sediment influx and is relatively unaffected by biological processes that can affect other elements post deposition (Hofer et al., 2010).

Vertebrate Microfossil Analyses: A single microvertebrate bonebed within Section C ('C26'), approximately $63 \mathrm{~m}$ from the base of the section, was sampled for fossil material, with its stratigraphic placement and associated facies noted during collection. Approximately $160 \mathrm{~kg}$ of material was collected from the site using shovels and burlap sacks. Additional microvertebrate material was sampled from the residues of sample $\mathrm{C} 32$ and sample $\mathrm{C} 1$. This material was processed via the methods described by 
Brinkman (1990). Initial screen washing was conducted at the Royal Tyrell Museum of Palaeontology (RTMP), and the concentrate was then shipped to Carleton University where it was again processed with hydrogen peroxide treatment through $62 \mu \mathrm{m}$ sieve to breakdown samples and separate fossil material from matrix. The final residue was examined under a dissection microscope to collect and identify any near microscopicsized vertebrate and invertebrate fossils. Identifications were made primarily by comparing the material to the descriptions and photographs in Brinkman et al. (2017).

Relative abundance of taxa was recorded to aid in classification of community structure and inferred palaeoenvironments. These data were compared to other microsite localities within the Foremost Formation described by Peng et al. (2001), Brinkman et al. (2004), Frampton, (2006), Cullen et al. (2016) and Cullen and Evans (2016).

Relative abundance data of vertebrate macrofossil material from the Foremost Formation was also provided by the Royal Tyrrell Museum, Royal Ontario Museum (ROM) and Canadian Museum of Nature (CMN). These abundances were compared to the microvertebrate material. Combined, both microvertebrate and macrovertebrate fossil assemblages are discussed and compared within the context of the entire Belly River Group.

Diversity changes within the vertebrate microsites were analyzed and compared via three commonly used diversity indices (Jost, 2006). These are:

the Shannon-Wiener Diversity Index, calculated via the equation:

$H=-\sum_{i}\left(\frac{n_{i}}{N}\right) \ln \left(\frac{n_{i}}{N}\right)$ 
where $n_{i}$ is the proportion of species $i$ and $\mathrm{N}$ is the total number of all species' individuals.

Additionally, equitability was calculated to determine the evenness of species distribution per sample via the equation:

$E=\frac{H}{H \max }$

where $\mathrm{H}$ is the Shannon Wiener Index and Hmax is the maximum possible Shannon Wiener index value, calculated by $\ln (\mathrm{S})$ where $\mathrm{S}$ is the total number of species.

The Simpson Diversity Index was calculated via the equation, utilized to generate additional support for values given by the Shannon-Wiener Index:

$D=\sum_{i}\left(\frac{n_{i}}{n}\right)^{2}$

where $n_{i}$ is the proportion of species $i$ and $\mathrm{n}$ is the total number of all species' individuals. Diversity is then calculated as

$\mathrm{SD}=1-\mathrm{D}$.

The Berger Parker Index was calculated via the equation:

$B P=\frac{n_{d}}{N}$

where $n_{d}$ is the population of the dominant species in the sampled site and $\mathrm{N}$ is the total population of all species in the site. This indicates the tendency of a community to be overrepresented by one particular group or species. 
Hill numbers were also calculated from the Shannon-Wiener Index via the equation:

$$
\text { Hill Number }=\operatorname{EXP}(H)
$$

Calculating the Hill number allows Shannon Diversity indices to be compared in a linear scale as "number of effective species", allowing a magnitude of difference in diversity to be found, which is impossible with the Shannon and Simpson indices due to their logarithmic nature (Jost, 2006). Rarefaction curves were also calculated using PAST 3.0 (Hammer et al., 2001).

Taphonomic Determinations: Taphonomic observations such as degree of weathering and abrasion of fossil elements were noted to aid the interpretation of the depositional environment of the sampled bonebed. Methods to describe degrees of abrasion follows those outlined by Fiorillo (1988), Cook (1995) and Phillips (2009) (Table 1.1). Size data for microvertebrate remains of different sites based on the methodologies of Brinkman et al., (2004) were compared to determine similarities in taphonomic size bias between Foremost Formation microsites (Table 2). Brinkman et al., (2004) noted that microsites that share relatively similar distributions of fossil material share similar taphonomic and depositional factors. Therefore, any differences noted between the faunas of sites with similar taphonomic conditions are due to actual difference in taxa distribution rather than taphonomic biases that may have altered relative abundance (Brinkman et al., 2004; Cullen et al., 2016)

Phylogenetic Analyses: A subset of vertebrate macrofossil material described within this study encompasses all the known material attributable to hadrosaurs collected from the Foremost Formation. This material has been collected by various researchers 
and is housed primarily in the collections of the CMN and the RTMP. Observations of hadrosaur morphological traits were guided by the character state descriptions of $\mathrm{Wu}$ and Godefroit (2012) and Prieto- Márquez (2016). Both matrices were coded using Mesquite v 3.04 build 725 (Maddison and Maddison, 2001) (see attached nexus files in Appendix F). The data matrix of $\mathrm{Wu}$ and Godefroit (2012) contained 26 taxa and 108 equally weighted characters, and was analyzed in PAUP 4.0b10 (Swofford, 2002). The data matrix of Prieto- Márquez et al. (2016) included 62 taxa and 273 equally weighted, unordered characters. It was analyzed using TNT 1.1 (Goloboff et al., 2008) using a search of 10,000 replicates with random additional sequences performed, with branch swapping by tree bisection-reconnection holding ten trees per replicate following the methodology of Prieto- Márquez et al. (2016). PAUP and TNT were used for the Wu and Godefroit (2012) and Prieto- Márquez et al. (2016) matrices respectively as these were the programs used in their original studies. The age class classification scheme created by Horner et al. (2000) was also used in order to describe the hadrosaur material. The material was photographed using a Canon Rebel t3i digital camera. Morphological traits were quantitatively measured using Mastercraft digital calipers for linear, flat features and flexible measuring tape for circumferences and curved features. Deflection and curvature angles were calculated during examination or at Carleton University by measurement from the photographs. 
Table 1.1: List of examined hadrosaur macrofossil material in this study. See Figs 6.1 and 6.2 for detailed locality information

\begin{tabular}{|l|l|}
\hline Catalogue Number & Associated Material \\
\hline CMN 58592.1 - 5 & Skeletal material from one individual, \\
\hline including the right ilium, ischia, a pubis, and \\
\hline unprepared femur. \\
\hline CMN 9954 & Left femur, tibia, and a partial associated foot. \\
\hline CMN 9955 & Metatarsal III \\
\hline TMP 2014.012.0019 & Two damaged vertebral elements, unprepared \\
\hline TMP 2010.120.0008 & femora (not described) \\
\hline TMP 83.180.0001 & Juvenile left humerus. \\
\hline & Juvenile left ilium preserved in a half plaster \\
\hline & jacket. \\
\hline & Juvenile left humerus. \\
\hline & Material from a bonebed of partial, non adult \\
\hline
\end{tabular}




\section{Hadrosaur Material Locality Information}

CMN 58592 was collected from the Foremost Formation approximately $1.6 \mathrm{~km}$ northeast and $3.2 \mathrm{~km}$ east from the town of Foremost, Alberta, within Chin Coulee (Alberta Township System [ATS] coordinates of 27-6-2-W4) (Fig. 6.2). CMN 58592 was collected during the summer of 1957 by Wann Langston Jr. It was found within deposits consisting of light coloured clays, sands, and iron nodules. The site of deposition was located approximately $15 \mathrm{~m}$ below prairie level and $6 \mathrm{~m}$ above indurated beds containing high numbers of shells attributed to the bivalve Ostrea and approximately $10 \mathrm{~m}$ below the first of several coal seams (W. Langston, Jr., unpublished 1957 field notes on file at the Canadian Museum of Nature). Based on these observations CMN 58592 is located in the upper Foremost Formation, just below the Taber Coal Zone.

CMN 9951 was collected by Langston, Jr. in 1960 (W. Langston, Jr., unpublished 1960 field notes on file at the Canadian Museum of Nature). It was located approximately $16 \mathrm{~km}$ northeast of the town of Wrentham within a cutbank in the Chin Coulee area (ATS coordinates 21-7-15-W3) (Fig 6.2). Details about the locality can be found on record at the CMN collections in Ottawa, Ontario, Canada. Although the locality cannot be relocated, based on the outcrop in the region it could only have come from the upper Foremost Formation.

The RTMP material was collected from multiple locations containing outcrops of the Foremost Formation, although none of the exact stratigraphic horizons are precisely known, with those that were recorded simply recording the "Taber Coal Zone". TMP 
83.180.0001, referred to as "Kritosaurus" sensu by Brett-Surman (1989) was recovered from the Chin Coulee area, just south of the community of Cranford, Alberta, located approximately $34 \mathrm{~km}$ east of the city of Lethbridge (Fig 6.2). TMP 2010.120.002 and TMP 2010.120.008 were collected in badlands along the South Saskatchewan River south of the town of Hays, Alberta (Fig 6.3). TMP 2014.012.0019 was collected north of Jenner, Alberta along the Red Deer River (Fig 6.3). Their precise stratigraphic horizons within the Foremost Formation are unfortunately not recorded.

\section{Institutional Abbreviations}

Canadian Museum of Nature, Ottawa, Canada (CMN); Royal Ontario Museum (ROM);

Royal Tyrrell Museum of Palaeontology, Drumheller, Canada (TMP). 


\section{Chapter 2: Lithostratigraphy}

\section{1: Geological Setting}

The Belly River Group encompasses, in ascending order, the Foremost, Oldman and Dinosaur Park formations (Fig. 1.2) and is underlain by the marine Pakowki Formation and overlain by the marine Bearpaw Formation (Eberth, 2005). Foremost Formation outcrops presently range from southern Alberta and Saskatchewan across the United States border where time-equivalent strata are recorded as part of the Judith River Formation in northern Montana (Caldwell, 1983; Eberth and Hamblin, 1993; Rogers et al., 2016). The Judith River Formation was deposited via a separate, more southerly sediment lobe (Rogers et al., 2016). Foremost Formation sediments are derived from the uplifted and exposed sedimentary, volcanic and plutonic igneous and metamorphic rocks of the eastern slopes of the Cordillera associated with the Laramide Orogeny (Ogunyomi and Hills, 1977; Eberth and Hamblin, 1993; Leckie and Smith, 1993). Specifically, this sediment was derived from areas of southwestern British Columbia and northwestern Montana with the resulting depositional lobe prograding northeastward based on previously observed palaeoflow directions (Eberth and Hamblin, 1993; Eberth, 2005). The Foremost Formation represents an easterly thinning clastic wedge deposited within the foreland basin along the Sweetgrass Arch and displays an overall prograding to aggrading profile of varying thickness and an overall regressional sequence that interfingers with the Pakowki Formation towards the northeast, with the regressional trend interrupted by brief transgressive intervals (Eberth and Hamblin, 1993). The Foremost Formation is recognized in outcrop and subsurface core by the two distinct coal bearing units, the McKay and Taber Coal zones, which traditionally been used to define 
its lower and upper boundaries respectively (Fig. 1.3). Several transgressive-regressive intervals separate these coal zones. Two successional facies models were proposed by Ogunyomi and Hills (1977) and Kwasniowski and Eberth (1993), which suggest the Foremost represents a transitional environment from fully marine to fully terrestrial deposits. The Foremost Formation is overlain by the fully terrestrial Herronton Sandstone unit, which is currently classified as the most basal subdivision of the Oldman Formation (e.g., Peng et al., 2001; Brinkman et al. 2004; Eberth, 2005, 2015; Cullen et al. 2016). However, this position is debated, as the boundary of the Herronton Sandstone is recognized as gradational and conformable with the sediments of the Taber Coal Zone (Eberth, 2005). In addition, a major sequence boundary separates the Herronton Sandstone from the Oldman Formation (Eberth and Hamblin, 1993; Ryan et al., 2012; Cullen et al., 2016). For these reasons incorporation of the sandstone within the top of the Foremost Formation seems more plausible.

Radiometric dates of $80 \mathrm{Ma}$ to $78 \mathrm{Ma}($ Error $= \pm 0.16 \mathrm{Ma})$ for the Foremost Formation have been derived using ${ }^{40} \mathrm{Ar} /{ }^{39} \mathrm{Ar}$ and $\mathrm{K}$-Ar isotope analyses from sanidine crystals within bentonites of the Mackay Coal Zone and the Taber Coal Zone, respectively (Eberth and Deino 1992; Rogers et al. 1993; Freedman-Fowler and Horner, 2015). The stratigraphic thickness of the Foremost Formation is approximately $170 \mathrm{~m}$ at maximum in core samples (Glass, 1997); however, outcrops in the Milk River area studied here typically expose approximately $80 \mathrm{~m}$ of strata, and exposed outcrops elsewhere are more commonly in the range of 10 to $30 \mathrm{~m}$ thick (Ryan et al., 2012). 


\section{2: Results}

\subsection{1: Stratigraphic Sections}

Section A

Section A (UTM 12 U0509422 5441219) is located on the south side of the Milk River and has a total thickness of $17.5 \mathrm{~m}$ (Fig. 2.2). The basal $7 \mathrm{~m}$ are composed primarily of alternating grey siltstone and light yellow fine-grained, 10 to 30-cm-thick sandstone interbeds (Fig. 2.2). Within this unit are two, $30 \mathrm{~cm}$ thick distinct dark grey to black coloured organic-rich beds of siltstone of which the lower has minor iron rich concretions and red and white alteration marking its exposed surface (Fig. 2.2). These concretions and alterations are carbonate rich, reacting readily with acid, and are likely composed of iron enriched calcite based on their orange colouration. A 5.5-m-thick sandstone dominated interval overlies the uppermost organic rich mudstone. Lithification of this sandstone interval increases within the last $2 \mathrm{~m}$ (Fig. 2.2). Within the middle of this unit is another 30-cm-thick band of organic rich siltstone (Fig. 2.2). Capping the whole section is a 5-m-thick well consolidated, siderite cemented layer of sandstone with tabular to slight cross bedded structures and an orange oxidized colouration (Fig. 2.2).

\section{Section B}

Section B (UTM 12 U0509580 5441087) is located approximately $57 \mathrm{~m}$ up section from Section A and an interval of $15 \mathrm{~m}$ was measured there (Fig. 2.3). The basal part of Section B is marked by a 50-cm-thick medium grained sandstone unit that is rich in bivalve fossil material assignable to the oyster Crassostrea subtrigonalis (Johnston and Hendy, 2005), with fossil abundance being high enough to classify the unit as a shell 


\section{Section Legend}

Planar bedded sandstone

Cross bedded sandstone

Sandstone

Siltstone
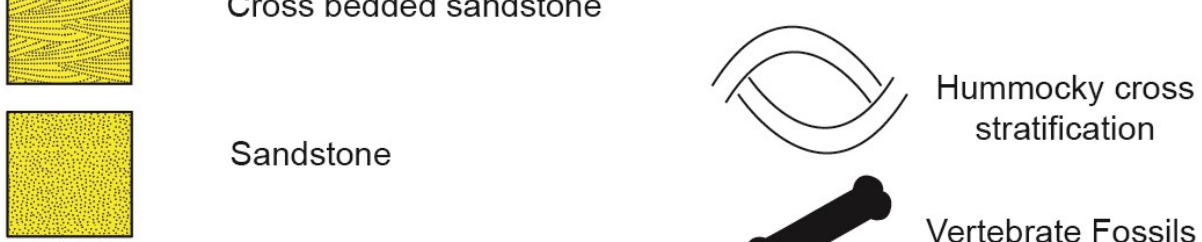

Sandstone
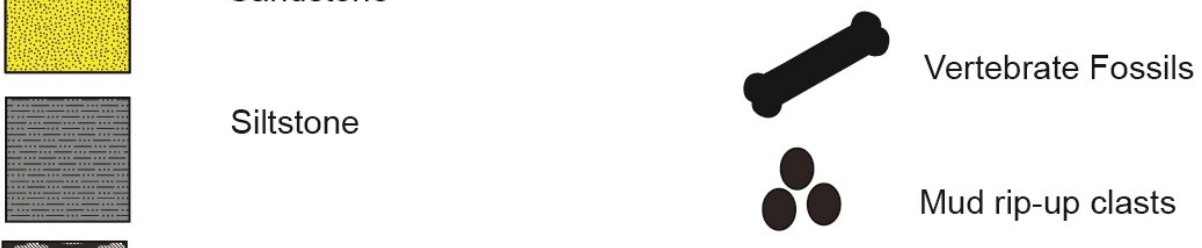

Coal
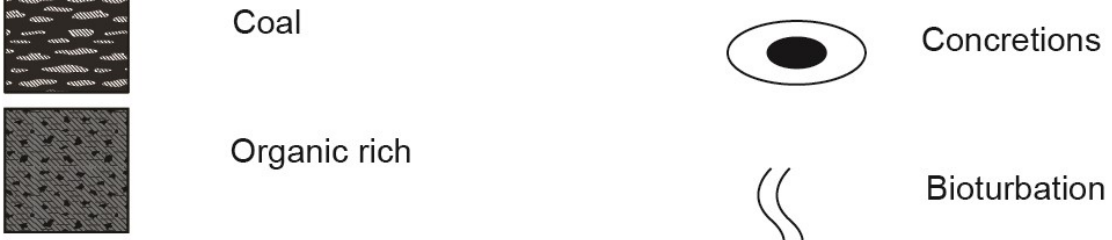

Organic rich
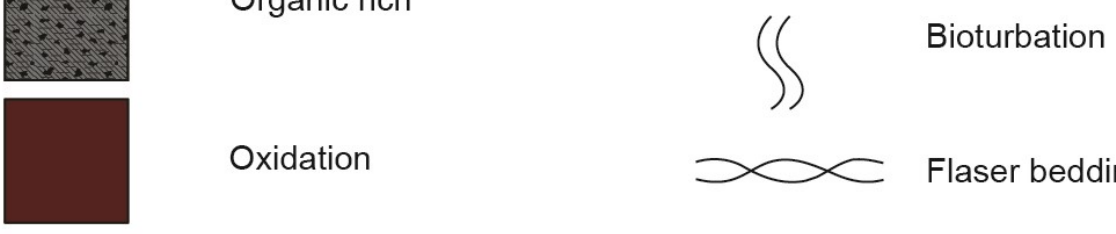

Oxidation

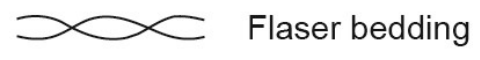

Shell bed

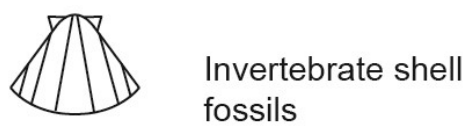

Covered section

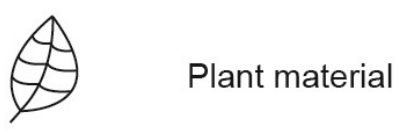

cly sts vf $\underset{\text { Sandstone }}{\mathrm{f}} \mathrm{c}$ vc

F1 Facies

\section{Grain Size Abbreviations}
cly-clay
vf - very fine
$\mathrm{m}$ - medium
sts - silt
$f$ - fine
c - coarse
vc - very coarse

Figure 2.1: Legend for the Stratigraphic Section illustrations presented in this study. 

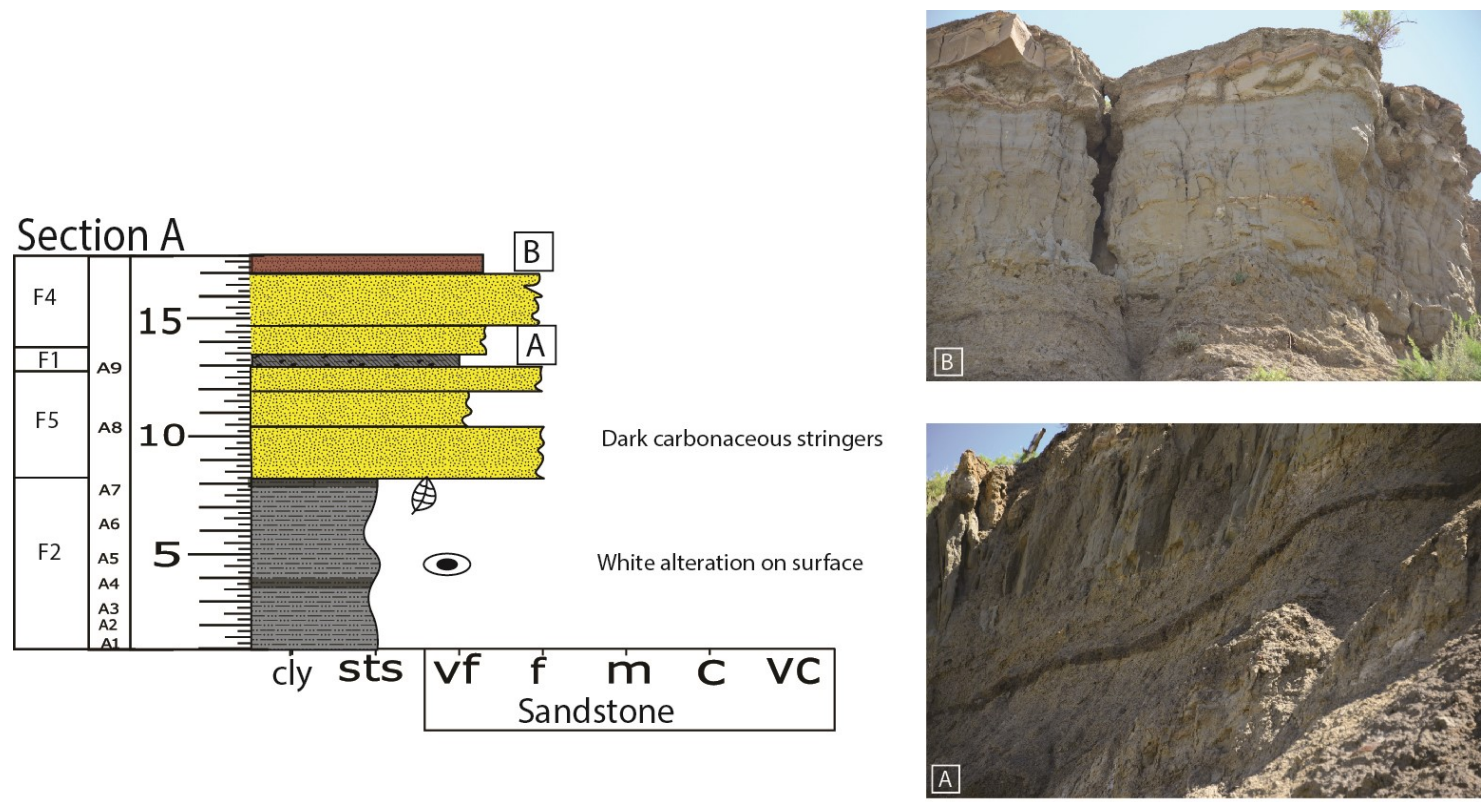

Figure 2.2: Stratigraphic log of Section A with facies on the left and outcrop photos on the right. A: Facies 1 outcropping as a dark grey to black, organic rich bed within lighter coloured siltstone and sandstone. B: Top of section $\mathrm{C}$ displaying Facies 4 barrier sandstone changing into an iron calcite cemented shoreface sandstone unit with undulatory appearance. For legend see Figure 2.1. 

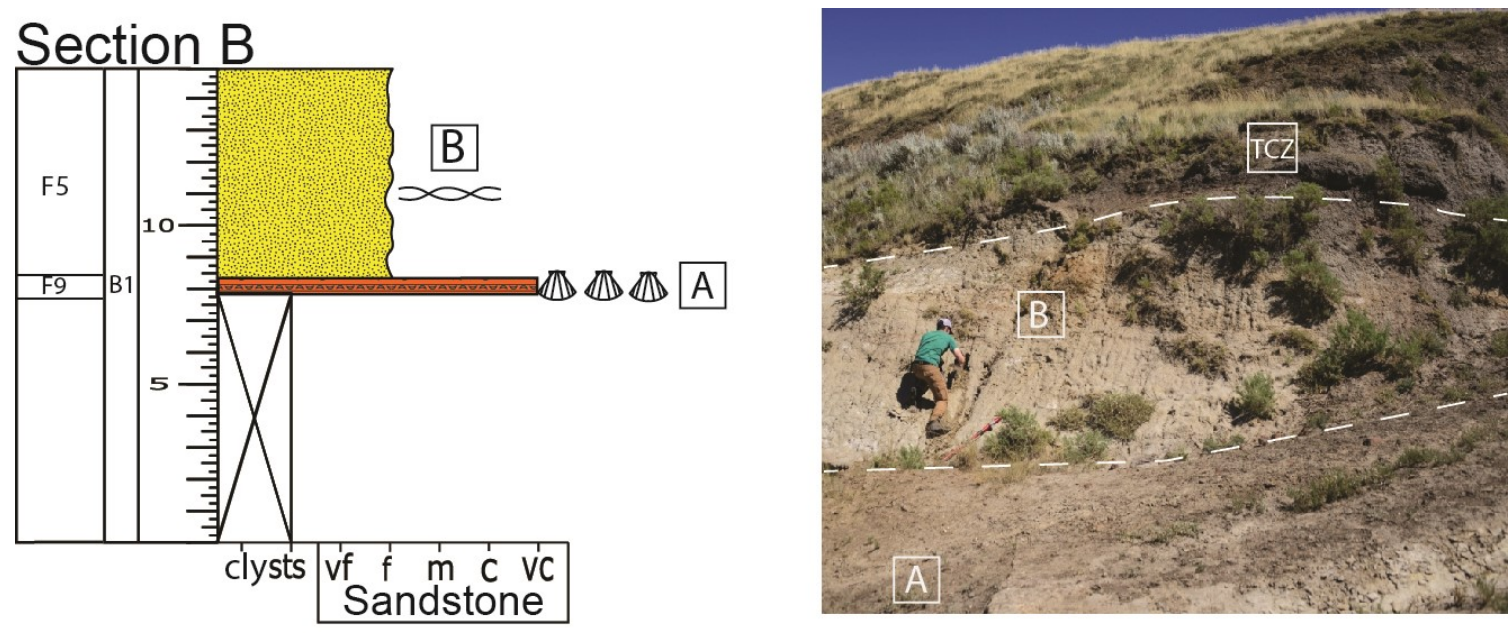

Figure 2.3: Section B with assigned facies and outcrop photo. A: Top of estuarine Crassostrea conglomerate. B: Flaser bedded sandstones. TCZ $=$ Taber Coal Zone, not measured due to partially covered. Human scale $=1.75 \mathrm{~m}$. For legend see Figure 2.1. 
conglomerate (Fig. 2.3). Valves are generally well preserved with little fragmentation or abrasion present and are in approximately the same direction. Above this shell unit are 7 $\mathrm{m}$ of loosely consolidated, grey to light yellow sandstone (Fig. 2.3). Overall abundance of organic material within the sandstone increases up section, with carbonaceous stringers present throughout as well as thin flaser bedded siltstone laminae.

\section{Section $C$}

Section C (UTM 12 U0509722 5442150), located on the north side of the Milk River forms the main section of the Foremost Formation with a measured section of 145 $\mathrm{m}$ (Figs. 2.4 and 2.5). The basal portion is represented by a 1-m-thick distinct dark, organic rich siltstone bed resembling that seen in the top level of Section A. A lone tooth attributable to Enchodus sp., several partial rib elements from a champsosaur and fragments of turtle shell fossils were found at the base of the section. A 1-m-thick grey, deconsolidated sandstone unit overlies this dark siltstone bed (Figs. 2.4 and 2.5). Directly above the sandstone is a fining upward succession of non-bioturbated interbedded siltstones and sandstones with a bed thickness of approximately $30 \mathrm{~cm}$ (Figs. 2.4 and 2.5). Sandstone interbeds often show hummocky cross stratification. Overlying this interbedded siltstone section is a grey, well consolidated sandstone approximately $10-\mathrm{m}-$ thick (Figs. 2.4 and 2.5). Bivalve fossils are restricted to thin lenses and are disarticulated. Medium grained, resistant, but laterally restricted sandstone units with cross stratification are found within this sandstone unit and are easily recognized in outcrop by their iron oxidized colouration.

Above these sandstones the section fines upward, changing into a 45-m-thick interbedded siltstone and sandstone unit essentially identical to the one described from 
Figure 2.4: (see page 41): Section $C$ with assigned facies and outcrop photos. A: Offshore siderite cemented firmground in outcrop. Note the concretionary appearance. Breakage is secondary due to weathering. B: Barrier Island sideritic mud rip-up intraclasts in sandy matrix. C: Outcrop appearance of vertebrate microsite C26 showing surface exposed vertebrate fossil material D: Crassostrea shell conglomerate displaying shell orientation and size. E: Outcrop appearance of unionid bivalve shell bed featuring shell orientation and breakage. For legend see Figure 2.1. 
Section C
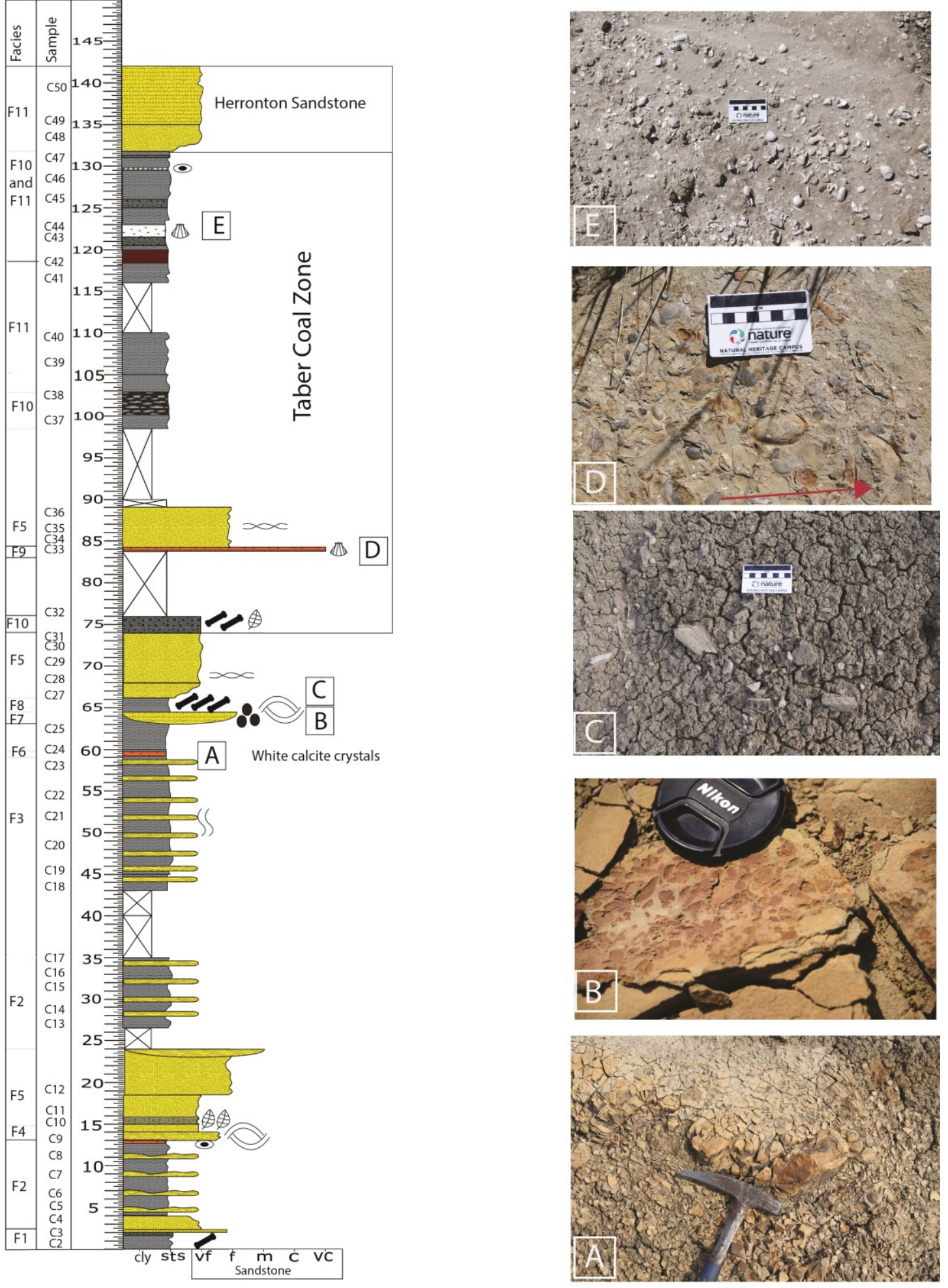
Figure 2.5: (see page 43): Measured Section $C$ and photograph of surrounding slope face. Black dotted lines show laterally correlative surfaces compared between illustration and outcrop. The red dot is located just to the left of the C26 microsite. Vertical white dotted lines indicate sections measured in outcrop. Scale bar $=5 \mathrm{~m}$ vertical. 


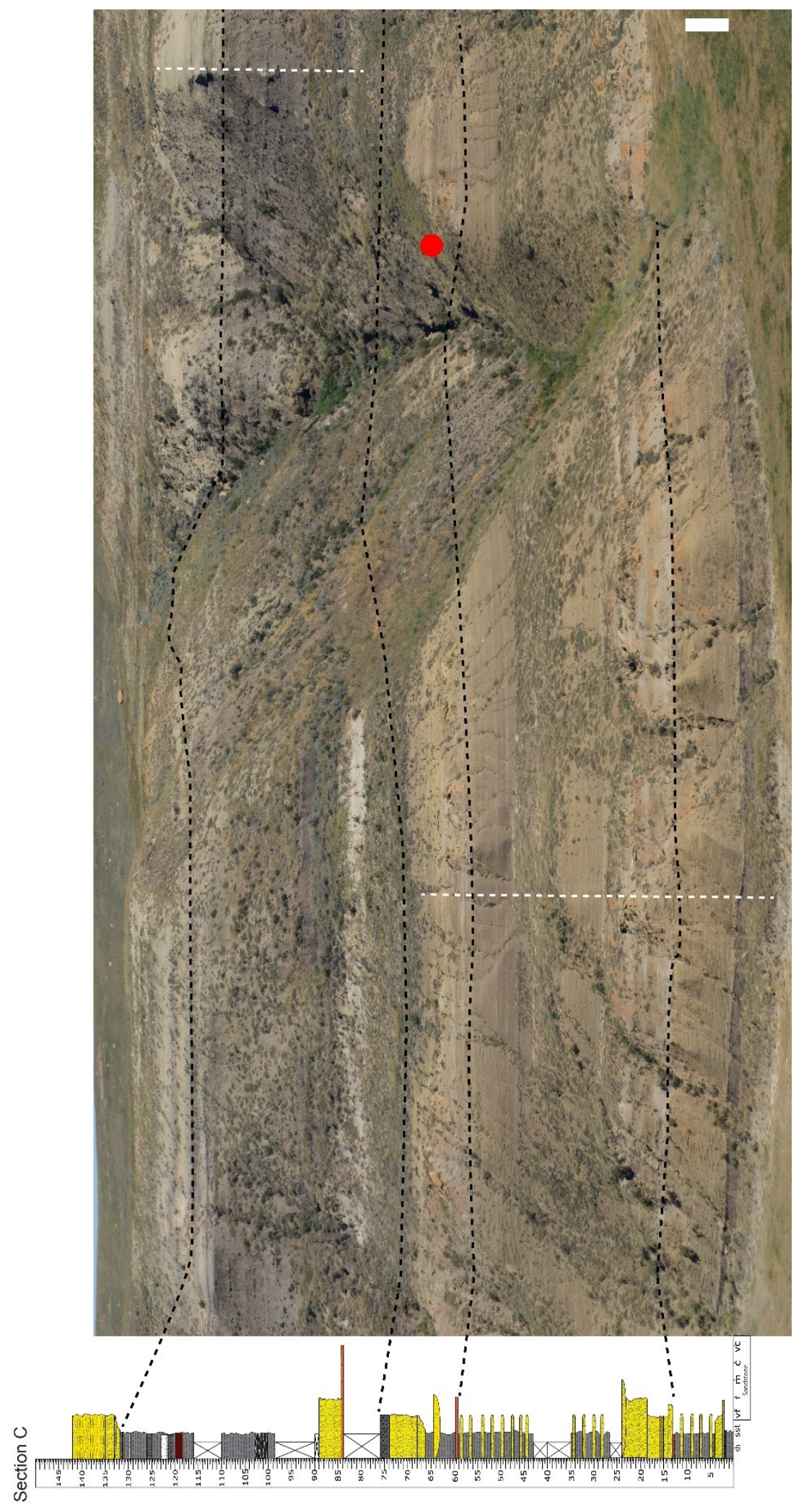


the lower portion of Section $\mathrm{C}$ in terms of lithology and bedding structure. This interbedded unit is interrupted by two covered sections (Figs. 2.4 and 2.5). Fossil plant content increases up section as do ichnofossils restricted to Planolites. The interbedded siltstone is terminated by a 30 -cm-thick, iron oxidized concretionary surface that is then overlain by approximately $1 \mathrm{~m}$ of dark grey siltstone that grades into sandstones not dissimilar to those encountered lower in section. However, this 1-m-thick sandstone bed contains mud rip-up clasts (Fig. 2.4). A vertebrate microsite labeled C26 overlies this sandstone horizon (Figs. 2.4 and 2.5). This microsite is overlain by fine grained sandstone changing into coal bearing, platy siltstone that marks the first coal bed of the Taber Coal Zone and is $7 \mathrm{~m}$ in stratigraphic thickness. After an 8-m-covered section, a Crassostrea subtrigonalis oyster bearing conglomerate like that in Section B is encountered, being overlain by the same flaser bedded sandstone encountered in Section B (Fig. 2.4).

Above an approximately $10 \mathrm{~m}$ covered section, a 11.5-m-thick fissile, structureless coal bearing siltstone was measured (Figs. 2.4 and 2.5). Plant fossil material within this unit decreases up section. This horizon is then overlain by lighter grey siltstone of similar overall lithology, but with no coal content and abundant white, mother of pearl style bivalve fossils attributable to the genus Unio in the upper portions. Above this bivalve-rich upper zone is another coaly horizon with some parts weathering slightly red, but overall being dark grey to brown in colour. The top of the section is formed by the light grey, fine grained Herronton Sandstone of the Oldman Formation containing a conspicuous, Unio valve rich layer at the base. 


\section{Section D}

Section D (UTM 12 U 05078425442111 ) is located near the road entrance to the Pinhorn Ranch and covers a stratigraphic interval of $15 \mathrm{~m}$ (Figs. 2.6 and 2.7). The base is characterized by a fine-grained sandstone unit with abundant valves of the oyster Crassostrea subtrigonalis (Fig. 2.7). Unlike those $C$. subtrigonalis shells observed in Sections B and C, these shells are not as indurated, nor do their axes align in a preferred flow direction. Valves encountered here are restricted to lenses approximately 5 to $10 \mathrm{~cm}$ thick. Additionally, there is a greater degree of broken valve material within this unit as opposed to the C. subtrigonalis conglomerate of Sections B and C. The sandstone within this unit is a dark grey as opposed to the orange of the bivalve conglomerate in B and C.

Moving up section, $9 \mathrm{~m}$ of grey, fine grained sandstone overlies the Crassostrea unit and becomes increasingly more consolidated in its latter half, finally terminating as a dark grey to black, highly organic rich unit (Figs. 2.6 and 2.7). This particular organic rich layer contains one notable 1-m-thick bed with a trough shaped, moderately sorted, medium sandstone with a sharp, erosional scour like contact (Figs. 2.6 and 2.7). This feature interpreted as a channel appears to be localized to this particular section. The channel is overlain by a $2 \mathrm{~m}$ thick laterally extensive read weathered bed. The upper part of Section D is rich in large (up to $5 \mathrm{~cm}$ ) plant fossil fragments. The top of section D is a dark grey, platy siltstone (Figs. 2.6 and 2.7), with abundant plant material, though albeit with lower concentration compared to the underlying unit. 


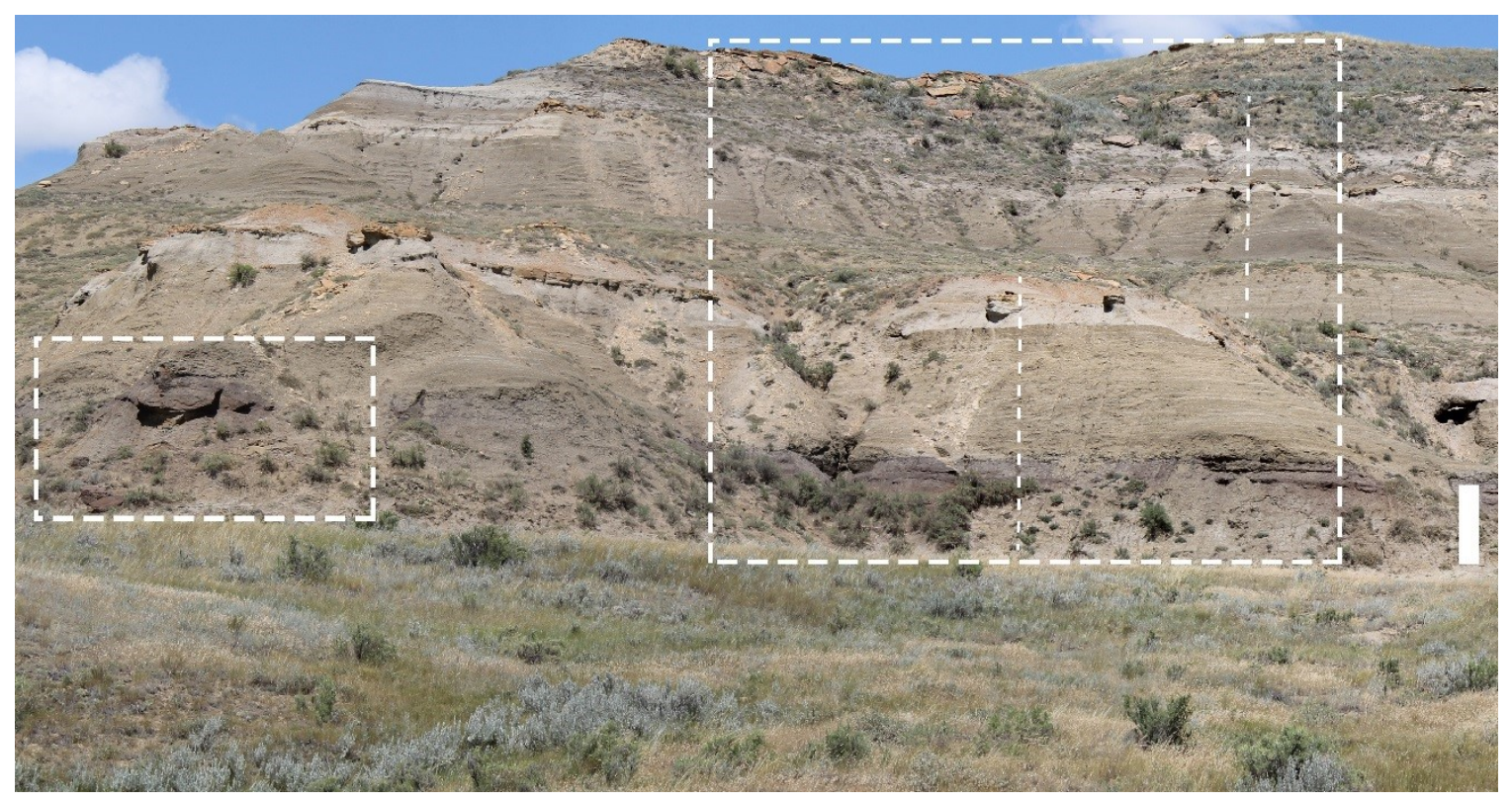

Figure 2.6: Outcrop profiles and relative positions of Section D (left box) and Section E (right box). Vertical dotted lines indicate position of composite sections measured for Section E. Scale bar $=5 \mathrm{~m}$ vertical. 


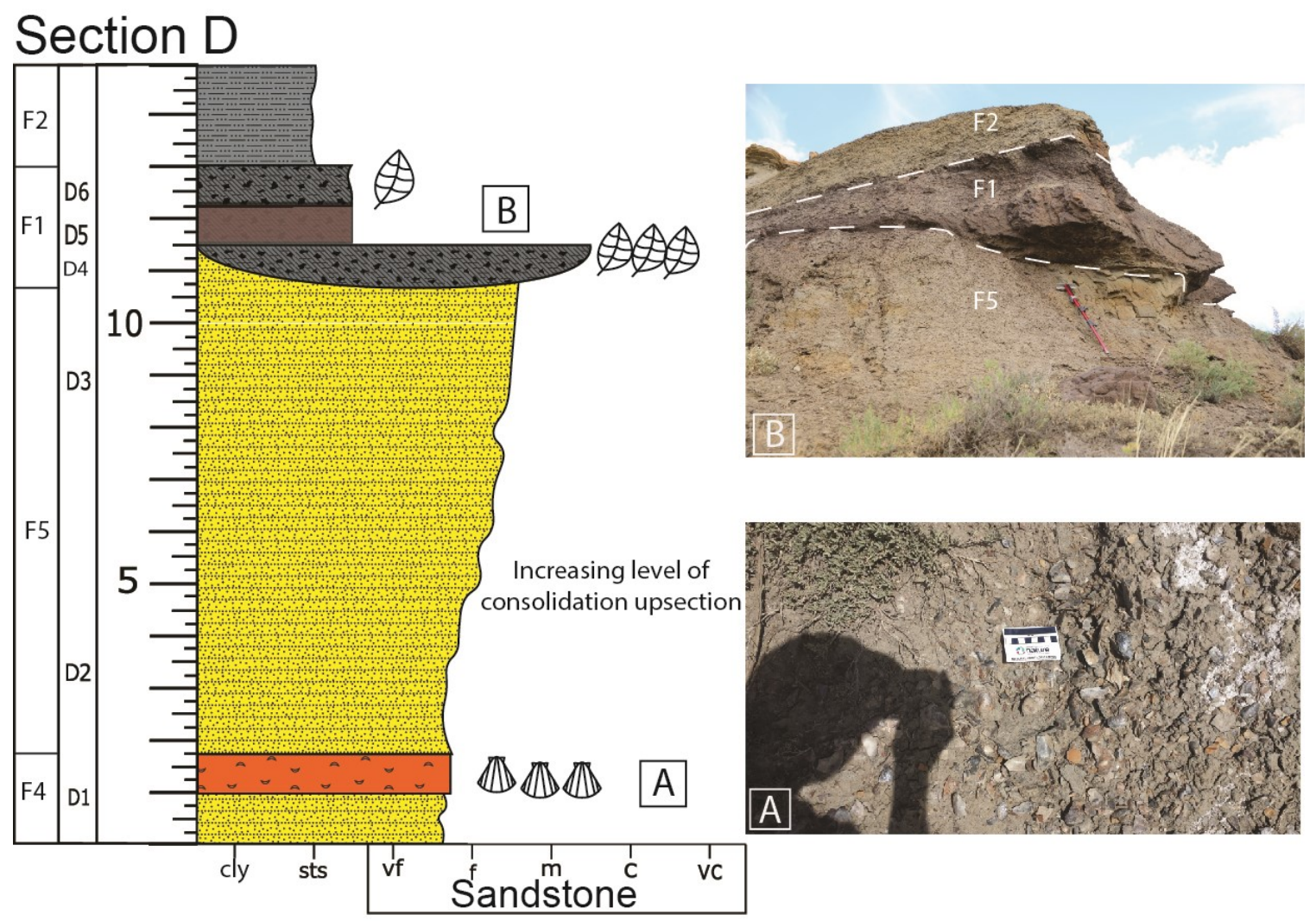

Figure 2.7: Section D with assigned facies on left and outcrop photos on right. A: Basal Crassostrea shoreface shell bed. Note the difference in colour of unit as well as sorting and preservation of shell material in relation to estuarine shell conglomerate in Section B and Section C. B: Facies 1 in outcrop at Section D. Note the preserved channel bed displaying a sharply erosional lower contact located just above the Jacob's staff (1.5 m). For legend see Figure 2.1. 

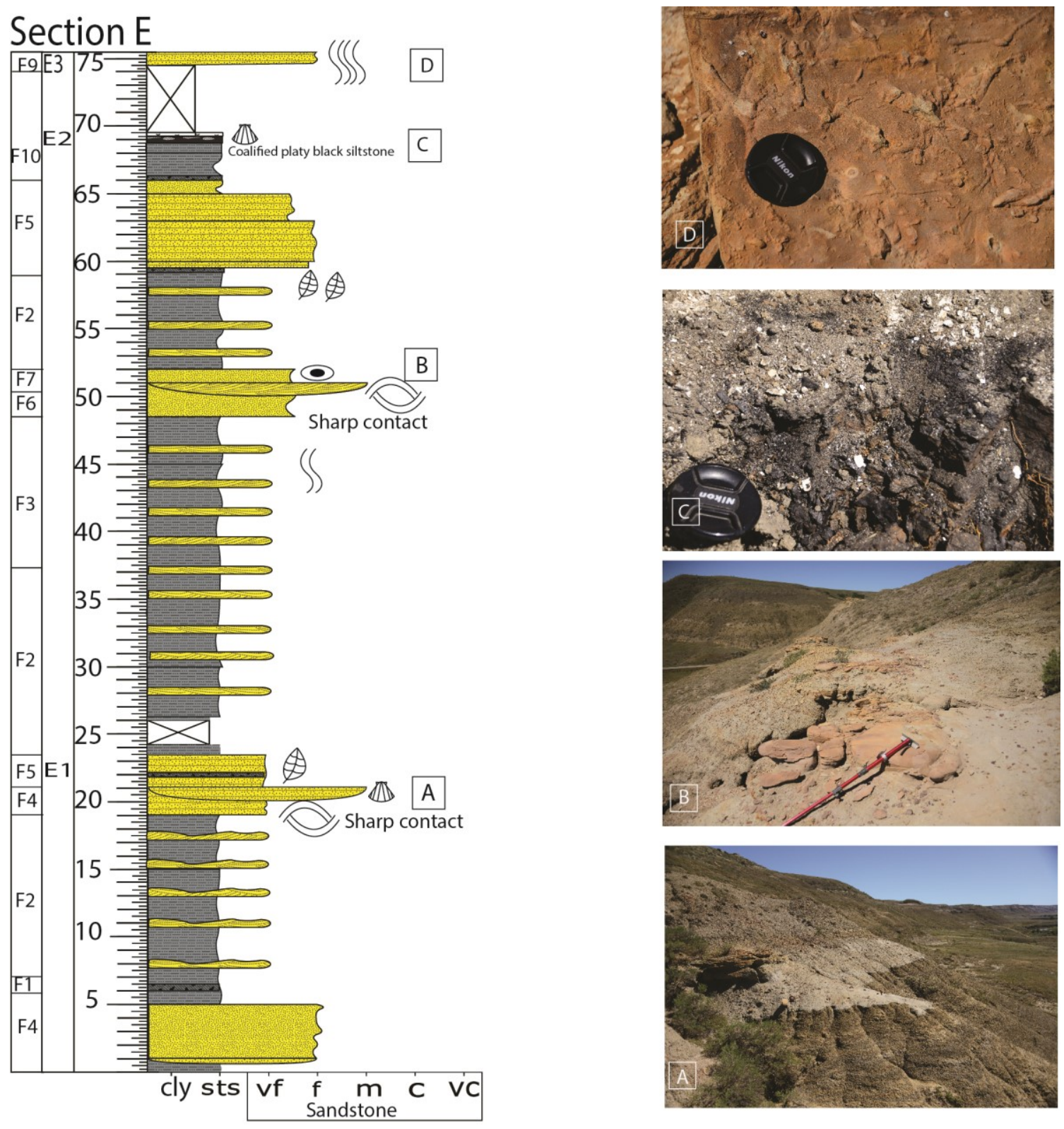

Figure 2.8: Section E with assigned facies on left and outcrop photos on right. A: Sharp, discontinuity between underlying lagoonal siltstones and barrier island sandstones. B: Barrier island sandstone outcrop with siderite cement. C: Highly organic, fossil-rich basal unit of the Taber Coal Zone. D: Heavily bioturbated, siderite rich estuarine sandstone located at the top of Section E. Burrows are assignable to Ophiomorpha. For legend, see Figure 2.1. 


\section{Section E}

Section E (UTM 12 U 0507878 5442117) is located further east adjacent to Section D and comprises $75 \mathrm{~m}$ of strata (Figs. 2.6 and 2.8). The base is formed by a 5- $\mathrm{m}$ thick, light grey, fine grained sandstone that is overlain by a $30-\mathrm{cm}$-thick organic fossil rich horizon (Figs. 2.6 and 2.8). This organic rich unit is laterally traceable to the organic rich unit in Section D, however its overall thickness is considerably reduced and no channel structures, medium sand content or red oxidization are observed. As in Section $\mathrm{C}$, siltstone and sandstone interbedded horizons follow this basal organic rich siltstone (Figs. 2.6 and 2.8). These set of interbedded siltstones and sandstones are approximately 13-m-thick and are identical to those in Section C. They are in turn overlain by a sharp, erosionally bounded $4 \mathrm{~m}$ thick sandstone bed that displays crossbedding structure and fragmentary bivalve material in isolated beds up to $1 \mathrm{~m}$ in thickness (Figs 2.6. and 2.8). Above these bivalve rich beds there is a general increase in organic material within the sandstone. Overlying the sandstones is another approximately $21.5 \mathrm{~m}$ thick siltstone and sandstone interbedded unit (Figs. 2.6 and 2.8). Sandstone interbeds are near identical in thickness and composition as Section C, displaying swaley to hummocky cross stratification in some sandstone beds. This interbedded unit is then overlain by another sharp bounded sandstone unit which in turn is overlain by $8 \mathrm{~m}$ of siltstone grading into fine grained sandstone terminated by a highly organic-rich, dark 10 to 20 -cm-thick siltstone bed (Figs. 2.6 and 2.8). Overlying this organic-rich bed is a light grey, medium sandstone that is well consolidated and approximately 3-m-thick that becomes fissile and less consolidated for an additional 3 m (Figs. 2.6 and 2.8). Directly overlaying these sandstones is a dark, coalified layer of fissile black siltstone, marking the first coal seam 
of the Taber Coal Zone as in Section C. This layer is approximated 4-m-thick and contains abundant white bivalve shell fragments within the top metre. There is a $4 \mathrm{~m}$ covered section that is then overlain by extremely well consolidated, orange to red oxidized, siderite rich fine to medium sandstone (Figs. 2.6 and 2.8). This sandstone layer is notable for its abundance of large Ophiomorpha burrows, approximately 1 to $5 \mathrm{~cm}$ in diameter and up to $30 \mathrm{~cm}$ long (Figs. 2.6 and 2.8). This sandstone also contains shell fossil deposits similar to the shell conglomerate of Sections B and C and occurs at approximately the same stratigraphic horizon. This sandstone terminates Section E.

\subsection{2: Facies Description}

Detailed logging of the Foremost Formation sections resulted in the differentiation of 11 distinct facies (summarized in Table 2.1). Visual outcrop observations were augmented by detailed lithological analysis of the sediment fraction using optical microscopy while sorting for Foraminifera and microvertebrate specimens.

\section{Facies 1 (Salt Marsh):}

\section{Lithofacies:}

Facies 1 consists of soft, black, mudstone with fissile breakage located at the base of Sections C and E, near the top of Section D and Section A (Figs. 2.1 - 2.8). Grain size ranges from clay to silt and fossil plant material constitutes up to $25 \%$ of total sediment. Plant material is black and coaly giving the dark colour to the unit. Units containing this facies are $30 \mathrm{~cm}$ to $3-\mathrm{m}$-thick in outcrop and display a sharp, erosional upper boundary with the overlying sandstone. There are no apparent bedding structures within outcrops of Facies 1. 
Table 2.1: Table outlining a summary of facies names and interpretations as identified within Chapter 2 of this study.

\begin{tabular}{|c|l|l|}
\hline Facies \# & \multicolumn{1}{|c|}{ Facies Name } & \multicolumn{1}{|c|}{ Facies Interpretation } \\
\hline F1 & Basal organic rich siltstone facies & Brackish relatively unrestricted lagoonal marsh \\
\hline F2 & $\begin{array}{l}\text { Siltstone with small sandstone } \\
\text { interbeds facies }\end{array}$ & $\begin{array}{l}\text { Lagoon with washover sand interbeds } \\
\text { very fine sandstone facies }\end{array}$ \\
\hline F3 & Gioturbated interbeded siltstone and & $\begin{array}{l}\text { Lagoon located more shoreward with greater } \\
\text { freshwater influence }\end{array}$ \\
\hline F5 & $\begin{array}{l}\text { Organic rich, grey sandstone facies, } \\
\text { with carbonaceous stringers and } \\
\text { flaser bedding }\end{array}$ & $\begin{array}{l}\text { Shoreface sands on the oceanward side of barrier } \\
\text { islands }\end{array}$ \\
\hline F6 & $\begin{array}{l}\text { Siderite rich calcite concretionary facies } \\
\text { over influence }\end{array}$ & $\begin{array}{l}\text { Transgressive flooding surface; early diagenetic } \\
\text { hardground in an offshore transitional setting }\end{array}$ \\
\hline F7 & $\begin{array}{l}\text { Laterally discontinuous, crossbedded } \\
\text { sandstones with rip up clasts facies }\end{array}$ & $\begin{array}{l}\text { Barrier shoreface sands influenced by high energy } \\
\text { storms and waves }\end{array}$ \\
\hline F8 & Vertebrate microsite facies & $\begin{array}{l}\text { Quiet water, brackish lagoon with slow fossil } \\
\text { accumulation rate }\end{array}$ \\
\hline F9 & $\begin{array}{l}\text { Crassostrea and Ophiomorpha bearing } \\
\text { sandstone facies }\end{array}$ & Brackish estuarine deposits \\
\hline F10 & Coal bearing silstone facies & Brackish to freshwater marshes on coastal plain. \\
\hline F11 & Unionid shell rich sandstone facies & Freshwater fluvial deposits \\
\hline
\end{tabular}




\section{Biofacies}

Facies 1 contains the most abundant and diverse Foraminifera assemblage from any strata studied here (see Chapter 3). Large quantities of plant fossil material are also present, ranging from medium sand size fragments to large, intact leaf impressions and carbonized body fossils. Fossils of Enchodus sp., and fragments of champsosaurs and turtles were also found within Facies 1 at the base of Section C (Sample C1).

\section{Interpretations}

Based on the presence of common plant fossil material, the lack of bedding structures, wide spread lateral continuity in association with the underlying sandstone facies, and clay to silt-sized grains suggesting low energy marine deposition, this facies is interpreted as a salt marsh situated on the shoreward side of a estuarine mouth barrier or barrier island complex (Boggs, 2006). This interpretation is primarily based on the presence of a distinct salt marsh Foraminifera assemblage further supports this interpretation (see Chapter 3). Additionally, portions of this facies from Section D that exhibit sharp upper and lower contacts, lateral discontinuity, and a significant proportion of medium sand grains are interpreted to be interdistributary channels connecting these marshes to the marine environment (see Section D; Fig. 2.6).

\section{Facies 2 (Outer Estuarine Central Bay/Lagoonal):}

\section{Lithofacies}

Facies 2 consists primarily of dark grey locally fissile siltstone interbedded by fine sandstone intervals. In outcrop, interbeds of siltstone and sandstone in this facies typically measure 10 to $20 \mathrm{~cm}$ thick. The colours of the sandstones vary from light grey 
to tan and yellow (Figs. 2.4 and 2.8). Swaley to hummocky cross stratification of these interbeds is observable, especially within lower units containing this facies, with hummocks measuring up to $0.5 \mathrm{~m}$ in width (Fig. 2.4). Facies 2 is found in the lower half of Sections C and E and at the top of Section D.

\section{Biofacies}

No visible trace fossils are present within Facies 2, nor are there any vertebrate fossils. Rare to common ( 5 to $10 \%$ ) plant fossil material and bivalve fragments are present when viewed under optical microscopy. A sparse, low-diversity agglutinated Foraminifera assemblage occurs and is outlined in greater detail in Chapter 3.

Interpretations

Facies 2 is characterized by cross-stratified sandstone beds interbedded with organic rich, finer grained siltstones, bearing agglutinated Foraminifera. Facies 2 represents a low energy back barrier estuarine central bay or lagoon (marine proximal) setting, with the sandstones likely deposited by storm-generated overwash events (Plint, 2010). Brackish conditions are suggested by the low diversity Foraminifera fauna, dominated by the brackish tolerant Haplophragmoides rota.

\section{Facies 3 (Inner Estuarine Bay/Lagoonal):}

\section{Lithofacies:}

Facies 3 contains the similar overall lithological composition as that seen in Facies 2, but with increased bioturbation. Facies 3 has a larger siltstone bed to sandstone 
bed ratio than Facies 2 which contributes to the darker colouration of Facies 3 compared to Facies 2. Facies 3 was recognized within Section C and Section E (Figs. 2.5 and 2.8).

\section{Biofacies:}

Foraminifera abundance and diversity decreases upsection within this facies and sediments eventually become barren (see Chapter 3 for more detail). The amount of plant fossil material slightly increases relative to Facies 2 , but decreases gradually up section. Common, well preserved horizontal ichnofossils are attributable exclusively to Planolites, and measure 2 to $6 \mathrm{~cm}$ in length and approximately $1 \mathrm{~cm}$ in diameter.

\section{Interpretations}

Facies 3 contains a larger percentage of siltstone beds relative to sandstone beds overall and increased horizontal bioturbation structures compared to Facies 2 and a net loss of Foraminifera. Thus, Facies 3 is interpreted as a brackish estuary central bay or lagoonal environment that experienced greater freshwater influence and reduced storm disturbance than that of Facies 2.

\section{Facies 4 (Estuary Mouth Barrier or Barrier Island):}

\section{Lithofacies:}

Facies 4 contains light grey and resistant fine-grained sandstones with inclined heterolithic strata (IHS) arranged as crossbeds. Facies 4 is found within Sections C, D and $\mathrm{E}$ at various levels, though always within close association with an underlying silty mudstone facies separated by a sharp boundary (Facies 2 or Facies 3). Some horizons 
also contain 1-m-wide, medium grained, resistant, crossbedded, iron oxidized and laterally discontinuous sandstone units.

\section{Biofacies}

Small lenses of cross bedded bivalve fossil fragments can be found, often within the base of units containing these facies. Bivalves are attributable to Crassostrea subtrigonalis. Valves are aligned relative to the same current direction, are compacted, abraded and fragmentary when present. Other fossil material is absent.

\section{Interpretations}

Facies 4 displays crossbedded, predominantly fine grained arenitic sandstone that suggest a high energy, wave influenced environment. Crossbedded lamina and beds containing abundant Crassostrea subtrigonalis valves are determined to be related to high energy storm events based on shared valve orientations, compaction of valves and relatively high abrasion of valve material. Crassostrea subtrigonalis is a common oyster species in shoreface to brackish environments, indicating relatively high freshwater influence (Hsieh et al., 2000). Facies 4 and Facies 5 are always found underlying the central bay/lagoonal deposits of Facies 2 . The laterally discontinuous, coarser grained portions are considered here to be small interbar channels that connected the bays/lagoons to the open ocean. Based on this evidence, Facies 4 represents barrier sandstones and their interdistributary channels found on the margin of coastal estuaries or lagoons. 


\section{Facies 5 (Back Barrier Tidal Bars):}

\section{Lithofacies:}

Facies 5 generally contains identical sand composition and texture as Facies 4 but with an increased degree of plant fossil material throughout and flaser bedding present in some sections. Facies 5 is poorly consolidated, with fine grained, yellow sandstone and abundant organic material preserved as dark carbonaceous stringers. Flaser beds are approximately 5 to $10 \mathrm{~cm}$ thick and arranged as low angle crossbeds. Facies 5 occurs in all sections measured, often in close association with Facies 4 and Facies 9 (Fig. 2.3).

Biofacies:

Plant fossil material decreases up section within this facies but is still relatively common compared with the other sandstone facies observed. Plant fossils are preserved as stringers. No body or trace fossils are present.

\section{Interpretations}

Intermittent flaser bedding indicates minor tidal influence, and large degrees of broken up plant fossil content suggests a relatively high energy setting adjacent to areas supporting abundant coastal plant growth. Crossbedding structures that would be expected from wave or current action are absent in Facies 5. This facies is interpreted as tidally influenced estuarine bar sand deposits receiving abundant plant material from nearby marshes. 


\section{Facies 6 (Iron Rich Calcite Firmground):}

\section{Lithofacies:}

Facies 6 is composed of a microcrystalline grain-sized layer with a hard concretionary appearance. It is orange to red with conspicuous $1 \mathrm{~mm}$ sized white carbonate crystals in weathered surfaces. Bedset thicknesses of Facies 6 range from 15 to $30 \mathrm{~cm}$. Its red colour, vigorous $\mathrm{HCl}$ effervescence, and enrichment in calcium and iron from geochemical evidence (see Chapter 4), indicate the presence of iron rich calcite and perhaps siderite as the premier mineral cementing the sand grains. This horizon is laterally continuous throughout the valley, though it is highly recessive in outcrop and appears as a rusty, surficial deconsolidated horizon in most areas. A single Facies 6 layer is present in sections $\mathrm{C}$ and $\mathrm{E}$ and found above Facies 3 in both.

\section{Biofacies:}

Trace and body fossil material are absent in this facies. Both the Glossifungites ichnofacies and an associated vertebrate microsite dominated by marine species have been associated with this facies by Beavan (1995).

\section{Interpretations}

The large concentration of iron rich calcite cemented fine grained sand and the fining upward trend in the mudstones that preceded it suggest that this facies represents an early diagenetic firmground surface associated with marine flooding and clastic sediment starvation. 


\section{Facies 7 (Storm Influenced Barrier Shoreface):}

\section{Lithofacies:}

Facies 7 is a yellow to grey, fine to medium grained sandstone with trough crossbedding in its lower half changing to hummocky cross stratification in its upper half. Truncating this shift in bedding style is a thin layer of dark orange to brown, angular to surrounded mud rip up intraclasts, approximately 1 to $3 \mathrm{~cm}$ in maximum dimension. This facies directly underlies the Facies 8 microvertebrate bonebed and overlies the siltstones in Section $\mathrm{C}$ and is present in Section $\mathrm{E}$ as well directly underlying the PHRN microsite (Fig. 5.13).

Biofacies

No fossil material is recognized in this facies.

\section{Interpretations}

Arenitic sand, mud rip up clasts and swaley to hummocky cross stratification separated by a sharp lower contact to underlying mudstones indicate high energy open marine conditions and possible storm activity. Facies 7 characterizes shoreface barrier deposits with pronounced storm activity located on the seaward side of estuarine mouth barriers or barrier islands.

\section{Facies 8 (Vertebrate Microsite):}

\section{Lithofacies:}

Facies 8 outcrops as a fissile siltstone unit with no apparent bedding structure. It is a dark grey colour on the outcrop surface that alters to a slightly metal blue colour 
when the outcrop is exhumed. In terms of bed morphology displayed, Facies 8 was only observed as a large siltstone wedge in section $\mathrm{C}$, measuring approximately $12 \mathrm{~m}$ wide and 0.3 to $2 \mathrm{~m}$ thick. This wedge is contained within a lighter grey unit of siltstone to fine sandstone and neither of these lithologies exhibit any bedding structures.

\section{Biofacies:}

Facies 8 contains increased plant fossil content with associated amber fragments. No Foraminifera are present, nor is there any bioturbation. Molluscs assignable to the bivalve Crassotrea subtrigonalis and the gastropod Viviparous sp. are common. $C$. subtrigonalis valves display fragmentation, but are unabraded and highly angular. They are stratigraphically evenly distributed and sorted randomly, indicating no apparent current direction. A diverse brackish water vertebrate microfossil assemblage is present and is the focus of Chapter 5.

\section{Interpretations}

Based on the prevalence of siltstone, large plant fossil constituent, lack of Foraminifera and large percentage of brackish water vertebrate fossils Facies 8 is interpreted as a central bay/lagoonal environment protected from wave action by bars or barriers with brackish water conditions that experienced significant freshwater influence (Frampton, 2006; Cullen et al., 2016) preventing Foraminifera to persist. Furthermore, as vertebrate microfossils and invertebrate macrofossils are exclusively seen as whole to fragmentary material that is unabraded to slightly abraded, oriented randomly with even distribution throughout the unit, deposition via high energy events is excluded as the force that condensed the fossil material (Kidwell, 1986; Brett and Baird, 1986). Thus, 
C26 is the result of slow, continuous natural attritional accumulation of fossil material as adjacent organisms died and became disarticulated during passive transportation to the site. Such an accumulation was able to form due to the effective protection from high energy events via estuarine bars or distal barrier islands.

\section{Facies 9 (Estuarine Sandstone/Oyster Banks):}

\section{Lithofacies:}

Facies 9 is present within sections $\mathrm{B}, \mathrm{C}$ and $\mathrm{E}$ following the first coal bed of the Taber Coal Zone and is approximately $30 \mathrm{~cm}$ thick in outcrop (Figs. 2.4 and 2.8). Facies

9 crops out in Section B and C as a heavily indurated, orange weathered bivalve conglomerate with medium grained sandy matrix. This is not the case in Section E where this unit crops out as a well consolidated, fine to medium grained orange sandstone and substantial bioturbation structures assignable to Ophiomorpha. In all sections this facies has a significant carbonate cement component. Internal structures attributable to waves or currents are absent. Lithic and mica fragments are common when viewed as a residue, and overall grains are subangular to subrounded.

\section{Biofacies:}

Bivalves within these beds are assignable to Crassostrea subtrigonalis. Shell valves are very well preserved, generally unbroken and are orange, brown or dark grey. Orientation of each valve is essentially in line along the same axial plane, indicating a consistent (or relative lack of) current flow regime and lower energy setting at the time of deposition. The valves within the unit are preserved in the same orientation as one another and are predominantly concave down. The valves appear to have very little 
breakage or evidence of transportation and are highly indurated. Large trace fossils attributed to Ophiomorpha are common in Section E, measuring up to $30 \mathrm{~cm}$ long and up to $5 \mathrm{~cm}$ in diameter.

Interpretations

Evidence for shallow water deposition and freshwater influence on salintiy is suggested by Crassostrea subtrigonalis fossils found in situ forming "oyster banks". C. subtrigonalis and other oysters prefer conditions with plentiful suspended terrestrially derived nutrients to sift via filter feeding and form large "banks" with many multiple individuals stacked beside and on top of one another in enclosed areas, often found in lagoonal and estuarine environments (Hsieh et al., 2000). Bank formation is suggested by the in situ nature of the fossils, whereby they are highly laterally continuous in the Milk River valley, unfragmented, unabraded, uncompacted, have high population density to the point of forming a conglomerate and show little evidence of current transport (Hsieh et al., 2000; Frampton, 2006). Ophiomorpha burrows further support this interpretation. Ophiomorpha is commonly associated with shallow water, high energy environments located above storm weather wave base dominated by Skolithos ichnofacies (MacEachern et al., 2010). Additionally, further support for high terrestrial sediment input stems from the abundance of micas and lithic fragments in samples of this facies (C33 to C35; up to $15 \%$ ), suggesting a possible bay head delta setting. Combined evidence suggests a shallow water estuarine environment with a significant freshwater influence for this facies. 


\section{Facies 10 (Coastal Marsh):}

\section{Lithofacies:}

Facies 10 comprises coaly mudstone seams exhibiting platy breakage that are separated by $1 \mathrm{~cm}$ interlaminae of very fine sand in outcrop. Coal seams are sometimes altered to a red to purplish brown colour. Extremely high organic material to the point where coalification has occurred makes it difficult to differentiate sediment from small organic fragments. This facies is highly continuous and occurs in outcrops all along the Milk River valley for several kilometres in each direction.

Biofacies:

Coalified plant fossil content dominates this facies to the point of obscuring lithological makeup. Certain horizons also contain higher abundances of vertebrate microfossil material less than $1 \mathrm{~cm}$ in size. These vertebrate fossils are often glassy in texture and translucent (see Chapter 5 for more detail). Fragments of unionid bivalves are also found in greater abundance up section.

\section{Interpretations}

The abundance of plant fossil material and lack of sedimentological structures suggests a quiet water depositional environment. The stratigraphically lowest horizons containing Facies 10 were under marine influence as suggested by the presence of a low diversity Foraminifera assemblage and the lack of in situ unionid bivalves which are known to be exclusive to freshwater environments (Vaughan et al., 2004). On the other hand, upper horizons have no Foraminifera and abundant unionid bivalves, suggesting a freshwater dominated environment. Facies 10 is representative of low energy brackish to 
fresh water, coastal plain marsh and swamp deposits, with greater marine influence in lower sections and greater freshwater influence in upper sections.

\section{Facies 11 (Low Energy Fluvial Plain):}

\section{Lithofacies:}

Facies 11 is comprised of light grey very fine to fine sandstone with no apparent bedding structures. This facies is relatively well consolidated and found interbedding with the organic-rich Facies 10 through the Milk River valley.

\section{Biofacies:}

Unionid bivalve shell bed, with valves displaying a white mother of pearl style preservation are associated with this facies. These fossils remain common throughout facies 11 and increase in abundance up section similar to those found in Facies 10.

\section{Interpretations}

As bivalve material is deposited essentially in situ with minimal fragmentation and abrasion, a relatively low energy environment is inferred. As well, all bivalve material is attributed to the exclusively freshwater Unionidae. Therefore, Facies 11 represents a freshwater environment that exhibits enough flow to winnow finer grains resulting in a sandstone but not enough to disarticulate or fragment bivalves and create notable sedimentary structures through wave or current action. Therefore, Facies 11 is interpreted as a low energy fluvial plain environment. 


\subsection{3: Depositional Units of the Foremost Formation}

The Foremost Formation as observed in the Pinhorn Ranch Area can be subdivided into three main depositional units based on fining upward vertical facies changes truncated by sharply bounded discontinuous surfaces observable in outcrop (Figs. 2.9 -11). These units will be referred to, in ascending order, as Unit I - III (Fig. 2.9).

Unit I

Unit I comprises all of Section A, the basal $14 \mathrm{~m}$ of Section C, all of Section D, and the first $19 \mathrm{~m}$ of Section E (Fig. 2.9). Unit I contains a fining upward facies succession from barrier sandstones (Facies 4 and 5 in Section D and E) overlain by back barrier salt marsh (Facies 1), and interbedded central bay/lagoonal siltstones (Facies 2) (Figs. 2.10 and 2.11). Unit I displays a fining upward trend overlain by a sharp discontinuity with the basal sandstone layers of Unit II. Due to the limited exposure of the base of Unit I the total vertical and lateral extent of Unit I in the Pinhorn Area is unknown. Unit I is considered equivalent to Unit 1a of Ogunyomi and Hills (1977) and the $\mathrm{C} 1$ portion of the middle succession of Kwasniowski and Eberth (1993).

\section{Unit II}

Unit II spans from $14 \mathrm{~m}$ to $59 \mathrm{~m}$ in Section C (last sample is sample C24; See Appendix Table A-1) and from $19 \mathrm{~m}$ to $49 \mathrm{~m}$ in Section E (Fig. 2.9). Unit II is also characterized by a fining upward succession, transitioning from basal barrier sandstone facies (Facies 4 and Facies 5) into siltstone and fine sandstone interbedded units representing central bay/lagoonal facies with increasing freshwater influence up section 
(Facies 2 and/or Facies 3) and capped by a thin, laterally continuous siderite rich firmground surface (Facies 6) (Figs. 2.10 and 2.11). Unit II is considered equivalent to Unit $1 \mathrm{~b}$ and 1c of Ogunyomi and Hills (1977) and the C2 and C3 portion of the middle succession of Kwasniowski and Eberth (1993).

\section{Unit III}

Unit III encompasses the entirety of Section B, and contains all pre-Oldman Formation sediments after the $59 \mathrm{~m}$ mark in Section C and the $49 \mathrm{~m}$ mark in Section E (Fig. 2.9). Unit III is recognized initially as the interval following the firmground surface of Unit II. This firmground is sharply overlain by offshore transitional to shoreface and barrier deposits (Facies 7) followed by the central bay/lagoonal vertebrate microsite facies (Facies 8) and then changing into shoreward beach and coastal marsh (Facies 10) deposits. Estuarine deposits represented by the Crassostrea conglomerate (Facies 9) and the thick succession of marsh deposits with coal seams (Facies 10) and fluvial siltstone to fine grained sandstones (Facies 11) in the upper portions of Unit III round out the section (Figs. 2.10 and 2.11). Unit III is considered equivalent to Unit 2 of Ogunyomi and Hills (1977) and the upper succession of Kwasniowski and Eberth (1993),

\section{Herronton Sandstone (Oldman Formation)}

The Herronton Sandstone directly overlies Unit III (Fig. 2.9) and is recognized primarily by its laterally continuous pale coloured, fine grained fluvial sandstone (Facies 11). Its boundary with the Foremost Formation is readily identified from a basal unionid rich bed directly overlying the last coal seam of the Taber Coal Zone (Figs. 2.10 and 
2.11). The contact between the top of the Foremost Formation and bottom of the Herronton Sandstone is observed to be gradational, with no discontinuity present.

\section{3: Summary}

Based on distinguished facies and their succession, a strong coastal influence on the depositional environment of the Foremost Formation is suggested, with its deposits defined by estuarine mouth barrier and central bay complexes or barrier island lagoon complexes overlain by coastal marsh and fluvial plain deposits. These interpretations somewhat confirm previous paleoenvironmental studies of the Foremost Formation in the Pinhorn Ranch area (Ogunyomi and Hills, 1977; Kwasniowski and Eberth, 1993; Beavan, 1995; Frampton, 2006). Overall, distinction between estuarine versus lagoonal settings in Unit I and II is difficult as a distinct bayhead delta facies as indicator for fluvial influence was not found, and larger scale stratigraphic features that may suggest one setting or the other (e.g. incised estuary valley wall were also not observed). Therefore, both marginal marine settings are considered equally possible interpretations. 


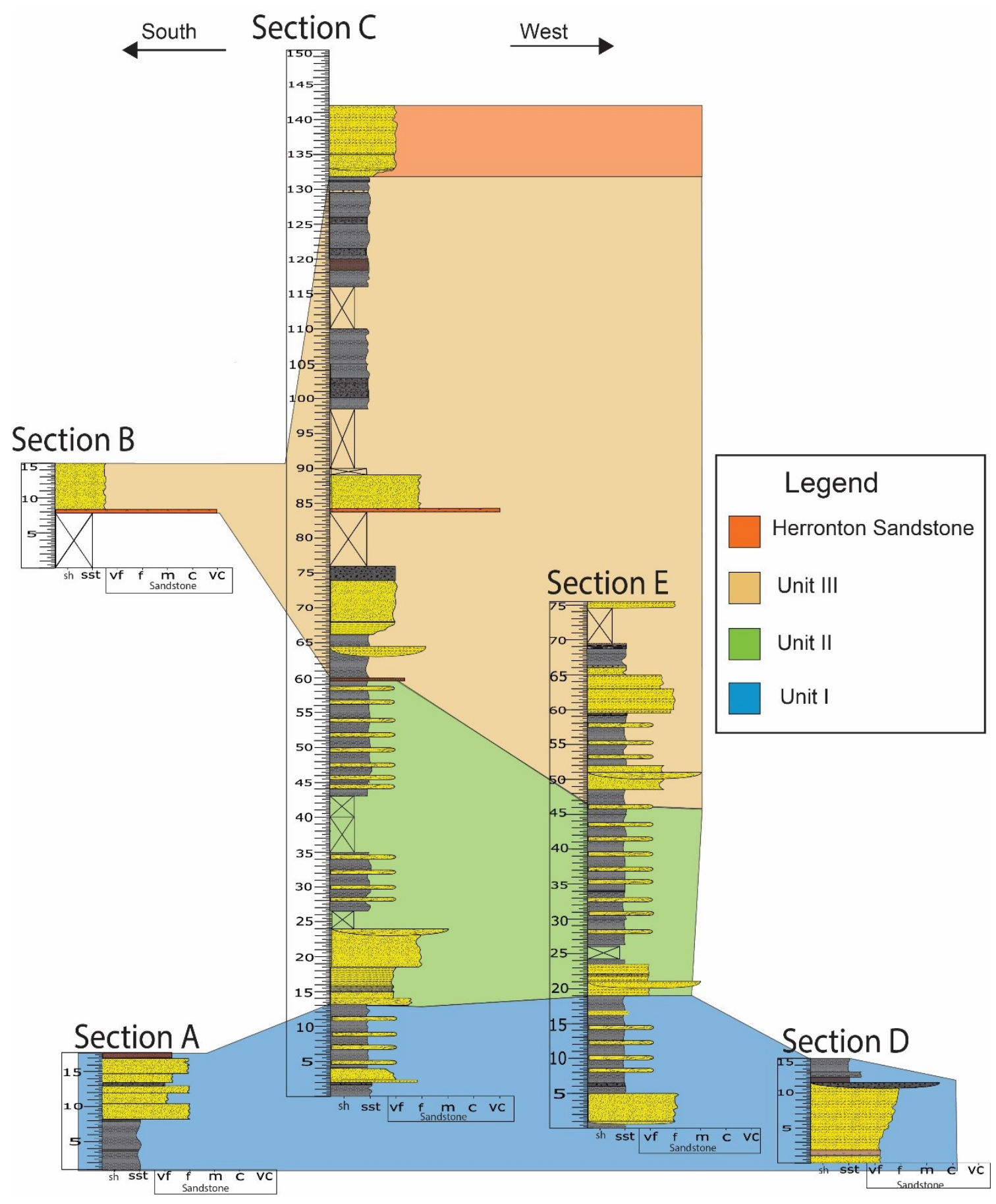

Figure 2.9: Lithostratigraphic correlations of proposed depositional units between the outcrop sections observed in this study. For location of sections see Figure 1.1.C. 
Section C

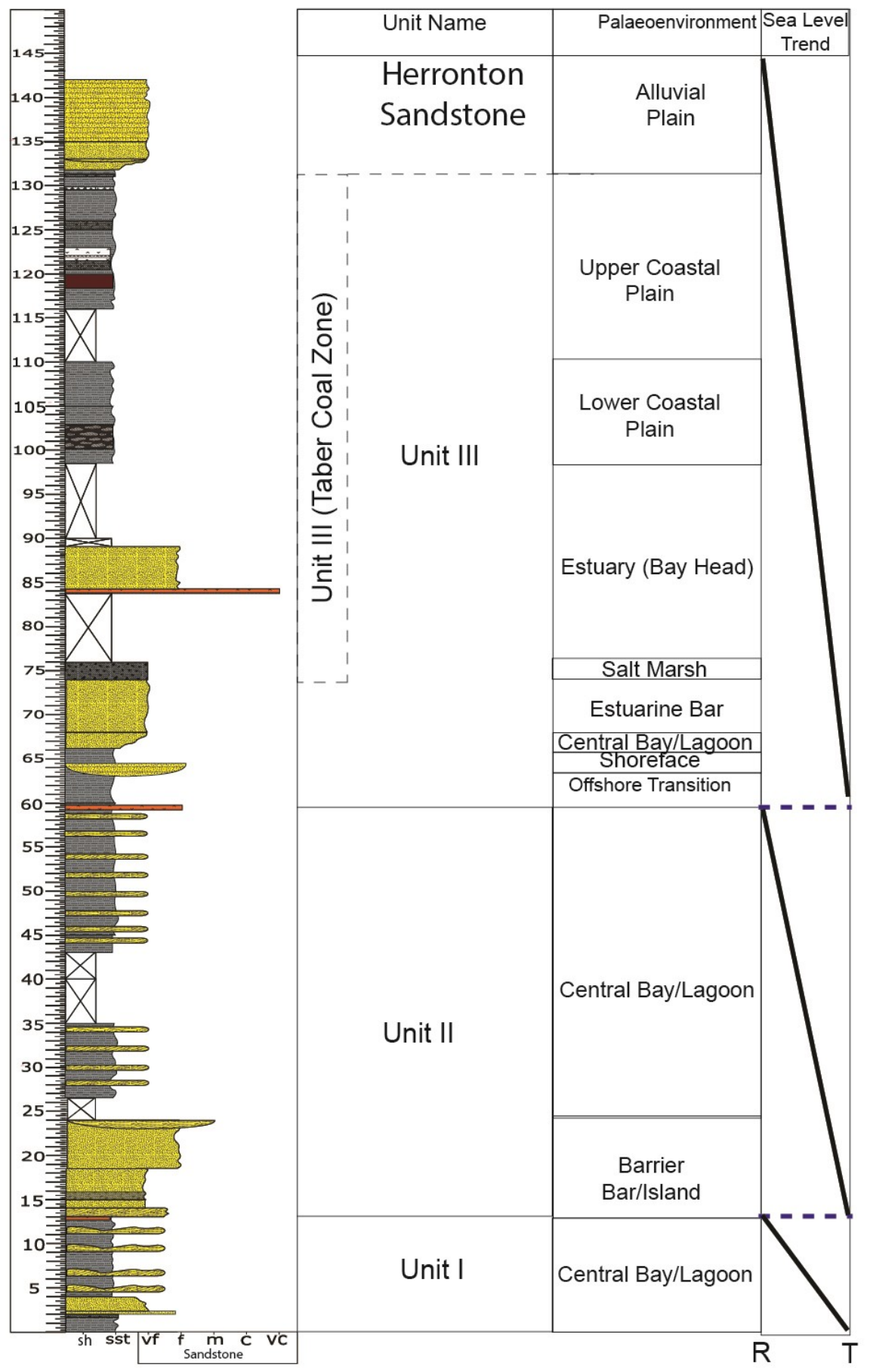

Figure 2.10: Depositional units of Foremost Formation as measured in Section $\mathrm{C}$ and their respective palaeoenvironmental and sea-level change interpretations. $\mathrm{R}=$ regressive, $\mathrm{T}=$ transgressive. Blue dotted lines $=$ discontinuities. For legend see Figure 2.1. 


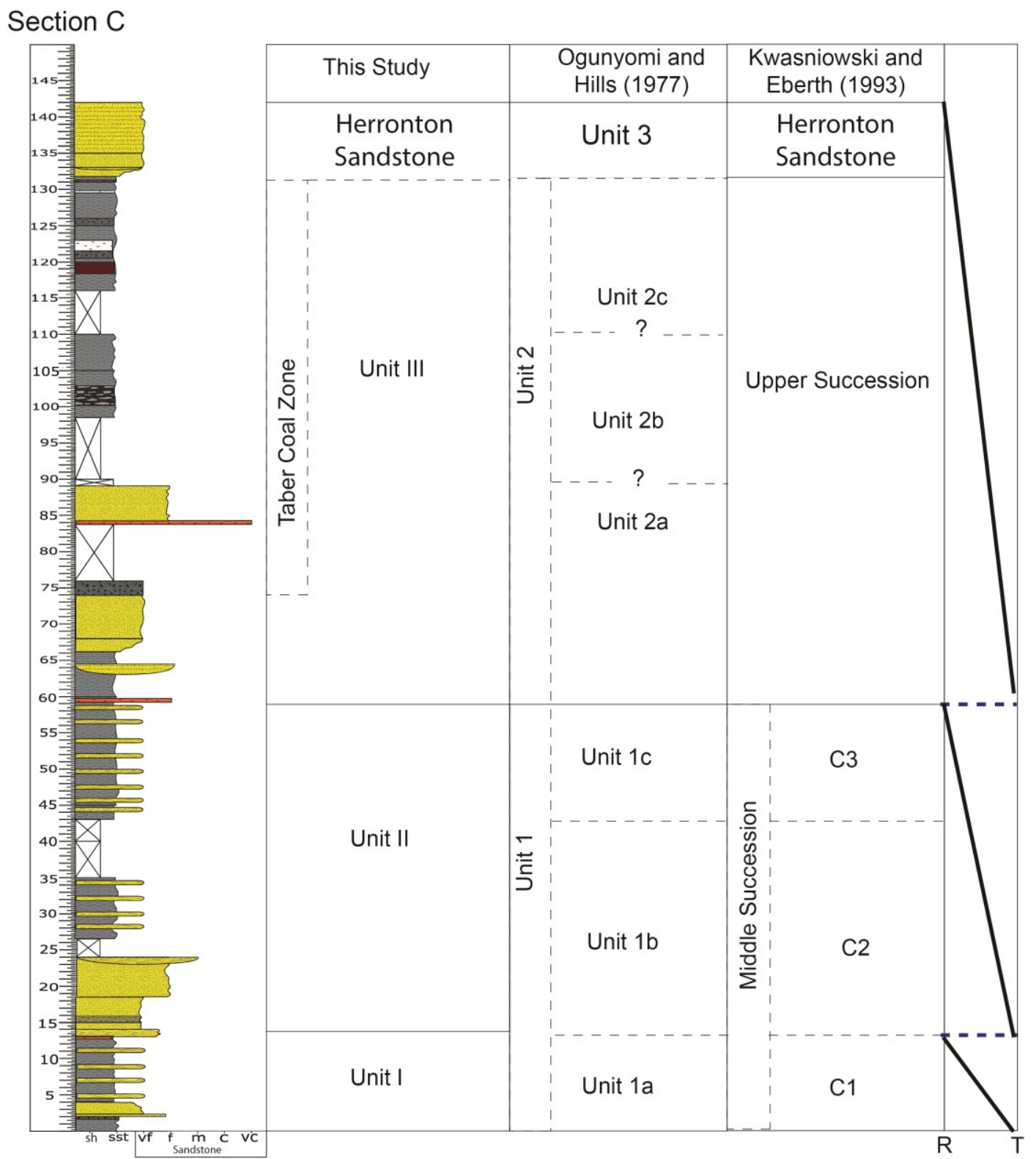

Figure 2.11: Proposed depositional units of the Foremost Formation as measured in Section C compared to those proposed by Ogunyomi and Hills (1977) and Kwaniowski and Eberth (1993), who also measured their sections in the Pinhorn Ranch area near Section D and E in this study and in several other localities in the valley. The right hand column displays sea-level transgressive $(\mathrm{T})$ and regressive $(\mathrm{R})$ trends. 


\section{Chapter 3: Foraminiferal Assemblages of the Foremost}

\section{Formation}

\section{1: Foraminiferal Zonation of the Foremost Formation}

Thus far, only two studies have addressed Foraminifera within the Foremost Formation of southern Alberta, however, neither examined the fauna in detail (Ogunyomi and Hills, 1977; McNeil et al., 1995). In contrast, the foraminiferal faunas of the underlying Pakowki/Lea Park Formation and the overlying Bearpaw Formation, have been well studied (North and Caldwell, 1968; Given and Wall, 1971; Caldwell et al., 1978). This leaves the foraminiferal composition of the Foremost Formation to be relatively unknown. Therefore, the placement of the Foremost Formation in southern Alberta within the Foraminifera biostratigraphic zonation of the WIS is speculative and based solely on correlations to age-equivalent formations to the west and east that have been integrated into the zonation established by Caldwell et al. (1978).

To the west, the undifferentiated Belly River Formation of the Rocky Mountain foothills of Alberta represents the westernmost shoreline of the WIS during the Campanian and contains no Foraminifera (Caldwell et al., 1978). However, the marine tongues of the Wapiabi Formation and Nomad Formation that interfinger with the Belly River Formation in this area do contain Foraminifera, represented by the early to middle Campanian Lenticulina sp. Zone (Fig. 3.1; Caldwell et al., 1978). The Lenticulina sp. Zone is recognized by being considerably less diverse than the equivalent zones in more eastern portions of the WIS, and is defined, in addition to the zonal indicator taxon, by the presence of Anomalinoides talaria, Eoeponidella cf. linki, Haplophragmoides cf. 


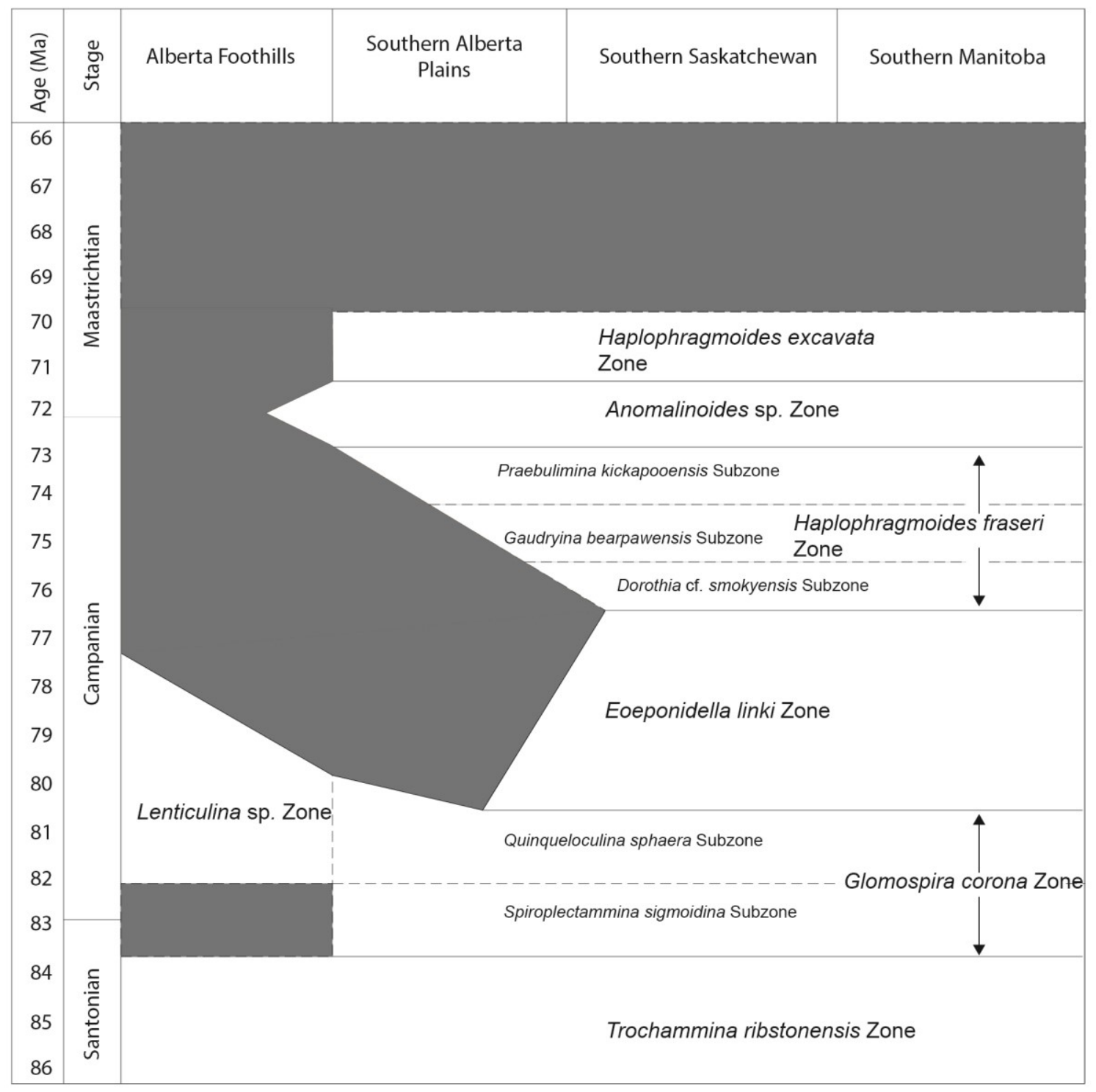

Figure 3.1: Foraminifera biostratigraphic zonation of the Santonian to Maastrichtian within the Western Interior Seaway based on Caldwell et al., (1978). Dark grey zones indicate areas that remain unsampled or have no marine deposits. Sizes of each province are not to scale. 
rota, Praebulimina venusae, and various unidentified species of Anomalinoides, Cibicides, Lenticulina, Neobulimina, and Vaginulina (Caldwell et al., 1978). Moving east, the assemblages of the Lenticulina sp. Zone becomes more differentiated, and is replaced by the considerably more diverse early Campanian Spiroplectammina sigmoidina Subzone and the Quinqueloculina sphaera Subzone of the Glomospira corona Zone and lower parts of the middle Campanian Eoeponidella linki Zone (Fig. 3.1; Caldwell et al., 1978). The Q. sphaera Subzone is identified by the most diverse Foraminifera fauna of the Cretaceous WIS with at least 30 unique taxa (Caldwell et al., 1978). The E. linki Zone is defined by the presence of Eoeponidella linki with the addition of Eoeponidella strombodes, Bolivina elkensis, Haplophragmoides rota, Marginulina subtilis, Nonionella austinana and Praebulimina venusae. The Q. sphaera Subzone is represented in the upper Lea Park (Pakowki) Formation in the Vermillion District of eastern Alberta, while the marine tongues of the Foremost Formation contain the E. linki Zone (Caldwell et al., 1978). The E. linki Zone is also present in the Foremost Formation from core samples taken in Saskatchewan near Saskatoon (Price and Ball, 1971; North and Caldwell, 1978) and has been recognized in the Lea Park and Foremost Formation time equivalent formations in Manitoba including the Millwood and Odanah members of the Pierre Shale (Fig. 3.1).

Caldwell et al. (1978) suggested the E. linki Zone as the likely candidate for the Foremost Formation of southern Alberta, as it is represented in time equivalent strata elsewhere in the WIS. However, it was also noted that foraminiferal diversity and abundance in the early and middle Campanian decreases westward as the $Q$. sphaera Subzone and E. linki Zone grade into the Lenticulina sp. Zone; however, this hypothesis 
has not been rigorously tested. The detailed analysis of the Foraminifera in the Foremost Formation of the Pinhorn Ranch area presented here is the first step in characterizing its assemblage.

\section{2: Results}

Within this study, a total of 733 foraminiferal specimens assignable to 14 genera and at least 24 species were retrieved from 20 samples (see Appendix B). The majority of foraminifera bearing samples are restricted to horizons within Unit I and Unit II, with one sample (C32) found in Unit III in the first horizon of the Taber Coal Zone (Fig. 3.2). All observed species possess an agglutinated test, with calcareous forms being completely absent. There is an overwhelming dominance of the genus Haplophragmoides (70.5\% of total Foraminifera identified) in all samples. Three distinct assemblages are recognized based on the composition of Foraminifera species and the presence or absence of Foraminifera displaying elongate test morphologies. Assemblage 1 occurs within Facies 1 and 2 of Unit I. Assemblage 2 occurs within the central bay/lagoonal facies of Unit II in Section C (Fig. 3.2). Assemblage 3 is present only in Sample C32 within the first coal bearing horizon of Unit III (Facies 10) (Fig. 3.2).

\section{Assemblage 1}

Assemblage 1 is observed within all samples from the salt marsh facies (Facies 1) and in several samples from the central bay/lagoonal facies (Facies 2) within Unit I. Assemblage 1 contains 463 individuals (Fig. 3.2; Appendix Table D-1). Assemblage 1 is the most diverse of the three, containing all but three of the species encountered in this study. Haplophragmoides and Trochammina are the dominant taxa (72\%) (Fig. 3.2). 
Haplophragmoides is the more common and diverse of the two genera, represented by six species and 260 individuals versus four species and 70 individuals identified as Trochammina (Appendix Table D-1). Assemblage 1 is differentiated from Assemblage 2 and Assemblage 3 by the notable presence (approximately $28 \%$ of Assemblage 1) of species with an elongate, multi-chambered test morphology (Ataxophragmiidae). These Ataxophragmiidae are dominated by Verneuilinoides bearpawensis within salt marsh deposits ranging from 16 to $68 \%$ (Fig. 3.2; Appendix Table D-1). V. bearpawensis is replaced up section in the outer central bay/lagoonal facies (Facies 2) by an assemblage consisting of Dorothia smokyensis, Gaudryina bentonensis, Ammobaculites fragmentarius, Spiroplectammina mordenensis, Textularia sp., Pseudoclavulina sp. and Reophax texanus, (Fig. 3.2; Appendix Table D-1). Foraminifera become absent in barrier facies (Facies 4 and Facies 5) of Unit II. Specimens in Assemblage 1 are mostly wellpreserved, but preservation quality diminishes up section, with increased breakage, colour change and compression. Elongate specimens show more varied taphonomic compression and breakage when compared to other morphologies, especially $V$. bearpawensis. Coloration of specimens in Assemblage 1 is pearly white in samples from salt marsh deposits and pale yellow in samples from lagoonal deposits.

\section{Assemblage 2}

Assemblage 2 is represented in samples from outer central bay/lagoonal facies (Facies 2) located within Unit II, approximately $16 \mathrm{~m}$ stratigraphically above the last appearance of Foraminifera in Assemblage 1 (Fig. 3.2). Haplophragmoides rota is the most common 


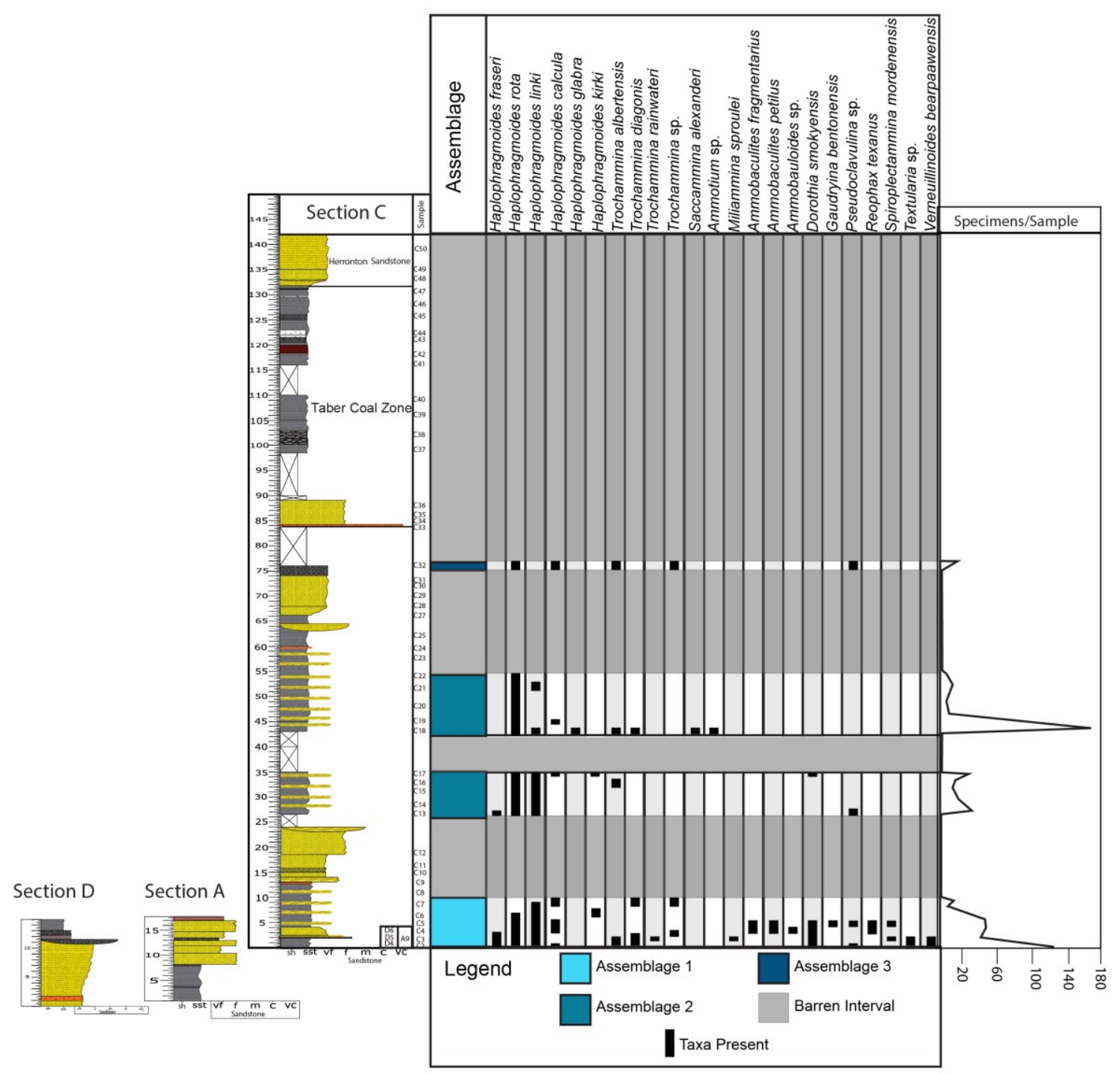

Figure 3.2: Biostratigraphic ranges (middle) and number of specimens per sample (right) taken of Foraminifera in sections of the Foremost Formation. Each Assemblage was identified by the presence of absence of infaunal morphotypes (see Chapter 3.3; Fig. 3.3). Samples D4 to D6 and A9 are considered equivalent to Sample C3 (all samples within 
species encountered within Assemblage $2(61 \%)$ and is present within each sample taken (Fig. 3.2). Rare (1 to 5) specimens of Haplophragmoides linki, Haplophragmoides calcula, Dorothia smokyensis, and Pseudoclavulina sp. are also present within the assemblage in stratigraphically lower samples (Fig. 3.2). Overall foraminiferal abundance is low in this interval ( $26 \mathrm{~m}$ to $35 \mathrm{~m}$ ) of Section C, with only 87 specimens being recovered (Fig. 3.2). Notably, sample $\mathrm{C} 18$, found in the first sample of the fresher water influenced central bay/lagoonal Facies 3, has the highest abundance of all studied samples with 156 individuals (Fig. 3.2), dominated by Haplophragmoides rota (57\% total assemblage). C18 also contains a single specimen of Ammotium sp. and the only records of Haplophragmoides glabra and Saccammina alexanderi (Fig. 3.2). Fossil preservation in C18 is exceptional, especially with regards to H. glabra and Ammotium, preserving these tests in a ruby red colour with fully-defined sutures and chambers (Fig. 3.4 specimens 8 and 5, respectively). Foraminiferal abundance further up section from this sample greatly decreases to only 1 to 8 specimens per sample until samples become barren (Fig. 3.2).

\section{Assemblage 3}

Assemblage 3 is only represented in one sample (C32) from the lowest horizon of the Taber Coal Zone in Unit III, which represents a restricted salt marsh environment (Facies 10). Sample C32 contains a small, but distinct assemblage that differs from those seen in assemblages 1 and 2. Assemblage 3 contains a total of nine specimens. All specimens show diminutive test sizes, averaging approximately 100 microns in diameter, whereas Assemblage 1 and 2 samples contain Foraminifera that range between 300 to 400 microns in maximum dimensions, if not larger (Fig. 3.4). Assemblage 3 contains 
primarily Trochammina sp. and Haplophragmoides rota, with a single specimen of Pseudoclavulina sp. (Fig. 3.2). This composition closely resembles Assemblage 2 by containing Haplophragmoides rota, but differs from Assemblage 2 by possessing an equal abundance of Trochammina sp. Tests are fragile resulting in poor preservation, making specific level identification of Trochammina sp. and Pseudoclavulina sp. difficult.

\section{3: Morphogroup Analysis}

Classification used here is based on the Foraminifera morphogroup identification and nomenclatural methods of Nagy et al. (2009), which is as follows:

\section{Morphogroup A}

Foraminifera in this group are those with tests displaying tubular and unilocular morphologies and are known to have epifaunal, suspension feeding habits (Nagy et al., 1992; Nagy et al., 2009; Murray et al., 2011). This morphogroup is completely absent within my study.

\section{Morphogroup B}

Tests with a unilocular to spheric or subspheric shape define these Foraminifera, which live as passive epifaunal deposit feeders (Nagy et al., 1992; Nagy et al., 2009; Murray et al., 2011). Only Saccammina represents this morphogroup within my study.

\section{Morphogroup C}

Foraminifera of this morphogroup display elongate, multichambered tests and are infaunal feeders that thrive in areas with large organic input (Nagy 1992; Nagy, 2009; 
Murray et al., 2011). They are further subdivided into Morphogroups C-1, C-2, and C-3. Morphogroup C-1 are those Foraminifera that have uniserial tests, a shallow or deep infaunal feeding lifestyle, and are represented in this study by the genus Reophax. Morphogroup C-2 have primarily uniserial tests that being with a planispiral or streptospiral initial stage, a shallow infaunal feeding lifestyle, and are here represented by the genera Ammobaculites, Ammobaculoides and Pseudoclavulina. Morphogroup C-3 have biserial or triserial elongate tests, a shallow to deep infaunal feeding lifestyle, and are represented by the genera Dorothia, Gaudryina, Spiroplectammina, Textularia, and Verneuilinoides in my study.

\section{Morphogroup D}

Morphogroup D are Foraminifera that have multichambered, spiraled tests and are epifaunal or shallow infaunal feeders (Nagy et al., 2009; Murray et al., 2011). Morphogroup D can be split into subgroups; Morphogroup D-1 and Morphogroup D-2. Morphogroup D-1 is characterized by trochospirally coiled tests that can be globular or plano-convex such as the genus Trochammina and are interpreted to be epifaunal feeders that can respond well to areas with high environmental variability, including hypersalinity and low oxygen conditions (Nagy et al., 2009). The Foraminifera of Morphogroup D-2 are represented exclusively by the genus Haplophragmoides in this study, with this morphogroup defined by a rounded, planispiral and epifaunal to shallow infaunal feeding mode, with habitat preferences varying widely at the species level (Nagy et al., 2009). 


\section{4: Morphogroups and Palaeoenvironmental Significance of Assemblages}

\section{Assemblage 1}

Assemblage 1 contains the largest foraminiferal species richness (Fig. 3.2) and a significant portion of morphogroup $\mathrm{C}$ taxa that are interpreted to be related to an infaunal feeding mode, with this assemblage being restricted to the salt marsh and central bay/lagoonal facies of Unit I (Fig. 3.3). Morphogroup C-3 comprise a significant portion of the Foraminifera encountered in the portion of the salt marsh deposits of Unit 1 (approximately 17 to $68 \%$ ) and are gradually replaced upsection in the central bay/lagoonal deposits of Unit I by morphogroups C-1 and C-2 as the dominant infaunal type (Fig. 3.3). However, in the upper central bay/lagoonal portions of Unit I nearing the boundary with Unit II, infaunal morphotypes are completely lost, and only Haplophragmoides and Trochammina are present in the assemblage (Fig 3.2).

Overall, Assemblage 1 represents a salt marsh fauna dominated by infaunal morphotypes that is replaced gradually shoreward by a central bay/lagoonal fauna of purely epifaunal and shallow infaunal morphotypes (Johnson et al., 2005).

\section{Assemblage 2}

Assemblage 2 is almost exclusively represented by morphogroup D-2, nearly completely comprised of Haplophragmoides rota, within the central bay/lagoonal deposits of Unit II (Figs. 3.2 and 3.3). Infaunal feeders of morphogroup C are rare or 
Figure 3.3: (see page 81): Distribution of foraminiferal morphogroups as expressed in percentage of each morphogroup in the total assemblage within each sample in Section C. Not pictured are Section A and Section D as they are equivalent to Section C. Also shown is the ratio of infaunal to epifaunal Foraminifera morphogroups per sample. Morphogroup C individuals are considered infaunal; Morphogroup D individuals were considered epifaunal sensu Nagy et al. (2009). 


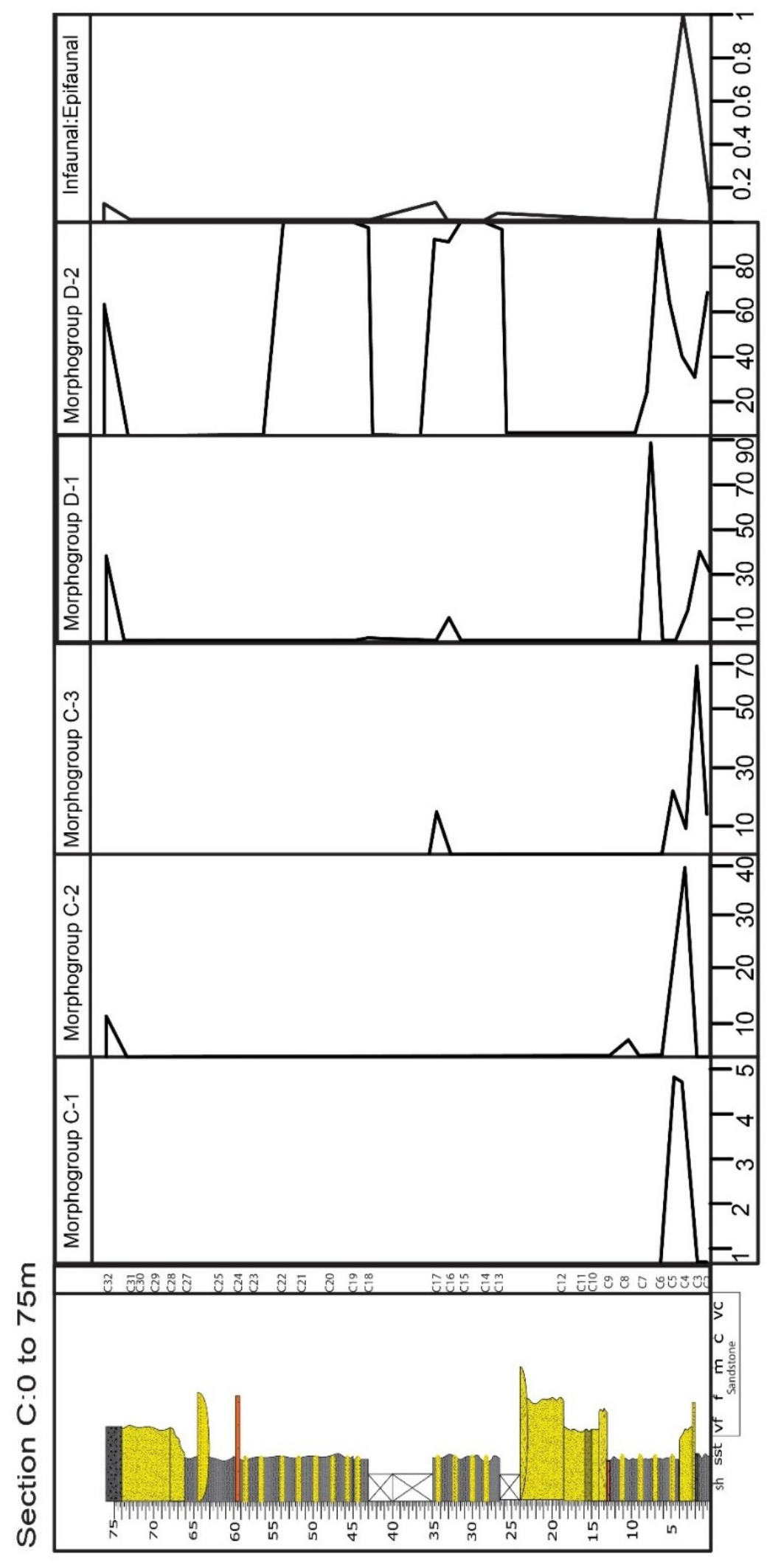


completely absent. Epifaunal exclusive morphogroup D-1 are also rare, with both them and morphogroup-C groups appearing only before and just immediately after the covered section within Unit II that truncates the outer central bay/lagoonal deposits and the more freshwater influenced inner central bay/lagoonal deposits (Facies 2 and Facies 3 respectively) (Figs. 2.4, 3.3 and 3.4). Foraminifera abundance then decreases within the upper portions of the freshwater influenced central bay/lagoonal facies, with this drop correlating to an increase in organic material and bioturbation and directly preceding the firmground surface that marks the boundary with Unit III (Figs. 3.2 and 3.3) (sample C24).

Assemblage 2 represents a central bay/lagoonal Foraminifera fauna, but with significantly less deep infaunal morphogroups and a dominance by the shallow infaunal to epifaunal Haplophragmoides rota compared to the central bay/lagoonal portions of Assemblage 1 (Fig. 3.2). (Morris, 1971, Johnson et al., 2005).

\section{Assemblage 3}

Assemblage 3 contains a large proportion of small bodied, epifaunal Trochammina sp. (Morphogroup D-1) and rare epifaunal to infaunal Haplophragmoides (Morphogroup D-2) and infaunal Pseudoclavulina (Morphogroup C-2) (Figs. 3.2 and 3.3). Facies observations support the interpretation of Assemblage 3 as being derived from the salt marsh deposits of the lowest portion of Unit III, with deposits displaying fine grained, highly organic rich siltstones that overly central bay/lagoonal deposits (Fig. 3.2). Foraminifera from Assemblage 3 are also noted to be diminutive in size relatively, which is reflective of the low oxygen and stressed salinity conditions of this environment (100 microns) (Boltovskoy and Wright, 2013) (Fig. 3.4). Therefore, Assemblage 3 is 
interpreted as a salt marsh fauna in relatively hypersaline, dysoxic conditions compared to those encountered in the salt marsh deposits of Unit I.

\section{5: Summary}

The outcrops of the Foremost Formation in the Pinhorn Ranch area contain a low abundance, low diversity Foraminifera fauna indicative of brackish salt marsh and central bay/lagoonal settings, supported previous facies interpretations. Similar

Haplophragmoides dominated faunas were observed by Ogunyomi and Hills (1977) and McNeil et al. (1995) in the same area, but a lower diversity of infaunal types was noted in their studies, suggesting relatively small scale lateral variability in habitat within the deposition of the Foremost Formation in the Pinhorn Ranch. Inferences from Foraminifera regarding benthic redox conditions can be compared to geological and geochemical evidence of these sediments for further resolution and in order to understand how these conditions varied through time. 
Figure 3.4: Plate 1 (see page 86): Photographs of Foraminiferal taxa of the Foremost Formation from the Pinhorn Ranch, Southern Alberta, Canada. Scale Bar $=0.5 \mathrm{~mm}$.

1. Saccammina alexanderi Loeblich and Tappan (1950), Sample C18

2. Miliammina sproulei Nauss (1947), Sample D6

3. Ammotium sp., Sample C18

4. Haplophragmoides fraseri, Wickenden (1932), Sample D5

5. Haplophragmoides calcula, Cushman and Waters (1927), Sample C5

6. Haplophragmoides glabra Cushman and Waters (1927), Sample C18

7. Haplophragmoides kirki Wickenden (1932), Sample C6

8. Haplophragmoides linki Nauss (1947), Sample C2

9. Haplophragmoides rota Nauss (1947), Sample C18

10. Trochammina albertensis Wickenden (1932), spiral view,

11. Trochammina albertensis umbilical view, Sample C2

12. Trochammina diagonis Carsey (1926), spiral view,

13. Trochammina diagonis umbilical view, Sample C4

14. Trochammina rainwateri Cushman and Applin (1946), spiral view, Sample C3

15. Trochammina rainwateri umbilical view, Sample C3

16. Trochammina sp. Spiral view Sample C32

17. Gaudryina bentonensis, Carman (1929), Sample 35 
18. Pseudoclavulina sp. Sample C5

19. Ammobaculoides whitneyi, Cushman and Alexander (1932), Sample C4

20. Ammobaculites petilus Eicher (1960), Sample C4

21. Ammobaculites fragmentarius Cushman (1927), Sample C4

22. Spiroplectammina sp., Sample C3

23. Textularia sp., Sample D6

24. Verneuilinoides bearpawensis Wickenden (1932), Sample D6

25. Reophax texanus Cushman and Waters (1927), Sample C4

26. Dorothia smokyensis Wall (1960), Sample C4 


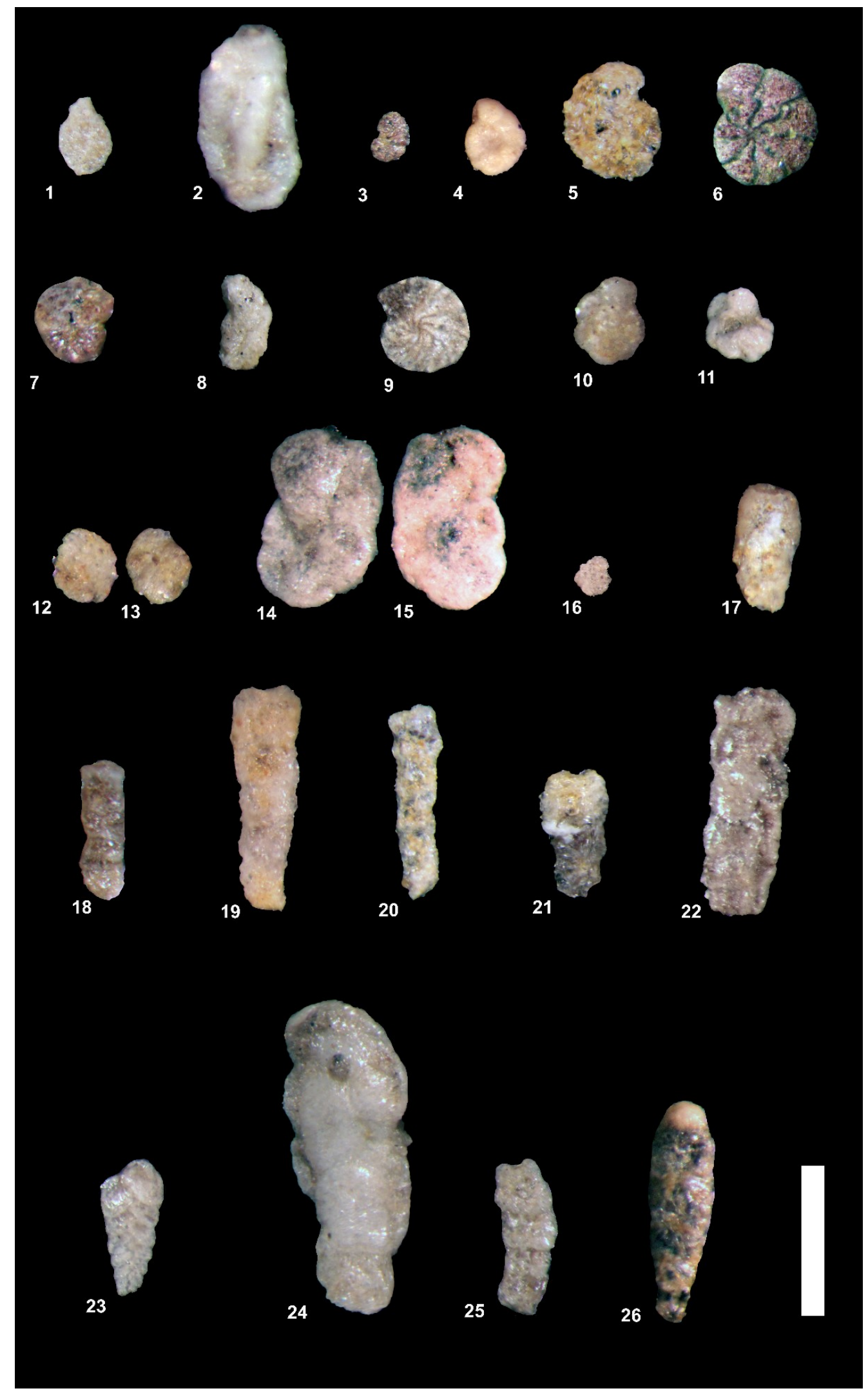




\section{Chapter 4: Whole Rock Geochemistry}

Geochemical analyses on Cretaceous deposits in Alberta have been performed to address paleosalinity conditions of the WIS (Bannerjee and Goodarzi, 1990) and sedimentary provenance and volcanic activity (Fanti, 2009). Only one study has been conducted using geochemistry to infer palaeoenvironmental conditions within the Belly River Group (Hills and Levinson, 1975), allowing for the geochemical data derived in this thesis to add to our understanding of ocean chemistry and sediment provenance within the Campanian WIS.

Redox sensitive major (iron and manganese) and trace metals (zinc, vanadium, molybdenum) were plotted together as potential indicators of benthic redox conditions (Fig. 4.1), and therefore oxygen levels of the water column, at time of deposition (Brumsack, 2006). Potassium and sodium (Fig. 4.2) were plotted together to showcase relative clay mineral distribution, whereby $\mathrm{Na}$ and $\mathrm{K}$ can be proxies for smectite and illite content respectively (Hofer et al., 2011). Aluminum and calcium (Fig. 4.2) were plotted with $\mathrm{K}$ and $\mathrm{Na}$ in order to determine correlation of terrestrial influence, whereby $\mathrm{Al}$ enrichments are strongly correlated to increased terrestrial influence (Brumsack, 2006). Because the percentage of calcite cement in hand samples was generally miniscule, large enrichments in $\mathrm{Ca}$ are primarily related to increased percentages of bivalve fossil material, which have been shown in this study to increase within the freshwater influenced facies in Unit III (Facies 10 and Facies 11). Therefore, Ca levels are compared to clay mineral and $\mathrm{Al}$ concentrations in order to further confirm and refine correlations 
between bivalve fossils and terrestrial influence. The elements boron and sulfur (Fig. 4.3) are plotted to determine changes in palaeosalinity (Bannerjee and Goodarzi, 1990).

\section{1: Chemostratigraphic Variations}

Redox elements show many similarities in enrichment and depletion to one another. The overall trends of $\mathrm{Fe}, \mathrm{Mn}, \mathrm{Zn}$ and $\mathrm{V}$ are relatively consistent, showing overall enrichment in the salt marsh and central bay/lagoonal horizons (Facies 1, Facies 2 and Facies 3) and depletion in the shoreface sandstones (Facies 4 and Facies 5) in Unit I and II (Fig. 4.1). Fe and Mn are considerably more variable on the individual sample scale compared to $\mathrm{Zn}$ and $\mathrm{V}$, and $\mathrm{Zn}$ and $\mathrm{V}$ share a near identical enrichment curve to one another (Fig. 4.1). Mo is an exception to the trend displayed by other redox sensitive minerals, and remains relatively constant and depleted, near $1 \mathrm{ppm}$ in Units I and II, but shows an enrichment (up to $5.9 \mathrm{ppm}$ ) within upper coal bearing marsh deposits within Unit III (Facies 10) (Fig. 4.1). There is also a notable increase in Fe and Ca, but decrease in $\mathrm{Zn}, \mathrm{V}, \mathrm{Mn}, \mathrm{Al}, \mathrm{K}, \mathrm{Na} \mathrm{B}$, and $\mathrm{S}$ in the firmground facies capping Unit II, likely reflecting the dominance of iron calcite in the composition of this facies (Sample C24, Facies 6). Redox minerals show overall slight depletion in the fluvial portions of Unit II and the Herronton sandstone, but relative enrichment in coal bearing marsh deposits (Fig. 4.1). Therefore, redox sensitive minerals in this study correlate to marsh and central bay/lagoonal deposits that are rich in organic material.

Regarding the potential clay mineral proxies, $\mathrm{Na}$ is relatively higher in concentration to $\mathrm{K}$ throughout the samples $(\mathrm{Na}=0.07 \%$ to $1.087 \%$ versus $\mathrm{K}=0.03 \%$ to $0.45 \%$ ), with a relative enrichment of $\mathrm{Na}$ and $\mathrm{K}$ in the central bay/lagoonal facies of Unit I, II and III, with the opposite trend present in the shoreface facies in Section C (Fig. 4.2). 


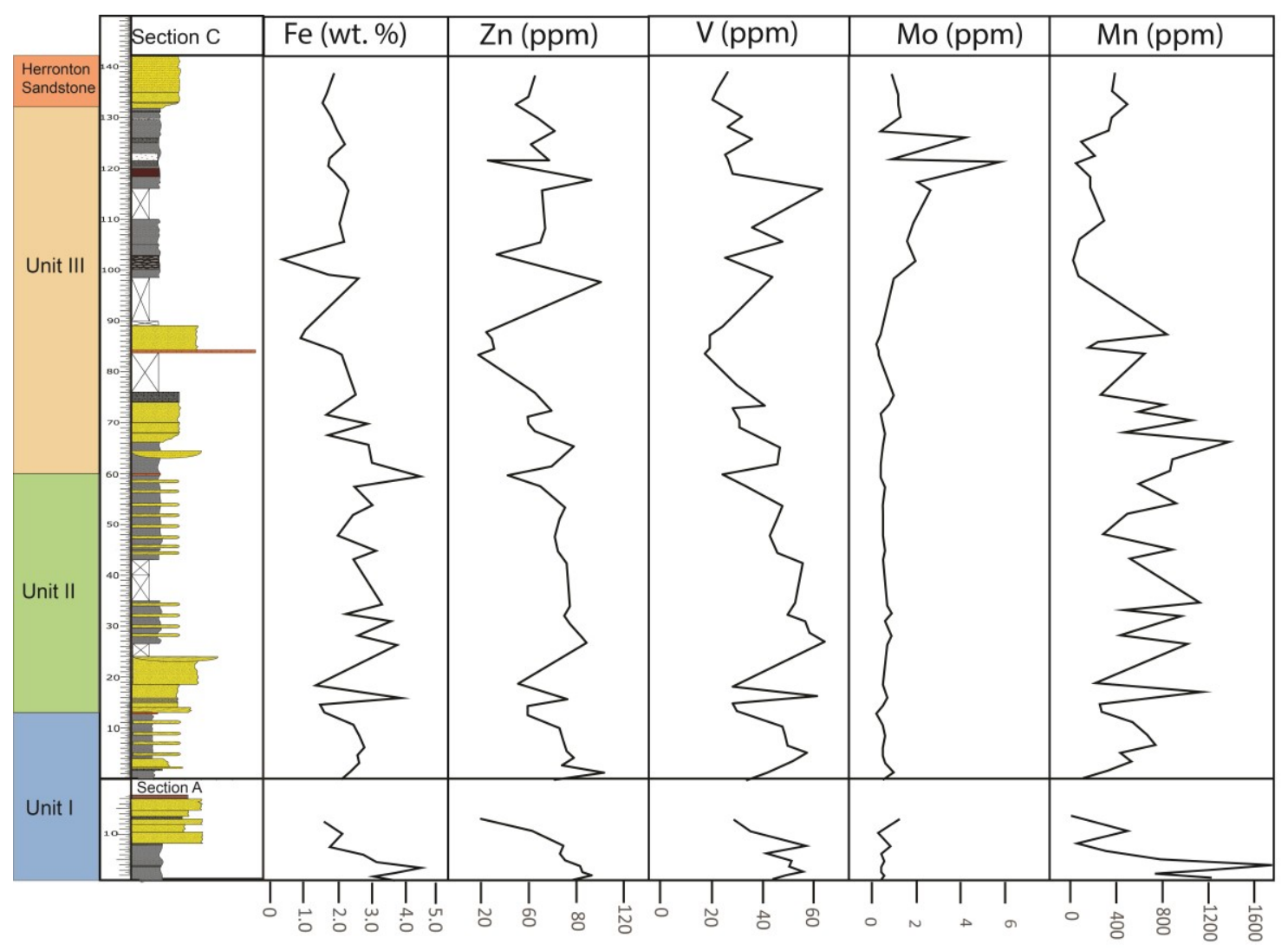

Figure 4.1: Chemostratigraphic profiles of the variation of Fe, Zn, V, Mo, and Mn concentrations within Sections A and C of the Foremost Formation plotted together to display potential correlations to redox conditions at time of deposition (Brumsack, 2006). 


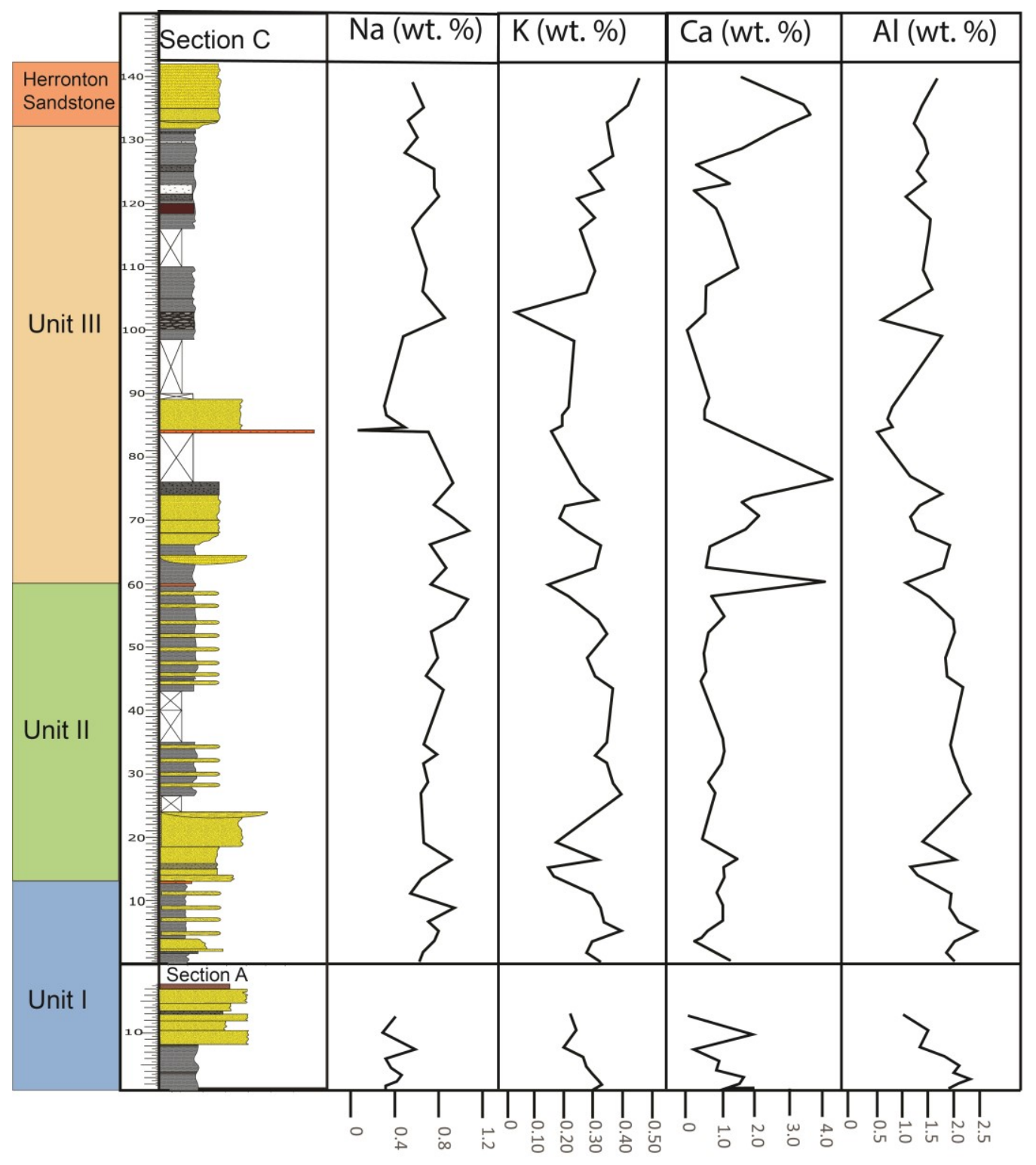

Figure 4.2: Chemostratigraphic profiles of $\mathrm{Al}, \mathrm{Na}, \mathrm{K}$, and $\mathrm{Ca}$ within sections $\mathrm{A}$ and $\mathrm{C}$ of the Foremost Formation. These elements were plotted together to display information regarding to clay mineral makeup and their associations to terrestrial sediment input (Al). Ca was included to compare bivalve fossil concentration in sediment samples to terrestrial sediment input $(\mathrm{Al})$. 
This suggests a greater overall smectite content compared to illite in the clay mineral assemblage (Hofer, 2013). There is a decrease in all clay minerals at the samples at or near the discontinuities between each unit and increases in $\mathrm{Na}$ directly preceding the discontinuities in the uppermost portions of the central bay/lagoonal facies of Unit I and Unit II (Fig. 4.2). Na concentrations remain relatively constant and show minor increases in marsh deposits in Unit III, where K shows decreases in marsh deposits and a relative increase in concentration in the uppermost fluvial portions of Unit III and the Herronton Sandstone (Fig. 4.2). Al shows a near identical overall trend to K, with minor enrichments in central bay/lagoonal facies, but unlike $\mathrm{K}$ it does not substantially increase through Unit III and the Herronton Sandstone, instead remaining relatively constant (Fig. 4.2). Calcium levels are low overall when compared to other element concentrations, with significant spikes correlating to horizons with large bivalve fossil concentrations, especially in the shoreface sandstones of Unit II, the estuarine bivalve conglomerate of Unit III and the unionid bearing fluvial horizons of Unit III and the Herronton Sandstone (Fig. 4.2). For example, in sample C33, the Crassostrea conglomerate (Facies 9) the percentage weight of $\mathrm{Ca}$ is over $23 \%$ of the total sample weight ( $\mathrm{Ca}$ is $<2 \%$ total weight for the majority of other samples; Figs. 4.3; Appendix C-1); therefore, sample C33 was excluded from the chemostratigraphic profile of $\mathrm{Ca}$ in order to better view the overall trend (Fig. 4.2). Overall, the clay mineral assemblage is dominated by smectite, and a greater input of terrestrial input is noted within the brackish central bay/lagoonal facies and fluvial Herronton Sandstone.

$\mathrm{B}$ is enriched in the lower, organic rich marsh deposits (Facies 1) of Unit I and especially so in the marsh deposits (Facies 10) in Unit III (Fig. 4.4). B remains at low 
concentrations overall in Unit II, being more enriched within the central bay/lagoonal facies than the barrier facies (Fig. 4.3). Sulfur concentrations are relatively stable and share a similar trend to B, with enrichment in marsh facies of Unit I and III and in the central bay/lagoonal facies of Unit II. The concentration of S is relatively greater in the lower marsh deposits of Unit III compared to B, and is in general more variable (Fig. 4.3). B and S enrichment in marsh deposits both decrease in Unit III up section (Fig 4.3).

When plotted as discrimination plots against $\mathrm{Al}$ to determine the influence of terrestrially introduced sediments on the deposition of the elements analyzed here, Fe, $\mathrm{Zn}, \mathrm{V}, \mathrm{Mn}, \mathrm{Na}$, and $\mathrm{K}$ display positive correlations to $\mathrm{Al}$ concentrations (Fig. 4.4; Fig. 4.5). This suggests a primarily terrestrial origin of these elements in the samples taken, with all but Na being supported by statistically significant percentages (Table 4.2, Fig 4.6). Conversely, $\mathrm{Ca}, \mathrm{Mo}, \mathrm{B}$ and $\mathrm{S}$ show varying degrees of negative correlation to $\mathrm{Al}$ concentrations suggesting a relatively marine origin for the majority of these elements, though none are strongly negatively correlated (Table 1; Fig. 4.5- 4.8).

$\mathrm{Na}$ and $\mathrm{K}$ were normalized to $\mathrm{Al}$ and were compared to each other to determine the smectite to illite content of the sediments. The overall higher percentages of $\mathrm{Na}$ to $\mathrm{K}$ and $\mathrm{Na} / \mathrm{Al}$ to $\mathrm{K} / \mathrm{Al}$ suggest an enrichment of smectite over illite in the clay mineral assemblage (Hofer, 2013) (Table 4.1; Fig. 4.6). K shows strong correlation to Al, which further indicates a terrestrial origin of Al within these samples (Hofer et al., 2011) (Table 4.1; Fig. 4.7). 


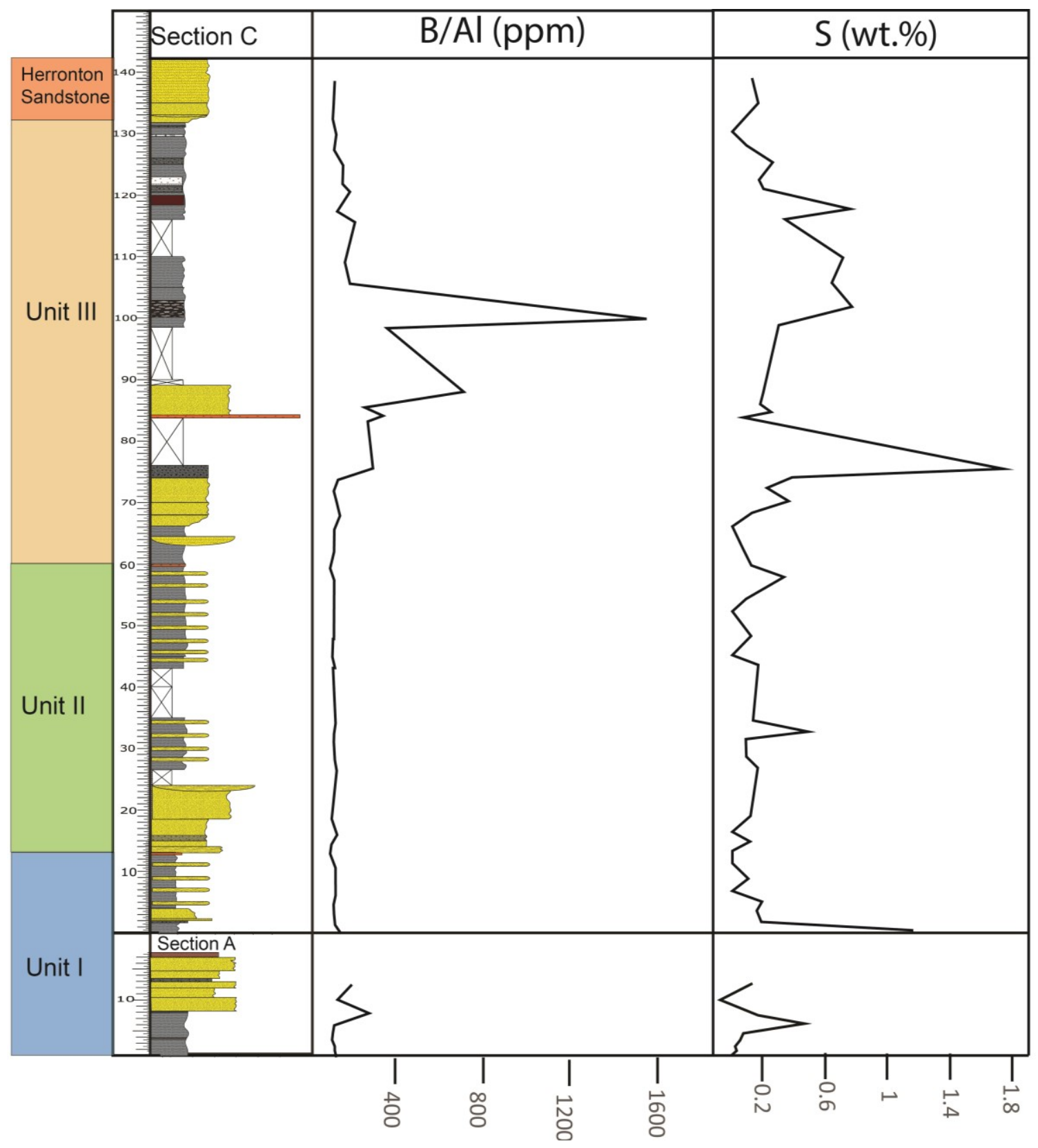

Figure 4.3: Chemostratigraphic profiles of $\mathrm{B} / \mathrm{Al}$ and $\mathrm{S}$ within Sections $\mathrm{A}$ and $\mathrm{C}$ from this study of the Foremost Formation. $\mathrm{B} / \mathrm{Al}$ and $\mathrm{S}$ were plotted together to display palaeosalinity trends. 


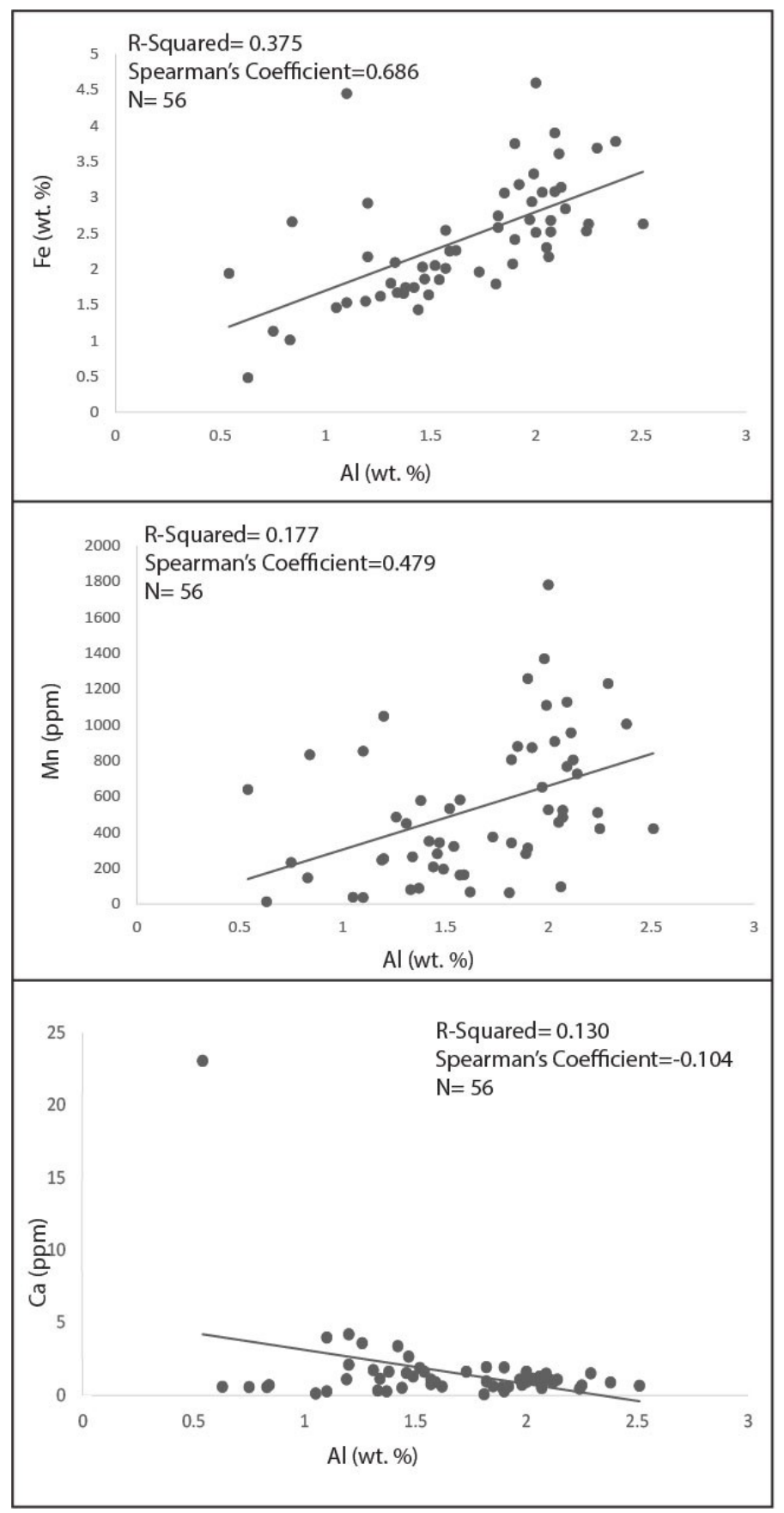

Figure 4.4: Discrimination plots for $\mathrm{Fe}, \mathrm{Mn}$ and $\mathrm{Ca}$ versus $\mathrm{Al}$ in order to determine association of these elements to terrestrial sediment input (represented by Al concentrations). Fe and Mn show strong positive correlation to terrestrial input, whereas $\mathrm{Ca}$ is shown to be negatively correlated to it, suggesting a relatively marine origin. 


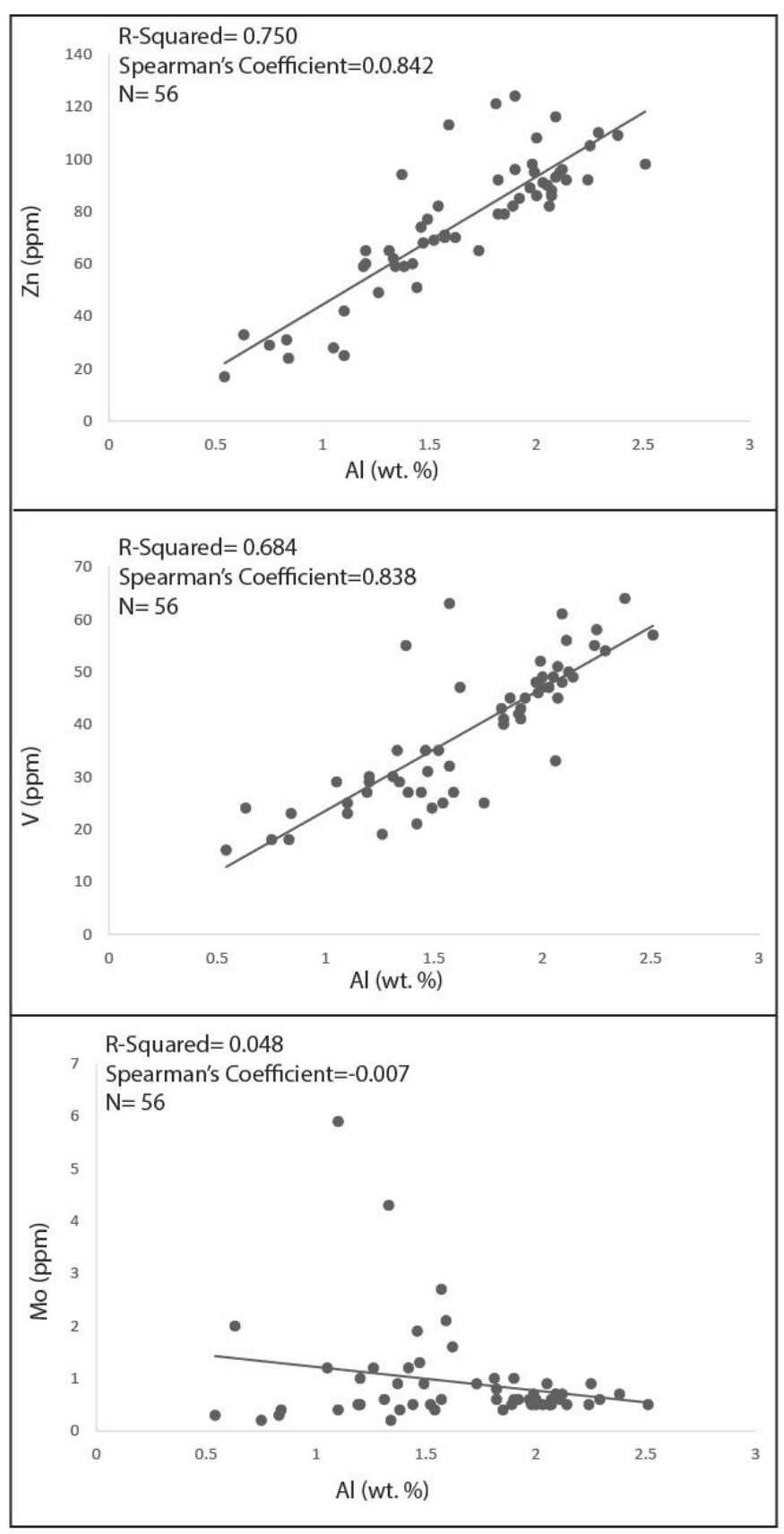

Figure 4.5: Discrimination plots for $\mathrm{Zn}, \mathrm{V}$ and Mo versus $\mathrm{Al}$ in order to determine association of these elements to terrestrial sediment input (Al used as a proxy). Zn and V are strongly linked to terrestrial sediment input, while Mo is weakly negatively corelated and suggested to have little relationship to terrestrial sediment amounts. 


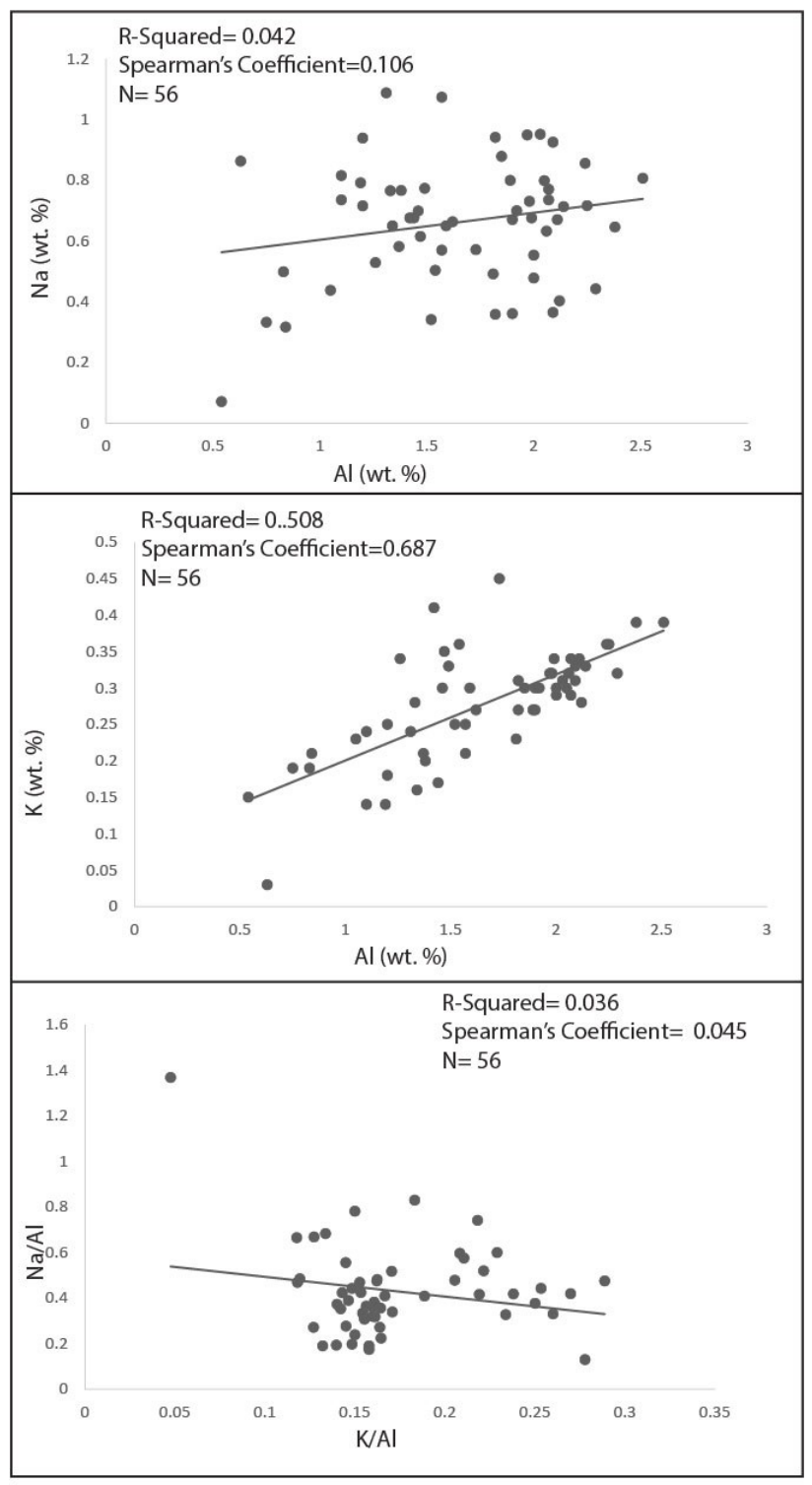

Figure 4.6: Discrimination plots for $\mathrm{Na}$ and $\mathrm{K}$ versus $\mathrm{Al}$ to determine association of these elements to terrestrial sediment input (Al used as a proxy) as well as $\mathrm{Na} / \mathrm{Al}$ vs $\mathrm{K} / \mathrm{Al}$ to determine the smectitie:illite ratio. $\mathrm{K}$ is strongly positively correlated to $\mathrm{Al}$, whereas $\mathrm{Na}$ is weakly positively correlated, suggesting a mix of fluvial introduction and other sources for the origin of $\mathrm{Na} . \mathrm{Na} / \mathrm{Al}$ ratios are greater than $\mathrm{K} / \mathrm{Al}$ ratios, suggesting a greater smectite mineral content is present in the samples of the Foremost Formation. 


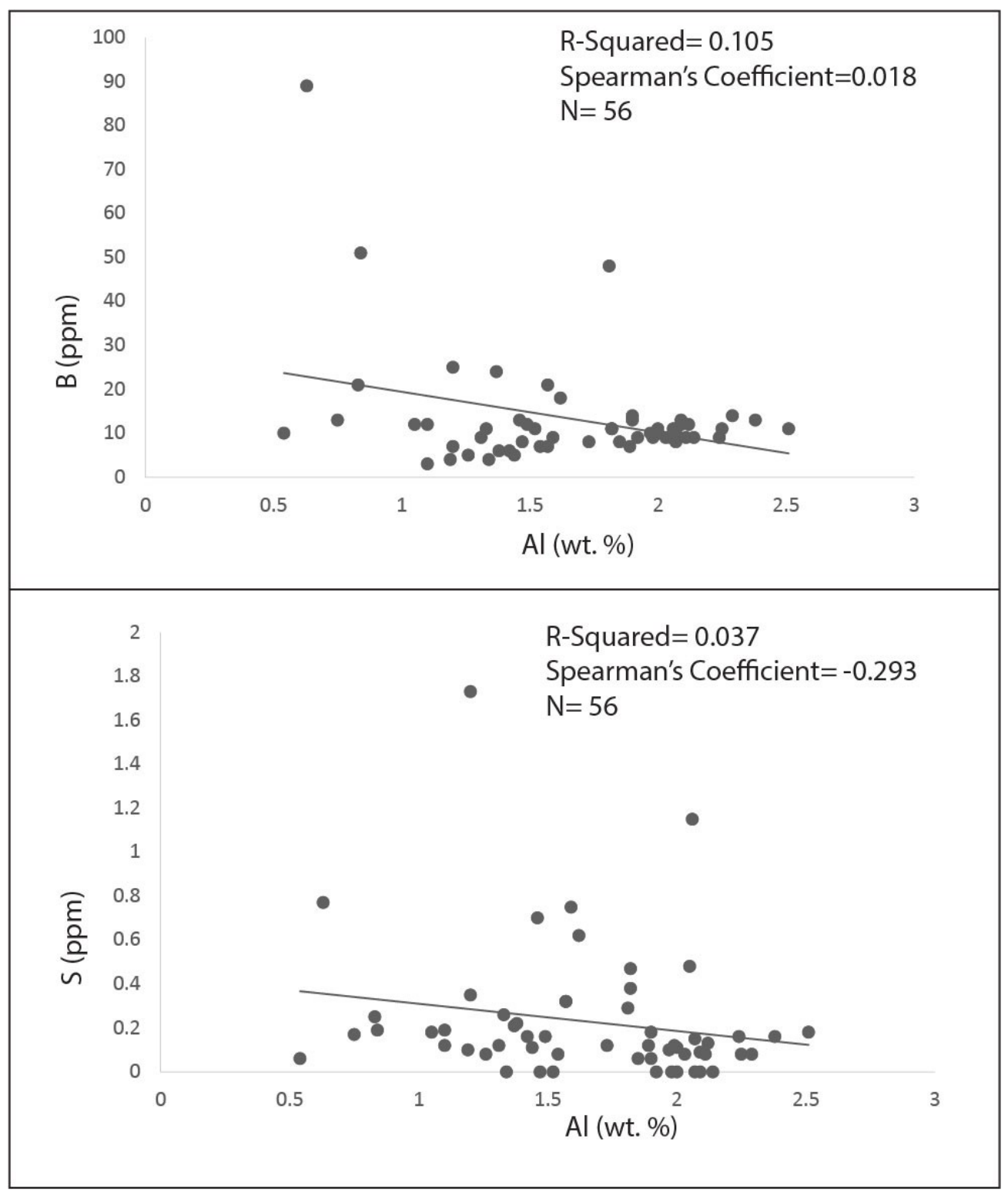

Figure 4.7: Discrimination plots for B and $\mathrm{S}$ versus $\mathrm{Al}$. Both $\mathrm{B}$ and $\mathrm{S}$ are shown to have negative correlations to $\mathrm{Al}$ (terrestrial indicator), supporting their marine origins. 
Table 4.1: $\mathrm{R}^{2}$ values and Spearman's Coefficient significance values for elements vs Al plots.

\begin{tabular}{|c|c|c|}
\hline Element & $\mathbf{R}^{2}$ Value & Spearman's Coefficient \\
\hline $\mathrm{Fe}$ & 0.375 & 0.686 \\
\hline $\mathrm{Zn}$ & 0.750 & 0.842 \\
\hline V & 0.686 & 0.838 \\
\hline Mo & 0.048 & -0.018 \\
\hline $\mathrm{Mn}$ & 0.177 & 0.479 \\
\hline $\mathrm{Na}$ & 0.042 & 0.106 \\
\hline K & 0.508 & 0.687 \\
\hline $\mathrm{B}$ & 0.105 & -0.018 \\
\hline $\mathrm{S}$ & 0.037 & -0.291 \\
\hline $\mathrm{Na} / \mathrm{Al}$ vs $\mathrm{K} / \mathrm{Al}$ & 0.036 & 0.045 \\
\hline
\end{tabular}




\section{2: Summary}

Redox sensitive elements (Fe, Zn, V, Mo, and Mn) are somewhat enriched in organic rich marsh and central bay/lagoonal facies in all units (Fig. 4.1) However, discrimination plots between these elements (with the exception of Mo) suggest a link between terrestrial deposition and these redox sensitive elements, with a general increase up section in both their concentration and in the concentration of other terrestrial indicators (Al and K) (Figs. 4.4-4.7). This suggests a stronger correlation of enrichments in redox minerals to terrestrial deposition than to redox conditions, making their validity as redox indicators questionable. Palaeosalinity indicators show a general decrease up section in Unit III in conjunction with an increase in fluvial deposits but with greater enrichment in the salt marsh facies (Facies 10) (Fig. 4.3). An overall greater abundance of smectite clays versus illite clays (Na vs K) is seen in Unit I and Unit II, with the two becoming relatively even in Unit III, and show the greatest enrichment in brackish central bay/lagoonal deposits (Fig. 4.2). In general, these clay trends suggest a decreased marine influence up section, with variable salinity levels. Although not definitively, the geochemical data support a marine to terrestrial depositional regime through the Foremost Formation as suggested by geological and faunal evidence previously discussed and have proven as a useful proxy for visualizing increases and decreases in terrestrial sediment input through the section. 


\section{Chapter 5: Vertebrate Microsite}

Vertebrate microsites are defined as those localities where $75 \%$ or more of the fossil elements present are less than or equal to $5 \mathrm{~cm}$ in their longest dimension (Eberth et al., 2007). Data from vertebrate microsites can be useful for palaeoenvironmental analysis as they often provide large sample sizes with high diversity compared to macrofossil bone beds (Brinkman, 1990; Brinkman et al., 2004; Cumbaa et al., 2010; Rogers and Brady, 2010; Cullen et al., 2016). Additionally, the remains found in microsites are an accurate representation of the fauna present in or very close to the area of deposition (Eberth, 1990). These attributes can allow for estimates of species abundance and regional faunal compositions.

The majority of the microsites in the Foremost Formation are relegated to marine environments represented in the deposits of the formation below the Taber Coal Zone, with samples from the upper terrestrial portions being relatively uncommon (Beavan 1995; Cullen et al., 2016). This scarcity in terrestrial fossil material is expected as most of the Foremost Formation is represented by marine to transitional depositional environment, but may also be related to biotic and/or abiotic taphonomic preservation bias, low sample number or sampling bias, or a combination of all of these factors (Brinkman et al., 2004).

In this study, a new vertebrate microsite (named C26 after its field sample number) was discovered within section $\mathrm{C}$ of the Foremost Formation. Detailed lithological and stratigraphic information of the site can be found in Chapter 2. 
Additional microvertebrate remains were sampled from sediment sample C32 and are briefly discussed within this chapter.

\section{1: Systematic Palaeontology}

Class CHONDRICTHYES, Huxley (1880)

Order ORECTOLOBIFORMES, Applegate (1972)

Family ORECTOLOBIDAE, Jordan and Fowler (1903)

Genus Squatirhina, Casier (1947)

Squatirhina roessingi Case (1987)

Figure $5.2 \mathrm{~A}$

Material: A single tooth identified within C32 residue, $2.3 \mathrm{~mm}$ wide and $1.2 \mathrm{~mm}$ tall.

Description and Diagnosis: The tooth is dorsoventrally compact, with a prominent, cone shaped central cusp that tapers to a point that is slightly recurved. Laterally to the apex are three small, triangular shaped cusplets on the mesiodistal margin of the main cusp. The root is damaged; however, the diagnostic nutrient canal of Squatirhina is still visible (Peng et al., 2001).

Superorder BATOMORPHII, Cappetta (1980)

Order RAJIFORMES, Berg (1940)

Superfamily RHINOBATOIDEA, Fowler (1941)

Genus Pseudomyledaphus, Kirkland et al., 2013 


\title{
Pseudomyledaphus sp.
}

Figure 5.2 B and C

Material: Fifty-five isolated teeth from $\mathrm{C} 26$ and one isolated denticle from C32. Teeth range between $0.8 \mathrm{~mm}$ to $7 \mathrm{~mm}$ in width, and between $0.6 \mathrm{~mm}$ to $5.2 \mathrm{~mm}$ in height from root to crown. The isolated denticle is approximately $1 \mathrm{~mm}$ wide and $1.2 \mathrm{~mm}$ tall.

Description and Diagnosis: All teeth have a hexagonal, enamel-covered crown, and complete bifurcate root that is smaller than the crown. This tooth is identified as Pseudomyledaphus rather than Myledaphus based on the lack of enamel folds on the outer edges of the crown and the presence of a distinct " $\mathrm{C}$ shaped" ridge on the occlusal surface on unbraided teeth (Kirkland et al., 2013; Freedman-Fowler and Horner, 2015). Assignment to a specific species requires greater scrutiny beyond this study; however, it has been noted by Kirkland et al. (2013) that these teeth are different from those found in the Milk River Formation and from age equivalent formations in Utah (Kirkland et al., 2013)

\author{
Class OSTEICHTHYES, Huxley (1880) \\ Order ACIPENSERIFORMES, Berg (1940) \\ Family ACIPENSERIDAE, Bonaparte (1831) \\ "Holostean B"
}

Figure 5.3 A

Material: Ten fragmentary scales from site $\mathrm{C} 26$, ranging between $0.3 \mathrm{~mm}$ to 0.4 $\mathrm{mm}$ in length. 
Description and Diagnosis: All scales show the diagnostic sinuous ridges of ganoine on the outer surface found in Holostean B (Peng et al., 2001; Frampton, 2006). These ganoine structures differentiate these scales from Holostean A, which lack them (Brinkman, 1990).

\author{
Order LEPISOSTEIFORMES, Hay (1929) \\ Family LEPISOSTEIDAE, Cuvier (1825)
}

Genus Lepisosteus, de Lacepède (1803)

Lepisosteus occidentalis Leidy (1856)

Figure 5.3 B

Material: Twenty-one scales from site C26. Each scale has an approximate maximum thickness of $0.4 \mathrm{~mm}$, and is between $4 \mathrm{~mm}$ to $20 \mathrm{~mm}$ in length in their maximum dimension.

Description and Diagnosis: These large, rhombohedral to sub-ovular shaped scales are common in the sampled assemblage. They exhibit minimal abrasion, and most are unbroken. They have a distinct, lustrous, dark ganoine coating with underlying striation patterns covering their outer surface which allows for their classification as $L$. occidentalis (Peng et al., 2001; Cullen et al., 2016). Many scales also display a central pit on the outer surface.

Subdivision TELEOSTEI, Muller (1846)

Order ELOPIFORMES, Sauvage (1875) 


\section{Family PHYLLODONTIDAE, Sauvage (1875) \\ Subfamily PARALBULINAE, Estes (1969a)}

Genus Paralbula, Blake (1940)

Paralbula casei Estes (1969a)

Figure 5.3 C

Material: Twenty-three isolated teeth and one tooth plate fragment. They range between 0.5 to $1 \mathrm{~mm}$ in thickness and can be up to $3 \mathrm{~mm}$ wide.

Description and Diagnosis: Each knob-like tooth has a convex occlusal surface and flat, or sometimes weakly, concave ventral surface. The ventral surface shows a central foramen surrounded by a ridged margin. The occlusal surface is slightly rugose, though some teeth are more worn than others which can mask this feature. The smaller size and presence of the foramen on the ventral surface matches the description of Paralbula casei. No other durophagous phyllodontid fish were identified in the assemblage (Peng, 2001; Frampton, 2006). The tooth plate fragment preserves five teeth in their original position, organized in a single occlusal plane.

Superorder CLUPEOMORPHA, Greenwood et al. (1966)

Family CLUPEIDAE, Bleeker (1859)

Genus ?Knightia, Jordan (1907)

Figure 5.3 D 
Material: One centrum from site C32. 0.8 to $2 \mathrm{~mm}$ wide and approximately $4 \mathrm{~mm}$ in length.

Description and Diagnosis: The neural arches and dorsal processes have not been preserved with this centrum. However, the centrum shows the characteristics attributed to clupeids such as a relatively gracile morphology with neural arch pits on the anterior end only and a prominent central dorsal ridge (Brinkman, 2017). It can be identified as a posterior dorsal centrum based on the relatively long anterior posterior profile and round shape of the articular face. This centrum is notable as it marks the first occurrence of this family in the Foremost Formation, and in any vertebrate microsite in Alberta outside of those at Onefour within the Oldman Formation (Brinkman et al., 2017) Order SALMINIFORMES, (Bleeker 1859) Family ENCHODONTIDAE, (Woodward 1901)

Genus Enchodus, (Agassiz 1843)

\section{Enchodus sp.}

Figure 5.4 A

Material: A single tooth with attached root. $3.7 \mathrm{~cm}$ in total length.

Description and Diagnosis: The tooth is abraded with the majority of enamel worn off and only a small portion of the anterior cutting edge preserved. The preserved enamel is strongly striated. The tooth crown is long and cone-shaped, tapering in a slight S-curve from the midpoint to the apex anteriorly. The root flares to almost twice the width from base to top and contains no enamel coating. This tooth is attributed to 
Enchodus sp. based on the lance-shaped, elongate crown and unserrated cutting edge (Shimada and Everhart, 2003)

Fish Tooth Indet

Figure 5.4 B

Material: Four teeth measuring $0.8 \mathrm{~mm}$ to $1.2 \mathrm{~mm}$ tall and $0.4 \mathrm{~mm}$ wide from C32.

Description and Diagnosis: Each tooth features a crown that is bulbous and subspherical, tapering thinner mesiodistally. The anterior portion of the crown is also capped by a recurved, hook-like cusp. The root is approximately three quarters the height of the crown. This tooth morphology is unknown from Albertan microsites but resembles the exceedingly small pycnodontiform incisor teeth known from the Cretaceous to Paleogene around the world (Kriwet, 2005).

Cycloid scales indet:

Figure $5.4 \mathrm{C}$

Material: 3 Scale fragments from C32, all approximately $1.2 \mathrm{~mm}$ long and up to $1 \mathrm{~mm}$ wide.

Description and Diagnosis: Identified as cycloid scales by the presence of enamel covered ornate thumbprint like ridges on the outer scale surface, which are known as circuli (Schultze, 1996). The long, subtriangular fragment likely represents the anterior radii of the scale. The other fragment is likely a posterior fragment based on the rounded curvature of the circuli. 


\title{
Class AMPHIBIA, Linnaeus (1758) \\ Order CAUDATA, Scopoli (1777)
}

Caudata indet

Figure 5.4 D

Material: One vertebra. $3.8 \mathrm{~mm}$ in length measured from anterior to posterior, and $3.5 \mathrm{~mm}$ wide dorsoventrally.

Description and Diagnosis: The amphicoelous vertebra possesses a distinct, tall neural spine that tapers posteriorly. As the basapophyses are absent, this could potentially be assigned to Scapherpeton; however, due to abrasion, the diagnostic presence of a subcentral keel and shape of the cotyles cannot be inferred. Therefore, it can only be assigned to Caudata indet. (Peng et al., 2001; Cullen et al., 2016)

\author{
Class REPTILIA, Laurenti (1768) \\ Order TESTUDINES, Batsch (1788) \\ Family ADOCIDAE, Cope (1870) \\ Genus Adocus, Cope (1868)
}

Adocus sp.

Figure $5.5 \mathrm{~A}$

Material: Twenty carapace fragments ranging from 1.5 to $4.3 \mathrm{~cm}$ in maximum dimension, collected from site C26. 
Description and Diagnosis: These carapace fragments are thin dorsoventrally with a smooth inner surface and punctate sculpturing (sensu Meylan and Gaffney, 1989) on the outer surface (i.e., shallow, rounded, pit-like structures separated by sculpted ridges) that is diagnostic of Adocus (Peng, 2001; Frampton, 2006). The fragmentary nature of these specimens precludes species level identification.

$$
\text { Family TRIONYCHIDAE, Gray (1825) }
$$

Trionychidae indet.

Figure $5.5 \mathrm{~B}$

Material: One carapace fragment from C26, measuring $2.1 \mathrm{~cm}$ in maximum length and $65 \mathrm{~mm}$ thick.

Description and Diagnosis: Similar to Adocus, this carapace fragment displays sculpturing on its surface. However, the pits are more irregularly shaped and deeper due to the taller ridges between each pit (Cullen et al., 2016). The sculpturing pattern superficially resembles that of crocodilians. Classification more inclusively than Trionychidae is not possible due to the fragmentary nature of the specimens.

Family HELOCHELYDRIDAE, Nopsca (1928)

Genus Naomichelys, Hay (1908)

Naomichelys sp.

Figure $5.5 \mathrm{C}$

Material: Eleven fragments of carapace ranging in length from $5 \mathrm{~mm}$ to $35 \mathrm{~mm}$. 
Description and Diagnosis: The carapace fragments display numerous small tubercules on their outer surface that are knob-to-pillar-shaped when viewed anteroposteriorly, and have a circular profile when viewed dorsally, which is diagnostic of Naomichelys (Frampton, 2006; Cullen et al., 2016). Species level diagnosis is not possible due to the fragmentary nature of the specimens.

\author{
Subclass DIAPSIDA, Osborn (1903) \\ Order CHORISTODERA, Cope (1876) \\ Family CHAMPSOSAURIDAE, Cope (1876) \\ Genus Champsosaurus, Cope (1876)
}

Champsosaurus sp.

Figure 5.6 D

Material: Two centra from C26, 1.3 to $1.6 \mathrm{~mm}$ long and wide and 0.9 to $1.1 \mathrm{~cm}$ tall.

Description and Diagnosis: Both centra are approximately equal in height and width and have an hourglass shape when viewed dorsoventrally. Both are mid-dorsal centra based on their rounded ventral surface, rib articulation processes on the lateral surfaces near the neural arch articulation point, and a thin, constricted ridge where the absent neural arch would connect on the dorsal surface (Peng, 2001; Cullen et al., 2016).

Clade ARCHOSAURIA, Cope (1869)

Clade EUSUCHIA, Huxley (1875) 
Eusuchia indet.

Figure 5.6 A and B

Material: Fourteen dermal scutes ranging from $0.4 \mathrm{~mm}$ to $20 \mathrm{~mm}$ in maximum length and five teeth ranging from $2 \mathrm{~mm}$ to $8 \mathrm{~mm}$ in length.

Description and Diagnosis: The teeth are restricted to shed, cone-shaped crowns only. Each tooth is also slightly recurved, lack denticles, and have paired cutting ridges running along the labial and lingual sides of the crown. Champsosaurid teeth are similar to these in being cone-like and pointed, but they are not recurved and lack cutting edges.

All but one dermal scute from $\mathrm{C} 26$ are from the dorsal neck region, identified as such by a distinct midline ridge that bisects the ornamented pits and ridges that cover the outer surface of each scales (Peng et al., 2001; Brinkman et al. 2017). One scute is from the ventral neck region as it lacks this prominent ridge, but has a similar, open pitted ornamentation pattern as those scutes from the dorsal neck. Scutes from other areas of the body have smaller and less numerous ornamentation pits (Brinkman et al., 2017).

?Crocodilia/Bird-Like Morphology

Figure 5.6 C

Material: A single tooth crown from C26 measuring $5 \mathrm{~mm}$ from base to apex and $2.5 \mathrm{~mm}$ in thickness at the base.

Description and Diagnosis: The crown of this single tooth is slightly compressed anteroposteriorly and slightly recurved with distinct ridges present on the enamel covered surface. This tooth bears most resemblance to the "bird-like" (morphology 4) teeth 
described in Brinkman et al. (2017). These teeth superficially resemble those of Hesperornis, but lack the vestigial denticles and display strong enamel striations not seen in Hesperornis.

\author{
Clade DINOSAURIA, Owen (1842) \\ Order ORNITHISCHIA, Seeley (1888) \\ Suborder ANKYLOSAURIA, Osborn (1923) \\ Family ANKYLOSAURIDAE, Brown (1908)
}

Figure 5.7 A

Material: A single dermal ossicle from C26 measuring $15 \mathrm{~mm}$ in length and 5 $\mathrm{mm}$ in thickness.

Description and Diagnosis: This small dermal armor fragment is differentiated from crocodilian dermal armor by the lack of distinct sculpturing attributable to crocodiles and instead has the subdued sculpturing found on some ankylosaurid ossicles (Cullen et al., 2016; Brinkman et al., 2017). The round, presumably dorsal, side is highly rugose and there are small foramina penetrating the ossicle. Overall, this ossicle is very thick, especially compared to crocodilian scutes collected from the same site.

\author{
Suborder ORNITHOPODA, Marsh (1881) \\ Family HADROSAURIDAE, Cope (1869)
}

Figure $5.7 \mathrm{~B}$ and $\mathrm{D}$ 
Material: One high tooth crown fragment from C26 and one fragmentary, juvenile manual or pedal element (maximum length, $40 \mathrm{~mm} ; 29 \mathrm{~mm}$, thickness).

Description and Diagnosis: A highly worn, fragmentary portion of a hadrosaur tooth crown was identified. This diagnosis is attributable to the preserved medial ridge running down the lingual surface of the crown, which is only found on hadrosaur teeth (Frampton 2006; Cullen et al., 2016).

The single, fragmentary hadrosaurid metatarsal was surface collected from C26, is identified by its dorsoventrally flattened, puck-shaped morphology (Horner and Weishampel, 2004). Only one proximal articular surface with it two nutrient foramina is well preserved.

\author{
Order SAURISCHIA, Seeley (1888) \\ Suborder: THEROPODA, Marsh (1881) \\ Clade MANIRAPTORA, Gauthier (1986)
}

Family DROMAEOSAURIDAE, Colbert and Russell (1969)

Genus: Saurornitholestes, Sues (1978)

Saurornitholestes langstoni, Sues (1978)

Figure $5.7 \mathrm{E}$

Material: A single tooth crown from $\mathrm{C} 26$ that is $10 \mathrm{~mm}$ in length from base to apex and approximately $3 \mathrm{~mm}$ in thickness. 
Description and Diagnosis: This tooth crown is highly abraded, with the apex completely worn down to a smooth, rounded point. The tooth is strongly labiolingually compressed and recurved. The tooth can be referred to $S$. langstoni based on the preserved denticles chisel-like denticle morphology of, with the anterior denticles being considerably smaller and less numerous than the posterior denticles (Currie et al., 1990; Peng et al., 2001).

Family TYRANNOSAURIDAE, Osborn (1905)

Tyrannosauridae indet.

Figure $5.7 \mathrm{C}$

Material: One fragmentary tooth from C26 measuring $45 \mathrm{~mm}$ in maximum length.

Description and Diagnosis: The highly abraded fragment of the outer surface of a tooth crown that is slightly recurved and preserves small portions of highly striated enamel and dentine portions of the eroded denticles. It is referred to Tyrannosauridae indet. based on its large size, recurved morphology, and preserved underlying structure of denticles (Peng et al., 2001). 


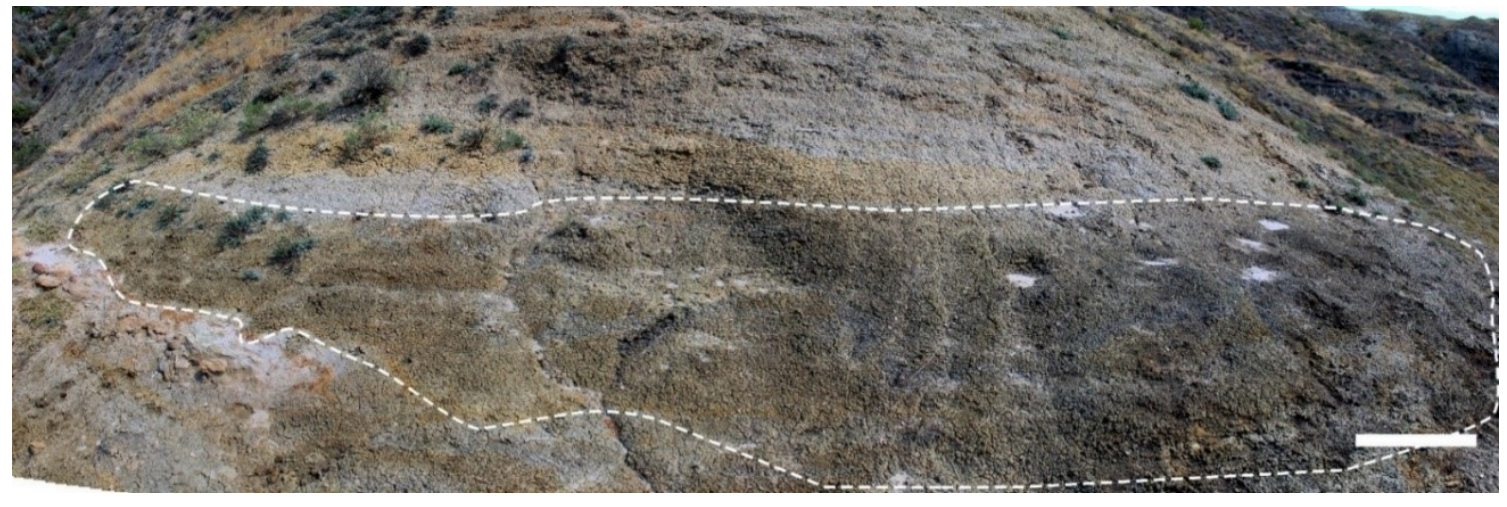

Figure 5.1: Outcrop profile of site C26 outlined in white. See Figs. 2.4 and 2.5 for stratigraphic position. Scale bar $=1 \mathrm{~m}$. 


\section{Plates}

Figure 5.2: (see page 117):

$\mathrm{A}=$ Squatirhina $\mathrm{sp}$. Scale Bar $=1 \mathrm{~mm}$

$\mathrm{B}=$ Pseudomyledaphus sp. tooth. Scale Bar=3 mm

C: Pseudomyledaphus sp. denticle Scale Bar $=1 \mathrm{~mm}$

Figure 5.3: (see page 118):
A: "Holostean-B" Scale. Scale Bar=2 mm
B: Lepisosteus occidentalis scale. Scale Bar $=5 \mathrm{~mm}$
C: Paralbula case $i$ tooth. Left $=$ ventral surface, right $=$ occlusal surface. Scale Bar $=1 \mathrm{~mm}$
D: ?Knightia centrum dorsal view. Scale Bar $=2 \mathrm{~mm}$

\section{Figure 5.4: (see page 119):}
A: Enchodus sp. tooth. Scale Bar $=10 \mathrm{~mm}$
B: Unidentified fish teeth from C32. Scale Bar $=1 \mathrm{~mm}$
C: Cycloid scale fragments. Scale Bar $=1 \mathrm{~mm}$
D: Scapherpeton sp. Vertebra. Left to Right; Lateral view, anterior view. Scale Bar=2
$\mathrm{mm}$

Figure 5.5: (see page 120):

A: Adocus sp. carapace fragment. Scale Bar $=10 \mathrm{~mm}$

B: Trionychidae indet. Carapace fragment. Scale Bar $=10 \mathrm{~mm}$ 
C: Naomichelys sp. carapace fragment. Scale Bar $=10 \mathrm{~mm}$

Figure 5.6: (see page 121):

A: Eusuchia indet 1. Scale $=5 \mathrm{~mm}$

B: Eusuchia Scute: Scale $=10 \mathrm{~mm}$

C: "Bird Tooth" morphology Eusuchian tooth. Scale $=4 \mathrm{~mm}$

D: Champsosaurus centrum. Left to right: Dorsal, ventral and anterior views. Scale $=20$ $\mathrm{mm}$

Figure 5.7: (see page 122):

A: Ankylosaur ossicle. Left $=$ dorsal, right $=$ ventral. Scale $=10 \mathrm{~mm}$

B: Hadrosaur tooth fragment. Left=lingual view, right $=$ dorsal view. Scale $=4 \mathrm{~mm}$

C: Tyrannosaur indet tooth. Scale $=20 \mathrm{~mm}$

D: Hadrosaur carpal/tarsal element. Scale $=20 \mathrm{~mm}$

E: Saurornitholestes langstoni tooth. Magnified view of denticles included. Scale $=5 \mathrm{~mm}$ 

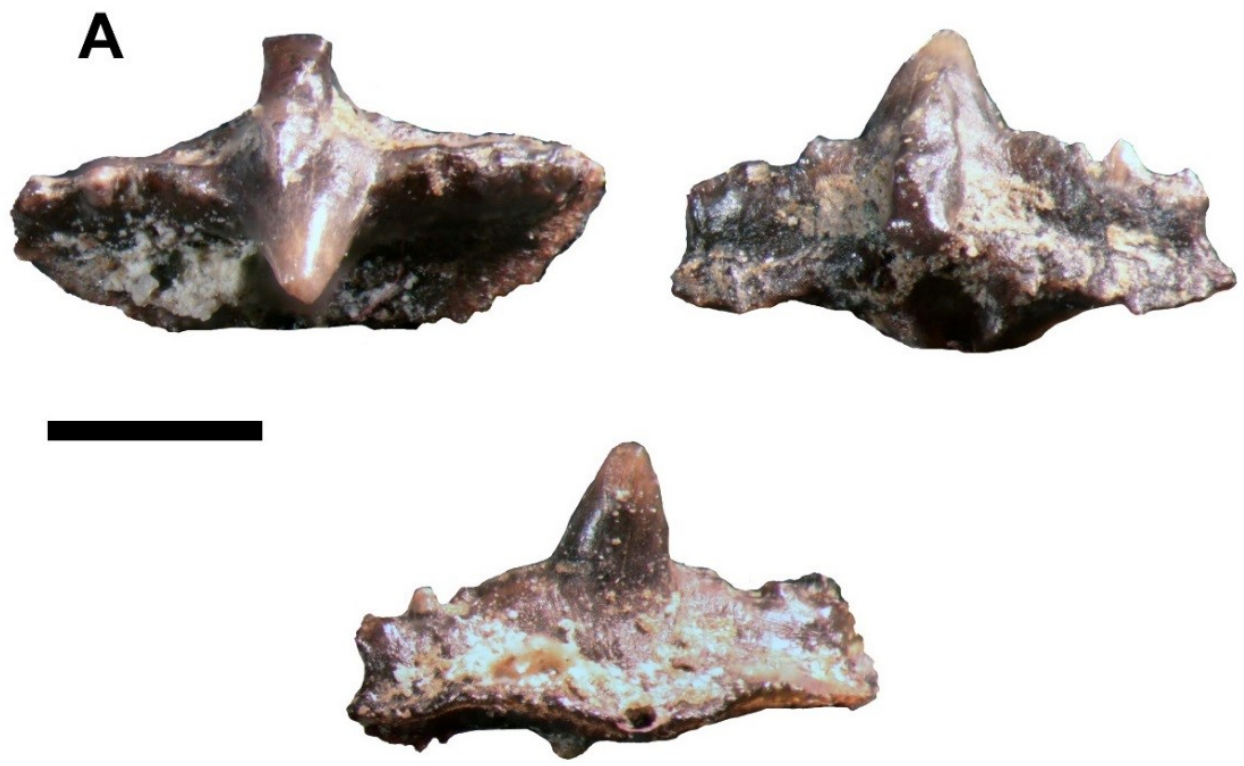

B
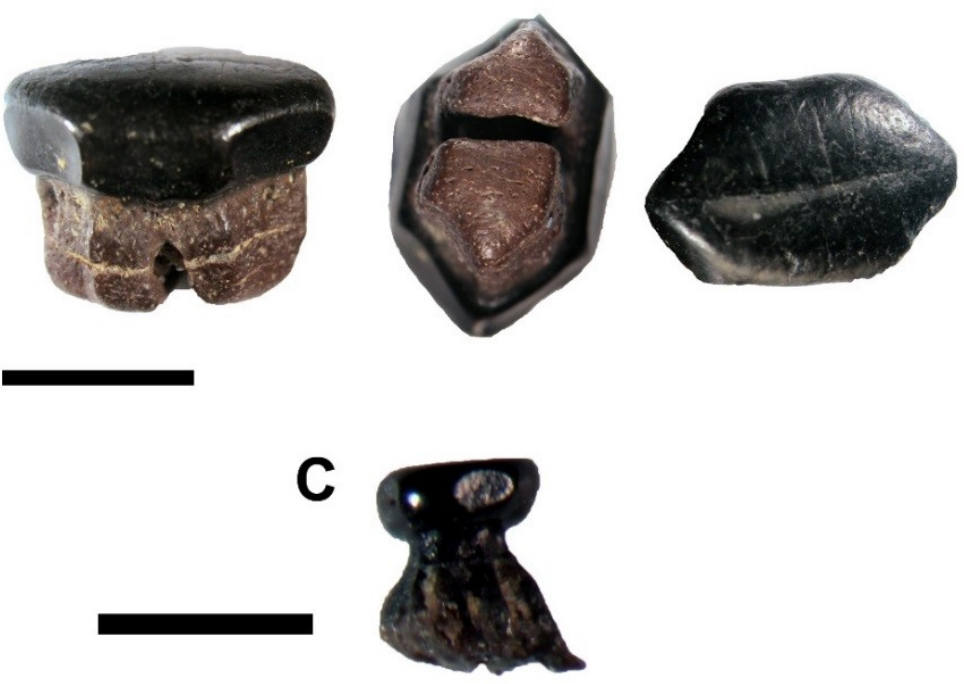

Figure 5.2 

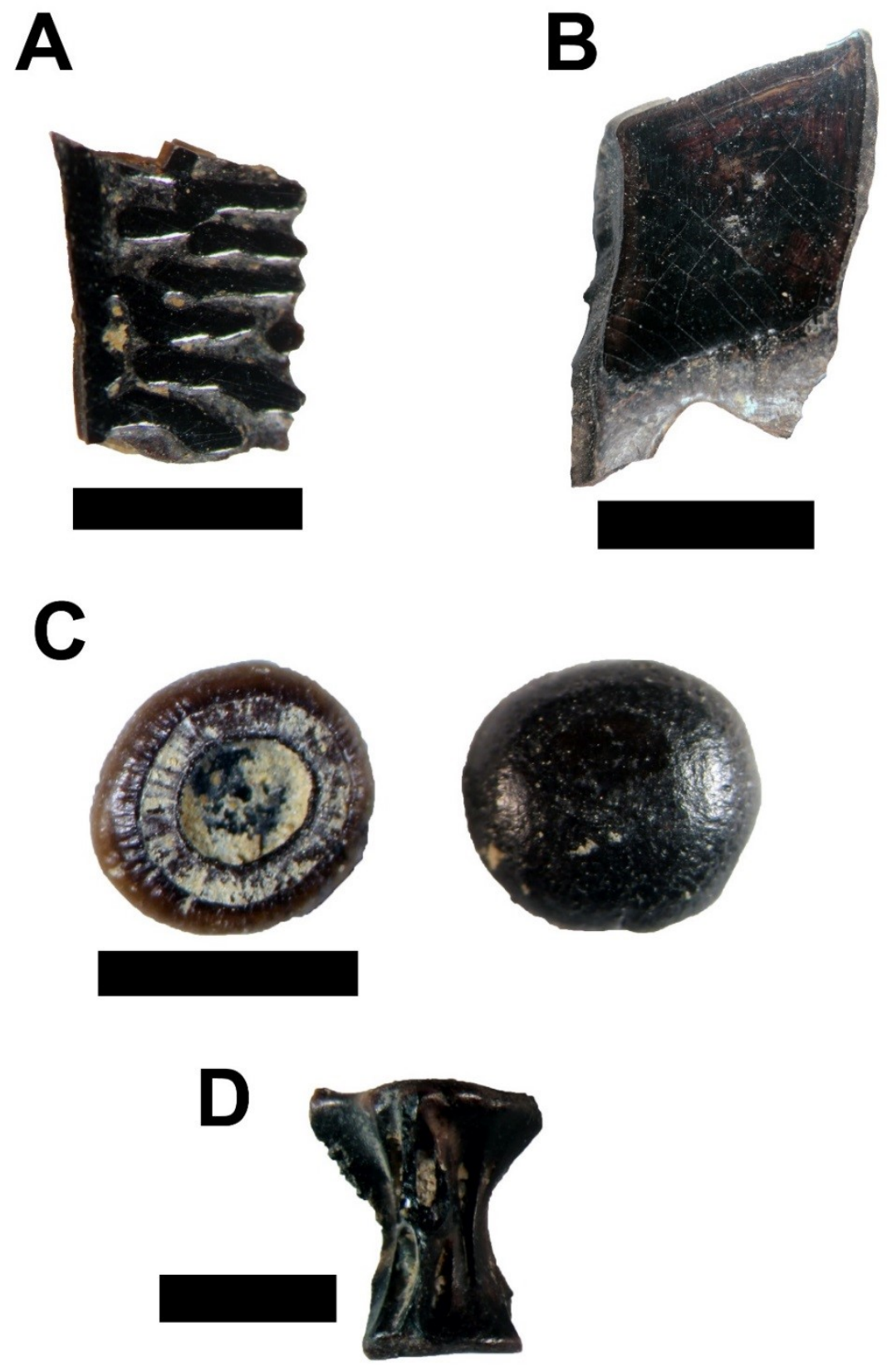

Figure 5.3 

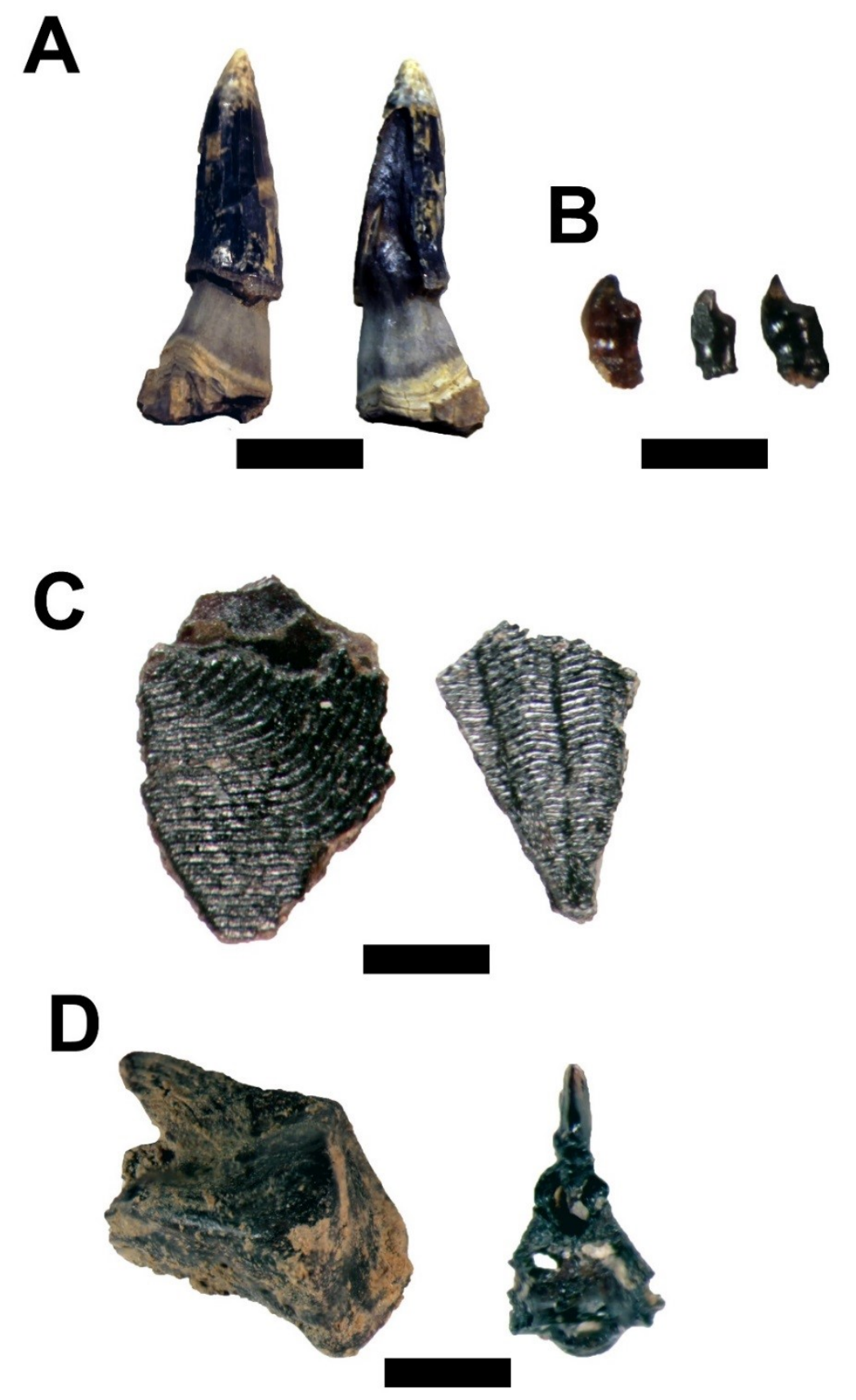

Figure 5.4 

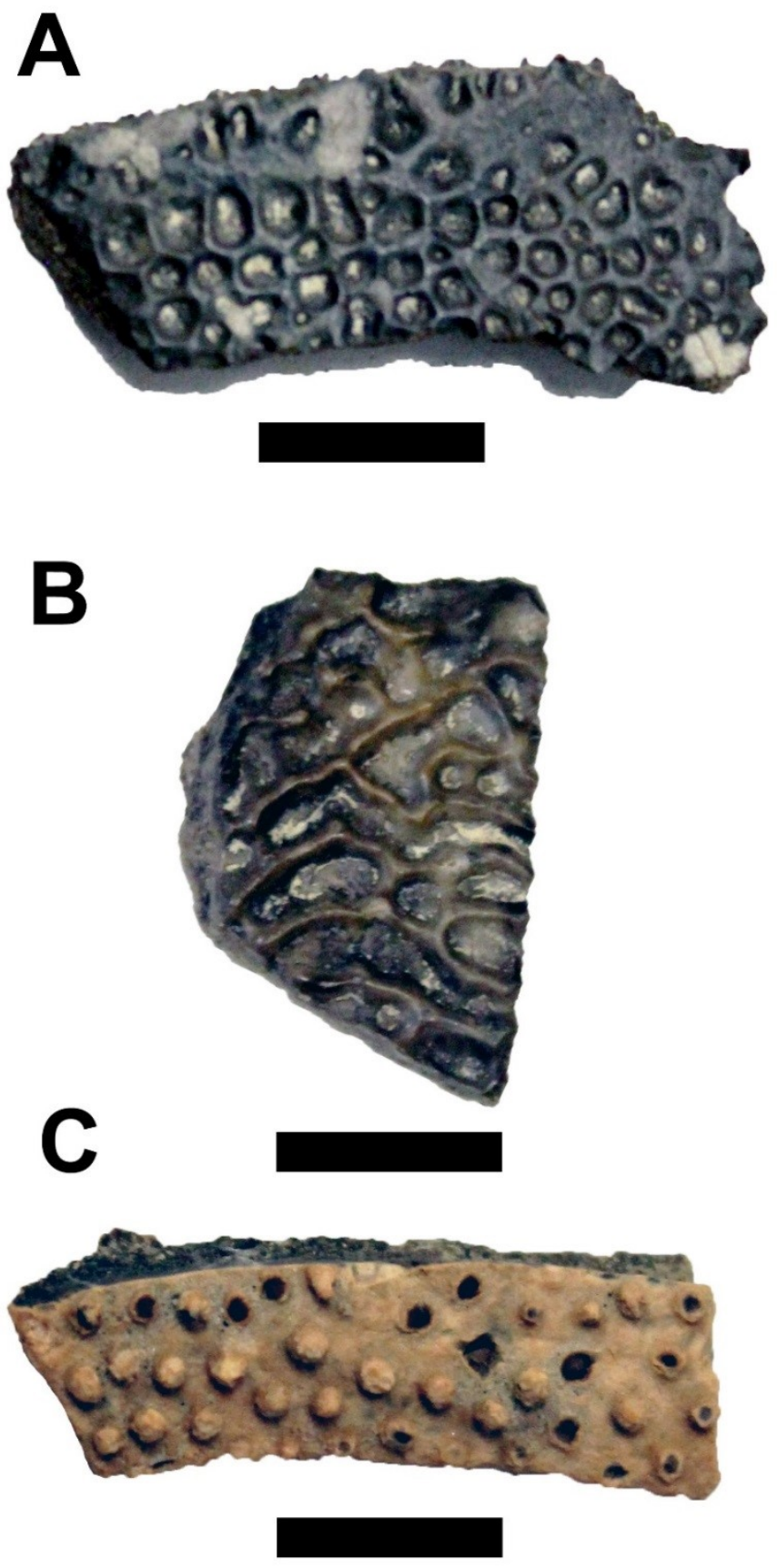

Figure 5.5 


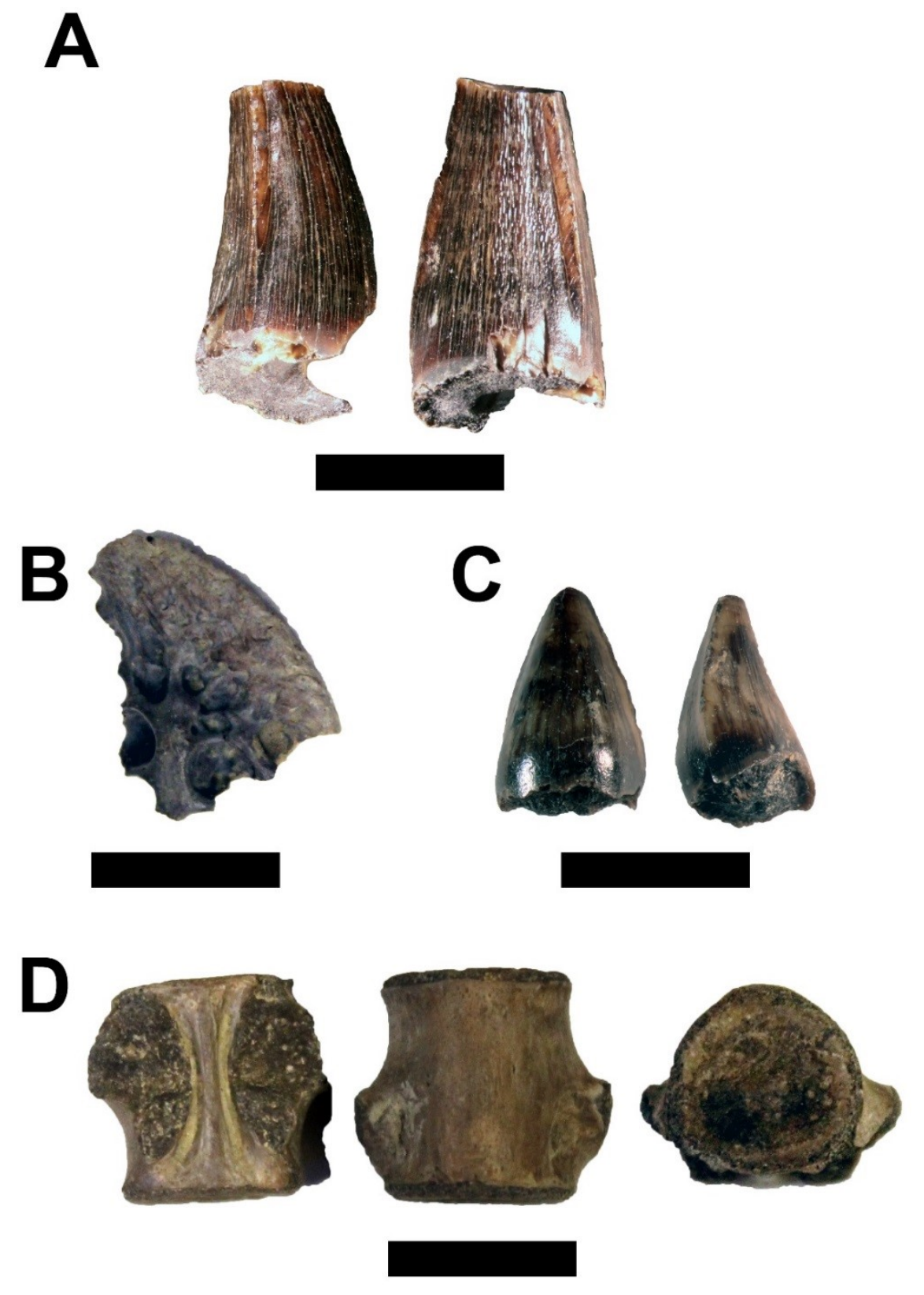

Figure 5.6 

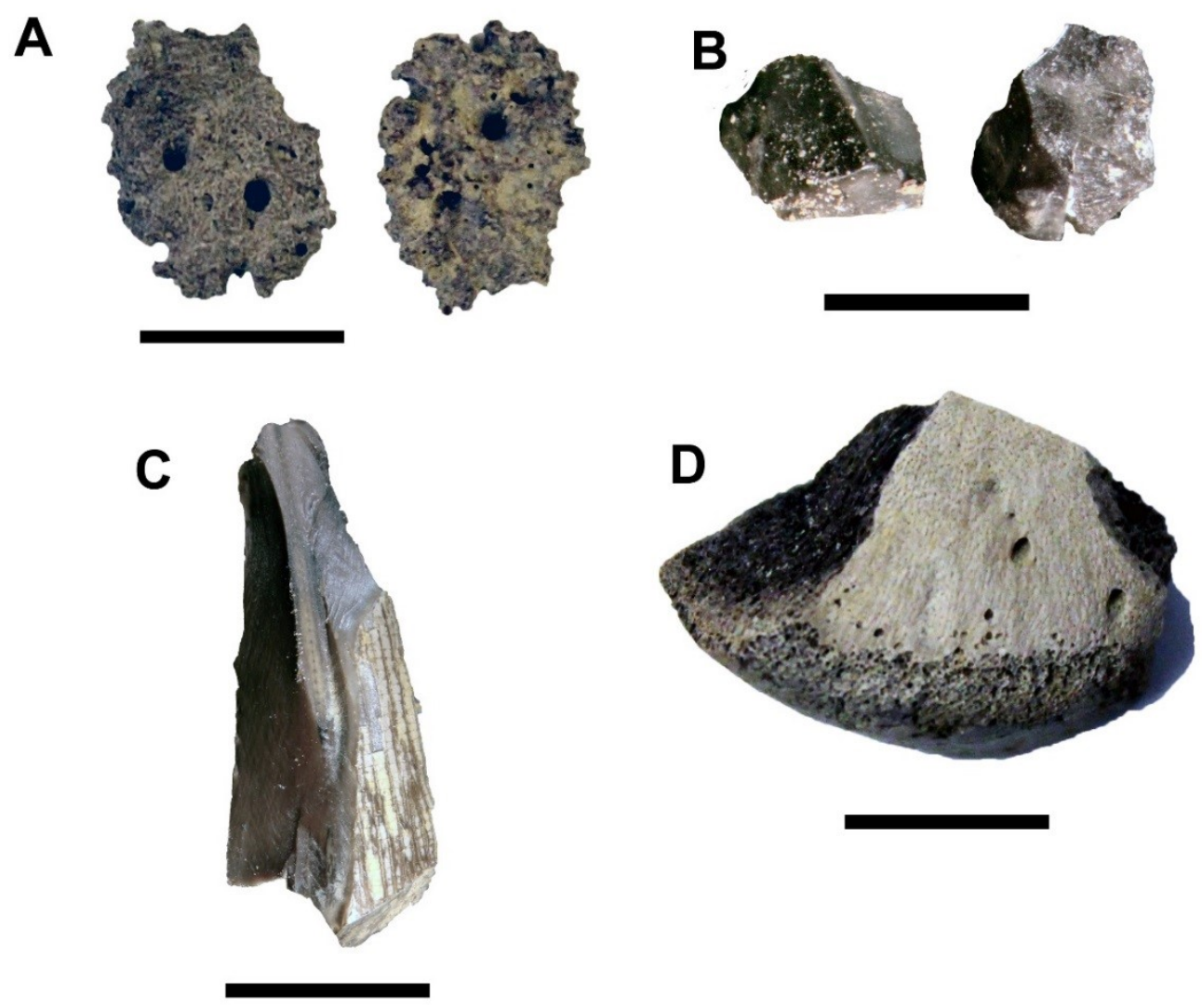

E
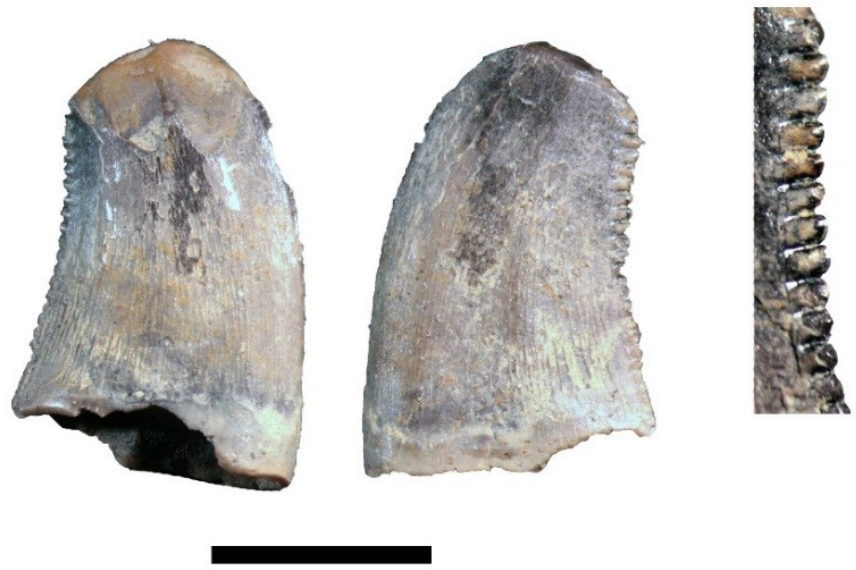

Figure 5.7 


\section{2: Results}

\subsection{1: Taxonomic Abundance}

\section{Site C26}

A total of 1022 elements were collected from site C26 with 179 of those elements being identifiable (17.5\%; Appendix Table D-1). Among those, the fish Pseudomyledaphus, Paralbula and Lepisosteus are the three most abundant fossil taxa represented (Fig. 5.2; Fig 5.6; Fig 5.12; Fig 5.13; refer to table 5.1 for category explanations; see Appendix D for detailed taxonomic counts). These fishes are known to be associated with brackish water conditions and have been found in every microvertebrate study of the Belly River Group in Alberta (Brinkman et al., 2004; Cullen et al., 2016). The acipenserid fish 'Holostean-B', the turtles Adocus and Naomichelys (Solemydidae), and eusuchian crocodiles are also common, with abundances similar to the brackish water fish Lepisosteus (Figs. 5.8 and 5.12; Appendix E-1). These taxa have also been interpreted to live in a variety of brackish coastal environments, but have a greater tolerance for freshwater conditions compared to other previously mentioned brackish water taxa (Brinkman et al., 2004; Frampton, 2006; Cullen et al., 2016). Terrestrially derived dinosaur and lissamphibian material and fully marine chondrichthyan material are rare, often represented by a single element if represented at all (Figs. 5.8 and 5.12; Appendix E-1). 
Taxonomic abundances were also analyzed without surface collected material to account for potential sample biases causing increases in the relative abundances of certain taxa. Overall abundances change very little when excluding surface material, with

Table 5.1: Stages of fossil material abrasion collected from vertebrate microsite C26 based on Fiorillo (1988), Cook (1995) and Phillips (2009).

\begin{tabular}{|c|l|}
\hline Stage & \multicolumn{1}{c|}{ Description } \\
\hline Stage 0 & $\begin{array}{l}\text { Angular: the fossil fragment is unabraded and its } \\
\text { features are well defined. }\end{array}$ \\
\hline Stage 1 & $\begin{array}{l}\text { Subangular: slight abrasion of any edges and pro- } \\
\text { cesses. }\end{array}$ \\
\hline Stage 2 & $\begin{array}{l}\text { Subrounded: edges have been rounded, processes } \\
\text { generally remain unaltered and recognizable. }\end{array}$ \\
\hline Stage 3 & $\begin{array}{l}\text { Rounded: edges are highly rounded and processes } \\
\text { are nearly to completely obliterated. }\end{array}$ \\
\hline Stage 4 & $\begin{array}{l}\text { Very rounded: fossil material has been rendered to } \\
\text { a nearly to totally spherical profile. }\end{array}$ \\
\hline
\end{tabular}


Table 5.2: Table showing the vertebrate taxa included within the 11 categories used in the relative abundance pie charts in this study (Figs 5.8; Fig 5.12; Fig. 5.13; Fig. 5.15; Fig. 5.16).

\begin{tabular}{|c|c|}
\hline Group & Taxa Included \\
\hline Rhinobatids & Pseudomyledaphus and Myledaphus \\
\hline Other Chondrichthyes & $\begin{array}{l}\text { Protoplatyrhina, Hybodus, } \\
\text { Centrophoroides Odontaspididae, } \\
\text { Cretolamna, Archaeolamna, } \\
\text { Orectolobidae, Synechodus, Rhinobatos, } \\
\text { Ischyrhiza, Chiloscyllium, Squatina, } \\
\text { Elasmobranchii indet., Elasmodus sp. }\end{array}$ \\
\hline Brackish Osteichthyes & $\begin{array}{l}\text { 'Holostean B', Acipenseriformes, } \\
\text { Belonostomus, Lepisosteus, } \\
\text { Phyllodontidae, Paratarpon, Enchodus }\end{array}$ \\
\hline Freshwater Osteichthyes & $\begin{array}{l}\text { 'Holostean A', Amiidae, Coriops, } \\
\text { Teleostei }\end{array}$ \\
\hline Amphibians & Caudata and Allocaudata \\
\hline Testudines & $\begin{array}{l}\text { Testudines indet., Solemydidae, } \\
\text { Basilemys, Trionychidae, Adocus, } \\
\text { Chelydridae, Baenidae }\end{array}$ \\
\hline Eusuchia & Eusuchia \\
\hline Champsosaurs & Champsosaurus \\
\hline Squamata & Squamata \\
\hline Dinosaurs & $\begin{array}{l}\text { Ceratopsidae, Ankylosauria, } \\
\text { hypsilophodontid, Hadrosauridae, } \\
\text { Theropoda indet., Dromaeosauridae, } \\
\text { Richardoestesia, Troodon, Paronychodon, } \\
\text { Tyrannosauridae, cf. Aves }\end{array}$ \\
\hline Mammalia & Mammalia \\
\hline
\end{tabular}




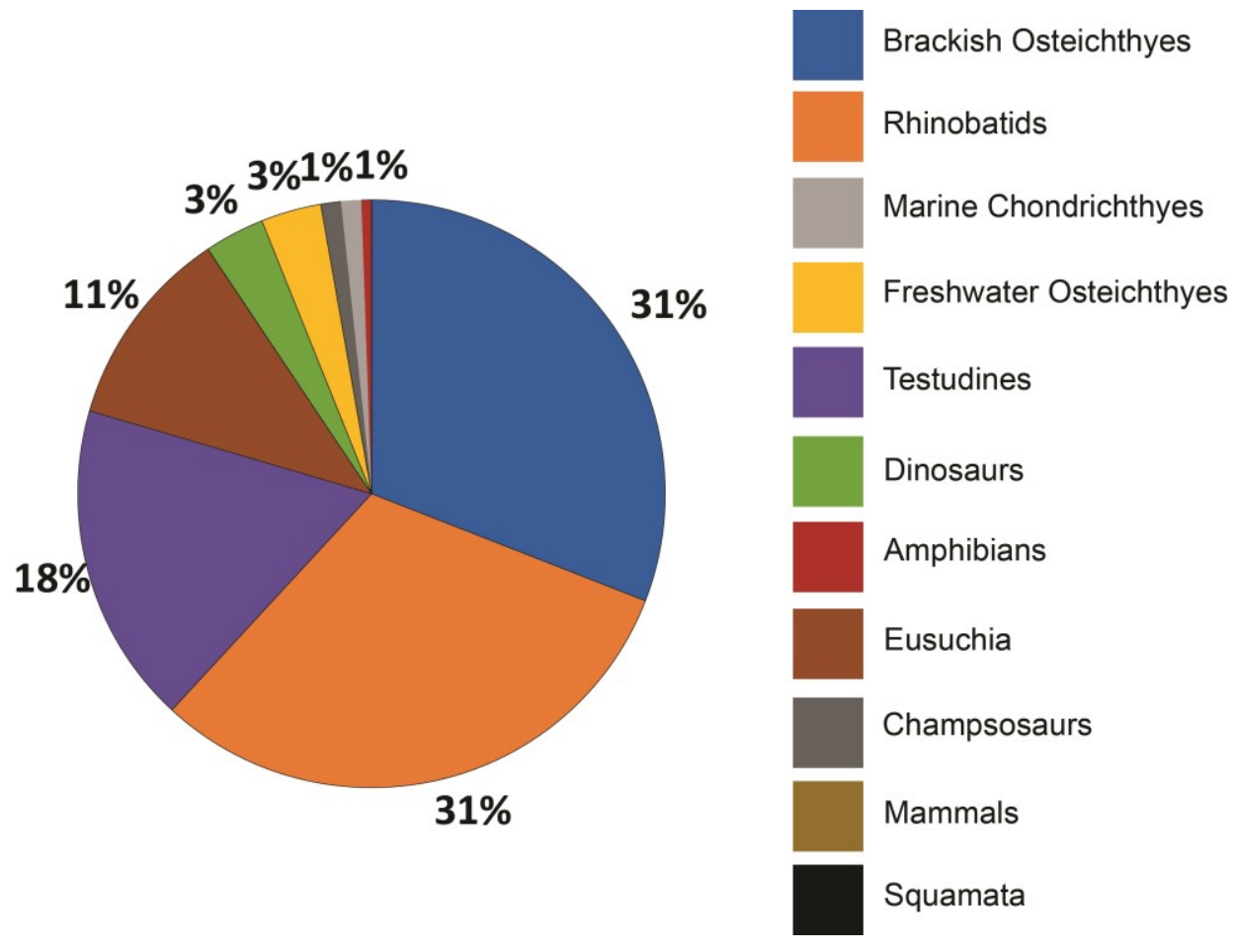

Figure 5.8: Pie chart of taxonomic relative abundance of identified fossil elements from the C26 microsite $(\mathrm{n}=179)$. Refer to Table 5.2 for category descriptions. 

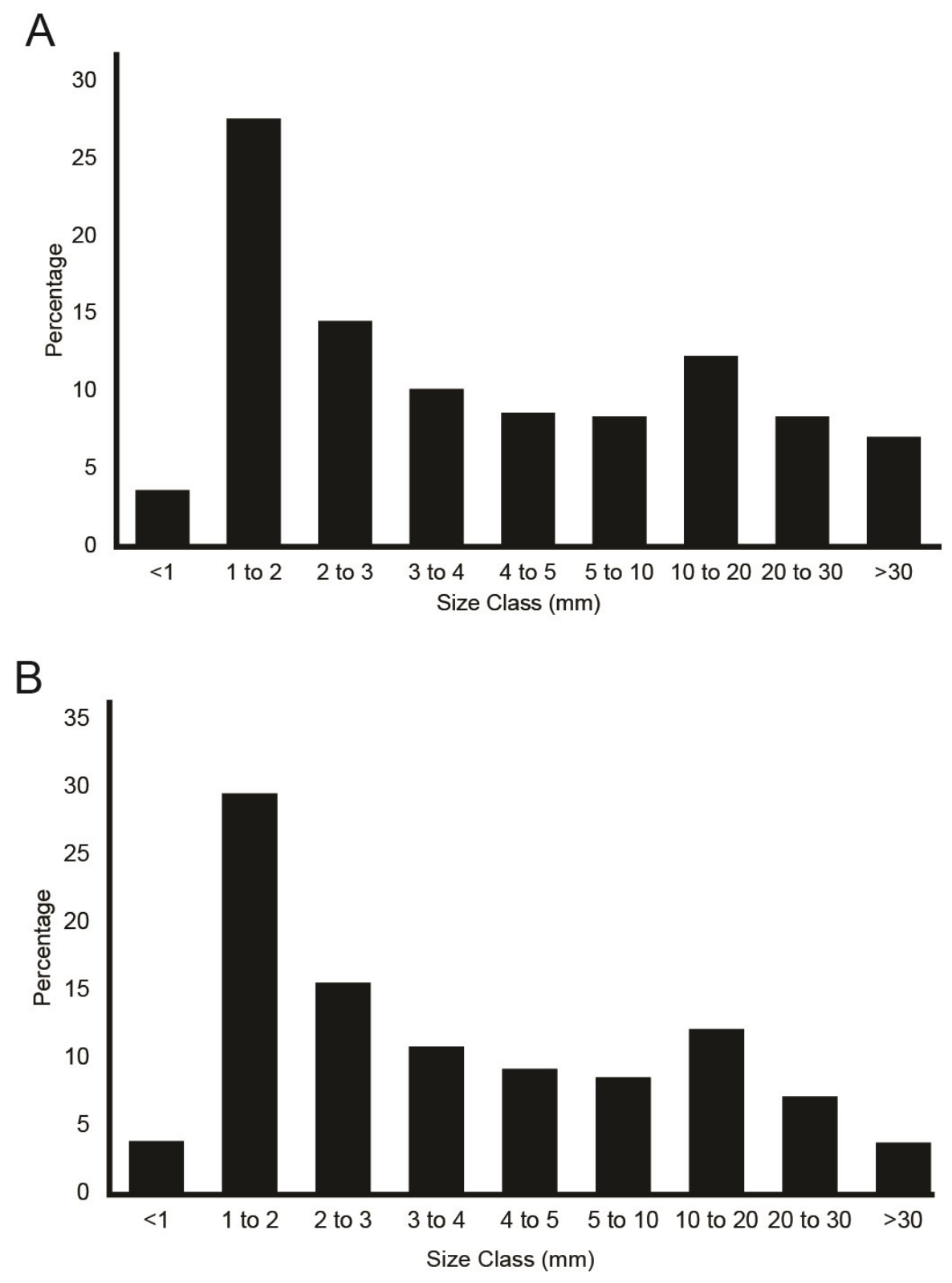

Figure 5.9: Size class distribution of microsite material based on Brinkman et al. (2004) for unidentified material from the $\mathrm{C} 26$ microsite. $\mathrm{A}=$ all material (Total Sample $=843$ ); $\mathrm{B}=$ material from screen washed samples only (Total Sample $=788)$. Material $5 \mathrm{~mm}$ or less in size dominates in both samples. 

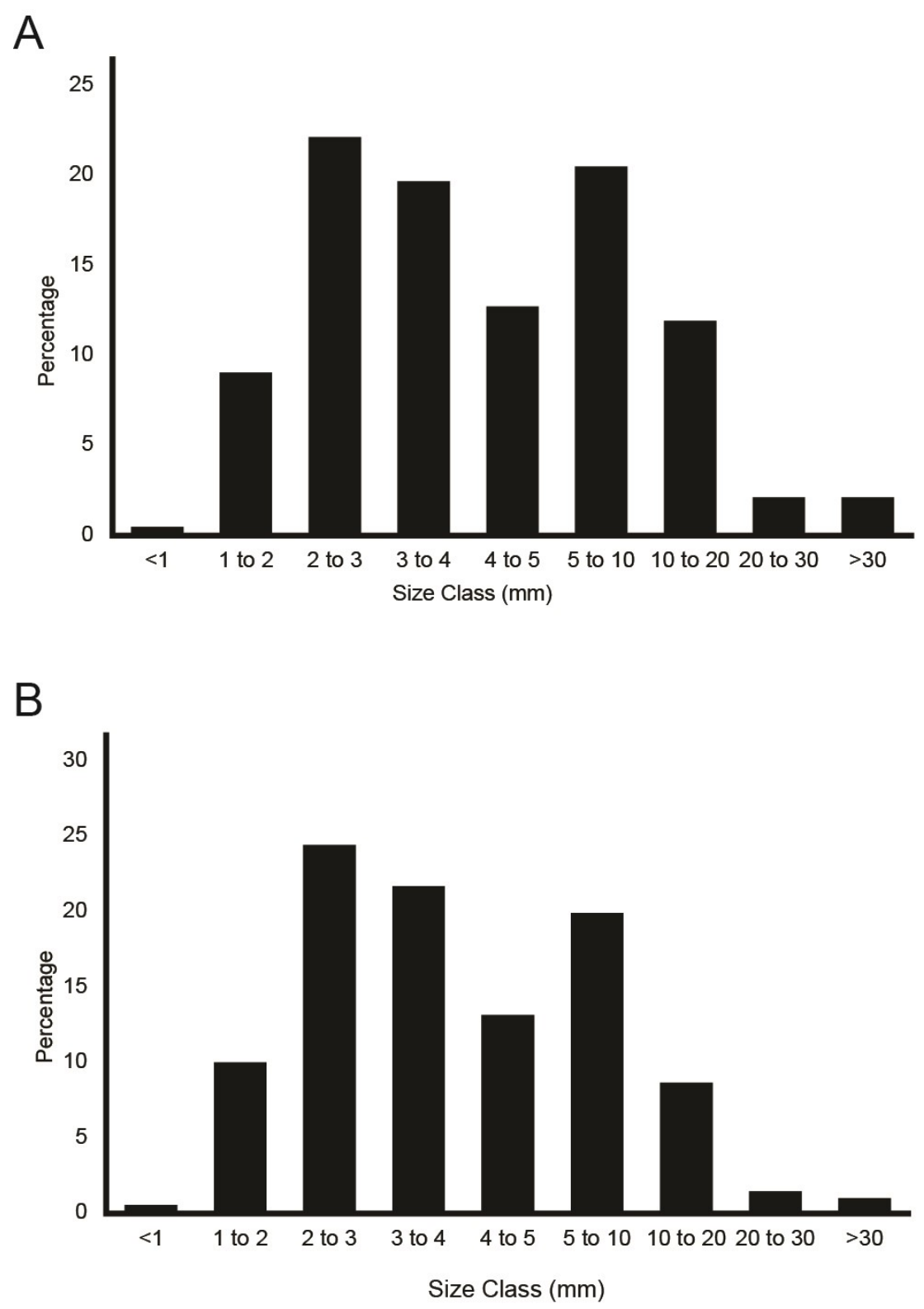

Figure 5.10: Size class distribution of microsite material based on Brinkman et al. (2004) for identified material from the $\mathrm{C} 26$ microsite. $\mathrm{A}=$ all material (Total Sample $=179)$; $\mathrm{B}=$ material from screen washed samples only (Total Sample $=156)$. The majority of material in both is $10 \mathrm{~mm}$ or less in size, with material larger that this decreasing in samples that were of screenwashed material only. 


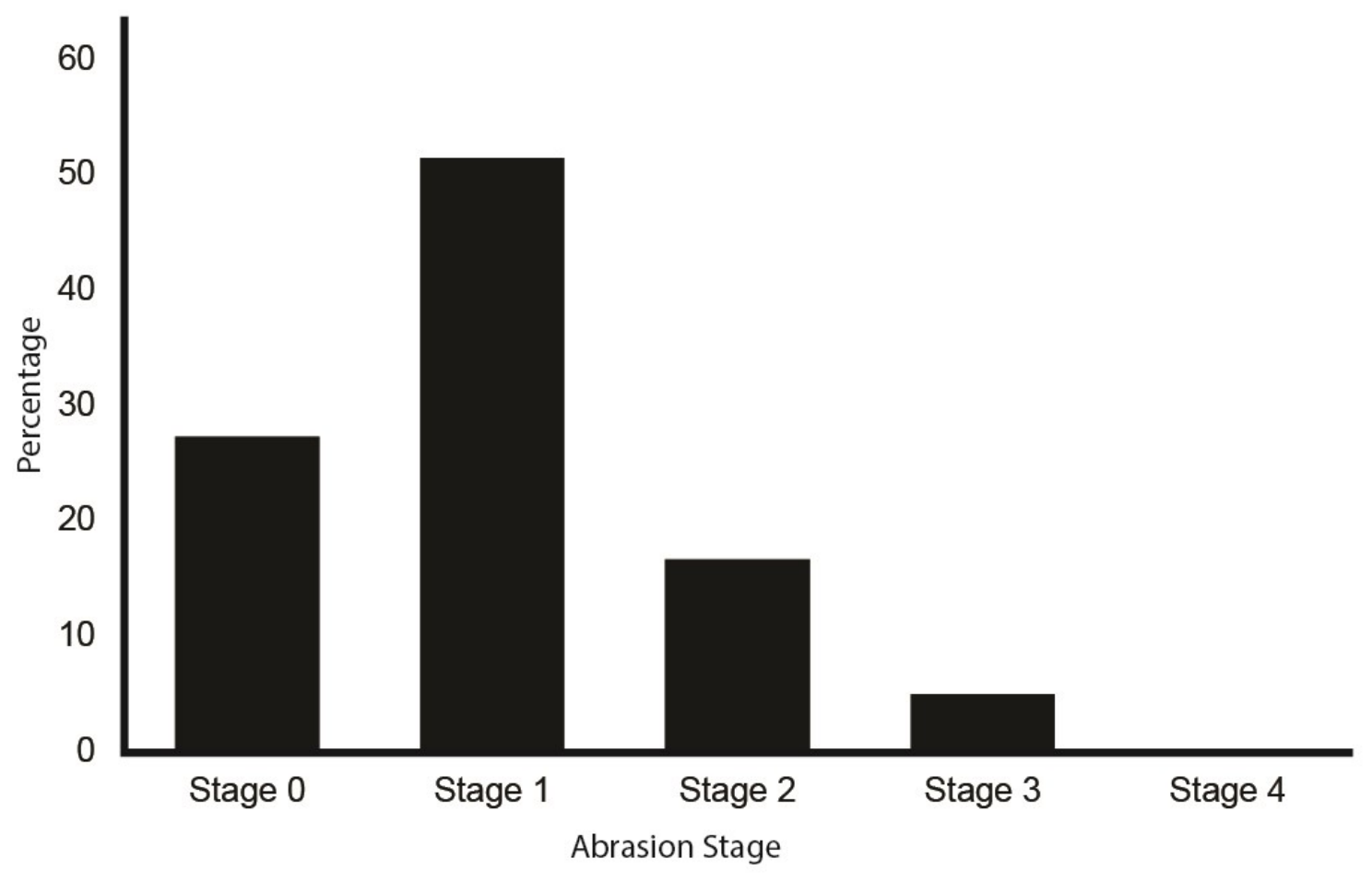

Figure 5.11: Abrasion stages based on Fiorillo (1988), Cook (1995) and Phillips (2009) for material sampled from microsite C26. (Total Sample \#=1022). Material from C26 is mostly Stage 0 or Stage 1, unabraded to slightly abraded. 


\section{Paleocommunity Distribution}

$\square=$ Inland $\quad \quad \quad=$ Mixed $\quad$ Coastal

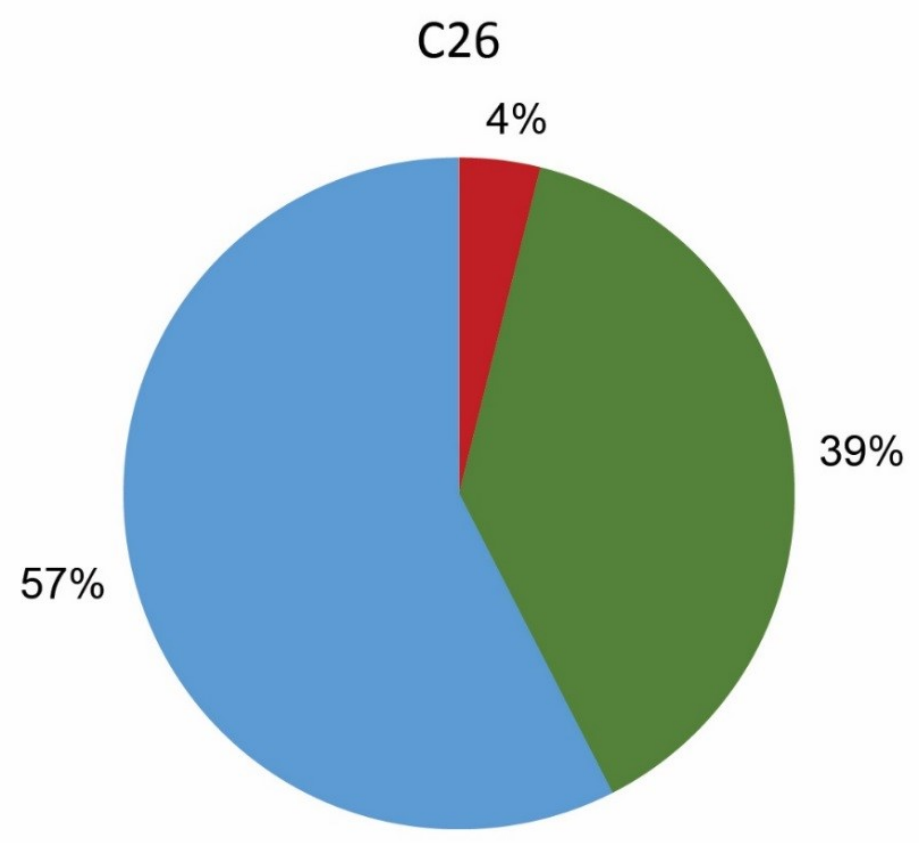

Figure 5.12: Palaeocommunity distribution of $\mathrm{C} 26$ based on the palaeoenvironmental categories and designations of Cullen et al. (2016). 
Pseudomyledaphus and Paralbula remaining the two most dominant taxa (Figs. 5.8 and 5.12; Appendix E-1). However, Lepisosteus totals drop significantly, positioning eusuchians as the third most abundant taxa, with an associated increased relative abundance of turtles and "Holostean-B" (Figs. 5.8 and 5.12; Appendix E-1).

\section{Sample C32}

Sample C32 (first coal of the Taber Coal Zone) contained eight elements including seven small unidentified fish teeth and scales, and a single fragmentary centrum that is referable to Clupeidae. The teeth were excluded from abundance analyses due to their classification being impossible. The clupeid vertebra is the first occurrence of this taxa in the Foremost Formation and is notable as it represents a primarily freshwater taxon (Cullen and Evans, 2016).

\subsection{2: Taphonomic Data for C26}

\section{Unidentified Fossil Material Size}

Unidentifiable fossil material was analyzed with the methods of Blob and Fiorillo (1995), Brinkman et al. (2004) and Cullen et al. (2016), utilizing the size bins methodology of Brinkman et al. (2004). This was done in order to compare potential taphonomic biases on the size of material present within C26 and compare similarities or differences regarding these biases between $\mathrm{C} 26$ and other Foremost Formation microsites. Unidentified fossil material in sample C26 ranges from $0.8 \mathrm{~mm}$ to $100 \mathrm{~mm}$ in maximum long axis measurement. Size distribution within unidentified fossil material is dominated primarily by material under $10 \mathrm{~mm}$, with the largest contributor being the 1 to $2 \mathrm{~mm}$ size bin ( $\mathrm{n}=232 ; 27.5$ to $29.4 \%$ total material; Fig. 25 ). Notably, material less than 
$1 \mathrm{~mm}$ in size is rare $(\mathrm{n}=30 ;<5 \%$ total $)$ and there is a significant contribution of material ranging from 10 to $20 \mathrm{~mm}(\mathrm{n}=103 ; 12 \%$ total material; Fig.5.9). Size distribution does not considerably vary in unidentified material based on a comparison between material that was screen washed only versus material sampled from both screen wash and surface collecting methods. The exception to this trend is displayed within the proportion of material over $30 \mathrm{~mm}$, which nearly doubles when surface collected material is included $(\mathrm{n}=59 ; 7 \%$ total material vs. $\mathrm{n}=29 ; 3.7 \%$ screen washed only material; Fig. 5.9).

For material that can be identified, the most common size bin includes elements of 2 to $3 \mathrm{~mm}(\mathrm{n}=54 ; 22 \%$ screened washed only material to $\mathrm{n}=54 ; 24 \%$ total material; Fig. 5.10). There is also a significant proportion of 3 to $4 \mathrm{~mm}$ sized material $(n=48 ; 19 \%$ screened only total to $n=48 ; 21 \%$ total material) and 5 to $10 \mathrm{~mm}$ sized material $(\mathrm{n}=44$ in screen washed and 50 in total material; approximately $20 \%$ total material in both screened and total material; Fig. 5.10). Very large (20 to 30 and $>30 \mathrm{~mm}$ ) and very small ( 1 to 2 and $<1 \mathrm{~mm}$; Fig. 26) material contributes less than $5 \%$ of total material $(n=10$ in total and $n=5$ in screen washed for large material; $n=1$ element for $<1 \mathrm{~mm}$ size material for both screen washed and not screen washed) (Fig. 5.10).

Overall, this taphonomic profile is approximately the same as other Pinhorn Ranch Foremost Formation microsites (Brinkman et al., 2004), but with a preservation of larger material (5 mm and greater) as seen in the PK site of Cullen et al. (2016). Indeed, faunal differences in the PK site were suggested to be influenced by this preservation style as well as its propensity for preserving "rare" material (Cullen et al., 2016). Thus, differences in faunal communities represented in C26 may be related to similar taphonomic preservation bias. 
Abrasion, Fragmentation and Weathering

Abrasion state of fossil material from sample C26 is primarily represented by Stage 0 and Stage 1 abrasion, which combined make up 78.5\% $(n=855)$ of the entire assemblage (Fig. 5.11; also see Table 5.1). Rounded material (Stage 3) is uncommon and associated exclusively with dinosaur fossil material. Very rounded material (Stage 4) is completely absent (Fig. 5.11). The majority of material is fragmented in C26, with only portions of material attributable to Pseudomyledaphus teeth and Lepisosteus scales exhibiting no fragmentation.

Surface collected material displays a weathered bleached outer surface colouration and a fragmented or desiccated-looking surface. Material beneath the outcrop surface appears not weathered.

\section{3: Comparison of Vertebrate Microsites from the Foremost Formation with C26}

C26 represents one of six microsites from the Foremost Formation that can be used to analyze the faunal trends within the formation. The other five sites are Kuehne's Site (Beavan, 1995), SPS, PHR-1, PHR-2 (Peng et al., 2001), PHRN (Frampton, 2006) and PK (Cullen et al., 2016) (Figs. 5.13 and 5.14; Appendix E-1). Individual taxa were condensed into more inclusive groups in order to better facilitate data presentation, with each group's members outlined in Table 5.1. Information for individual taxa for all listed sites is available in Appendix E.

PHRN (Frampton, 2006) is the stratigraphically lowest site, sitting above the shoreface sandstone that makes up the base of Unit II (Figs. 5.13 and 5.14). Its depositional setting has been interpreted as a low energy brackish coastal environment 
(Frampton, 2006). The majority of its faunal composition is represented by the brackish marine Pseudomyledaphus (45\% total assemblage), other brackish fish species (29\% total assemblage), especially Paralbula, and other marine chondrichthyans (15\% total assemblage) (Figs. 5.13 and 5.14). The faunal assemblage of PHRN suggests a primarily brackish marine palaeoenvironmental setting, with more marine taxa than of other Foremost Formation sites (Figs. 5.13 and 5.14).

Kuehne's site (Beavan, 1995) directly overlies the siderite firmground that caps Unit II (Facies 6) (Figs 5.13 and 5.14). Unfortunately, only data for elasmobranch assemblages is known for this site and, therefore, a full taxonomic comparison cannot be done. The author noted, however, that elasmobranchs dominated the assemblage, suggesting a marine-dominated paleoenvironment (Beavan, 1995).

PHR-1 and PHR-2 are approximately at the stratigraphic midpoint of exposed outcrop of the Foremost Formation, located within the same stratigraphic horizon in Unit III as C26 (Peng et al., 2001) (Figs. 5.13 and 5.14). Evidence to suggest a stratigraphically equivalent position comes from the fact that both sites are situated at or above the same shoreface sandstones that contain mud rip up clasts underlying C26 and are contained within siltstone to very fine sandstone, as is C26 (Peng et al., 2001; Cullen et al., 2016). Both sites are attributed by Peng et al., (2001) to a shoreface environment, with both being contained within silty to fine sandstone grained facies. Both sites contain broadly similar faunal assemblages, with large abundances of Pseudomyledaphus and 


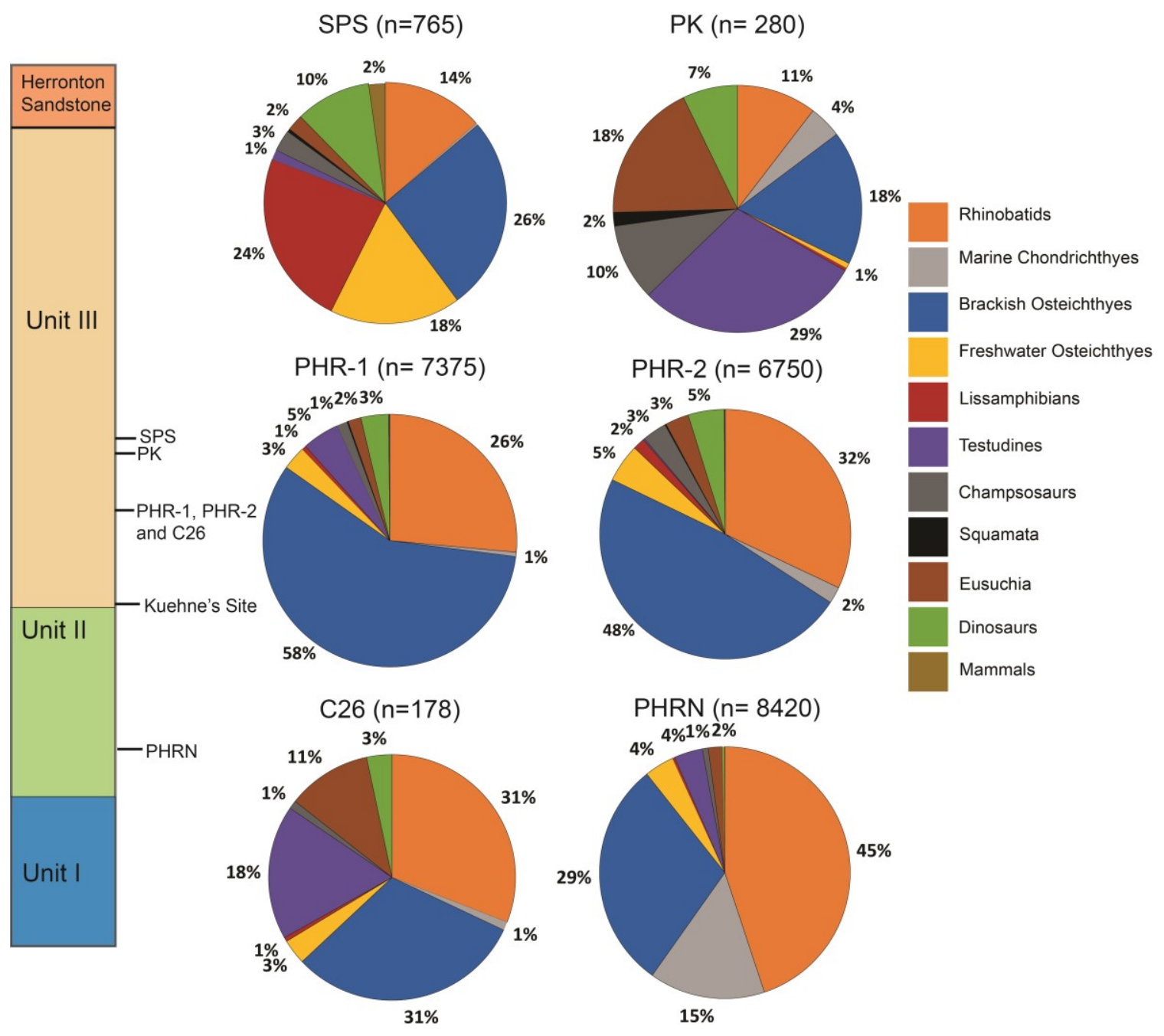

Figure 5.13: Relative abundance pie charts of taxa for the PHRN site of Frampton (2006), the C26 site of this study, the PHR-1 and PHR-2 sites of Peng et al. (2001), the PK site of Cullen et al. (2016) and the SPS site of Peng et al. (2001). The stratigraphic positioning of each site relative to eachother within the context of units proposed in this thesis is displayed on the left hand column. An increase in freshwater and terrestrial taxa is encountered upsection. Refer to Table 5.2 for category descriptions. 


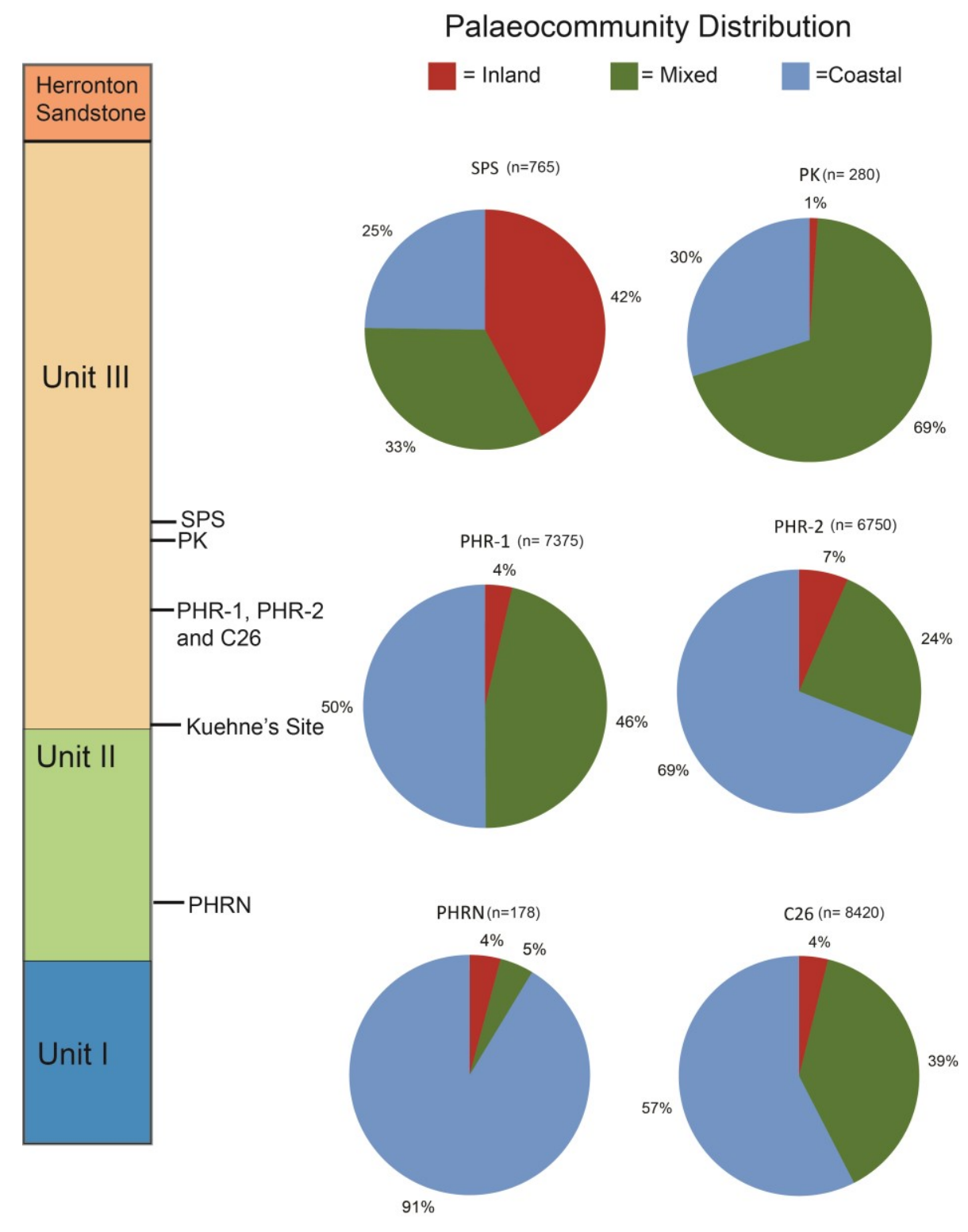

Figure 5.14: Palaeocommunity relative distribution (based on Cullen et al., 2016) for the Foremost Formation microsites and their approximate relative stratigraphic placement to the depositional units described in this study. Stratigraphic positioning of each site relative to eachother within the context of units proposed in this thesis is displayed on the left hand column. Dominance of brackish species and an increase in freshwater and terrestrial species is encountered upsection following the Claggett marine regression. 
Figure 5.15: (see page 138): Rarefaction curves plotting number of taxa versus number of fossil specimens calculated for each microsite from the Foremost Formation examined in this study. Top and bottom lines of each curve represent upper and lower standard deviations respectively. C26 and PK are noted to be below sampling threshold. 


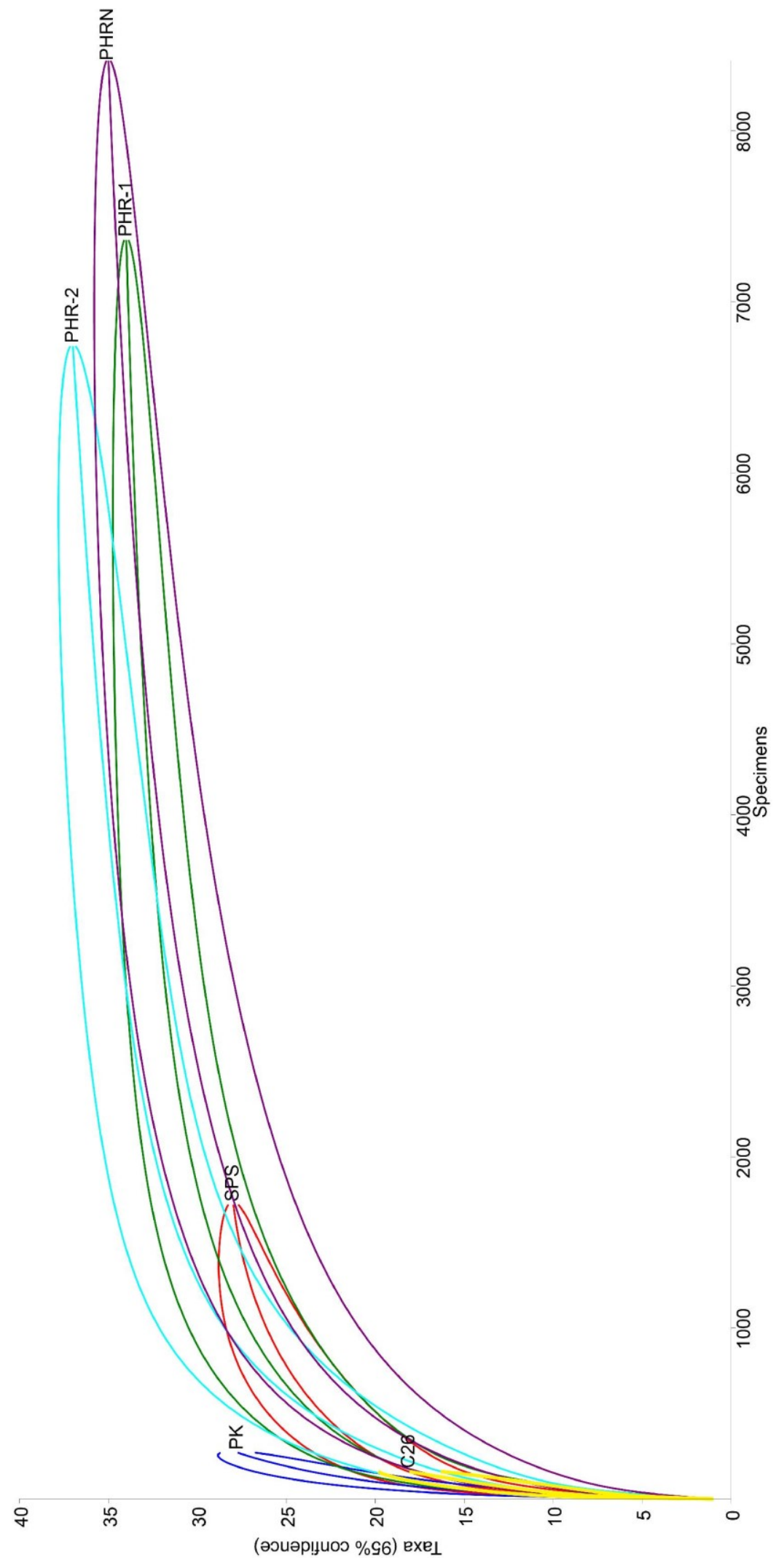


other brackish indicator taxa such including Lepisosteus and Paralbula (PHR-1=26\% Pseudomyledaphus, 58\% brackish water fish; PHR-2=32\% Pseudomyledaphus, $48 \%$ brackish fish) similar to what was found in the PHRN site. PHR-1 contains a notably larger proportion of turtle material than PHR-2 (5\% of the total assemblage) (Fig. 5.13). PHR-2 contains a greater percentage ( $2 \%$ total assemblage vs $1 \%$ in PHR- 1 ) of shark and other chondrichthyan material suggesting more marine influence than PHR-1 (Fig. 5.13). Both sites are suggested to represent a coastal brackish environmental setting based on their faunal assemblages, thus supporting a shoreface barrier or possible central bay/lagoonal setting based on their geological setting (Peng et al., 2001) (Figs. 5.13 and 5.14).

The faunal assemblage of $\mathrm{C} 26$ is most similar to the stratigraphically equivalent PHR-1 and PHR-2 sites, with all three sites containing large proportions of the brackish water fish Pseudomyledaphus, Lepisosteus and Paralbula (Figs. 5.13 and 5.14). Like PHR-1, C26 contains a larger proportion of turtle material, but contains considerably more turtle material relatively than PHR-1 (C26=18\%, PHR-1=5\%) and a large proportion of eusuchian material (C26=11\%, PHR-1=2\%) (Figs. 5.13 and 5.14). C26 contains less overall chondricthyan material than PHR-2, but more than PHR-1 (Figs. 5.13 and 5.14). Thus, environmentally C26 may be intermediate between PHR-1 and PHR-2 in terms of terrestrial vs. marine influence on faunal composition, but with overall brackish coastal palaeoenvironmental signatures being quite similar between all three suggesting that any environmental differences between them are small (Figs. 5.13 and 5.14). 
The PK microsite is located within the first coal seam of the Taber Coal Zone (within Unit III of this study, though exact stratigraphic correlations are difficult to ascertain), and represents a coastal low energy environment with greater freshwater influence than the previously mentioned sites (Cullen et al., 2016). The PK site is most notable for containing a faunal assemblage with a large proportion derived from turtles and crocodilians ( $29 \%$ and $18 \%$ respectively) but retaining a relatively large abundance of brackish water species and other chondrichthyans (18\% brackish fish, $11 \%$ Pseudomyledaphus, 4\% other Chondrichthyans) (Figs. 5.13 and 5.14). The palaeoenvironmental setting for the PK site contains a large proportion of taxa that indicate a mixture of coastal and terrestrial affinities $(69 \%)$ and coastal taxa (30\%), and a miniscule proportion of inland taxa (1\%), suggesting that it is transitional between the coastal environments of the lower Foremost Formation sites and the upper terrestrial SPS site of the Foremost and lower Oldman Formation sites (Fig. 5.14).

The SPS locality (Peng et al., 2001) is located near the boundary between the Taber Coal Zone and the Herronton Sandstone and is the only site from the Foremost Formation studied to date that is not located in the Manyberries area, instead located along the South Saskatchewan River southwest of Medicine Hat (Fig. 1.1). The most abundant taxa are brackish water fish, amphibians and freshwater fish taxa $(26 \%, 24 \%$ and $18 \%$ respectively), suggesting an overall dominance by freshwater conditions (Figs. 5.13 and 14). Based on this faunal assemblage and the similarities to microsites from the fully terrestrial lower unit of the Oldman Formation noted in Cullen et al. (2016), SPS is the only microsite from the Foremost Formation to date with a significant terrestrial assemblage. 
Geographically, PHRN, Kuehne's Site, PHR-1, PHR-2, and C26 all lie within the Pinhorn Grazing Reserve, within an approximately $9 \mathrm{~km}$ span of each other on an east to west transect (Fig. 1.1). This supports the implication that their similar palaeoenvironmental and faunal assemblages are due to their close proximity; while the differences noted in the lower PHRN and Kuehne's sites are attributable to differences in sea level (marine influence) between the two localities. The C26, PHR-1 and PHR-2 localities reside in the same stratigraphic horizon within Unit III, therefore, their extremely similar faunal and taphonomic assemblages are complementary to the fact that the material in these sites was deposited in close proximity at approximately the same time. Differences in their faunal structure, such as increased turtle proportions in C26, PHR-1 and PK, could then be attributed to more proximal or distal locations relative to the shoreline. The PK locality is located $40 \mathrm{~km}$ north and $20 \mathrm{~km}$ west northwest of these sites near the town of Foremost, and the SPS site is $40 \mathrm{~km}$ further north than the PK site (Cullen et al., 2016; Fig. 1.1). This would position these sites further inland, thus explaining the increased abundance of more terrestrially associated taxa such as amphibians, freshwater fish and sauropsids (Cullen et al., 2016).

Diversity in the analyzed Foremost Formation microsites generally increases up section (Appendix E-2). The lowermost PHRN site has the lowest diversity (Hill Number = 5.57; see Appendix E for raw diversity index data). The C26, PHR-1 and PHR-2 localities each have a similar diversity, with C26 having the highest of the three sites (approximately 13\% higher than either siteC26, PHR-1, or PHR-2 which have Hill numbers of 8.61, 7.56, and 7.42, respectively (Appendix E-2). The stratigraphically highest, more terrestrially influenced sites, (PK and SPS) have the largest diversity values 
(13.3 and 11, respectively) (Appendix E-2). Rarefaction analysis suggests relatively similar diversity in each site (within standard error), with the PK site and C26 site also suggested to be undersampled relative to the other Foremost Formation sites (Fig 5.15). The rarefaction profile of C26 matches very closely to PHR-1, PHR-2 and PHRN, pointing to a similar diversity level between those sites though C26 is undersampled. Notably, rarefaction curves show that the PK site to be relatively more diverse than other sites.

\section{4: Belly River Group Microsite Assemblage Comparisons}

Chondrichthyan and osteichthyian taxa comprise the majority of fossil material from the Foremost Formation ( $86.2 \%$ total assemblage), with a significant portion of this material attributed to the brackish water fish Pseudomyledaphus (33.2\% of the total assemblage) (Figs. 5.16 and 5.17), Lepisosteus (15\% of the total assemblage) and Paralbula (22.7\% of the total assemblage), and a low proportion of terrestrial indicators such as amphibians ( $3 \%$ of the total assemblage) and freshwater fish (4\% of the total assemblage) such as Holostean-A (see Appendix E for total compositional data) (Figs. 5.15 and 5.16). Overall, the Foremost Formation, therefore, shows a predominantly coastal influence in its taxonomic assemblages (Figs. 5.18 and 5.19).

The Foremost and the lower Oldman formation in the Milk River area share little in common in terms of overall assemblages, with a distinct decrease in chondrichthyan fauna in localities reported from the lower Oldman ( $1.2 \%$ of total lower Oldman assemblage) and a notable increase in terrestrially associated amphibians ( $21 \%$ of the total assemblage) (Figs. 5.20 and 5.21). The exception to this is the fauna preserved in the 
Figure 5.16: (see page 144): Relative abundance of taxa from Dinosaur Park Formation and Oldman Formation (Comrey Unit) microsites within the Dinosaur Provincial Park (DPP) area compared with all Foremost Formation microsite data (data from Cullen and Evans, 2016). LCZ= Lethbridge Coal Zone. The enivornmental change up section shifts from marginal marine in the Foremost ( 6 sites; $n=24742$ ) to fully terrestrial in the Oldman Formation ( 7 sites; $\mathrm{n}=7685$ ) and majority of the Dinsoaur Park Formation (18 sites Pre LCZ; $n=24797$ ) with a marine transgression occuring at the top of the Dinosaur Park Formation (2 sites; Post LCZ; n=3354). 


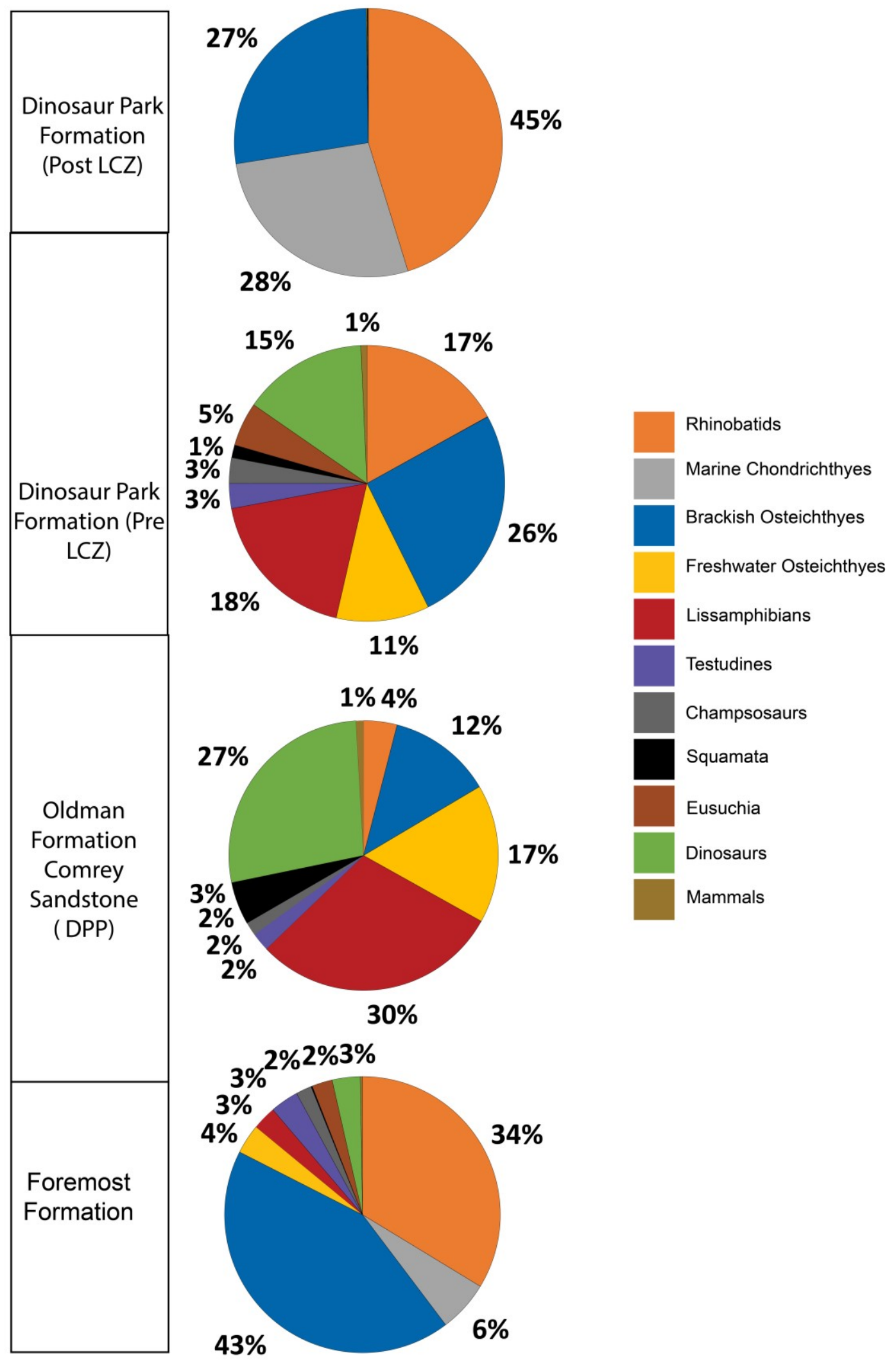


Figure 5.17: (see page 146): Relative abundance of taxa from the Oldman Formation (upper, Comrey (11 sites; $\mathrm{n}=8674$ ) and lower Oldman Formation units ( 5 sites; $\mathrm{n}=6038)$ ) and Foremost Formation (6 sites; $\mathrm{n}=24742$ ) microsites (data from Cullen and Evans, 2016). Upper and Comrey units of the Oldman Formation were considered one unit based on faunal similarity as in Brinkman et al. (2004) and Cullen et al. (2016). A transition from marginal marine deposition in the Foremost Formation to fluvial plain deposition in the Oldman Formation is displayed and reflected by the faunal assemblages presented here. 


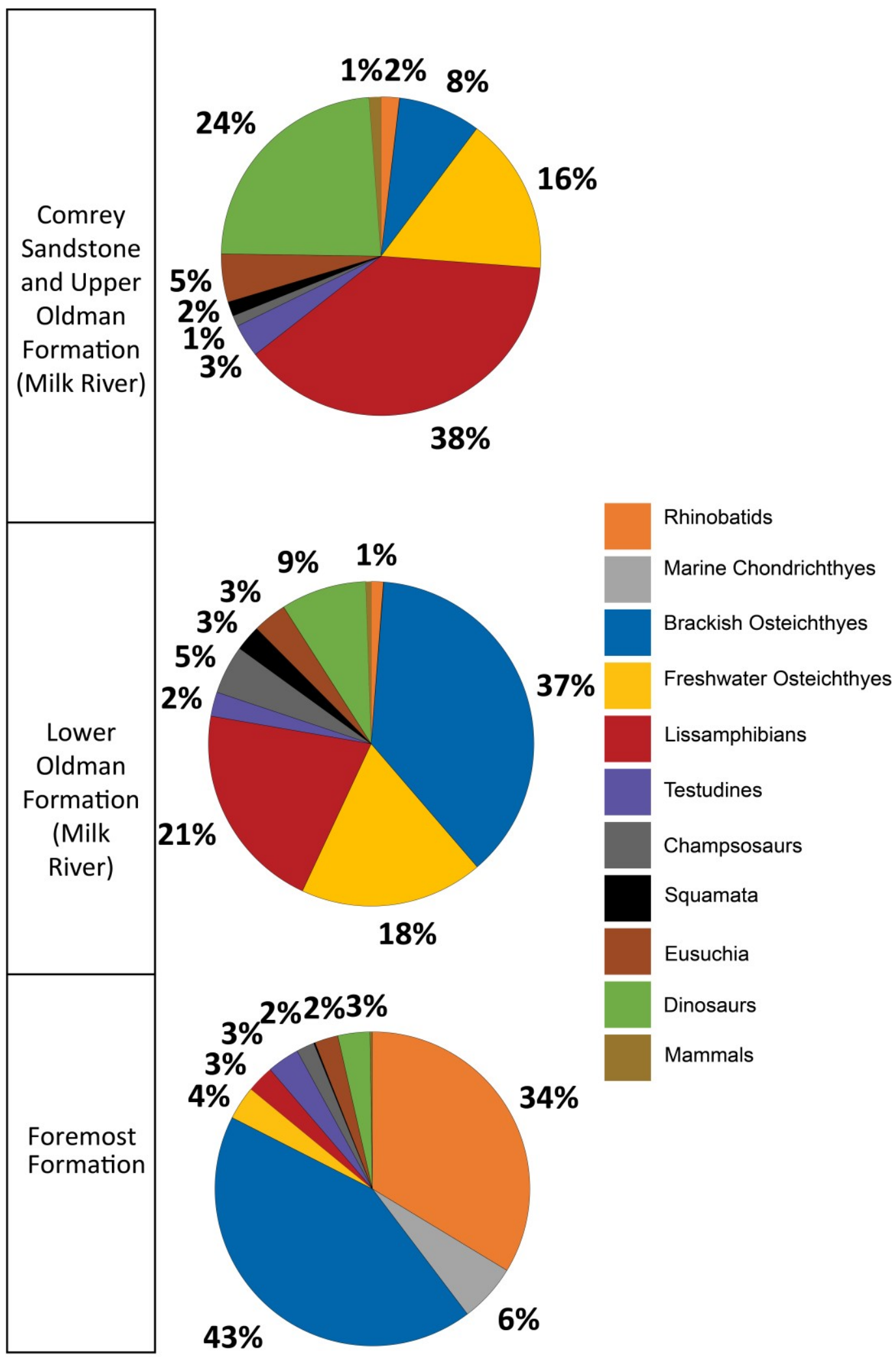


Figure 5.18: (see page 148): Palaeocommunity distributions for the Dinosaur Park Formation and Oldman Formation (Dinosaur Provincial Park area) microsites based on Cullen et al. (2016). LCZ= Lethbridge Coal Zone. The enivornmental change up section shifts from marginal marine in the Foremost ( 6 sites; $n=24742)$ to fully terrestrial in the Oldman Formation ( 7 sites; $\mathrm{n}=7685$ ) and majority of the Dinsoaur Park Formation (18 sites Pre LCZ; $n=24797$ ) with a marine transgression occuring at the top of the Dinosaur Park Formation (2 sites Post LCZ; $\mathrm{n}=3354$ ). 


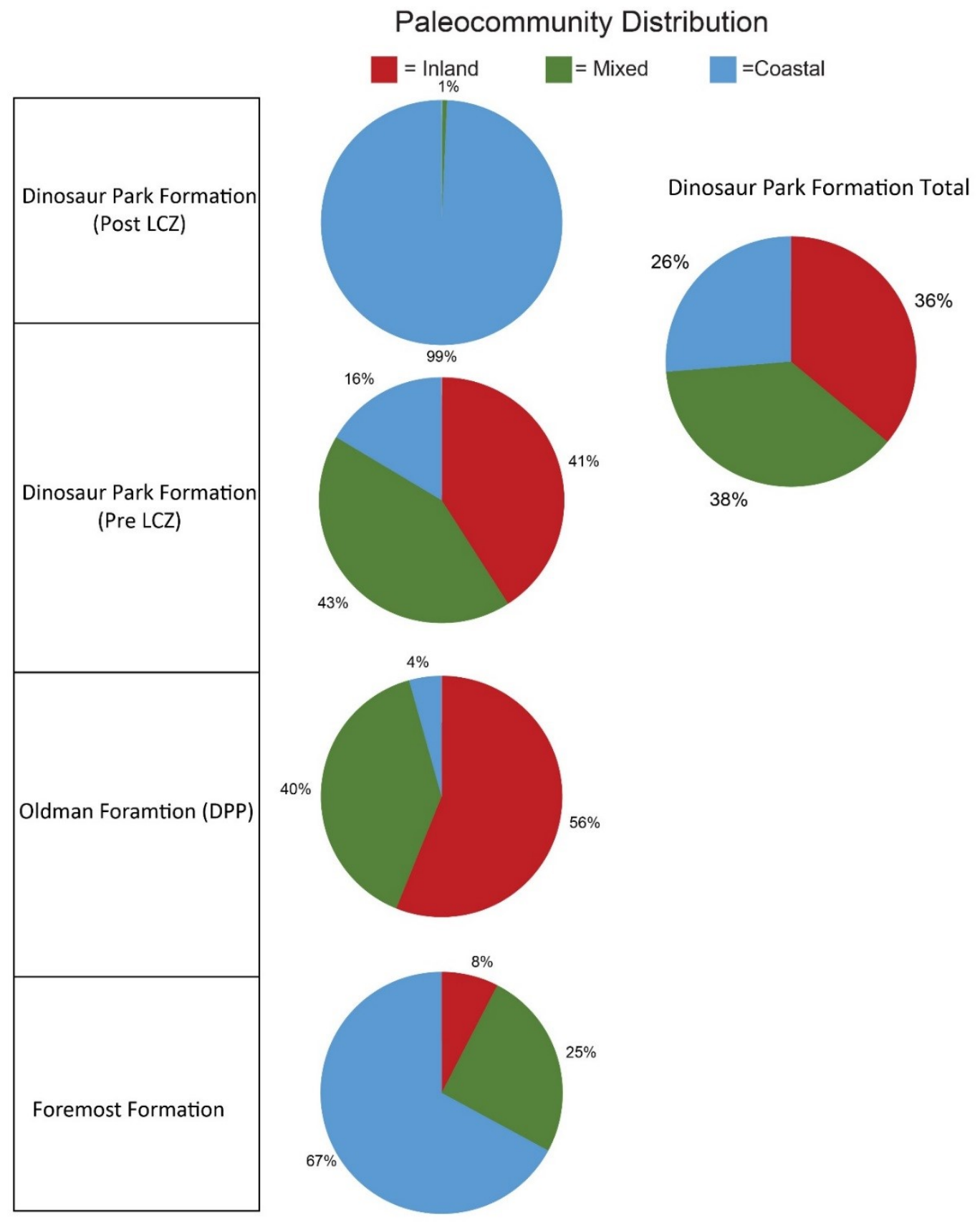


Figure 5.19: (see page 150): Palaeocommunity distributions for the Foremost Formation and Oldman Formation (Milk River area) microsites based on Cullen et al. (2016). An environmental shift from a marginal marine to fluvial plain is experienced between the Foremost Formation and the Oldman Formation. (upper an Comrey Units = 11 sites; $\mathrm{n}=8674$, lower unit $=5$ sites $; \mathrm{n}=6038$, Foremost Formation $=6$ sites; $\mathrm{n}=24797$ ) 


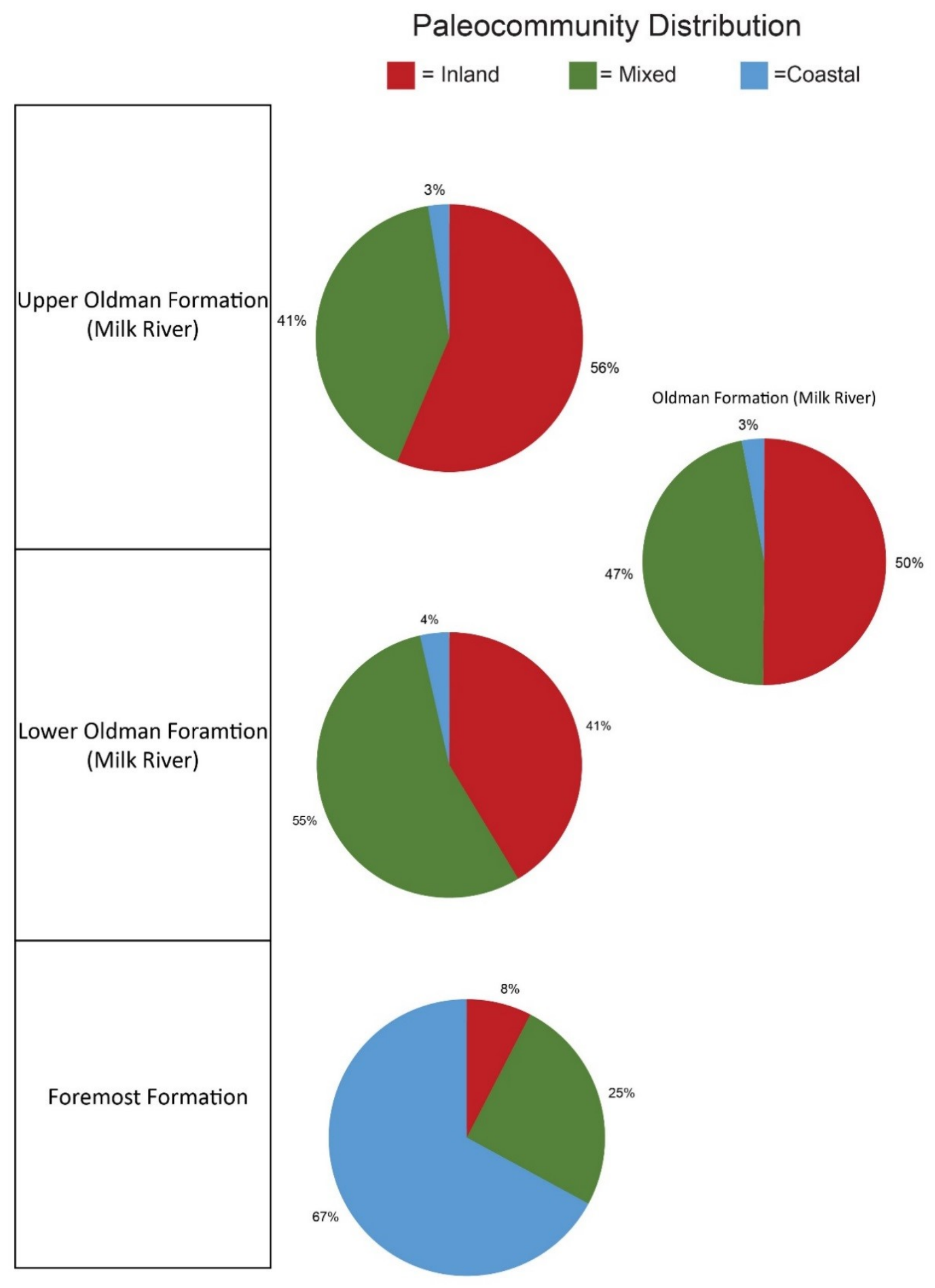


Figure 5.20: (see page 152): Rarefaction curves plotting number of taxa versus number of fossil speciemns calculated for each microsite from the Belly River Group examined in this study. Top and bottom lines of each curve represent upper and lower standard deviations respectively. $\mathrm{OM}=$ Oldman Formation, $\mathrm{DPF}=$ Dinosaur Park Formation, $\mathrm{LCZ}=$ Lethbridge Coal Zone, DPP= Dinosaur Provincial Park region. 


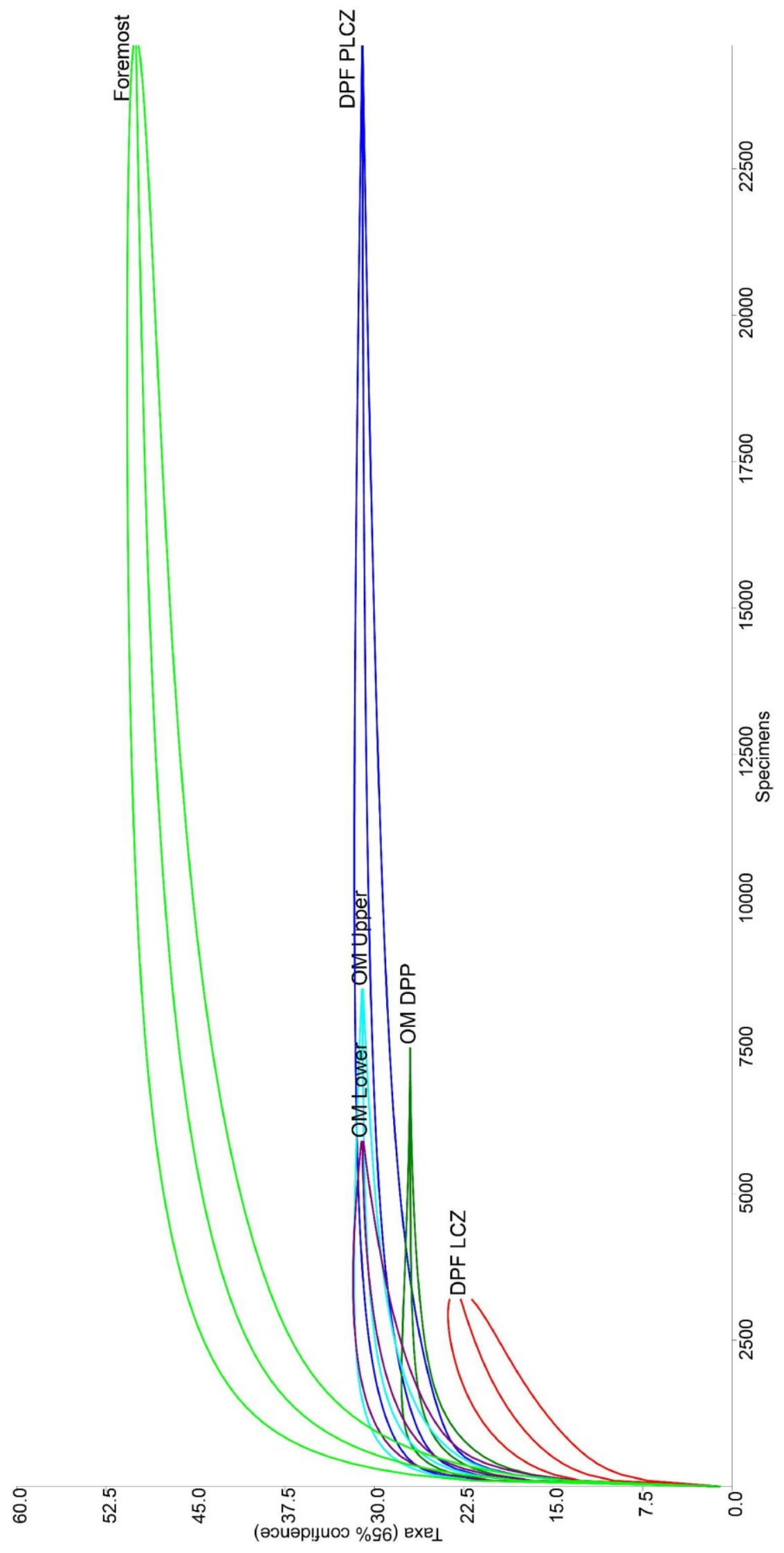


SPS site near the top of the Foremost Formation which contains abundant terrestrial lissamphibians and freshwater fish remains, making it generally similar to the lower Oldman sites (Figs. 5.20 and 5.21). A large proportion of the taxa in the lower Oldman Formation are within the mixed palaeoenvironmental assemblage zone, such as brackish fish species ( $37 \%$ of the total assemblage) and champsosaurs $(5 \%$ of the total assemblage), suggesting a relatively greater marine proximity compared to the middle (Comrey) and upper Oldman units (Fig. 5.17) (Brinkman et al., 2004; Cullen et al.,2016). Only one microsite is known from the Comrey Sandstone member of the Oldman Formation in the Milk River area, but, as noted in Brinkman et al. (2004) and Cullen et al. (2016), its faunal composition is near identical to those in the upper unit of the Oldman Formation. For this reason, the single Comrey Unit site in the Milk River area and the upper Oldman Unit sites were combined for analysis for this study as they have been in previous studies (Brinkman et al., 2004; Cullen et al., 2016). The large proportion of taxa with mixed palaeoenvironmental associations (e.g. rhinobatids, brackish fish such as Lepisosteus and Paralbula, approximately 38\% total) seen in the lower Oldman Formation is lost in the Comrey and upper units of the Oldman in the Milk River area (Fig. 5.17), with a corresponding major increase in terrestrial lissamphibian taxa (approximately $21 \%$ in the lower Oldman and upper units of the Oldman Formation (21\% and $31 \%$ ), respectively.

The Comrey Unit of the Oldman Formation in the Dinosaur Park area (which is the only portion of the Oldman Formation outcropping in that area) displays a predominately inland faunal assemblage nearly identical to that of the Comrey and upper units of the Oldman Formation in the Milk River area, with a significant portion of 
amphibian taxa (30\% of the total assemblage) and dinosaur material ( $27 \%$ of the total assemblage) and a conspicuous decrease in chondrichthyan taxa $(<1 \%$ of the total assemblage). This supports the interpretation that the faunal composition of the upper Oldman Formation in the Milk River is more similar to the Comrey unit of the Oldman Formation in Dinosaur Provincial Park than it is to the Dinosaur Park Formation, for which the upper unit of the Oldman Formation is time equivalent (Brinkman et al., 2004; Eberth, 2005; Cullen et al., 2016) (Figs. 5.18 and 5.19).

The Dinosaur Park Formation shows a mixture of both inland and coastal taxa (Figs. 5.18 and 5.19), owing to the major depositional shift following the onset of the transgressive portion of the Bearpaw Marine cycle, which is represented in outcrop by the Lethbridge Coal Zone, deposited in an estuarine to near marine coastal environment not dissimilar to those of the Foremost Formation (Eberth, 2005; Johnston and Hendy, 2005). Further similarity between the upper Dinosaur Park and Foremost formations are seen in the faunal assemblages of the Lethbridge Coal Zone that have a large percentage of the brackish guitarfish Myledaphus (45.2\% of the total assemblage) and the brackish water phyllodontid fish, such as Paralbula (26.7\% of the total assemblage) (Figs. 5.18 and 5.19). The fish in the pre- Lethbridge Coal Zone horizons of the upper Dinosaur Park Formation closely resembles that of Foremost Formation with a significant proportion of Myledaphus (14.2\%) and Lepisosteus (18.9\%), but with more freshwater associated aquatic taxa such as Holostean A (16.2\%), suggesting lower overall marine influence in pre-Lethbridge coal zone deposits of the Dinosaur Park Formation compared to the Foremost and post-Lethbridge Coal horizons of the Dinosaur Park Formation (Figs. 5.18 and 5.19). 
Overall, microvertebrate diversity increases upsection in both the Milk River and Dinosaur Park regions (See Appendix E-7). The Foremost Formation has the lowest overall diversity, likely owing to the dominance of Pseudomyledaphus in its sampled (Hill Number $=9.24$ effective taxa), while diversity relative to the Foremost Formation increases by $21 \%($ Hill Number $=11.7$ effective species $)$ and $33 \%($ Hill Number $=13.8$ effective species) respectively in the Oldman Formation and Dinosaur Park Formation respectively in the Dinosaur Park region. The post-Lethbridge Coal Zone deposits of the Dinosaur Park Formation displays the lowest overall diversity (Hill Number $=4.90)$. The Oldman Formation units in the Milk River region display approximately similar diversity to the Oldman Formation in the Dinosaur Park region (Hill Number $=11.7$ effective species). Rarefaction analysis shows that the formations of the Belly Group are relatively similar to one another in diversity, with the Dinosaur Park Formation and Oldman Formation in the Milk River area exhibiting similar profiles (Fig. 5.20). The Foremost Formation is suggested to be more diverse, somewhat counter to the diversity indices calculated for each formation. This reflects that the Foremost Formation contains marine species not encountered in other formations but in addition to the terrestrial species that are encountered in those formations. However, as rarefaction does not account for species evenness as in other diversity analyses, therefore making the Foremost appear more diverse than it should be. Rarefaction curves also show that the microsites from the Lethbridge Coal Zone are undersampled relative to the other Belly River Group formations, which were well sampled. 


\section{5: Dinosaur Abundances of the Belly River Group based on Microsite Data}

Based on teeth from microsites, the dinosaur community of the Foremost Formation is dominated by ornithischians, with an approximate ratio of $99.1 \%$ to $0.9 \%$ ornithischian to theropod (Fig. 5.21). Within the ornithischians, the Foremost Formation shows similar abundance patterns to the other BRG formations, with hadrosaurs being the most dominant taxa, as they are in both the Oldman and Dinosaur Park formations, comprising $60 \%$, or more, of total assemblages throughout the Belly River Group (Figs. 5.21 and 5.22). Overall contribution of hadrosaurs to dinosaur diversity decreases slightly up section in both the Milk River and Dinosaur Park areas (Figs. 5.21 and 5.22). A notable decrease in ceratopsian microvertebrate remains occurs between the Foremost Formation ( $9 \%$ of the total assemblage) and the Oldman Formation in the Dinosaur Park area $(\sim 1 \%$ total assemblage), with a slight increase in the Dinosaur Park Formation (5\% total assemblage). However, ceratopsian microvertebrate abundance remains relatively stable between the Foremost Formation (9\%) and the three units of the Oldman Formation (lower, 7\%; middle and upper, 6\% each) in the Milk River area. A large positive gain in ankylosaur material is encountered in the Oldman Formation in the Dinosaur Park area ( $\sim 30 \%$ total assemblage), with a larger than normal proportion of ankylosaurs continuing into the sampled assemblages of the Dinosaur Park Formation ( $\sim 12 \%$ total assemblage, approximately $4 \%$ or less in Milk River area sites) that is not displayed in the Milk River area (Figs. 5.21 and 5.22).

Based on the microsite data gathered here, diversity at the family level in dinosaurs changes very little compared to the total vertebrate faunal assemblage 
Figure 5.21: (see page 158): Dinosaur relative abundance trends for the Dinosaur Park Formation, Oldman Formation (Dinosaur Provincial Park area), and Foremost Formation microsites based on the data of Cullen et al. (2016) and this study showing differences in relative abundance upsection. The enivornmental change up section shifts from marginal marine in the Foremost ( 6 sites; $n=795$ ) to fully terrestrial in the Oldman Formation ( 7 sites; $n=1724$ ) and majority of the Dinsoaur Park Formation (18 sites; Pre LCZ; $n=$ 3045) with a marine transgression. All formations are dominated by hadrosaurs, with notable enrichment of ankylosaur material in the Oldman Formation. 

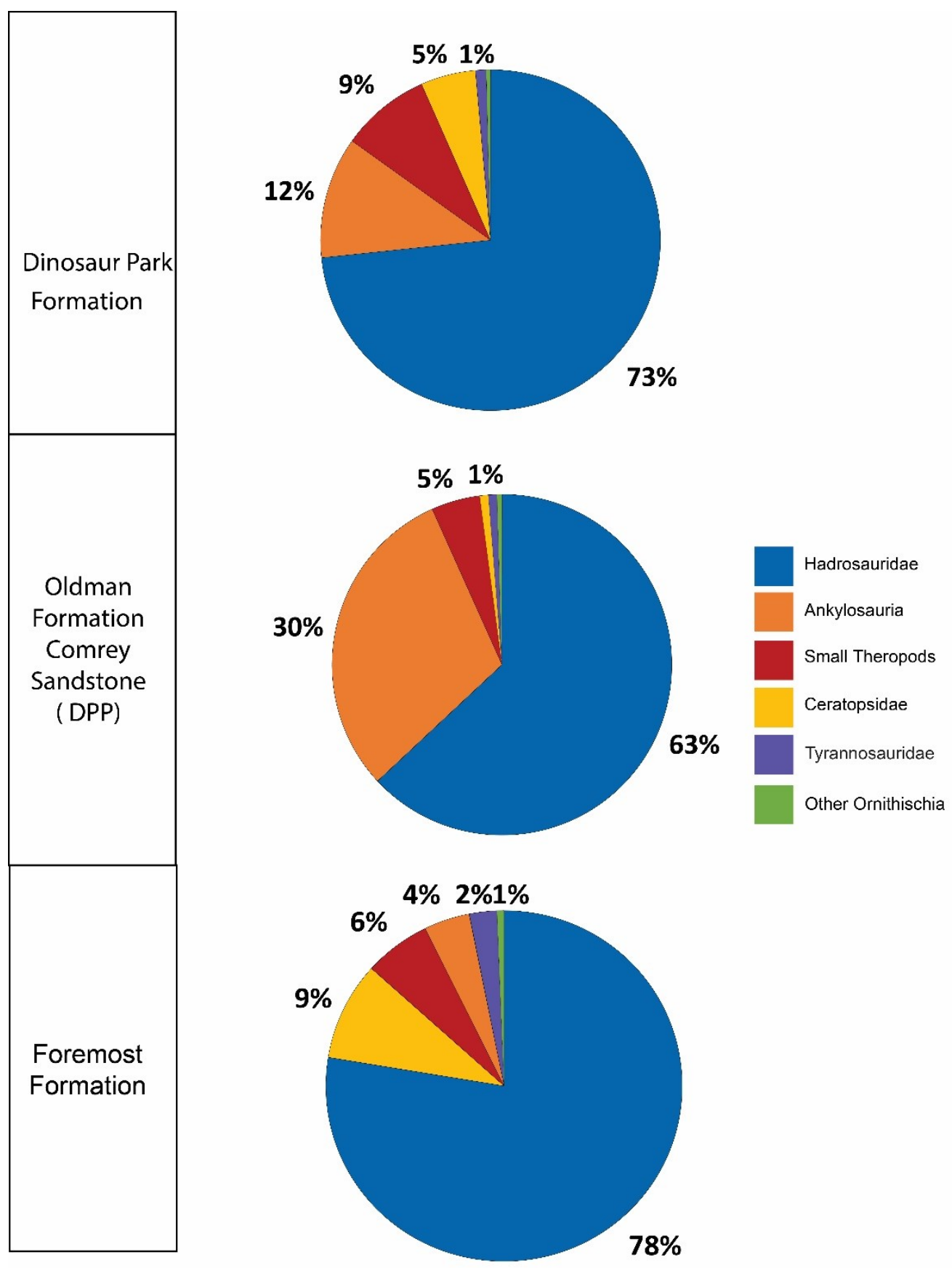
Figure 5.22: (see page 160): Dinosaur relative abundance of taxa from the Milk River Area Oldman Formation (upper, Comrey (11 sites; $\mathrm{n}=1941)$ and lower units (5 sites; $\mathrm{n}=490)$ ) and Foremost Formation (6 sites; $\mathrm{n}=795)$ microsites (data from Cullen and Evans, 2016). Upper and Comrey units of the Oldman Formation were considered one unit based on similarites noted by Brinkman et al. (2004) and Cullen et al. (2016). Hadrosaurs dominate assemblages in the Milk River area Belly River Group, with a notably larger ceratopsian component in these assemblages than found in the Dinosaur Park Area. 

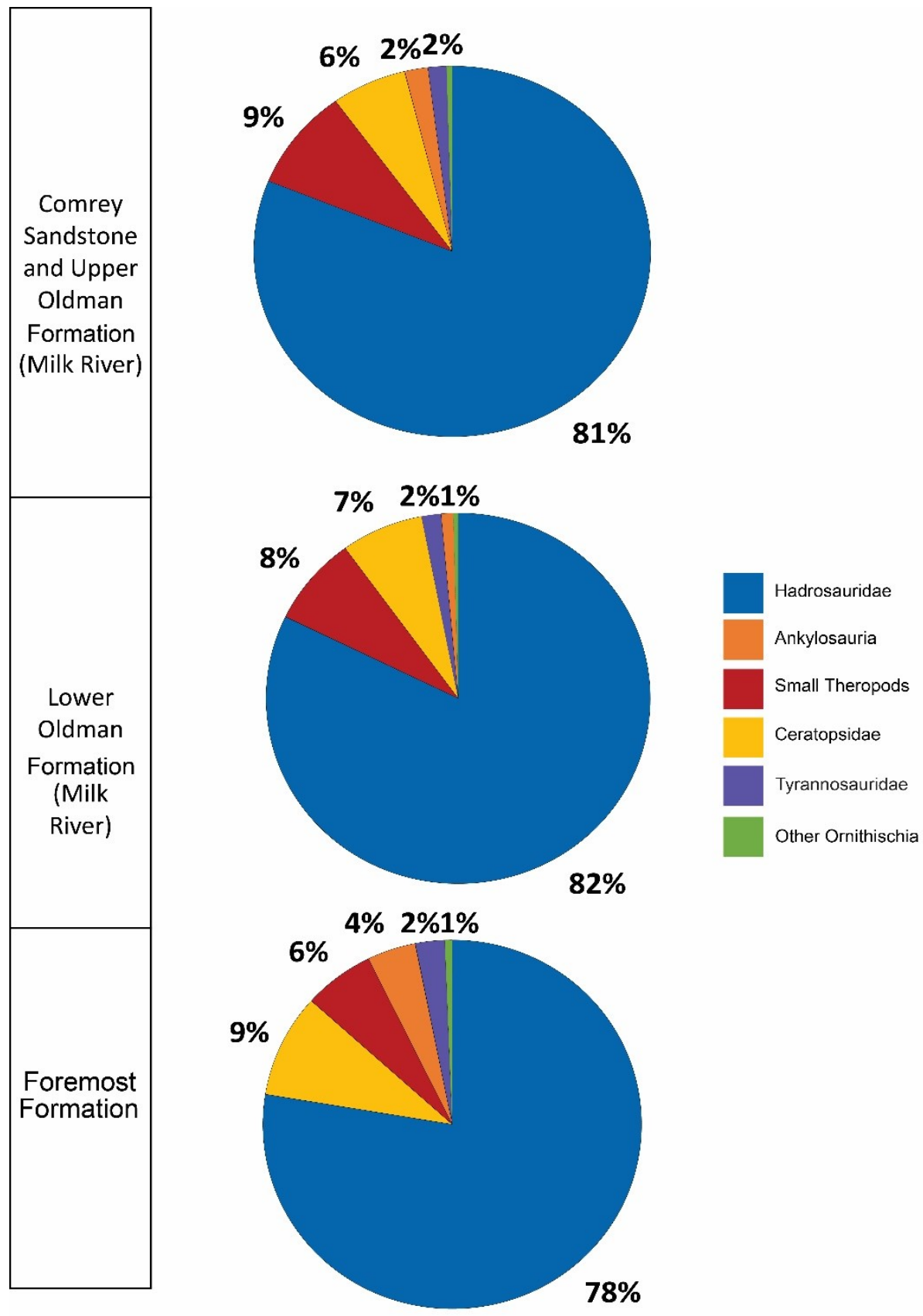
Figure 5.23: (see page 162): Rarefaction curves plotting number of taxa versus number of dinosaur fossil specimens calculated for each microsite from the Belly River Group examined in this study. Top and bottom lines of each curve represent upper and lower standard deviations respectively. $\mathrm{OM}=$ Oldman Formation, $\mathrm{DPF}=$ Dinosaur Park Formation, DPP $=$ Dinosaur Provincial Park region. 


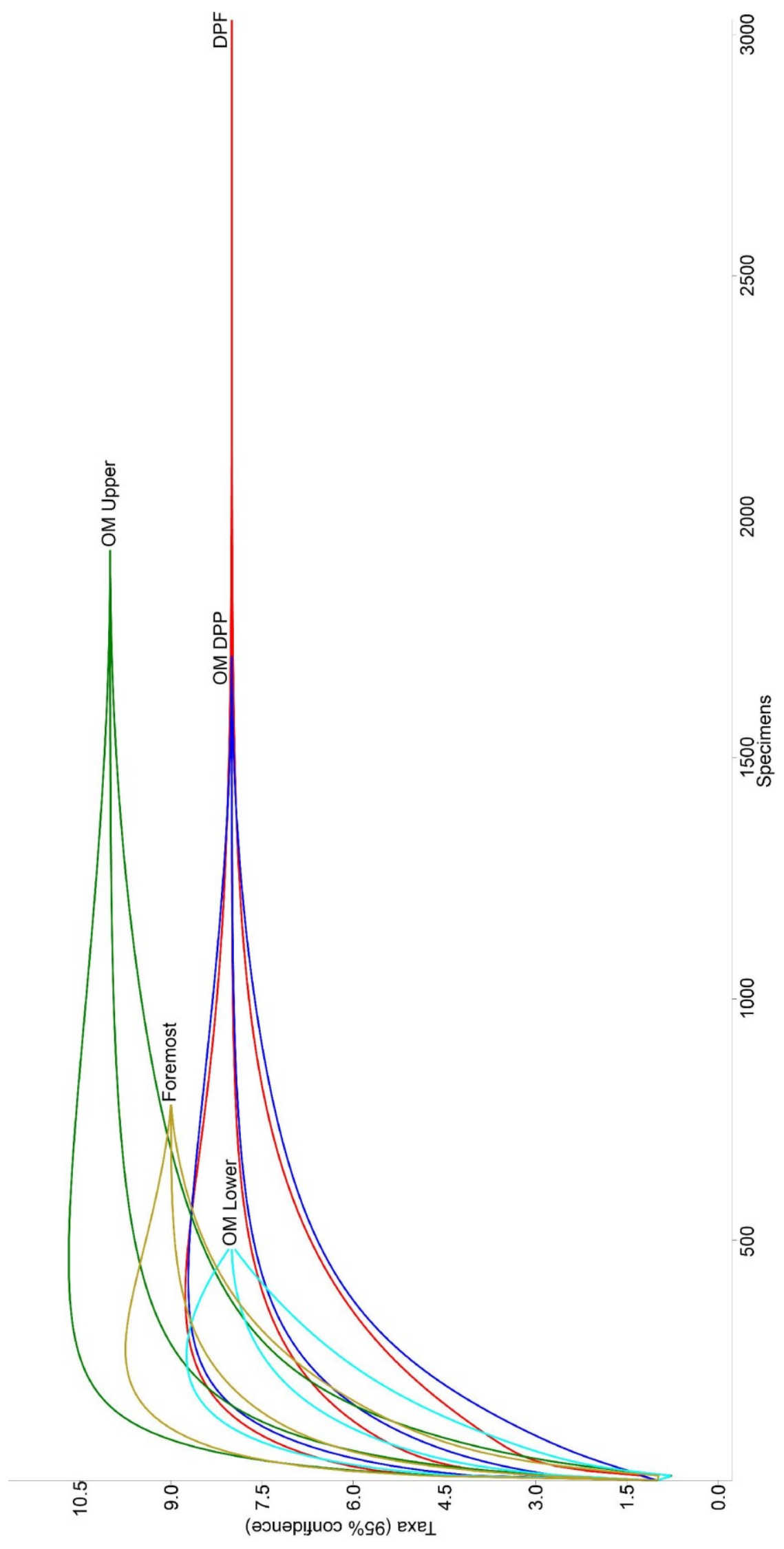




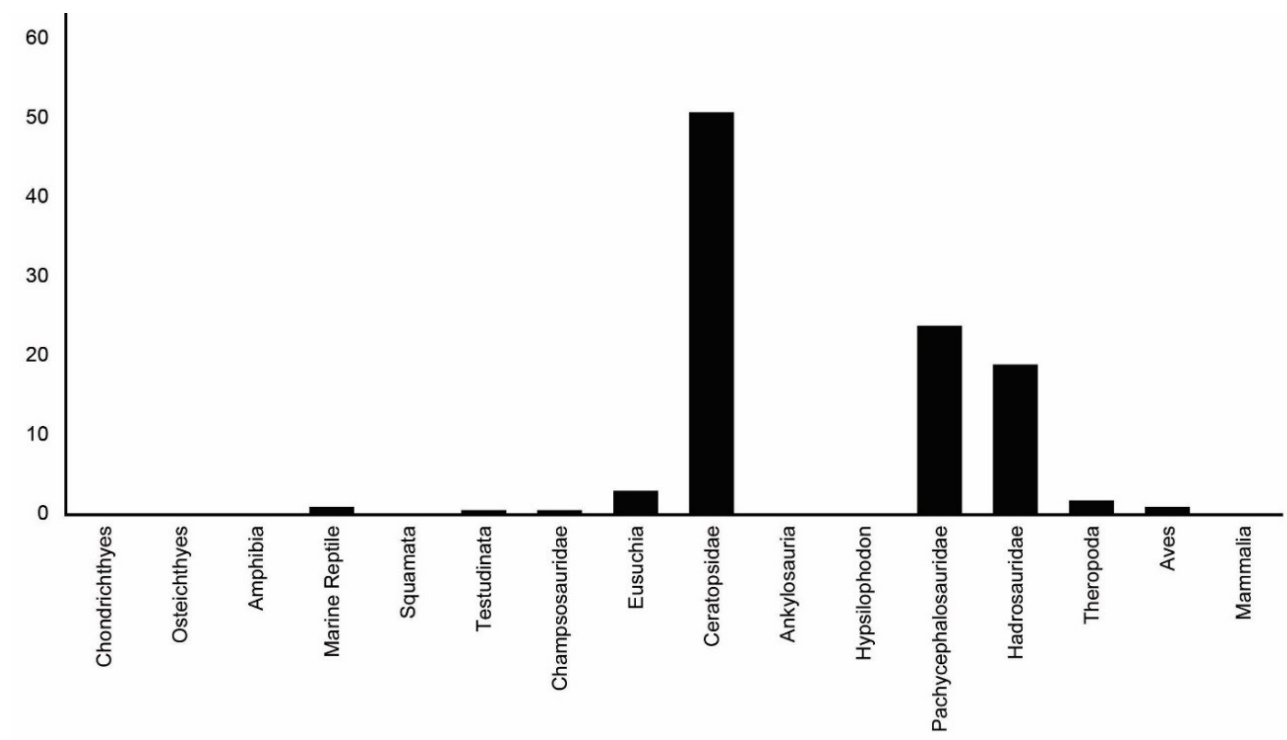

Figure 5.24: Bar graph of vertebrate macrofossil abundance of the Foremost Formation, showing a dominance of ceratopsian material. Total material $=273$, see Appendix E-9 for further detail. 


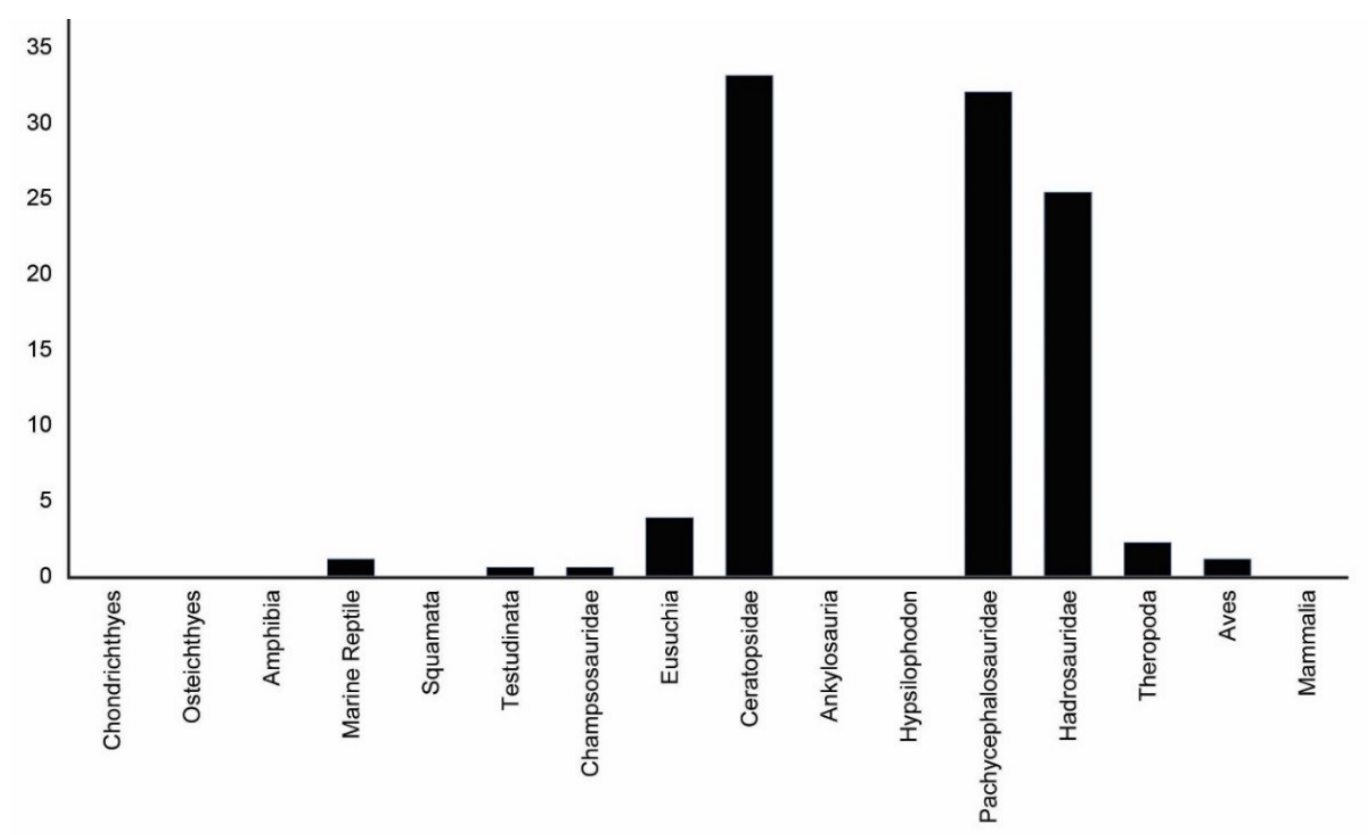

Figure 5.25: Macrofossil abundance of the Foremost Formation with Xenoceratops foremostensis bonebed material excluded to account for sampling issues.Ceratopsian material is still the dominant component, however hadrosaur and pachycephalosaur material contibutes nearly the same amount without the $X$. foremostensis bonebed. Total elements $=209$. See Appendix E-9 for more detail. 
lower Oldman Formation, returning to approximately the same diversity as the Foremost Formation in the Comrey and upper units (Appendix E-8). Rarefaction analyses show similar trends, with all sites clustering closely together within the standard error (Fig. 5.23). As well, rarefaction analysis suggests relatively complete sampling from microfossil assemblages of the Belly River Group for dinosaur material.

\section{6: Dinosaur Assemblages of the Foremost Formation Based on Macrofossils}

Non-avian dinosaurs dominate the macrofossil assemblages of the Foremost Formation, with marine reptiles, turtles, champsosaurs, crocodilians and birds comprising only $5.3 \%$ of total macrofossil remains (Figs. 5.21 and 5.22) and are almost exclusively limited to the Taber Coal Zone (Schott et al., 2009; Ryan et al., 2012; this study), which is the most terrestrial portion of the Foremost Formation.

Ornithischian dinosaurs make up 93\% of macrofossil material, and non-avian theropods make up approximately $2 \%$ of the assemblage (Figs. 5.21 and 5.22). The macrofossil assemblages of the Foremost Formation are notable for the unusually significant contribution of ceratopsian remains, making up approximately $50 \%$ of all known macrofossil material from the Foremost (Figs. 5.17 and 5.18). Most of this material is derived from a Xenoceratops foremostensis bonebed located in Chin Coulee; therefore, a separate tally was taken that excluded this material to account for overrepresentation that this bonebed may make to the faunal tallies. However, even without this material, ceratopsians remain the most numerous macrofossil taxa at approximately $33 \%$ of the catalogued material (Figs. 5.24 and 5.25). Pachycephalosaurs make up another notable contribution as the second most macrofossil material collected from the Foremost, ranging from approximately $23 \%$ to $32 \%$, respectively, of macrofossils if the 
Xenoceratops bonebed is or is not included in results. Hadrosaurs are the next most numerous taxa (20\% total with Xenoceratops bonebed; $25 \%$ without Xenoceratops bonebed), while the remaining dinosaur and other faunal groups contributing to the assemblage fall well below 5\% total contribution (Figs. 5.24 and 5.25).

\section{7: Summary}

The microsites of the Foremost Formation show a decrease in marine and brackish taxa and increase in inland taxa up section correlated to the increase in terrestrial deposition note in this study, with an accompanying increase in faunal diversity. Brackish and marine taxa then decrease in abundance drastically in the fluvial Oldman Formation in both the Milk River and Dinosaur Park Areas coinciding with the continued Claggett marine regression. Brackish and marine taxa return to near Foremost Formation abundances in the Dinosaur Park Formation, especially in horizons located above the Lethbridge Coal Zone following the marine influence associated with the Bearpaw transgression. However, the time equivalent upper Oldman Formation in the Manyberries area does not reflect this, instead maintaining the dominance of inland taxa noted for the lower members of the Oldman Formation in both areas. Diversity of vertebrates also increases overall through the Belly River Group up section in both the Dinosaur Park area and Milk River area, but increases in diversity are greater up section in the Dinosaur Park sites. Dinosaur communities based solely on microsites are comparable between the Dinosaur Park and Milk River area portions of the Belly River Group, with a greater contribution of ceratopsians in the Milk River area and greater abundance of ankylosaurs in the dinosaur park area. Dinosaur diversity based on this data remains similar up section 
in the Belly River Group in the Dinosaur Park area and Milk River area, with a notable decrease in diversity experienced in the lower Oldman unit in the Milk River area. 


\section{Chapter 6: Hadrosaurs of the Foremost Formation}

\section{1: Introduction}

Hadrosauroidea was a group of globally distributed, highly successful ornithopod dinosaurs that existed during the Late Cretaceous (Horner et al., 2004; Godefroit et al., 2012; Eberth and Evans, 2014). Hadrosauroidea can be defined as the group containing all taxa more closely related to Hadrosaurus foulkii than to Iguanodon bernissartensis (Prieto- Márquez, 2010). The latest diverging clade of Hadrosauroidea, Hadrosauridae, is defined as the group that consists of the most recent common ancestor of Hadrosaurus foulkii, Edmontosaurus regalis, Saurolophus osborni and Lambeosaurus lambei (PrietoMárquez, 2010). Hadrosauridae is diagnosed by several synapomorphies including a dorsoventrally compressed and mediolaterally widened rostral region, large tooth batteries composed of up to thousands of teeth, and modified nasal and facial bones that may form elaborate crest structures (Horner et al., 2004; Prieto- Márquez, 2010). Hadrosauridae can be subdivided into two major families, Saurolophinae and Lambeosaurinae (sensu Prieto- Márquez, 2010)). Saurolophinae are typically distinguished from Lambeosaurinae by lacking the increasingly elaborate, hypertrophied nasal crest ornamentation seen in Lambeosaurinae (Horner et al., 2004; Evans et al., 2009). Saurolophines (Brown, 1914; Prieto- Márquez, 2010) were widespread in North America during the Late Cretaceous (Sankey, 2001; Mori et al., 2015) likely originating in Appalachia during the Santonian at the latest, and arriving in Laramidia later in the Campanian (Gates et al., 2011; Prieto- Márquez et al., 2016). 
Hadrosaurid biodiversity was at its peak in North America during the Campanian (Sankey, 2001; Evans et al., 2006; Gates and Sampson, 2007; Bell and Campione, 2014). Within the Belly River Group of Canada, hadrosaur biodiversity is highest in the Dinosaur Park Formation (Ryan and Evans, 2005; Mallon et al., 2012). Hadrosaurs are less known within the underlying Oldman and Foremost Formations due, in part, to the smaller amount of latterly extensive badlands available in outcrop for each, and the relative lack of prospecting (Eberth, 2005; Ryan et al., 2012). Until recently, most of the hadrosaur material from these formations consisted of teeth collected from vertebrate microsite localities, prohibiting higher level taxonomic identifications (Brinkman, 1990; Brinkman et al., 2004; Ryan et al., 2012).

Newly described saurolophine species from Campanian deposits include Probrachylophosaurus bergei Freedman-Fowler and Horner (2015) from the Judith River Formation and Acristavus gagslarsoni (Gates et al., 2011) from the Two Medicine Formation, both from Montana. Additionally, the description of Brachylophosaurus canadensis (Sternberg, 1953) from the Oldman Formation of Alberta and upper Judith River Formation of Montana has been recently revised (Cuthbertson and Holmes, 2010). Together these taxa comprise Brachylophosaurini (Gates et al., 2011; Fig 6.34). Several genera belonging to the clade Kritosaurini (Fig 6.34) are also known from Campanian deposits, including the two South American taxa, Willinakaqe salitralensis (Valieri et al., 2010) and Secernosaurus koerneri (Brett-Surman, 1979), Kritosaurus navajovius (Brown and Pepper, 1910) from the southern United States (Prieto- Márquez, 2014) and the temporally long-lived (83 -75 Ma) genus Gryposaurus (Lambe, 1914) from several 
formations in the midwestern United States and Dinosaur Park Formation of Alberta (Gates and Sampson, 2007).

To date, hadrosaur body fossils (excluding teeth and other small elements recovered from microvertebrate fossil localities) from the Foremost Formation have only rarely been collected (Appendix D-10). None of the material has been formally described, although elements from what is probably a bonebed have been referred to as cf. Kritosaurus by Brett-Surman (1989).

The majority of hadrosaur fossils from the Foremost Formation are teeth recovered from microvertebrate assemblages (Beavan, 1995; Peng et al., 2001; Frampton, 2006; Cullen et al., 2016). In total, there are 617 hadrosaur teeth collected from the six Foremost Formation vertebrate microsites, comprising approximately $2.5 \%$ of all microvertebrate remains from the formation (Cullen and Evans, 2016; with data from this study; Appendix D). All of these teeth have been referred to as shed crowns, with none having the attached root. The majority of hadrosaur teeth in Foremost Formation microsites exhibit at least moderate abrasion (Stage 2 or higher; Fiorillo (1988), Cook (1995) and Phillips (2009)), suggesting most have been transported a relatively long distance before burial (Kidwell, 1986; Frampton, 2006). Hadrosaurs also contribute approximately one- third of the recovered macrofossil material from the formation when data from museum collections and this study are combined (Appendix D). This is less than that for the Dinosaur Park Formation, where hadrosaurs make up approximately 40 to $50 \%$ of all macrofossil material (Brinkman 1990; Brinkman et al., 1998; Eberth and Currie 2005), but nevertheless shows that hadrosaurs were similarly an important member of their ecological community. 
The material described within this chapter is from multiple localities within the Foremost Formation in the Manyberries area of southern Alberta and, with the exception of the teeth, all is postcranial. This lack of diagnostic cranial material limits the resolution that can be obtained by the phylogenetic analysis, as this material is the most informative, resulting in most be referred to the level of Hadrosauroidea, with some being referred to Hadrosauridae. Their stratigraphic placement (Fig 6.1.) in the Foremost Formation makes some of the material the earliest Campanian potential hadrosaurids from Laramidia described to date, and the oldest so far discovered in Canada (Bell and Campione, 2014). The description of this material provides information on dinosaur diversity during the poorly known time period recorded within the Foremost Formation and adds to the knowledge of dinosaur assemblage changes throughout the Belly River Group.

Some material was unavailable for description at the time of this study, but is included in macrovertebrate data counts and summarized in Appendix Table D-10. Additionally, some of the material described here was not fully prepared and time constraints did not allow for proper preparation of this material. Therefore, only material that was prepared enough for measurement and handling was examined for this study. 
Table 6.1: Age class assignments of examined hadrosaur specimens based on the criteria of Horner et al., (2000)

\begin{tabular}{|l|l|}
\hline Age Class Name & Body Length Criteria \\
\hline Small Nestling & 45 to $90 \mathrm{~cm}$ body length \\
\hline Large Nestling & 90 to $120 \mathrm{~cm}$ body length \\
\hline Early Juvenile & $120 \mathrm{~cm}$ to $3.5 \mathrm{~m}$ body length \\
\hline Late Juvenile & 3.5 to $4.7 \mathrm{~m}$ body length \\
\hline Subadult & 4.7 to $7 \mathrm{~m}$ body length \\
\hline Adult & $7 \mathrm{~m}$ or greater body length \\
\hline
\end{tabular}




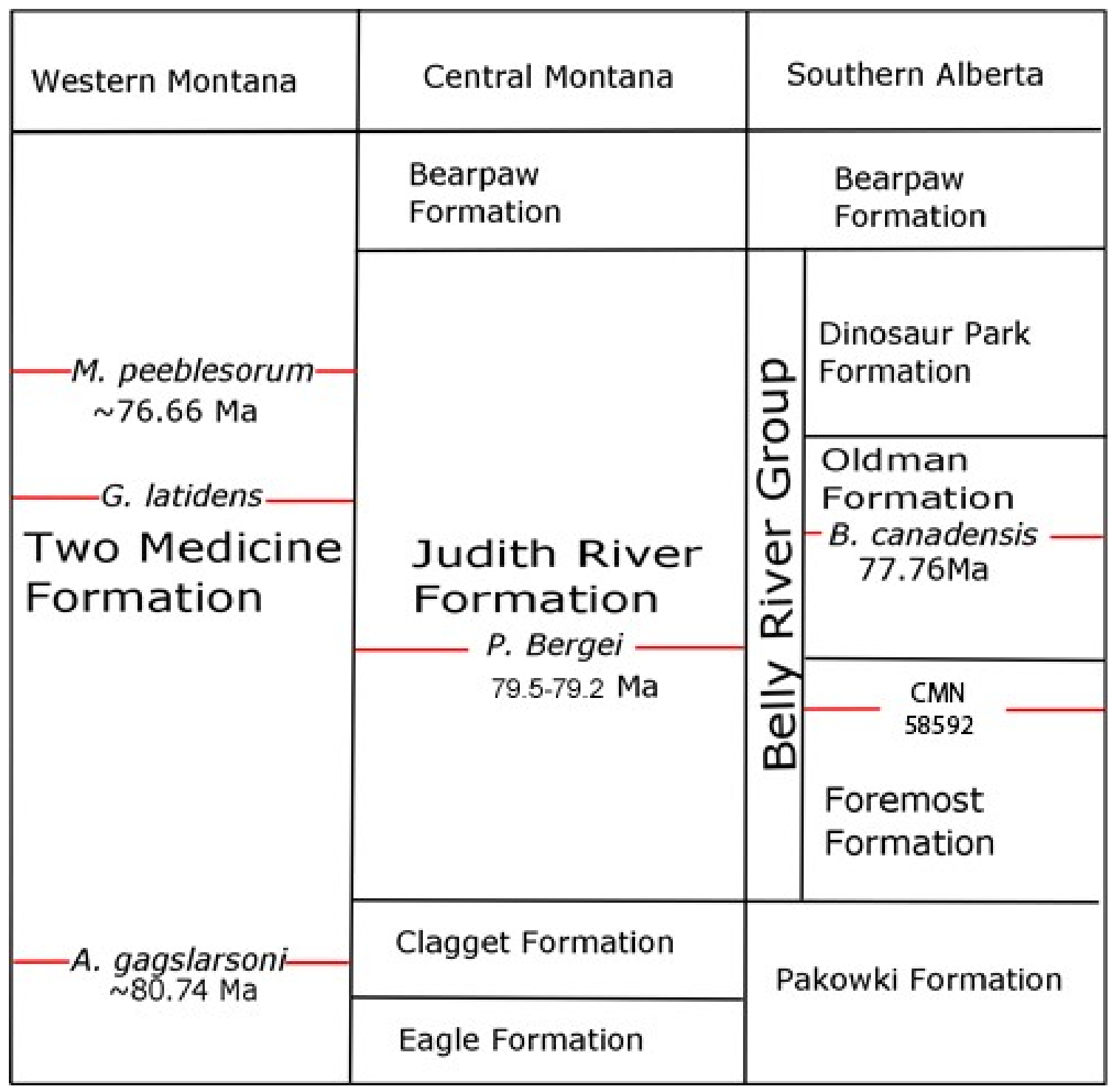

Figure 6.1: Table displaying stratigraphic placement of hadrosaurs of similar age from Western and Central Montana to the material represented by CMN 58592 from Southern Alberta. Ages recorded are those specific to the locality of each taxa listed. G. latidens' last known appearance placement is shown, is also known from lower Two Medicine Formation approx. 83 Ma. Data adapted from Freedman-Fowler and Horner, 2015). 


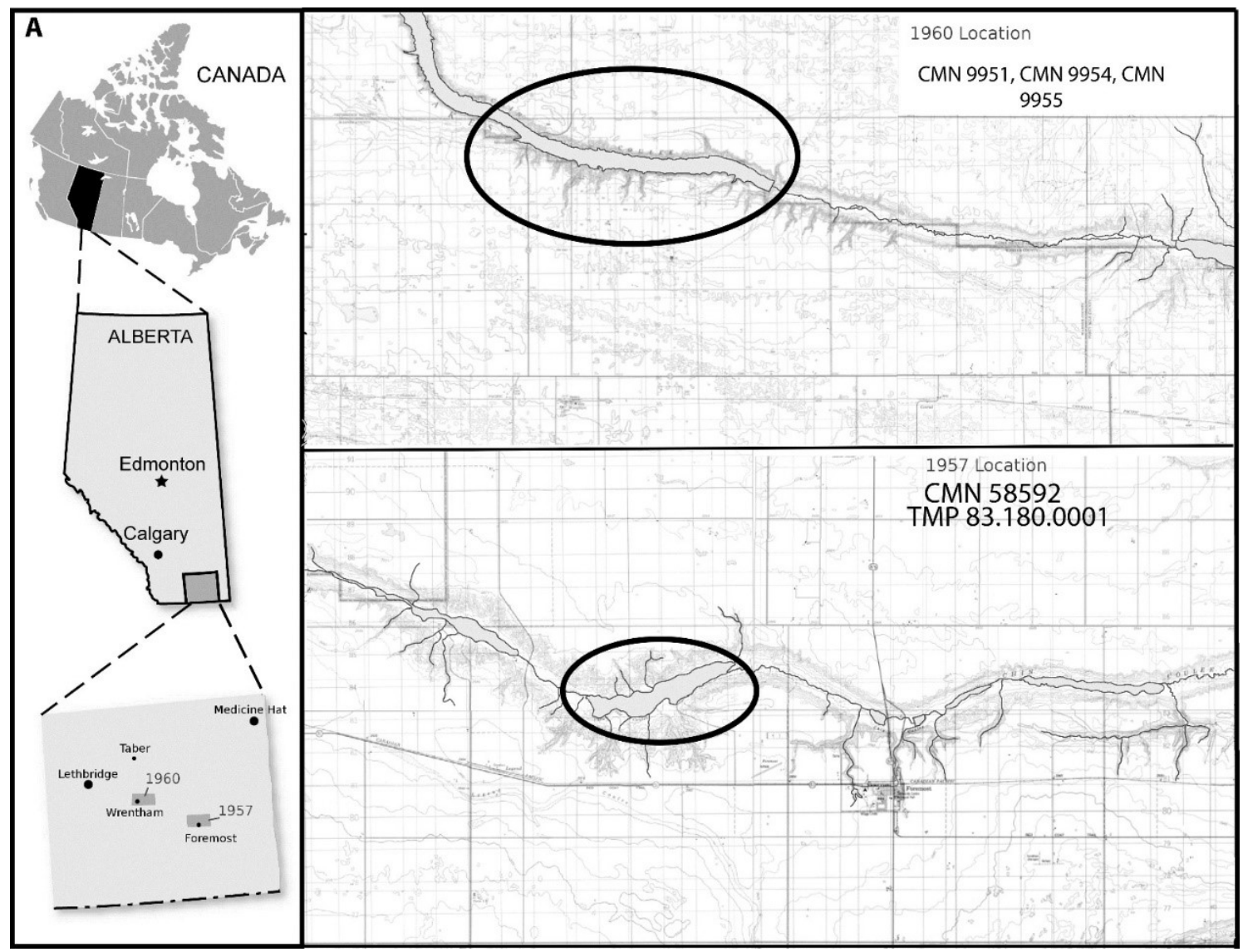

Figure 6.2: Locality map of Chin Coulee, which contains the sites of CMN 58592, CMN 9951, CMN 9954 and CMN 9955 and TMP 83.180.0001. 


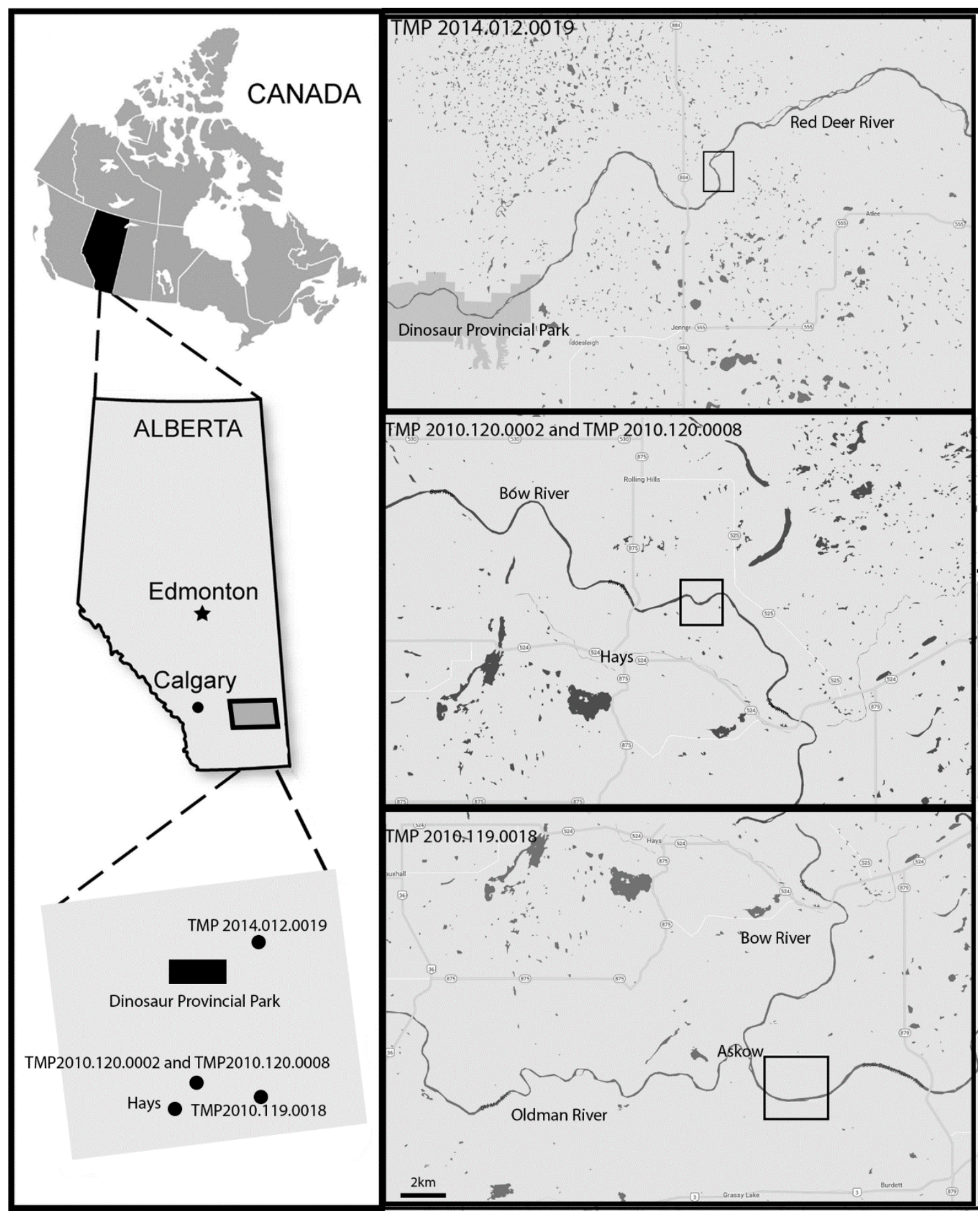

Figure 6.3: Locality map for TMP 2014.012.0019, TMP 2010.120.0002, TMP

2010.120.0008, and TMP 2010.119.0018 in southeastern Alberta. Site locations are marked by rectangles on the maps. Maps altered from Google Maps data (C2017 


\section{2: Descriptions}

CMN 58592 (Figs 6.4 to 6.7) represents elements from one adult individual, including the right ilium (CMN 58592.1 and CMN 58592.2), a pubis (CMN 58592.3), both ischia (CMN 58592.4 and CMN 58592.5), and a right femur (CMN 58592.1) that is currently encased in a full plaster jacket and, thus, could not be described for this project.

\section{CMN 58592}

Ilium

CMN 58592.2 (Fig. 6.4) is left adult-sized ilium, with the preacetabular process being completely separated from the central plate. The posterior part of the postacetabular process is missing and substantial deformation of the medial side of the central plate and posterior portions of the ischiac peduncle has occurred. The contacting surfaces of the preacetabular and the central plate have been eroded so that they cannot be reconnected. The total estimated maximum length of the ilium is $1150 \mathrm{~mm}$, with the preacetabular and the central plate measuring $502 \mathrm{~mm}$ and $650 \mathrm{~mm}$ in craniocaudal length, respectively. The central plate height is $505 \mathrm{~mm}$. The exact angle of ventral deflection of the pre-acetabular process cannot be accurately measured; however, the distinct strong ventral deflection displayed in nearly all hadrosaurids is preserved (PrietoMárquez et al., 2016 Character 224, State 1) (Horner et al., 2004). The dorsal margin of the preacetabular process expands mediolaterally, displaying the anterior portion of the sacral ridge along much of its preserved length (Fig. 6.4).

The supra-acetabular process is anteroposteriorly broad, comprising approximately $390 \mathrm{~mm}$ of the length of the central plate, and extends ventrally 
approximately to $120 \mathrm{~cm}$ at maximum depth. The ventral apex of the supraacetabular process is craniodorsally displaced relative to the caudodorsal portion of the ischiac peduncle. The ventral margin of the supraacetabular process is subtly demarcated into two separate lobes, although not to the extent seen in other saurolophines displaying this trait (e.g., Brachylophosaurus canadensis; Prieto- Márquez, 2010- Fig. IL12). The supraacetabular process displays a nearly symmetrical, sub-rectangular profile with a slight asymmetric skew cranially. The caudodorsal margin of the supraacetabular process is poorly defined overall and does not form a continuous ridge with the proximal portion of the postacetabular process.

The dorsal margin of the central plate displays a slight sigmoidal curve and a caudally directed asymmetric skew. The sacral ridge is clearly visible along the medial margin of the central plate, as well as the preacetabular process, but the ridge is difficult to distinguish in caudal view due to taphonomic distortion. The pubic peduncle displays a triangular shape tapering to the apex. The pubic peduncle is $97 \mathrm{~mm}$ long and $86 \mathrm{~mm}$ wide at the dorsal most margin. A double-lobed ischiac peduncle morphology is still preserved.

The post-acetabular process is dorsally directed in lateral profile. The caudalmost end was likely rounded, and does not end in a brevis shelf. Viewed from the posterior end, its dorsal margin deflects medially while its ventral margin deflects laterally, forming a smooth reverse S-shaped curvature dorsoventrally. 


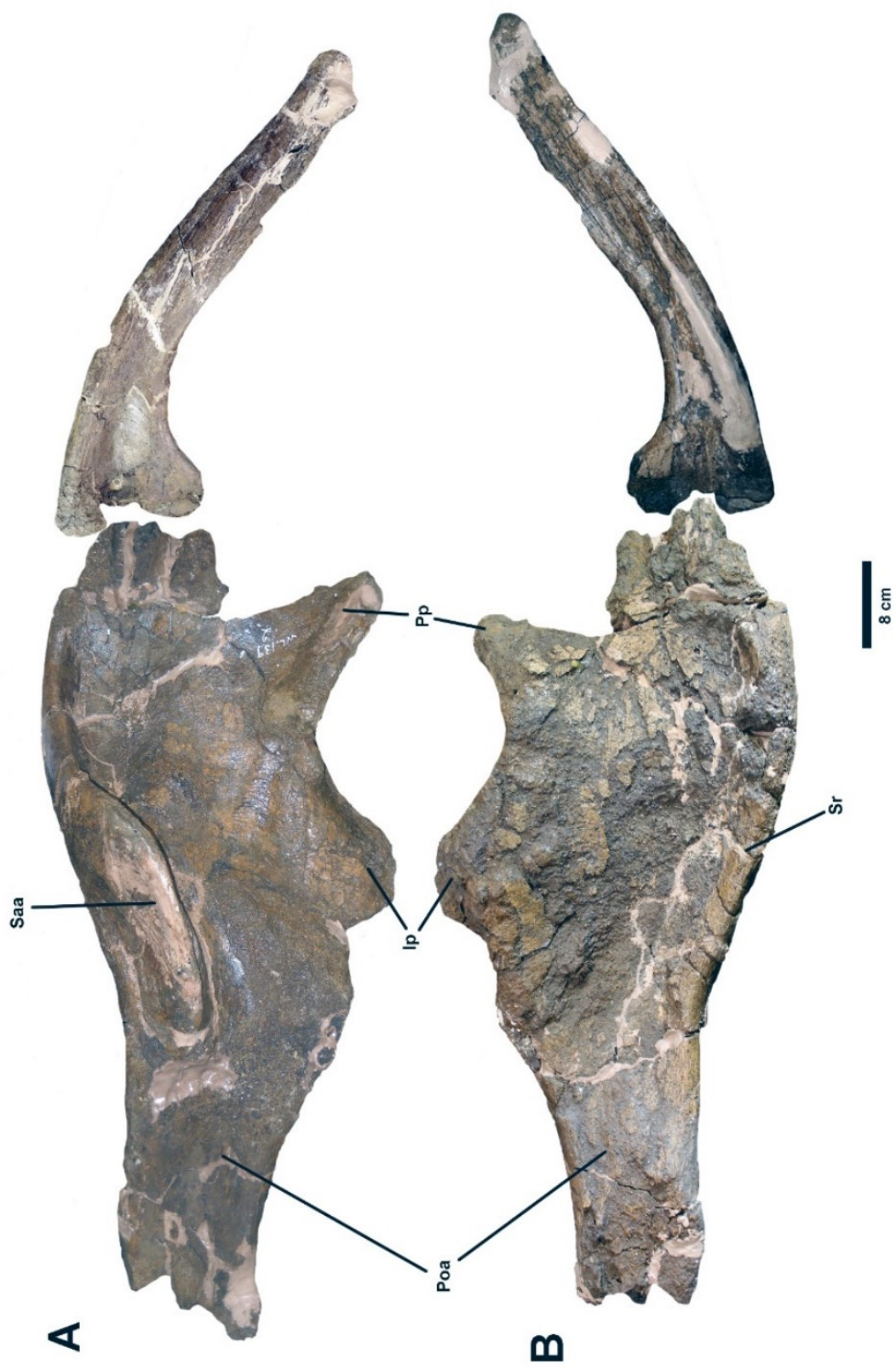

Figure 6.4: Central plate (left) and pre-acetabular process of the right ilium of CMN 58592.2. Lateral view (A) and medial view (B). Abbreviations: supra-acetabular process $=$ Saa, sacral ridge $=\mathrm{Sr}$, post-acetabular process $=$ Poa, ischiac peduncle $=\mathrm{Ip}$, pubic peduncle $=$ Pp. Lateral view (A) and medial view (B). 


\section{Pubis}

CMN 58592.3 (Fig. 6.5) is a pubis missing the anterior most portion of the pubic blade. The blade of the pre-pubic process has been extensively reconstructed, and measures $102 \mathrm{~mm}$ at its most narrow portion, $142 \mathrm{~mm}$ at its widest portion, and is 498 $\mathrm{mm}$ in length. The widest part of the blade is expanded to approximately 1.4 times the dorsoventral height of the narrowest portion of the neck. The curvature of the neck suggests an anteroventrally directed pre-pubic area. The points of maximum dorsoventral concavity of the pubic neck occur at approximately equal points on both the dorsal and ventral surfaces (Prieto- Márquez, 2010: Fig. IL5, Character 235).

The obturator foramen and process are missing due to breakage. The proximal portion of the postpubic process is preserved, but it has been eroded distally. Similarly, both the ischial and iliac peduncle have been nearly destroyed by weathering. The preserved portion of the iliac process is approximately equal in height and width, and measures $159 \mathrm{~mm}$. The iliac process displays a ridge along its lateral margin, merging into the pubic body prior to contact with the ischial peduncle. The ischial peduncle is found proximal to the main body of the pubis.

Ischia

CMN 58592.4 (Fig. 6.6) is a nearly complete right ischium measuring $662 \mathrm{~mm}$ craniodorsally, with a mid-shaft thickness of $52.3 \mathrm{~mm}$. The majority of the ischial head is present, with only the dorsal margin of the pubic peduncle being moderately weathered. Due to this weathering, the actual curvature of the region between the pubic and iliac 
peduncle is uncertain. The iliac peduncle is incompletely preserved and has been reconstructed to mirror the opposite side which is complete.

The obturator process and pubic peduncle are fused in the ventral obturator gutter region, creating a fully enclosed obturator foramen. This feature is seen in ontogenetically mature saurolophines, including Saurolophus osborni, S. angustirostris, and Brachylophosaurus canadensis (Brett-Surman and Wagner, 2007; Godefroit et al., 2012). The arcuate shaft is mediolaterally compressed, probably explaining the slightly unequal lengths of the pair. The majority of the distal shaft is preserved, except the terminus. The width of the shaft along the dorsoventral axis is inflated due to postmortem taphonomic deformation. The shaft displays no dorsoventral curvature.

CMN 58592.5 (Fig. 6.7) is a left ischium preserving a partial ischiac head and entirety of the shaft, with a total craniocaudal length of $640 \mathrm{~mm}$. The ischial head is considerably more fragmented and less complete than in CMN 58592.4, although the shaft is undeformed. The iliac peduncle is complete, albeit slightly abraded along its dorsal margin. The iliac peduncle projects craniodorsally and is approximately rectangular in lateral profile. The dorsal articulating surface of the iliac peduncle is straight along the distal margin of its posterodorsal corner. The acetabular and caudodorsal margins of the iliac peduncle are weakly convergent towards the dorsal articular surface. The pubic peduncle and obturator process are completely absent in this specimen, but were likely equivalent to those displayed in CMN 58592.4. 


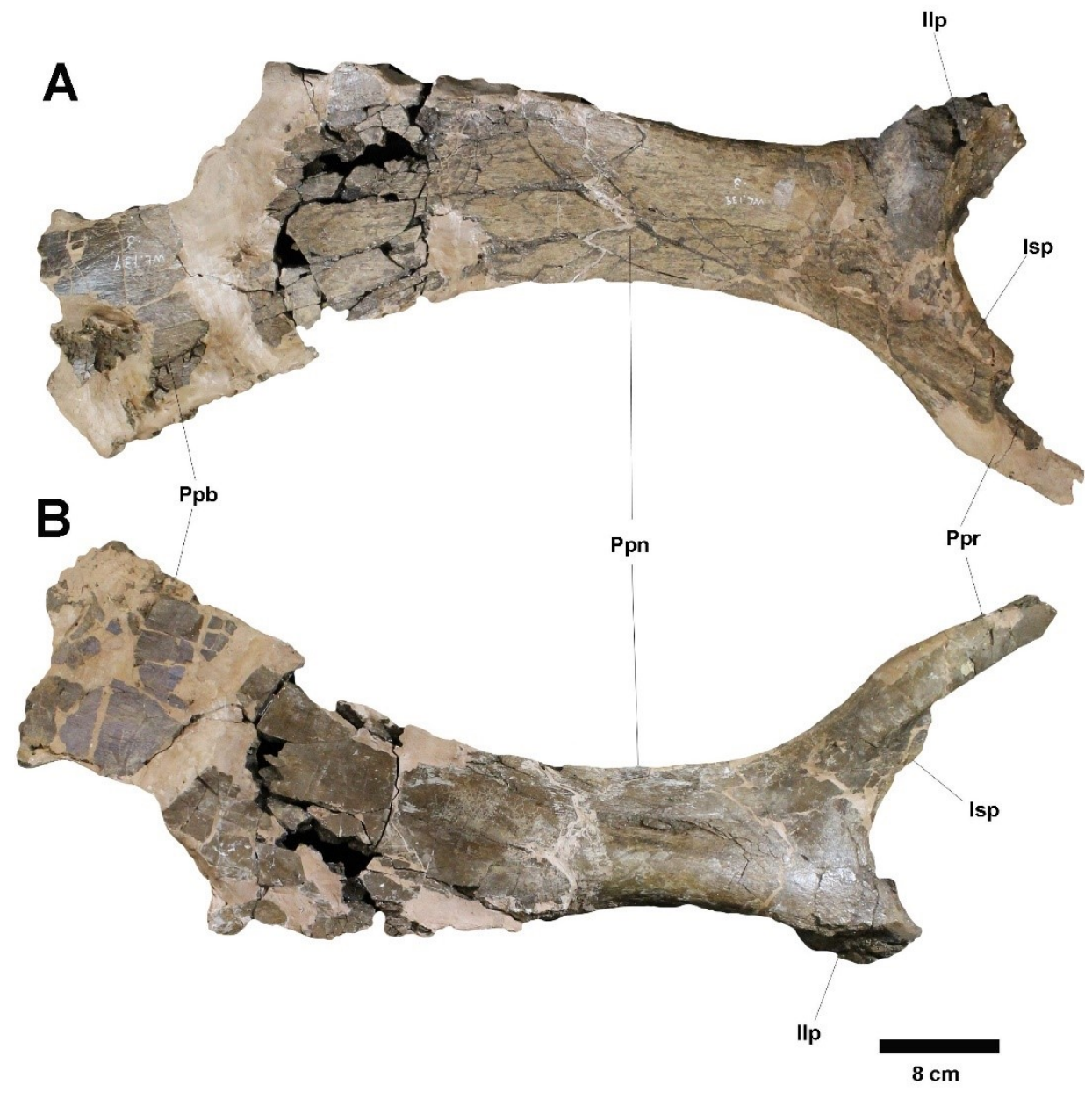

Figure 6.5: Right pubis of CMN 58592: Lateral view (A) and medial view (B). Abbreviations: Ilp=iliac peduncle, Isp=ischiac peduncle, $\mathrm{Ppr}=$ post pubic process, $\mathrm{Ppn}=$ pre-pubic neck, $\mathrm{Ppb}=$ pre-pubic blade. 


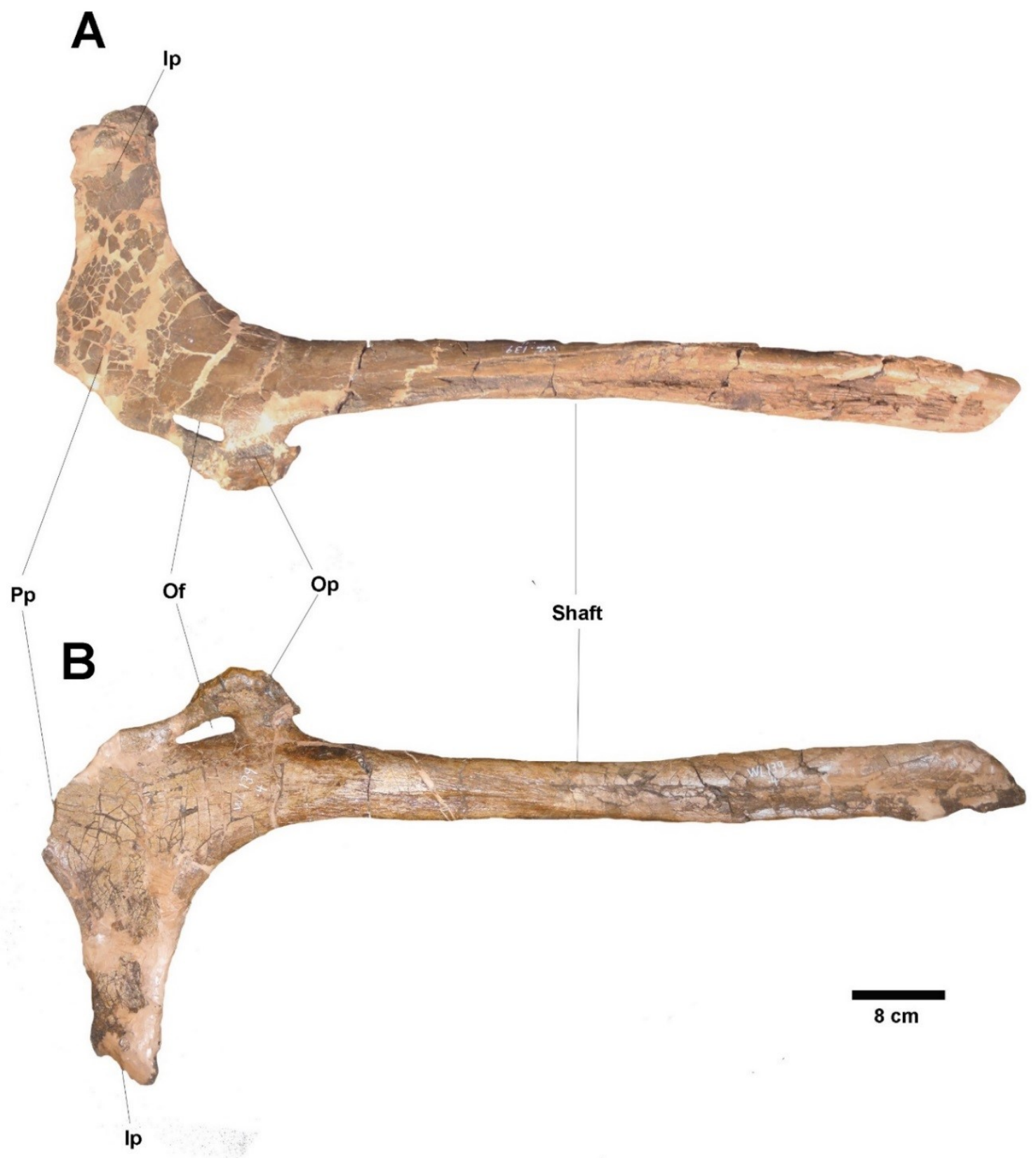

Figure 6.6: Right ischium CMN 58592.4: Lateral view (A) and medial view (B). Abbreviations: $\mathrm{Ip}=$ iliac peduncle, $\mathrm{Pp}=$ pubic peduncle, $\mathrm{Of}=$ obturator foramen, $\mathrm{Op}=$ obturator process. 


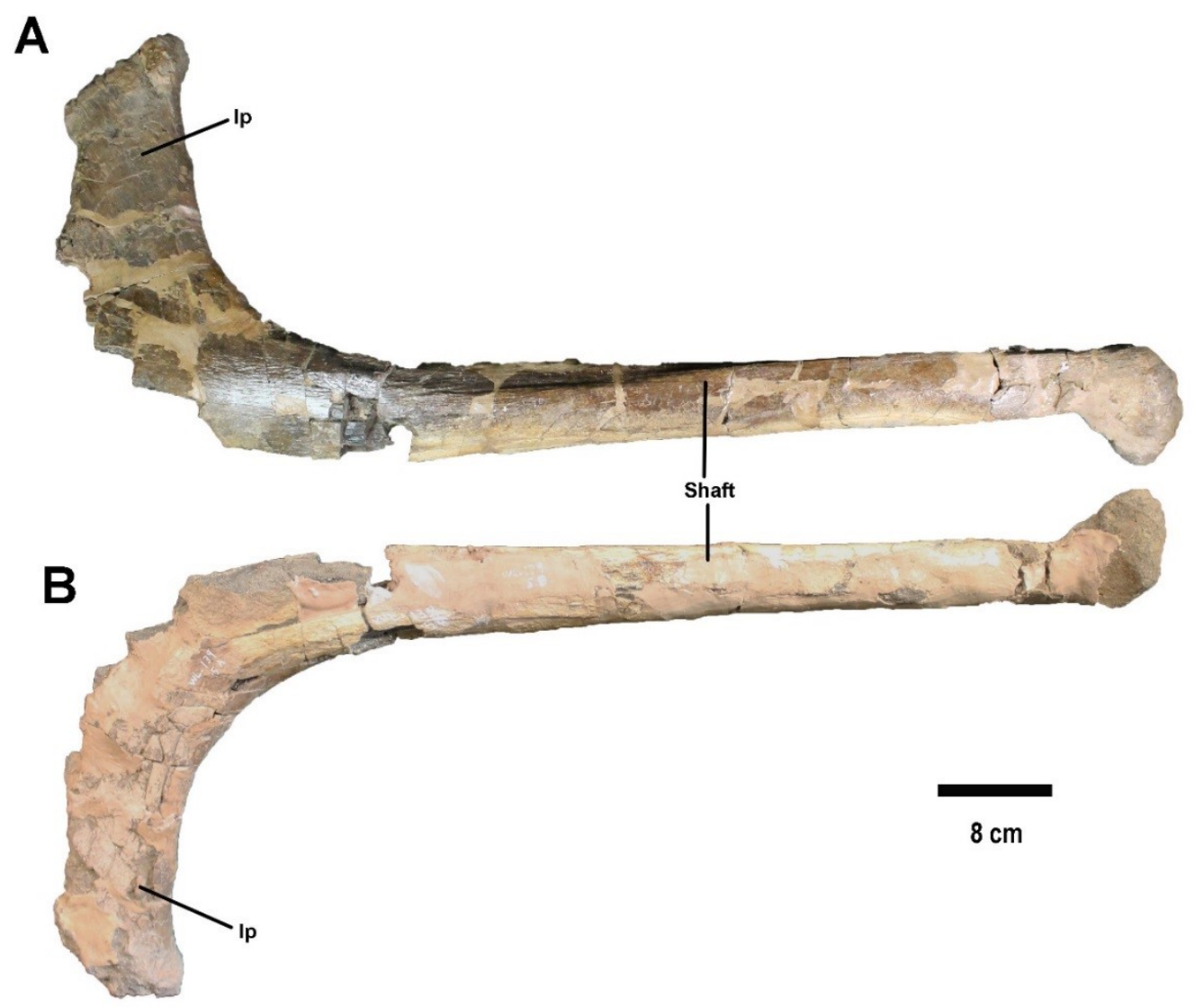

Figure 6.7: Left ischium CMN 58592.5. Lateral view (A) and medial view (B). Abbreviation: $\mathrm{I}=\mathrm{Iliac}$ process. 
The distal end of the shaft terminates in a small, ventrally expanded process. With a dorsoventral depth of $85 \mathrm{~mm}$, this protuberance is significantly smaller than the terminal ischial "boots" found in lambeosaurine taxa and are, therefore, not considered to be equivalent (between $175 \mathrm{~mm}$ and $302 \mathrm{~mm}$ in Lambeosaurinae; see Horner, 2004; Brett-Surman and Wagner, 2007; David Evans, personal comm. 2016).

\section{TMP 83.180.0001}

TMP.83.180.001 (Fig. 6.8 through Fig 6.19) is a composite specimen containing two dentaries, a single scapula, ulna, rib, ilium, ischium, femur, fibula, ilia, metatarsal, and two metacarpals elements that represents late juvenile to subadult-sized individuals based on the size criteria of Horner et al. (2000).

Dentary 1 (Fig. 6.8) is a left early juvenile-sized dentary in an opened plaster jacket displaying its lateral side. It has a minimum preserved craniocaudal length of 208 $\mathrm{mm}$ and a maximum depth through the coronoid process of $115 \mathrm{~mm}$. The coronoid process is rostrocaudally expanded and lacks the sharp rostrally directed point found in ontogenetically mature hadrosaurs (Freedman-Fowler and Horner, 2015). The rostralmost portion of the dentary has a strongly ventrally-angled profile, with a ventral deflection angle of approximately $33^{\circ}$ (Prieto- Márquez et al., 2016: Fig. DT4, Character 26, State 2).

Dentary 2 is also a late juvenile-sized, left dentary (Fig. 6.9), with a highly-eroded medial surface displayed in an opened plaster jacket. This specimen is poorly preserved, missing the anterior edentulous portion. The coronoid process appears to be 


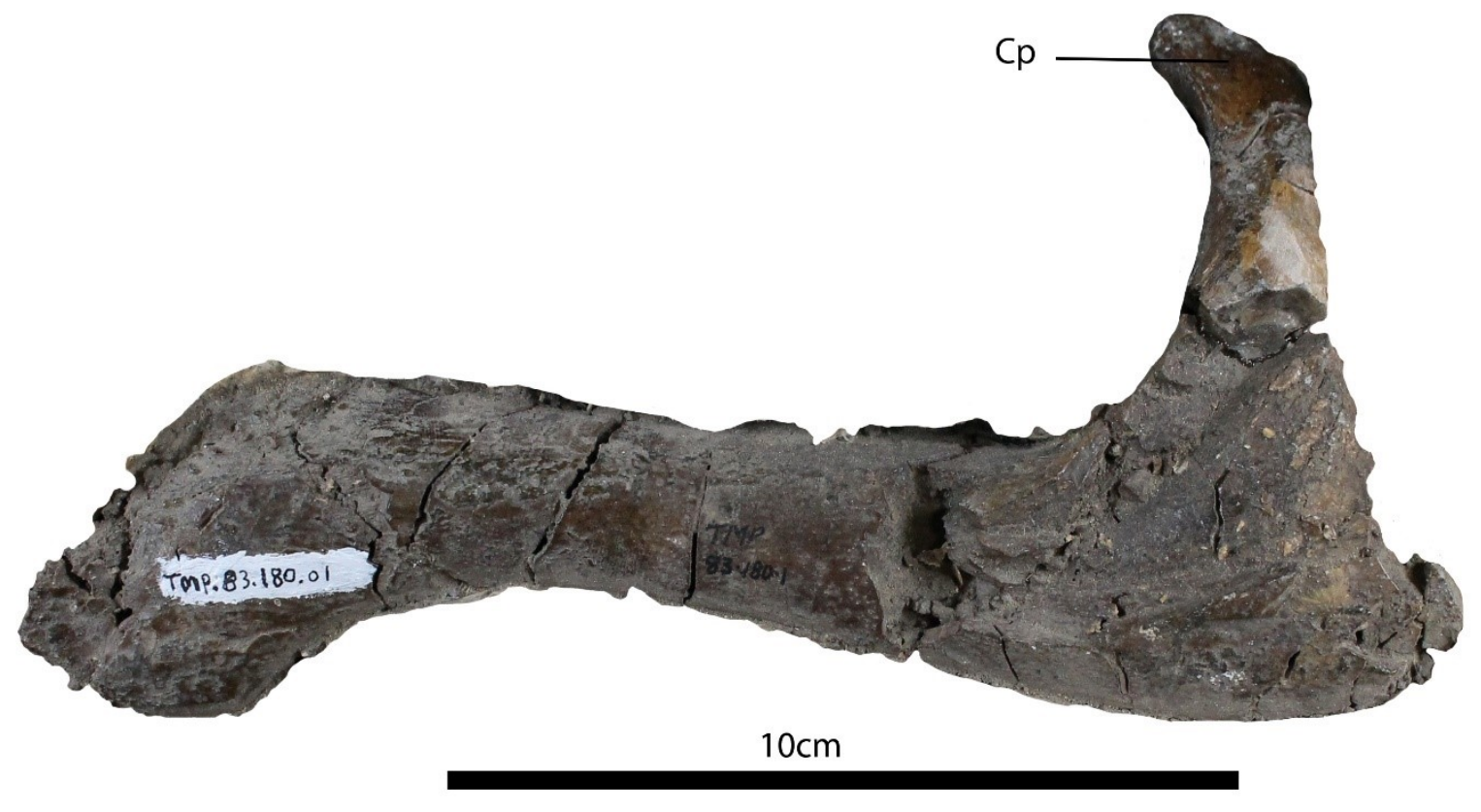

Figure 6.8: Left dentary of TMP 83.180.0001. $\mathrm{Cp}=$ Coronoid process. 


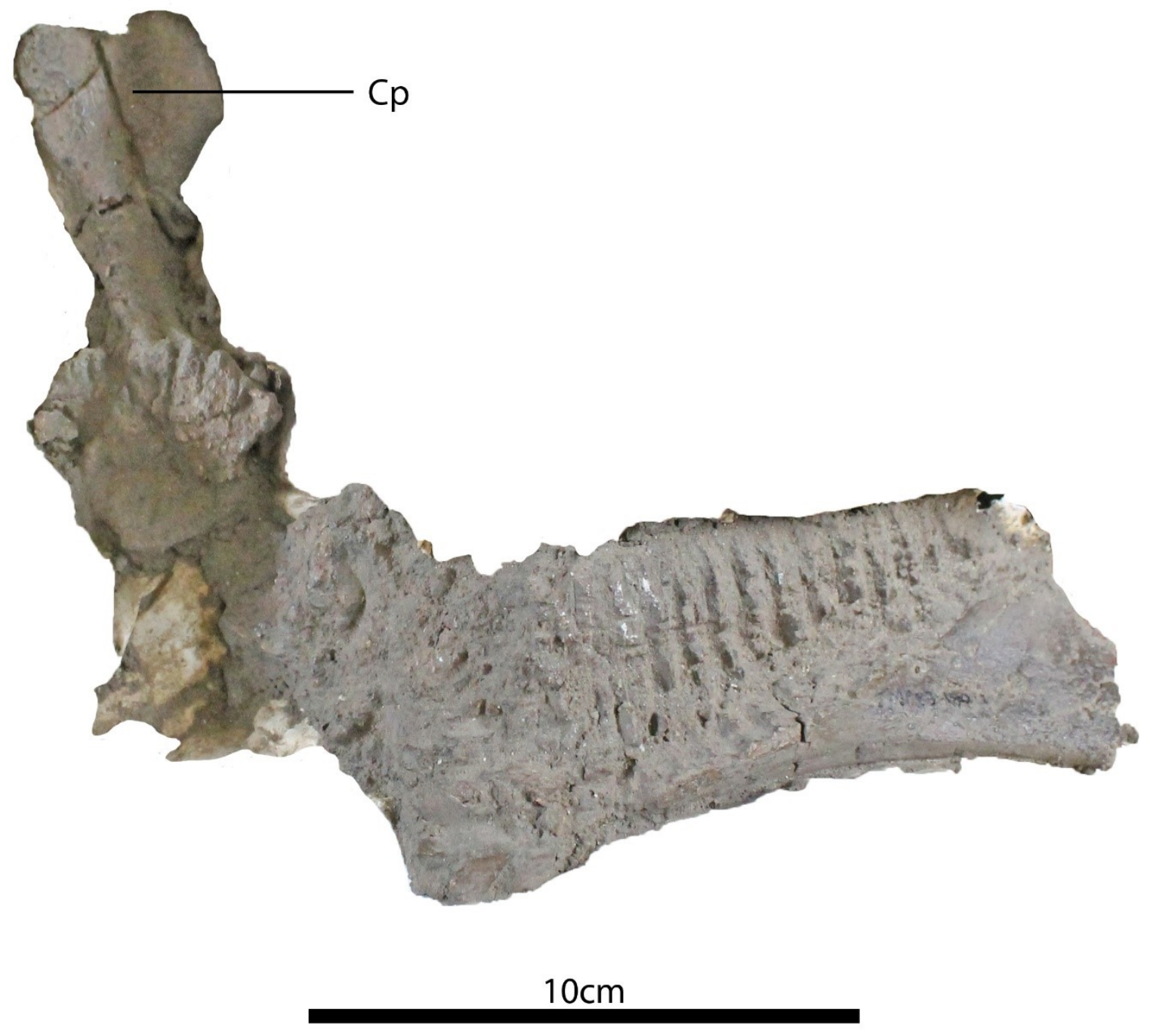

Figure 6.9: Left dentary from TMP $83.180 .0001 . \mathrm{CP}=$ Coronoid process. 
identical to Dentary 1. No teeth are present in the dentary, with only the remnants of the alveolar sulci being preserved.

A left, putative late juvenile-sized scapula (Fig. 6.10), missing only the posterior end of the blade has a preserved anteroposterior length of $252 \mathrm{~mm}$. Dorsoventral expansion of the distal portion of the blade appears slight, similar to the morphology seen in Gryposaurus (Prieto-Marquez, 2012). Its dorsal margin is strongly convex, and the pseudoacromion process is slightly weathered and has a slight curvature that directs the cranial portion dorsally. The deltoid ridge is deep with a well-demarcated ventral region.

A fragmentary left late juvenile ulna (Fig. 6.11) measures approximately $274 \mathrm{~mm}$ in length. The articulating surfaces are damaged; however, the expansion and overall triangular morphology of the proximal head in medial and lateral views is still preserved, as is part of the extension of the olecranon process.

Two metacarpal elements (Fig. 6.12) are present, both measuring approximately $93 \mathrm{~mm}$ in length. They are both relatively straight with a very slight expansion at their distal ends. The distal end of one metacarpal bends medially slightly, marking it as a right Metacarpal IV (Fig 6.12). The other is straighter, and likely represents metacarpal III of the right forelimb.

One small rib from the left side of the body is present, with a maximum dorsoventral depth of approximately $225 \mathrm{~mm}$ (Fig. 6.13). The proximal end of the capitulum and tuberculum, as well as the distal end of the rib, has been damaged due to erosion. The specimen sits in an open plaster jacket that encases its posterior surface. The rib displays a strong laterally convex curvature typical of a rib from a mid-body position. 


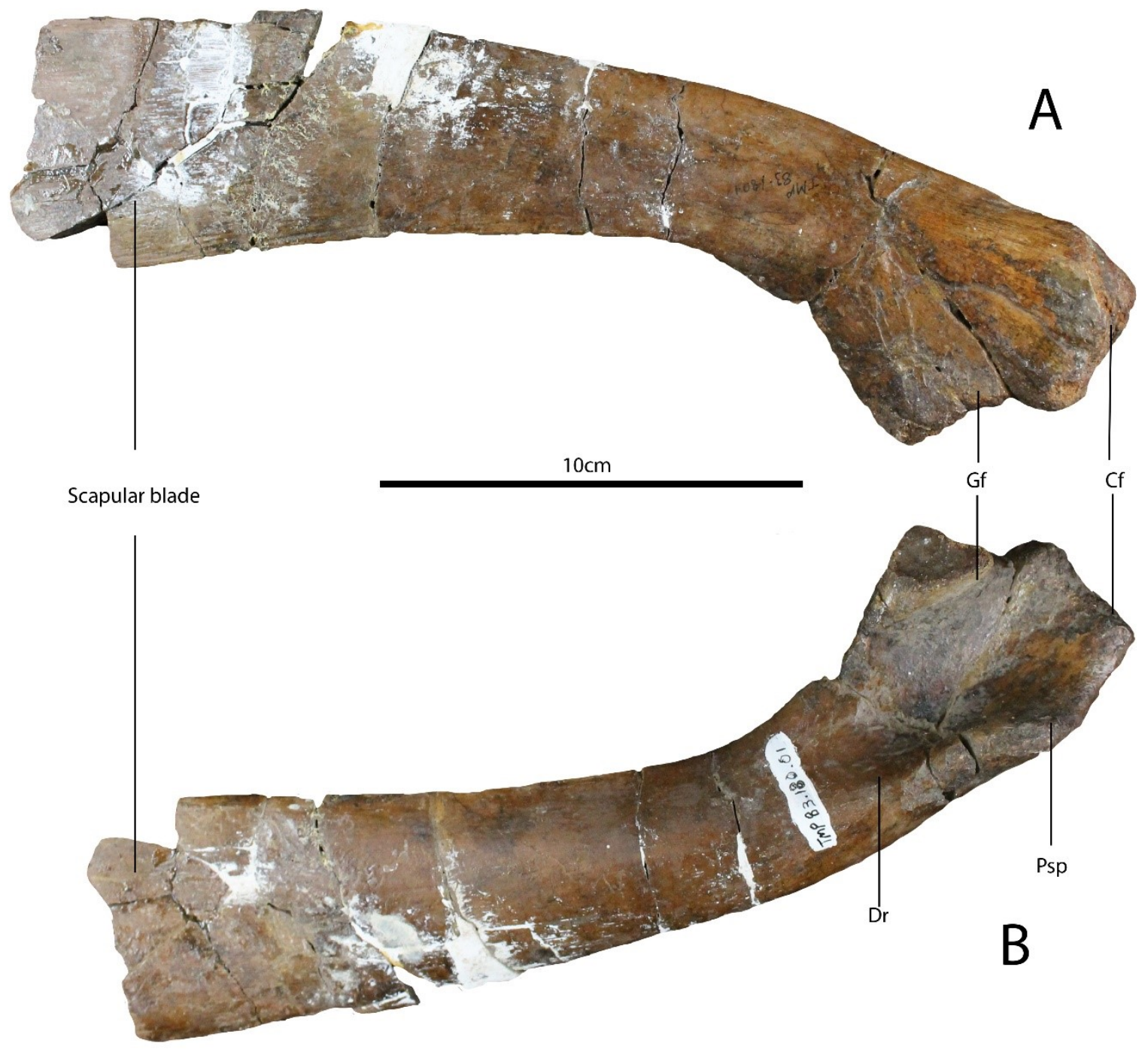

Figure 6.10: Left scapula of TMP 83.180.0001: Medial view (A) and lateral view (B). $\mathrm{Dr}=$ deltoid ridge; $\mathrm{Gf}=$ glenoid facet; $\mathrm{Psp}=$ Pseudoacromion process; $\mathrm{Cf}=$ coracoid facet 


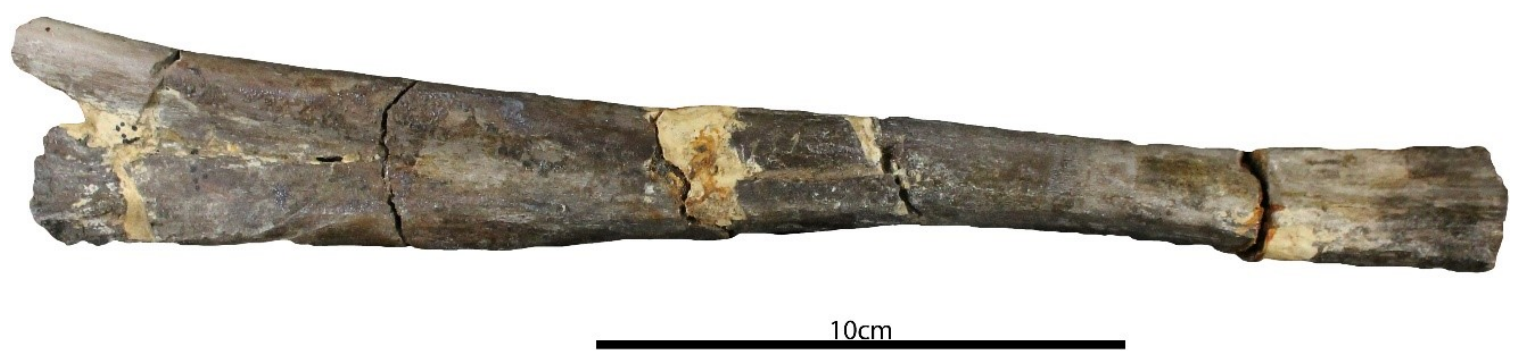

Figure 6.11: Ulna of TMP 83.180.0001 


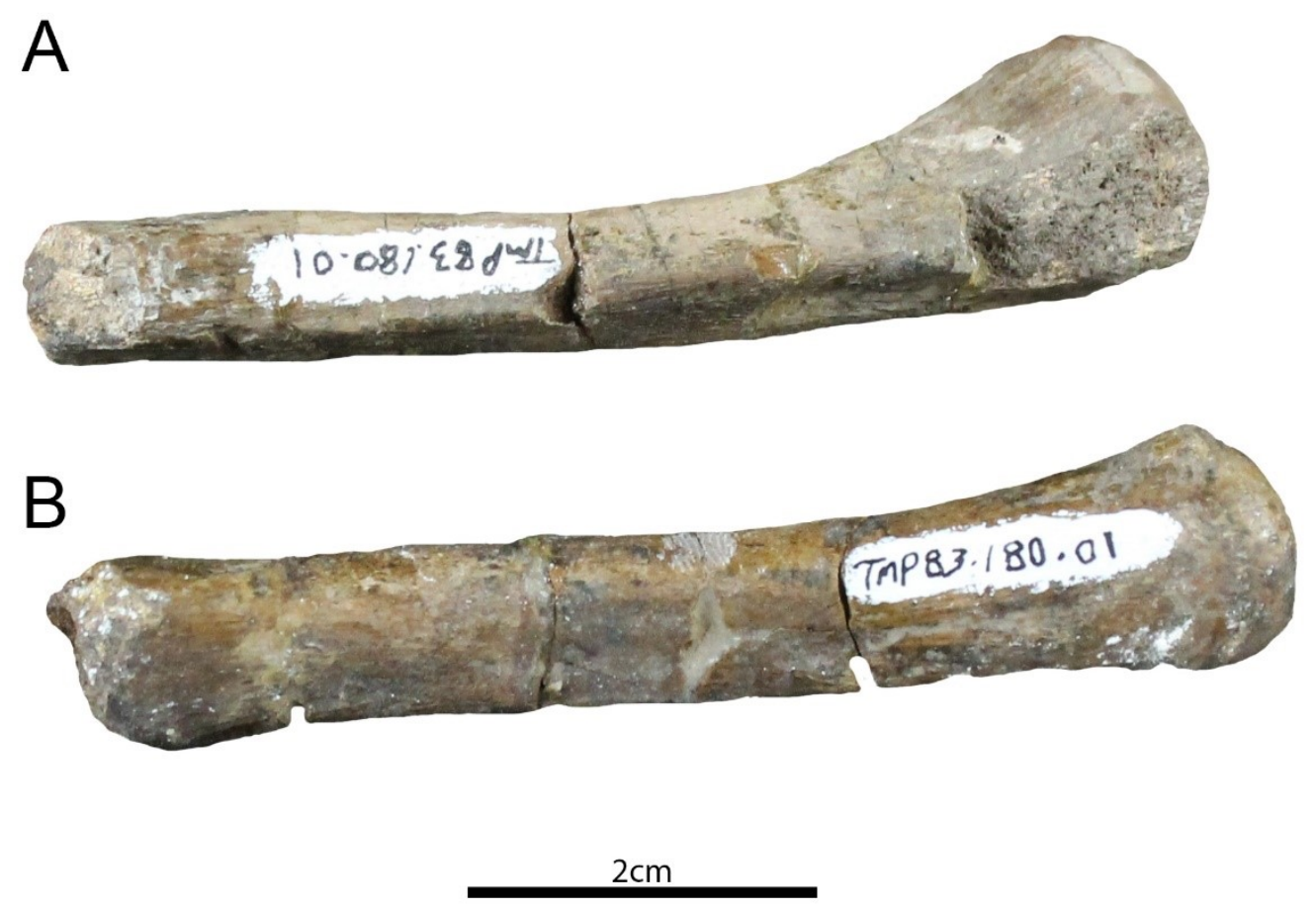

Figure 6.12: Metacarpals of TMP 83.180.0001. A= Metacarpal IV, B= Metacarpal III 


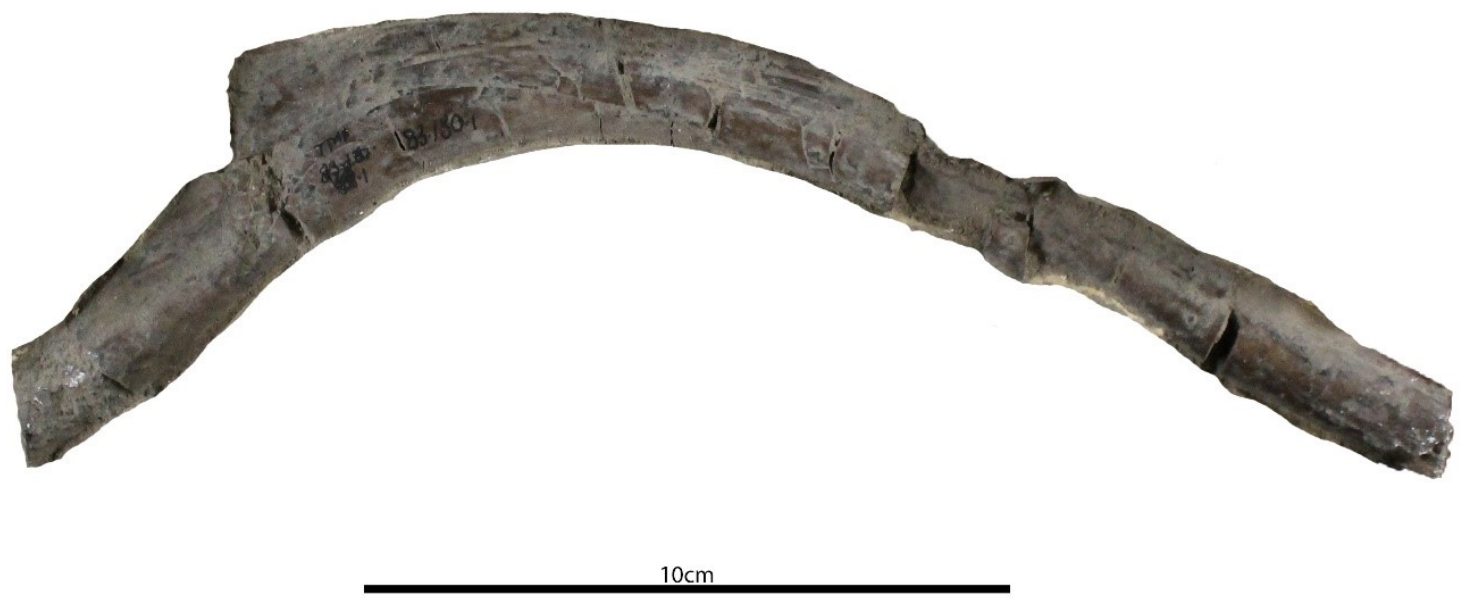

Figure 6.13: Left rib of TMP 83.180.0001 
A complete left, late juvenile-sized ilium is well preserved, with only the pubic peduncle missing (Fig. 6.14). The ilium is supported by a metal sheet glued to its lateral surface. The total length of the ilium is approximately $421 \mathrm{~mm}$; depth cannot be determined due to the missing pubic peduncle. The preacetabular process is strongly ventrally deflected. The supraacetabular process is not well-developed, swelling laterally and unbowed ventrally, indicative of its putative juvenile status (Guenther, 2009). The overall morphology of the supraacetabular process is asymmetrical with a pronounced caudally directed skew, and a U-shaped profile without a pronounced caudal margin. The ischiac peduncle preserves a bilobed morphology, with the cranialmost lobe being approximately $50 \mathrm{~mm}$ and the caudal lobe measuring approximately $40 \mathrm{~mm}$ in length. The post-acetabular process is completely preserved, and is slightly shorter in total length $(115 \mathrm{~mm})$ than that of the central plate length $(130 \mathrm{~mm})$. The postacetabular process terminates in a subcircular caudal margin, and is caudodorsally oriented in lateral view. The pronounced sacral ridge is confined to the dorsal margin and extends along the dorsal margin of the preacetabular process, bowing ventrally over the supra-acetabular process.

The largest individual element of the assemblage is a right ischium, likely from a subadult-sized individual (Table 6.2). The ischium has a complete ischial head and a shaft missing the distal end (Fig. 6.15). The dorsal margin of the iliac peduncle closely resembles that seen in CMN 58592.4, with a nearly rectangular profile. The ischium displays ontogenetically immature features including an open obturator foramen and a slender shaft region (Guenther, 2009). The ischium has a preserved shaft length of 521 


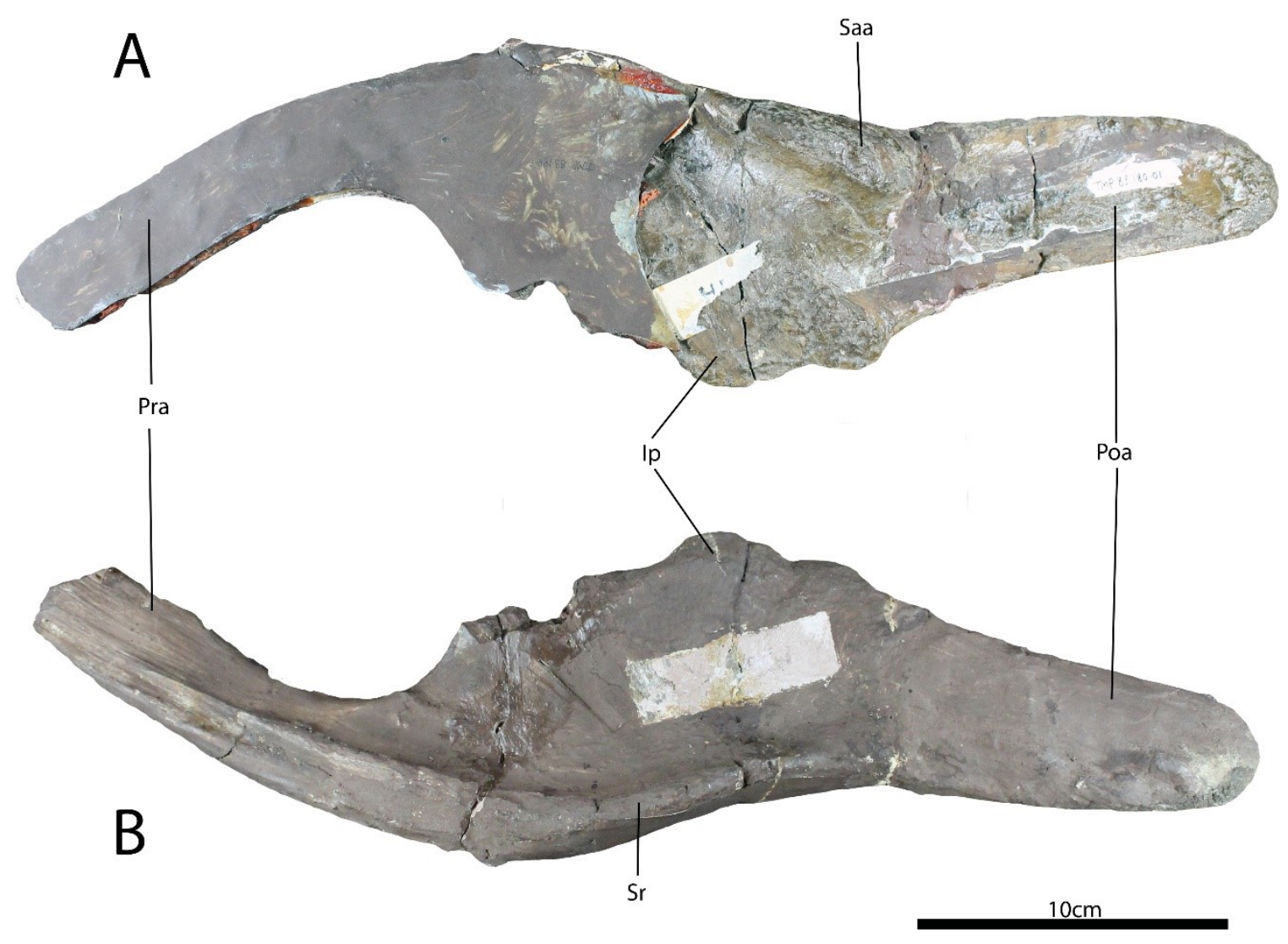

Figure 6.14: Left ilium of TMP 83.180.0001 in lateral (A) and medial (B) views. Pra=Pre-acetabular process; $\mathrm{Sr}=$ Sacral Ridge; $\mathrm{I} p=$ Ischiac peduncle; Saa=Supra-acetabular process; Poa $=$ Post-acetabular process 


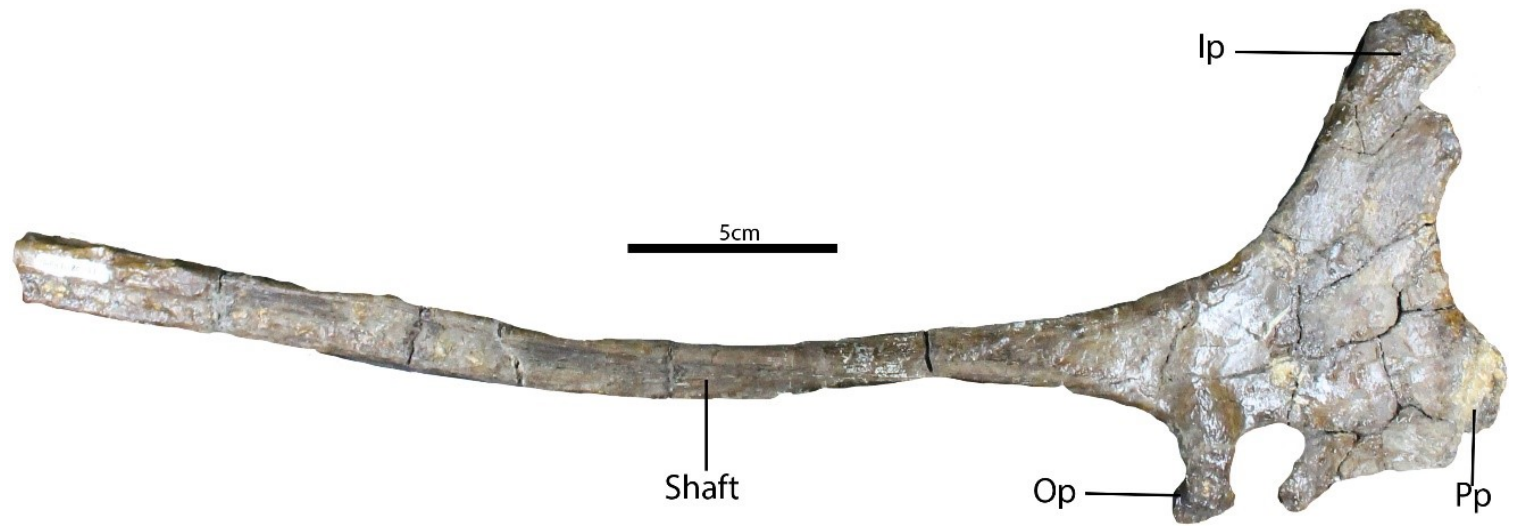

Figure 6.15: Ischium of TMP 83.180.0001. Op=Obturator Process; Pp=Pubic peduncle; $\mathrm{Ip}=$ Iliac Peduncle. 
$\mathrm{mm}$, and is approximately $78 \%$ the total length of CMN 58592.5. The dorsal margins of the iliac peduncle converge dorsally with no apparently dorsal curvature, and the pubic peduncle is wider than long. The dorsal margin of the pubic peduncle is dorsal relative to the dorsal margin of the shaft. The narrow, curved shaft that thins caudally and is bowed dorsally concave in the mid-shaft. The ischium probably did not have an ischial boot.

A late juvenile-sized left femur (Fig. 6.16) measuring $494 \mathrm{~mm}$ in total length has a straight lateral profile and a broken fourth trochanter. The proximal trochanters and distal condyles are completely preserved and typical of hadrosaur femora, with a significant craniocaudal expansion (Horner et al., 2004).

A late juvenile to subadult-sized left tibia (Fig. 6.18) is possibly associated with the preserved femur based on similar proportions between these bones. The element measures $404 \mathrm{~mm}$ in maximum length (from the medial malleolus to the lateral condyle). The tibia is straight, with a greater expansion in the proximal end than the distal end. The cnemial crest extends to the cranial surface of the tibia but is otherwise obscured by the plaster jacket.

A right fibula (Fig. 6.17) has a length of $466 \mathrm{~mm}$. The element is complete, albeit heavily fractured. The shaft is nearly straight with both ends being expanded and flattened. The proximal head exhibits higher degree of expansion and fits into the complimentary cnemial crest of tibia from the assemblage.

A well-preserved metatarsal III (Fig. 6.19) measures $160 \mathrm{~mm}$ in maximum length and has an approximately $26 \mathrm{~mm}$ mid-length thickness. It has the typical hadrosaur morphology with a subrectangular distal end and notch for the insertion of metatarsal II. 

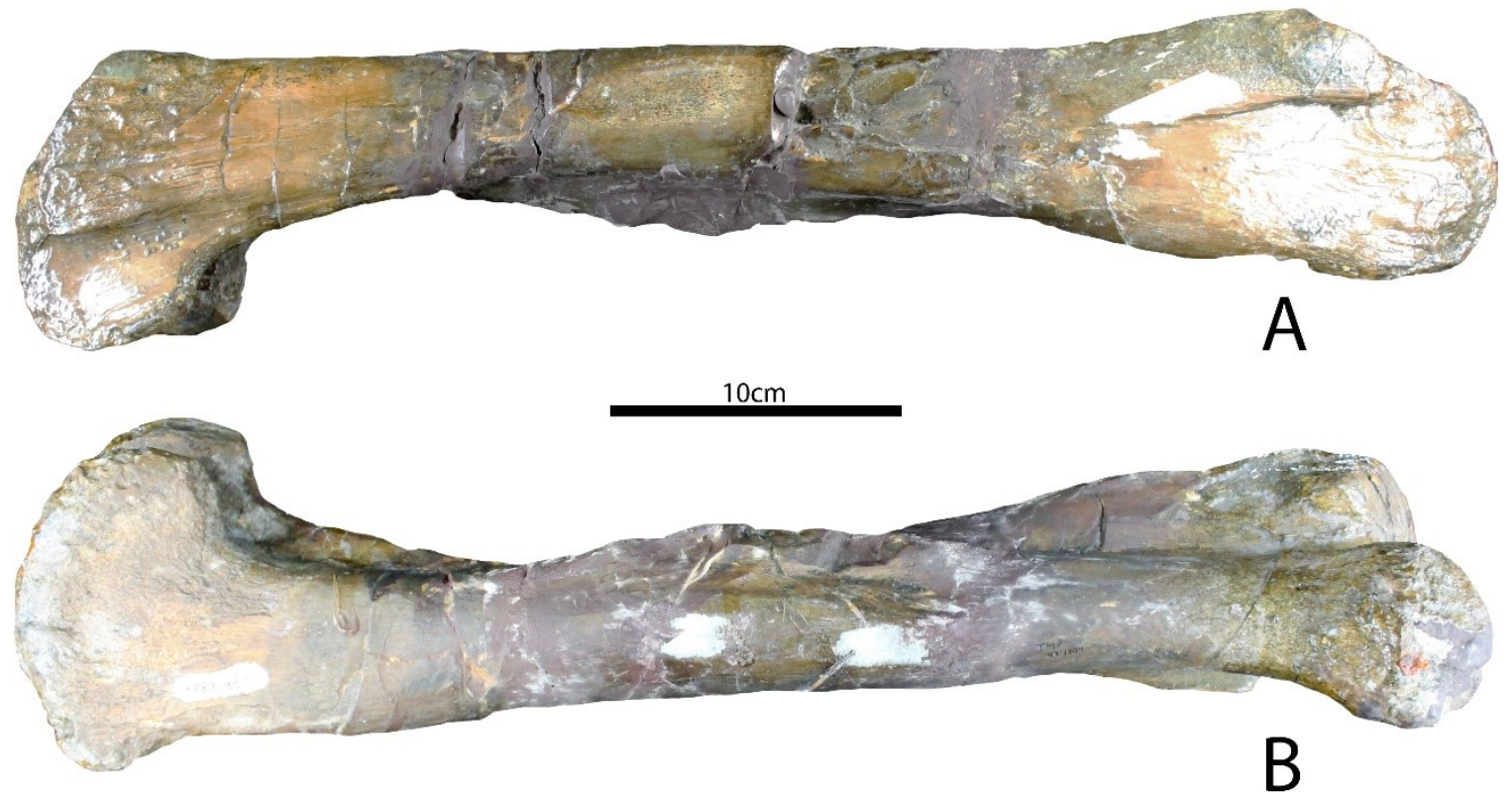

Figure 6.16: Left femur of TMP 83.180.0001 


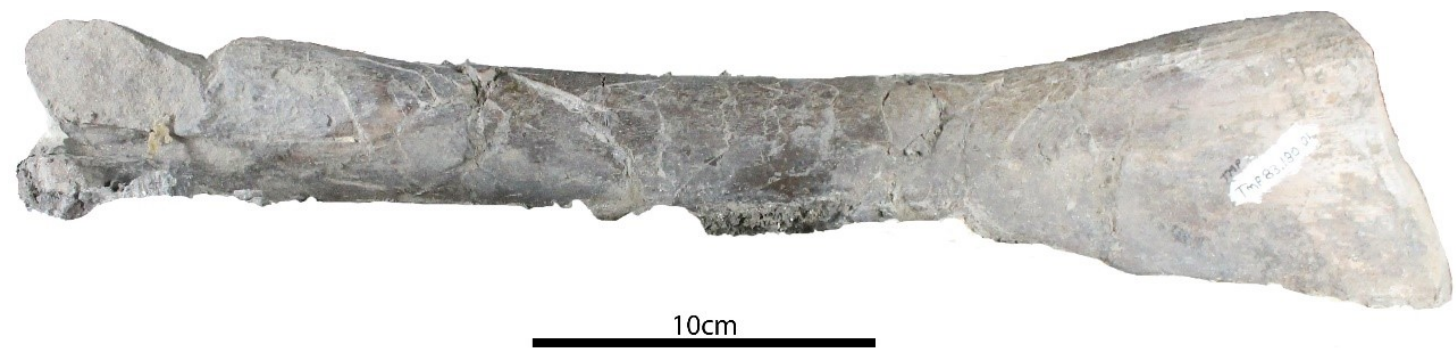

Figure 6.17: Left tibia of TMP 83.180.0001 


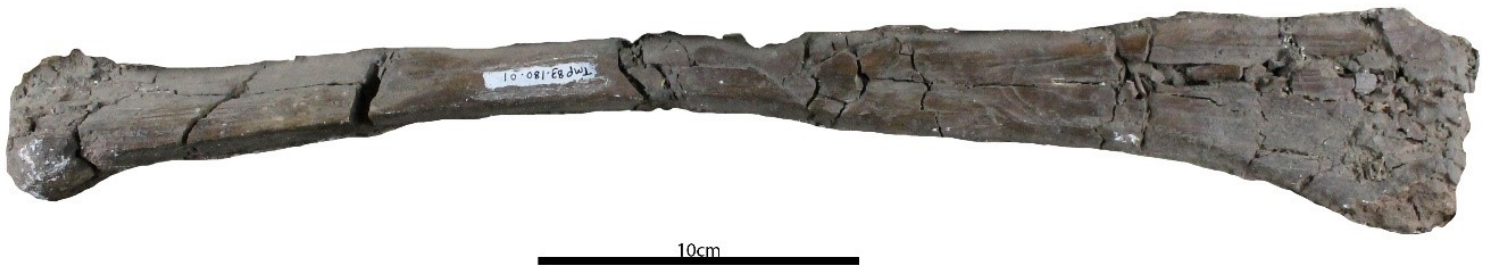

Figure 6.18: Left Fibula of TMP 83.180.0001. 


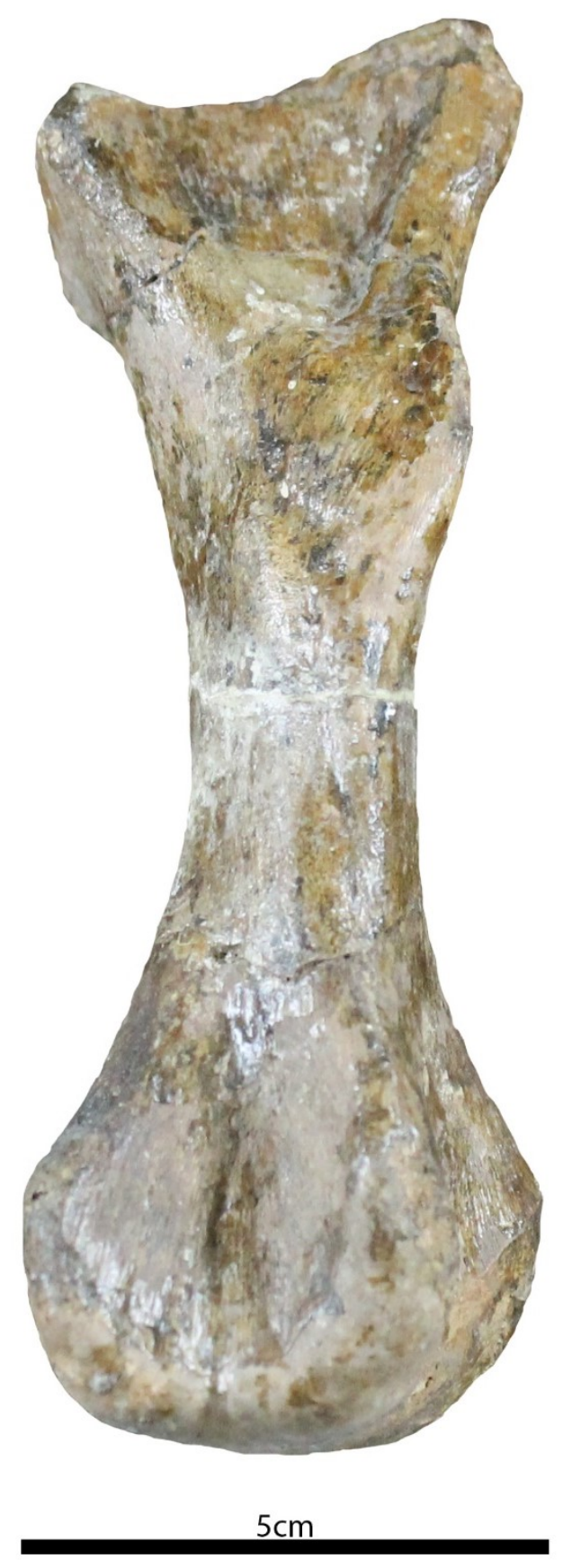

Figure 6.19: Metatarsal III from TMP 83.180.0001 


\section{Additional material}

TMP 2010.119.0018 (Fig. 6.20) is an incomplete quadrate with only the proximal articular surface preserved. The anterior portions of the lateral condyle are damaged and the degree of offset of the medial condyle and overall morphology cannot be confirmed.

Weathering has left the original proportions of the two vertebrae catalogued together as CMN 9955 unidentifiable as to body position (Fig. 6.21). The larger vertebra measures $115 \mathrm{~mm}$ dorsoventrally, while the better preserved, shorter vertebra measures $69 \mathrm{~mm}$ craniocaudally.

TMP 2014.012.0019 (Fig. 6.22) is a complete late juvenile-sized humerus with a total length of humerus $373 \mathrm{~mm}$. The posterior margin is highly fractured from modern exposure. The deltopectoral crest (total preserved length approximately $177.5 \mathrm{~mm}$ ) terminates midshaft. The condyles are damaged by modern erosion.

TMP 2010.120.002 (Fig. 6.23) is a well-preserved early-juvenile-sized humerus, lacking the humeral head. It resembles TMP 2014.012.0019, but with a total length of $179 \mathrm{~mm}$, it is $52 \%$ shorter. The deltopectoral crest is $88.9 \mathrm{~mm}$ in length, making up approximately one-half its total length. The ulnar condyle is larger than the radial condyle in overall dimensions, and they are separated by a relatively shallow, wide depression.

TMP 2010.120.0008 is a complete left, late juvenile-sized ilium with a total length of $699 \mathrm{~mm}$ (Fig.6.24). The specimen is still partially embedded in a half plaster jacket with a grey, medium- to-coarse-grained sandy matrix completely obscuring the ischiac peduncles and postacetabular process. The pre-acetabular process deflects ventrally as in all hadrosaurids (Prieto- Márquez, 2010). The supra-acetabular is robust 


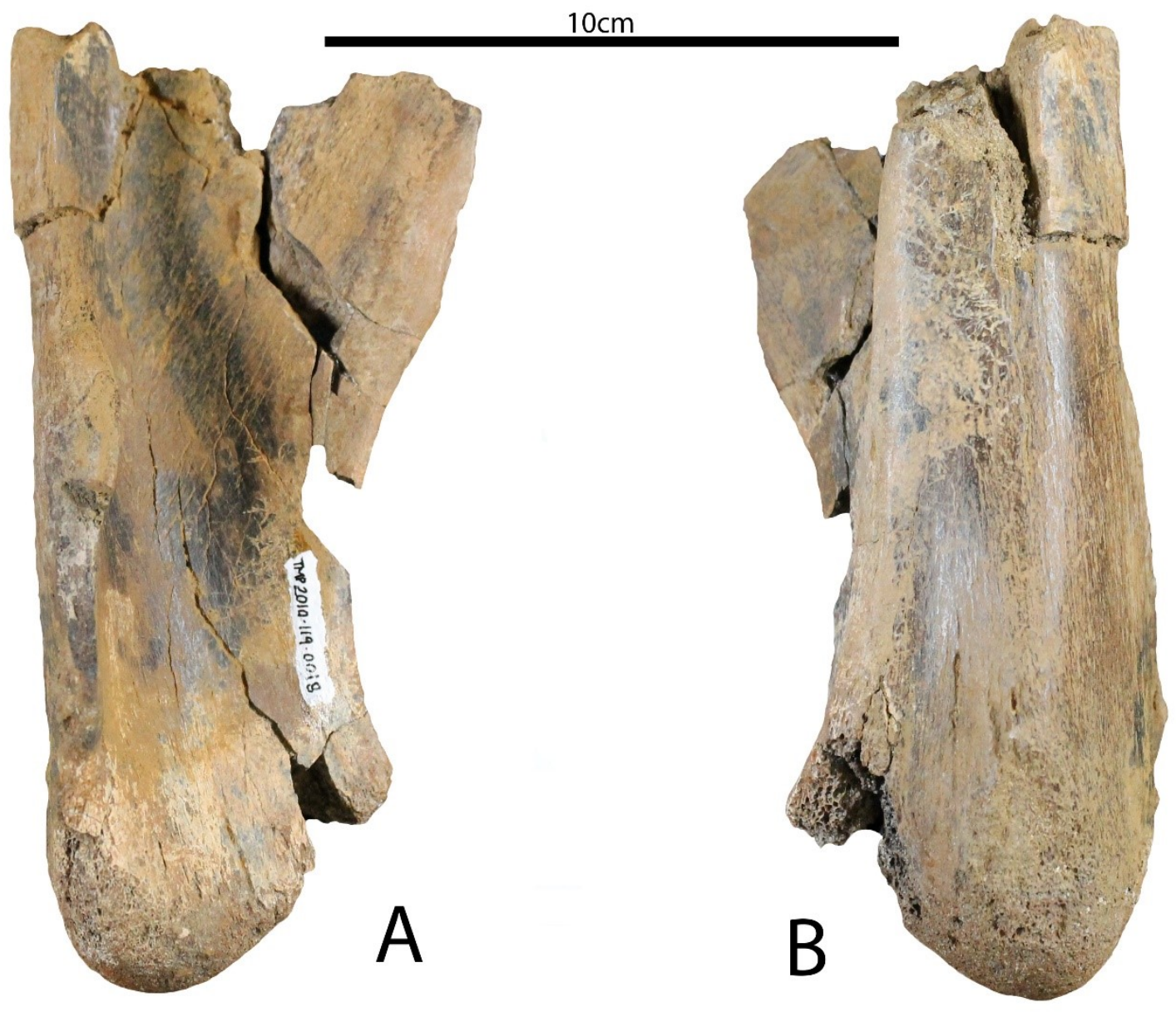

Figure 6.20: Left partial quadrate from TMP. 2010.119.0018. Lateral view (A) and medial view (B). 


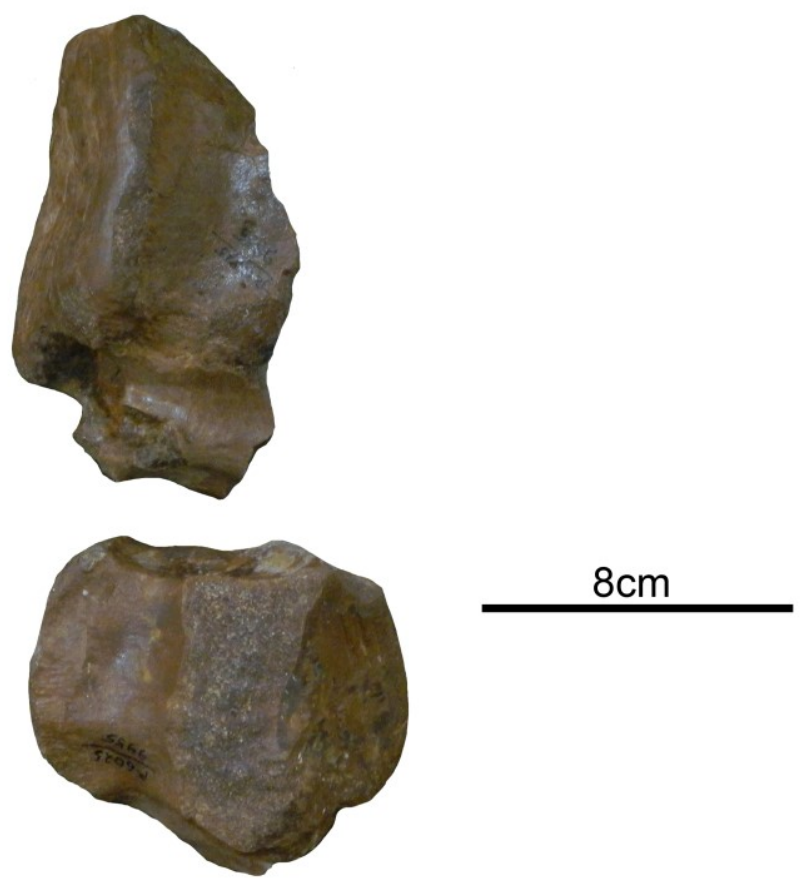

Figure 6.21: Disarticulated and heavily weathered vertebrae of CMN 9955 


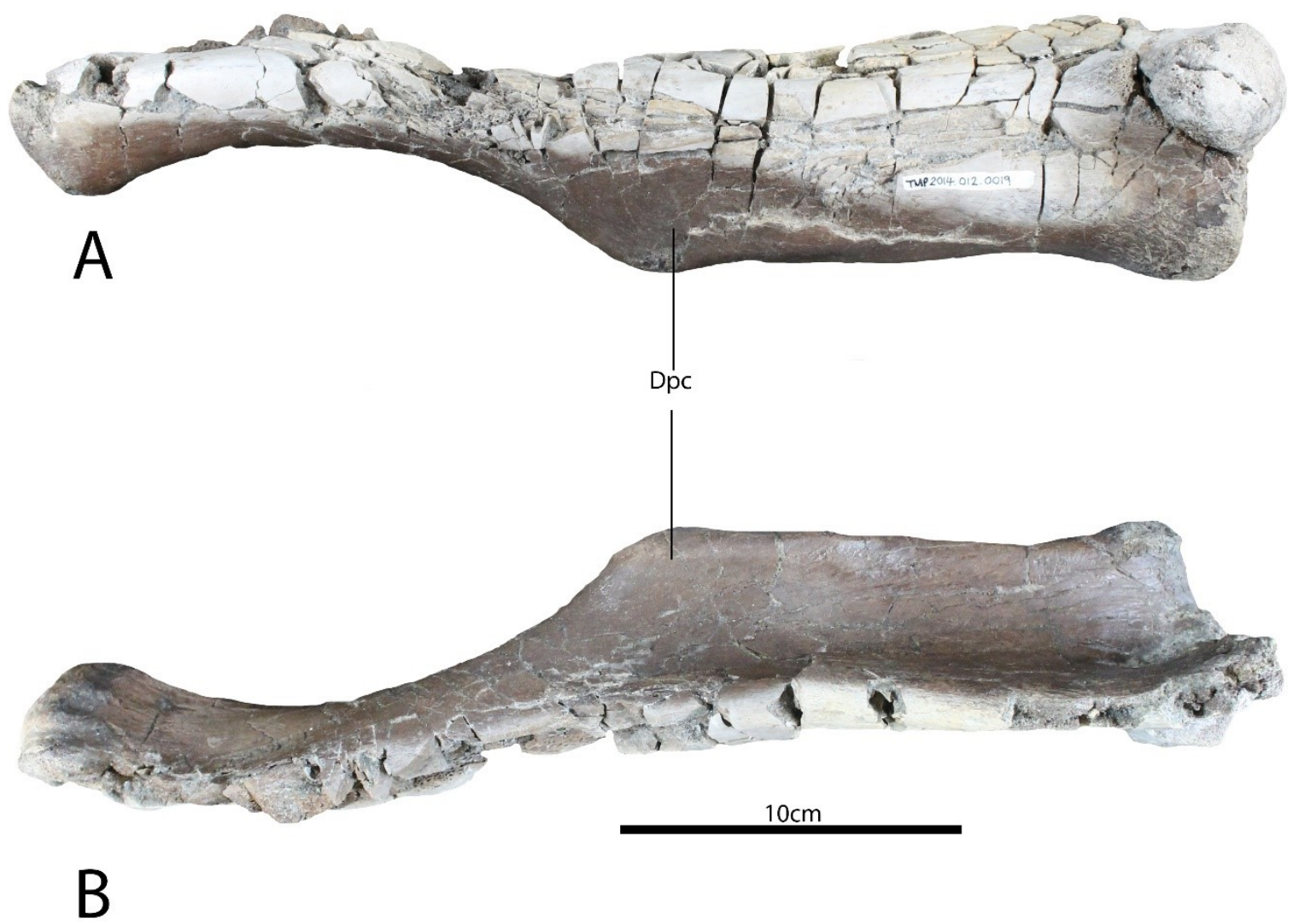

Figure 6.22: Left humerus from TMP 2014.012.0019. Medial view (A) and lateral view (B). Dpc=Deltopectoral crest 


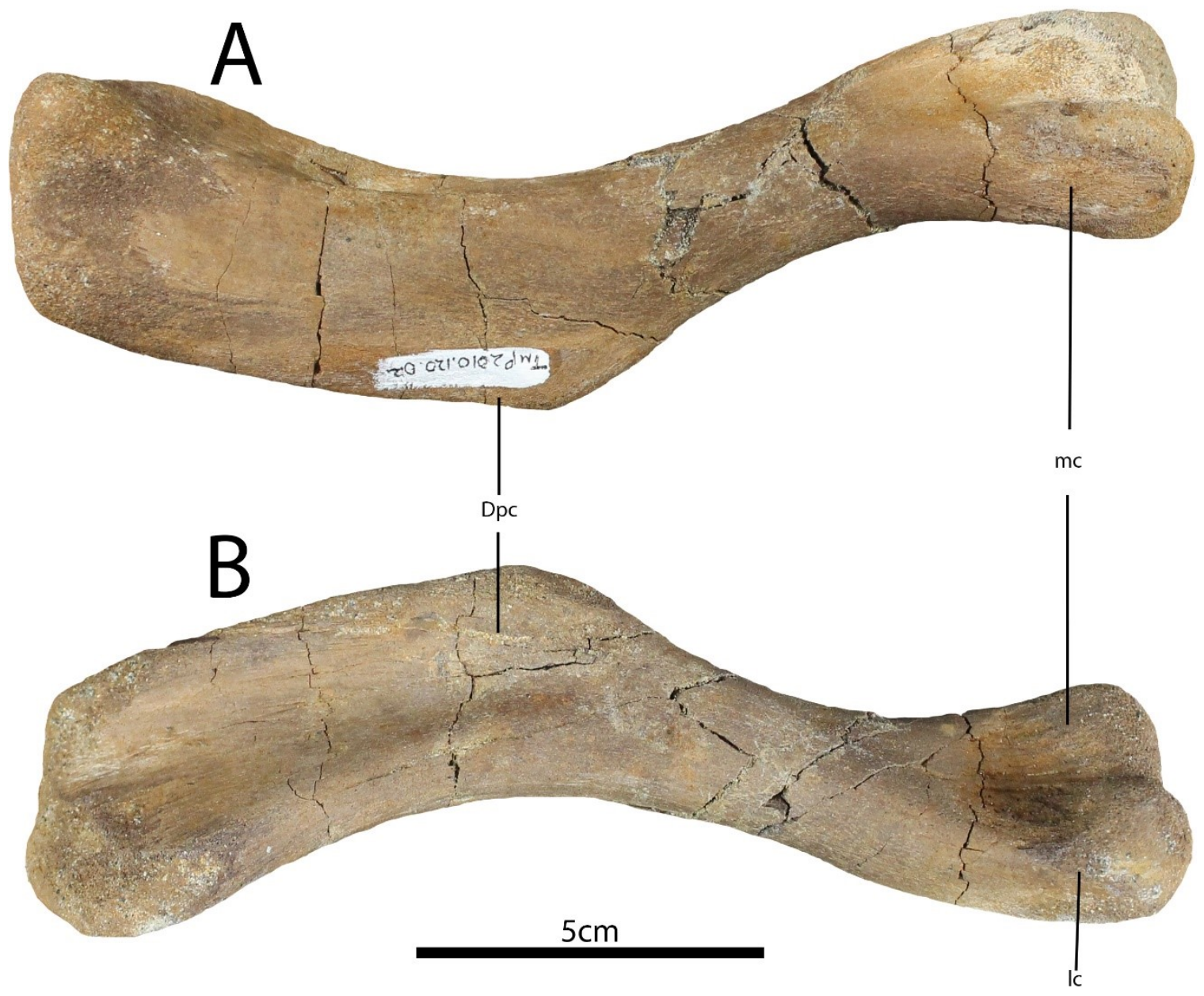

Figure 6.23: Left humerus from TMP 2010.120.002. Lateral view (A) and medial view (B). Dpc $=$ Deltopectoral Crest, $\mathrm{mc}=$ medial condyle, $1 \mathrm{c}=$ lateral condyle. 


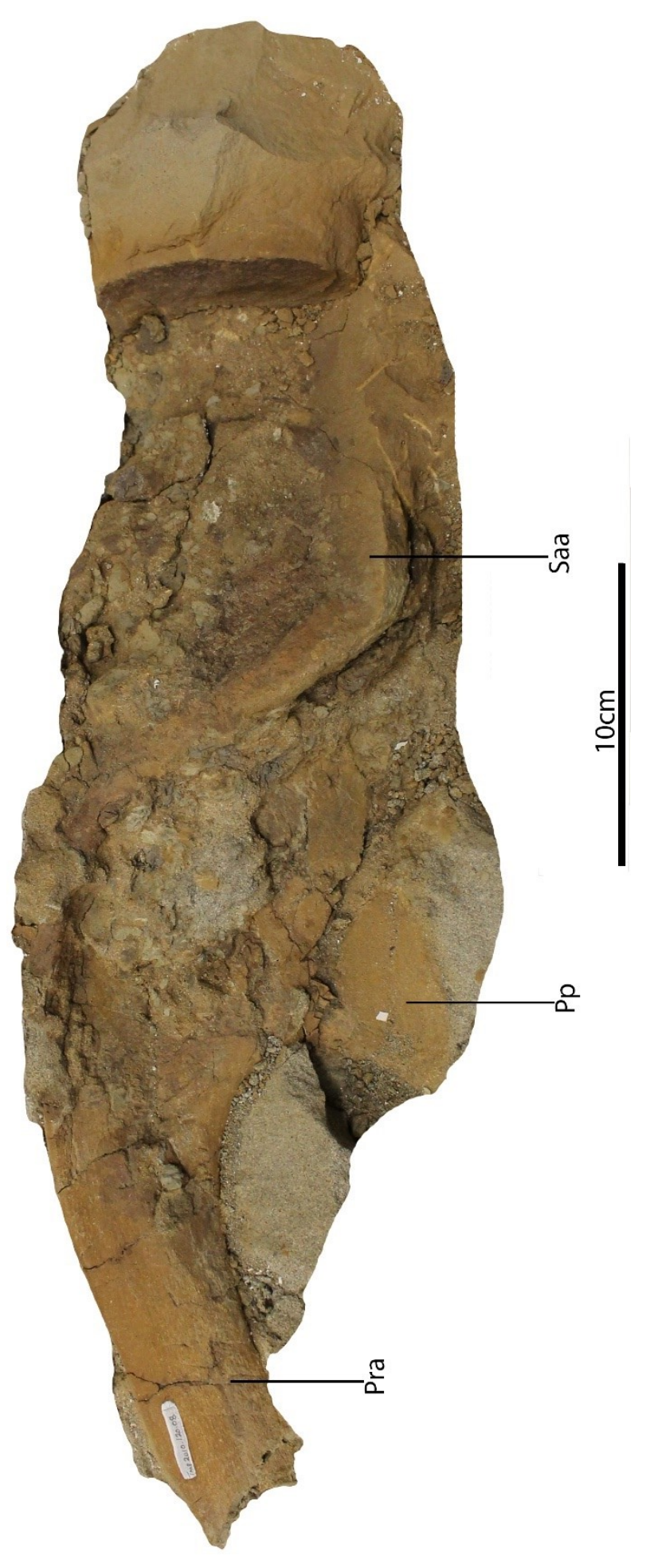

Figure 6.24: Left ilium of TMP 2010.120.0008 in lateral view. Pra=Pre-acetabular Process; Pp=Pubic Peduncle; Saa=Supra-acetabular process. 
and displays a U-shaped lateral profile, where exposed. The ilium is dorsally concave above the supraacetabular process. It overlaps the dorsal portion of the ischiac process giving it a sinusoidal lateral profile. The pubic peduncle has a triangular profile, tapering to its distal apex.

TMP 87.47 .3 (Fig. 6.25) is a distal femoral end measuring approximately $232 \mathrm{~mm}$ both anteroposteriorly and proximodistally (Fig. 63). Both of the large, cranially expanded condyles are present and well preserved.

TMP 87.64 .3 (Fig. 6.26) is a fibular articular proximal end, probably a proximal head, measuring $110 \mathrm{~mm}$ wide and $83 \mathrm{~mm}$ tall proximodistally.

Three partial adult metatarsals from digits II, III and IV (CMN 9951) are preserved within part of a plaster jacket along with a single phalanx associated with digit IV (Fig 6.27; Fig 6.28; Table 6.2; Table 6.3). The proximal portions of the metatarsals are not preserved. These metatarsals display typical hadrosaurid morphology. Metatarsal II is expanded craniodorsally at both of its ends, is more dorsoventrally compressed than the other metatarsals, and it splays outward from the midline of the foot. Metatarsal III possesses a subrectangular distal end, is nearly straight, and is the most robust of the metatarsals. Only the distal end of Metatarsal IV is preserved. It has a similar subrectangular shape as the distal ends of the other metatarsals, but not as expanded as Metatarsal III.

Three loose phalanges are associated with the articulated Digit IV (Fig 6.28). All but one phalanx are highly dorsoventrally compressed, with overall dimensions being puck shaped. The smallest of these phalanges is recognizable as a pedal ungual based on 


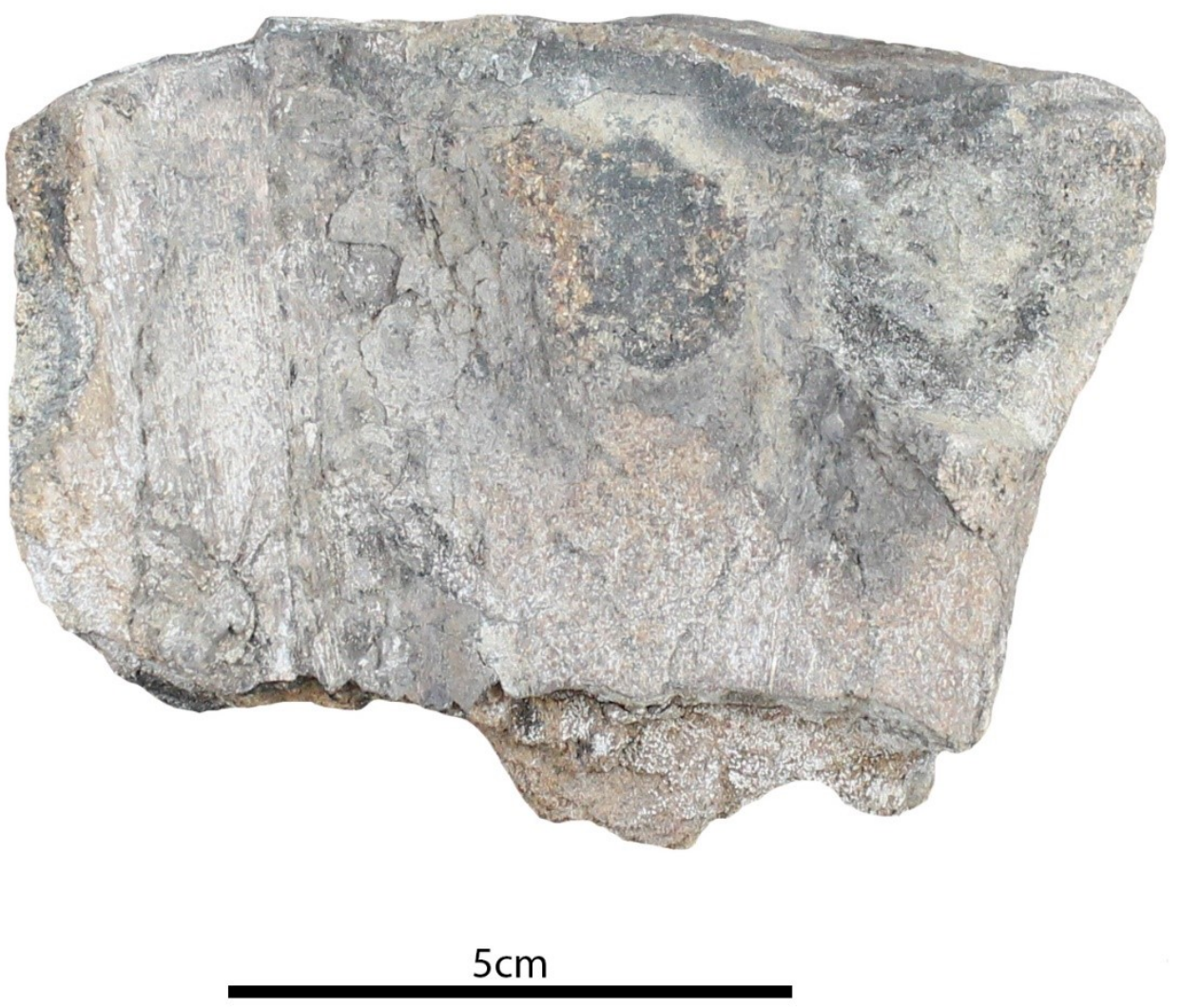

Figure 6.25: Fibular head from TMP 87.064.0003 


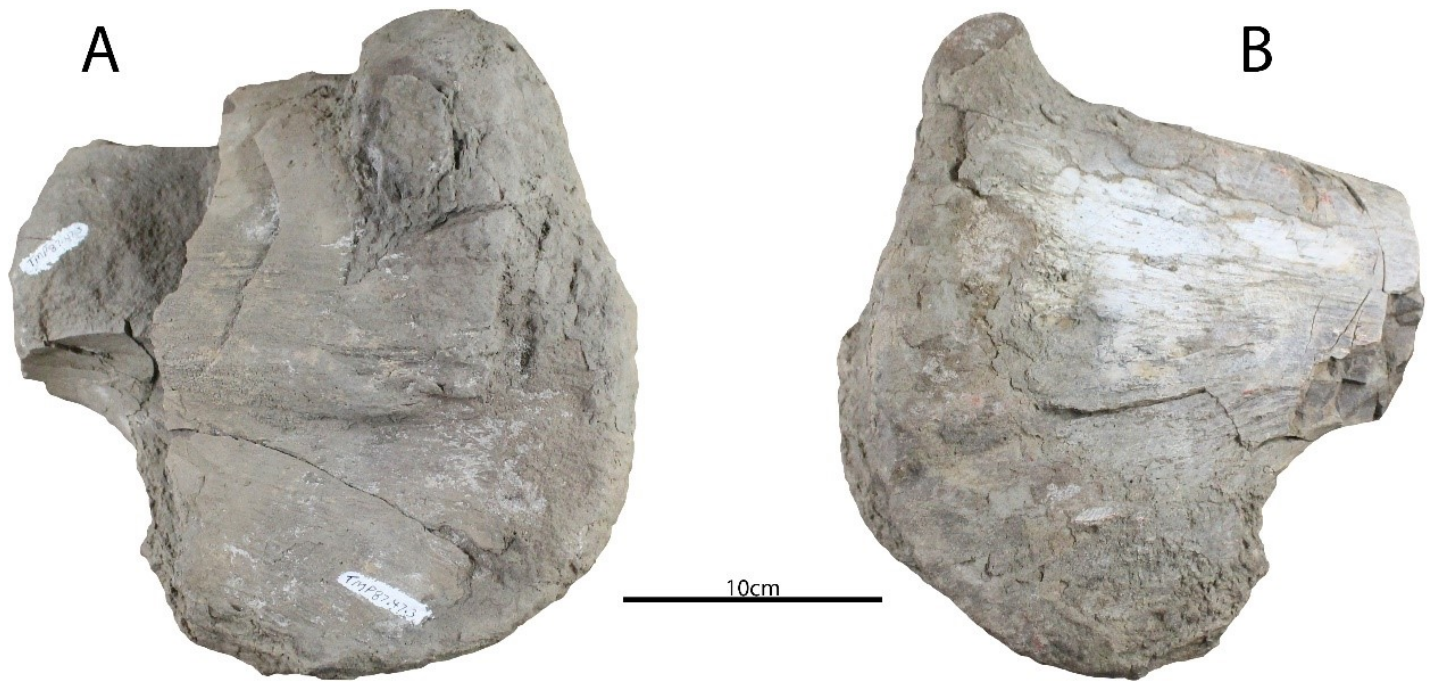

Figure 6.26: Femoral head from TMP 87.047.0003 

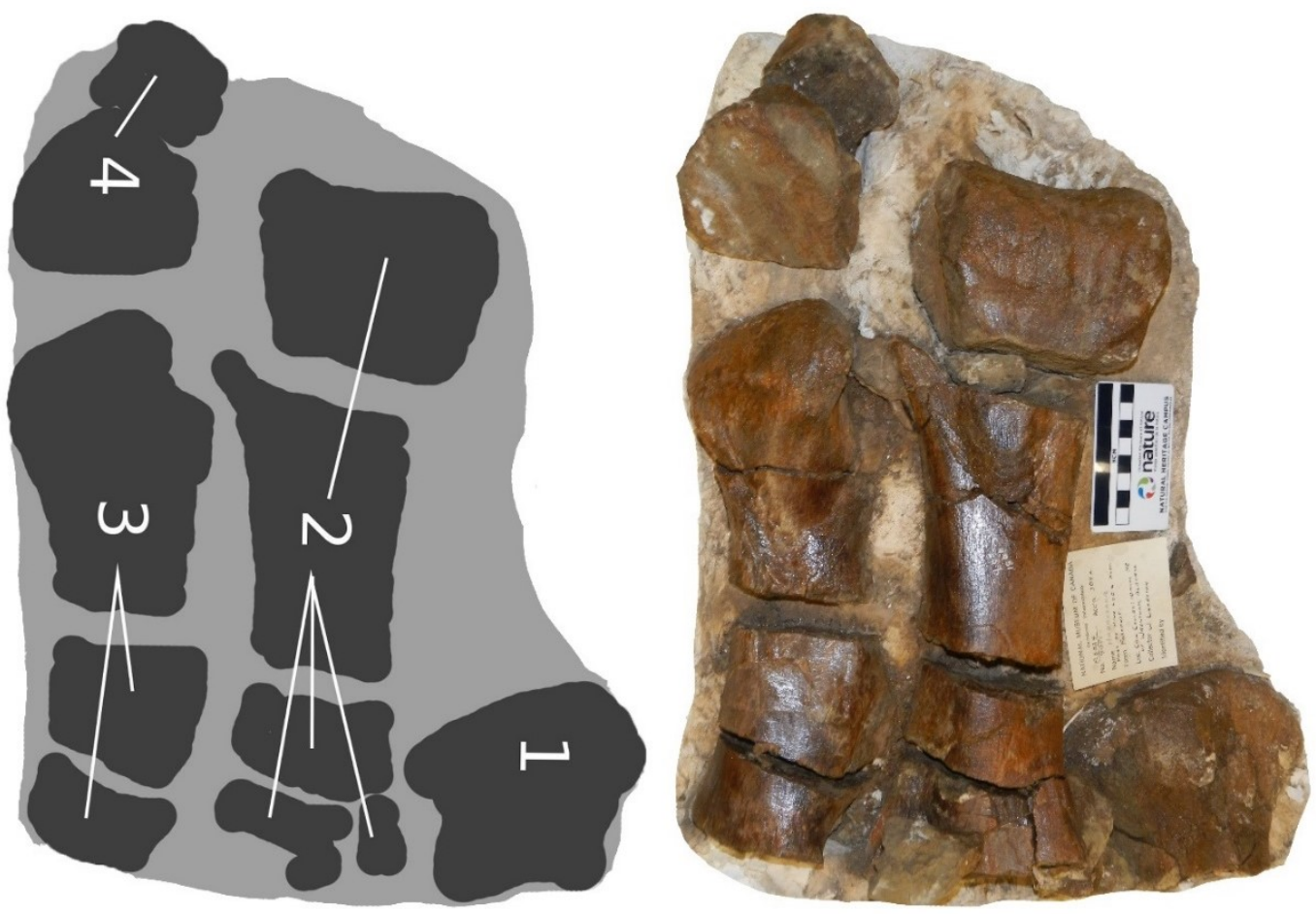

Figure 6.27: Left hind foot CMN 9951 pedal elements described from CMN 58592.

Provided by Bedek 2015. Element $1=$ metatarsal II, Element $2=$ metatarsal III, Element $\mathrm{III}=$ metatarsal and proximal tarsal IV 
Table 6.2: Measurements of individual elements of CMN 9951. Length=proximodistal measurement, width= mediolateral (top row) and craniocaudal (bottom row) measurements. Only mediolateral was taken for digit II as it was too damaged to handle outside of its jacket.

\begin{tabular}{|l|l|l|}
\hline Element & Total Length (mm) & Max. Width (mm) \\
\hline 1 & 108 & 153 \\
\hline 2 & 324 & 133 \\
\hline 3 & & 77 \\
\hline 4 & 264 & 99 \\
\hline & & 78 \\
\hline & & 95 \\
\hline
\end{tabular}



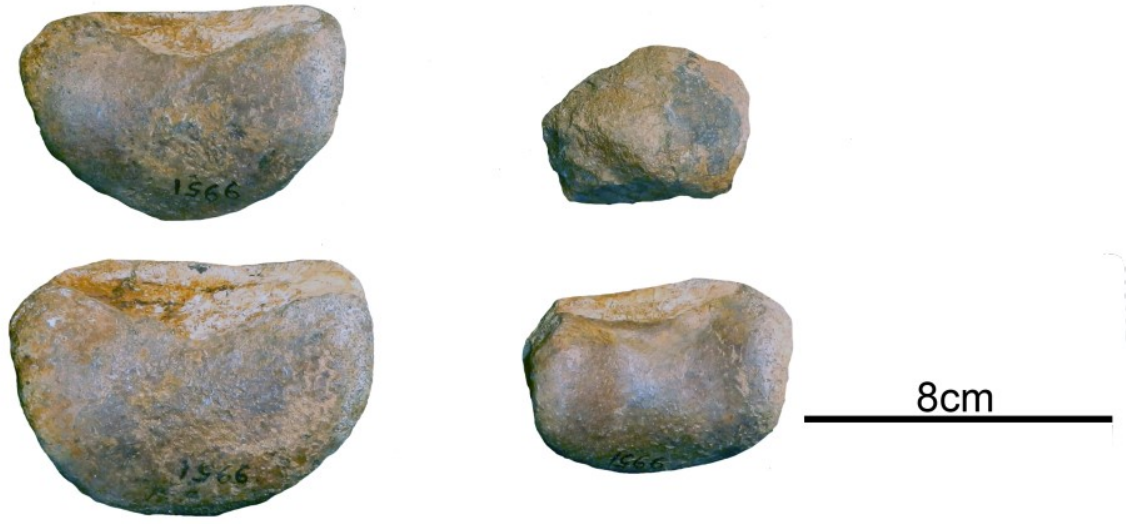

Figure 6.28: Loose podials of CMN 9951 from Digit IV. Bottom left= proximal, top left $=$ sub-proximal, bottom right $=$ sub-distal, top right $=$ distal (pedal ungual) . 
Table 6.3: Individual element measurements for CMN 9951. Height= proximodistal measurement, width $=$ mediolateral measurement and length $=$ craniocaudal measurement.

\begin{tabular}{|c|c|c|}
\hline Element & Character & Measurement (mm) \\
\hline \multirow[t]{3}{*}{ Proximal } & Height & 54 \\
\hline & Width & 87 \\
\hline & Length & 60 \\
\hline \multirow[t]{3}{*}{ Sub-proximal } & Height & 52 \\
\hline & Width & 80 \\
\hline & Length & 33 \\
\hline \multirow[t]{3}{*}{ Sub-distal } & Height & 43 \\
\hline & Width & 67 \\
\hline & Length & 37 \\
\hline \multirow[t]{3}{*}{ Distal } & Height & 44 \\
\hline & Width & 54 \\
\hline & Length & 22 \\
\hline
\end{tabular}




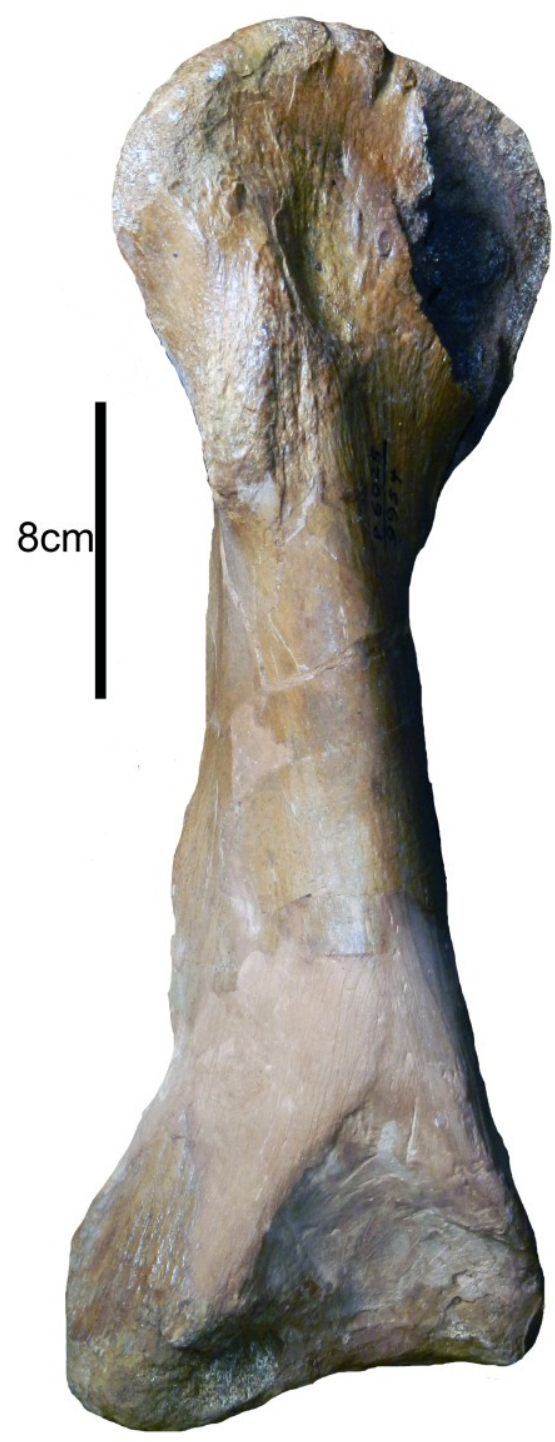

Figure 6.29: Metatarsal III of CMN 9954. 
its tapered lateral margins and overall hoof-like morphology. However, weathering has destroyed any distinguishing ridges present on the ventral side of this ungual.

CMN 9954 (Fig. 6.29) is a well-preserved adult-sized hadrosaur metatarsal III with a maximum length of $349 \mathrm{~mm}$, a minimum diameter of $122 \mathrm{~mm}$, and a minimum circumference of $214 \mathrm{~mm}$. There is some damage to the distal articular surface. It has a typical hadrosaur metatarsal III morphology with craniocaudally expanded dorsal and ventral surfaces, a notch on the medial side for the insertion of metatarsal II, and a dorsoventrally straight profile.

\section{3: Phylogenetic Analyses}

To determine the phylogenetic placement of the hadrosaur material from the Foremost Formation, taxonomically informative (i.e, CMN 58592 and TMP 83.180.0001) specimens were phylogenetically analyzed. CMN 58592 is the most complete specimen, representing one adult-sized individual. The elements from this specimen were scored into the data matrices of Prieto- Márquez et al. (2016) and Wu and Godefroit (2012), and run in two separate phylogenetic analyses. The data matrix of $\mathrm{Wu}$ and Godefroit (2012) is more restricted in terms of number of taxa and characters included, thus allowing for a general phylogenetic placement of CMN 58592 without a more inclusive resolution.

Prieto- Márquez (2016) was chosen as it is currently the most comprehensive phylogeny of hadrosaurs, allowing for higher resolution. Neither of the matrices was modified beyond the addition of the CMN 58592 data.

CMN 58592 was coded using Mesquite v 3.04 build 725 (Maddison and Maddison, 2001) (see appendix F for attached nexus files). The modified $\mathrm{Wu}$ and 
Godefroit (2012) data matrix included 26 taxa and 108 equally weighted characters, that were analyzed in PAUP 4.0b10 (Swofford, 2002). The modified data matrix of PrietoMárquez (2016) included 62 taxa and 273 equally weighted, unordered characters that were analyzed using TNT 1.1 (Goloboff et al., 2008) as used by the authors of this study. A heuristic search of 10,000 replicates using random addition sequences was performed, with branch swapping by tree bisection-reconnection holding ten trees per replicate following the methodology of Prieto- Márquez et al. (2016).

TMP 83.180.0001 includes multiple elements collected from what appears to be a monospecific bonebed. Following the example of other such bonebed analyses, the material is assumed to represent a single taxon, and, thus, phylogenetically informative elements (dentary (Fig 6.13); ilium (Fig 6.19); ischium (Fig 6.20); and scapula (Fig 6.15)) were grouped together as one operational taxonomic unit (OTU), coded and analyzed as per the previous analyses of CMN 58592. TMP83.180.0001 was also analyzed using the matrix provided by Prieto- Márquez, 2016 using the same parameters as the CMN 58592 analyses.

\section{4: Results}

The $\mathrm{Wu}$ and Godefroit (2012) analysis of CMN 58592 recovered 42 best trees of 191 steps each. The strict consensus tree (Fig. 6.30) has a Consistency Index $=0.63$; Retention Index $=0.82$ and Rescaled Consistency Index of 0.51 . The taxon represented by CMN 58592 was recovered in a polytomy as the sister taxon to the other members of Hadrosauridae (Saurolophinae + Lambeosaurinae) (Fig. 30). The Prieto- Márquez et al. (2016) analysis of CMN 58592 returned 56 trees of 900 steps. The strict consensus tree (Fig. 6.31) had a Consistency Index of 0.42, Retention Index of 0.77 and a Rescaled 
Consistency Index of 0.33 . The taxon represented by CMN 58592 was recovered as a basal hadrosauroid outside of Hadrosauridae, as the sister taxon with the Appalachian early Campanian hadrosauroid Lophorhothon atopus (Fig. 6.31). The CMN 58592 taxon status is supported by two unambiguous characters; Ch. $240(0 \rightarrow 1$; (caudodorsally oriented dorsal margin of the postacetabular process is positioned anterior relative to the acetabular margin); and Ch. $254(0 \rightarrow 1$; (the distal margin of the iliac peduncle of the ischium has a slight curvature in the caudodorsal corner).

The Wu and Godefroit (2012) analysis of TMP 83.180.0001 produced a strict consensus tree which had a Consistency Index of 0.70, a Rescaled Consistency Index of 0.61, and Retention Index of 0.87 (Fig. 6.32). TMP 83.180.0001 was recovered with the same topology as the analysis of CMN 58592 (Fig 6.32). The Prieto- Márquez et al. (2016) analysis of TMP 83.180 .0001 returned 56 best trees of 900 steps each. The strict consensus tree had a Consistency Index of 0.420 , Retention Index of 0.774 , and a Rescaled Consistency Index of 0.327 (Fig. 6.33). This analysis recovered the TMP 83.180.0001 as the sister taxon to the UTEP Big Bend OTU of Texas and the South American hadrosaurs Willinaqake salitralensis and Secernosaurus koeneri (Fig 6.33) This grouping is supported by a single synapomorphy, Character $235(0 \rightarrow 1)$, the postacetabular process nearly as long as the central plate, ratio greater than 0.80 , but less than 1.1. Autapomorphies supporting the TMP 83.180.0001 OUT are as follows; Ch. 226 


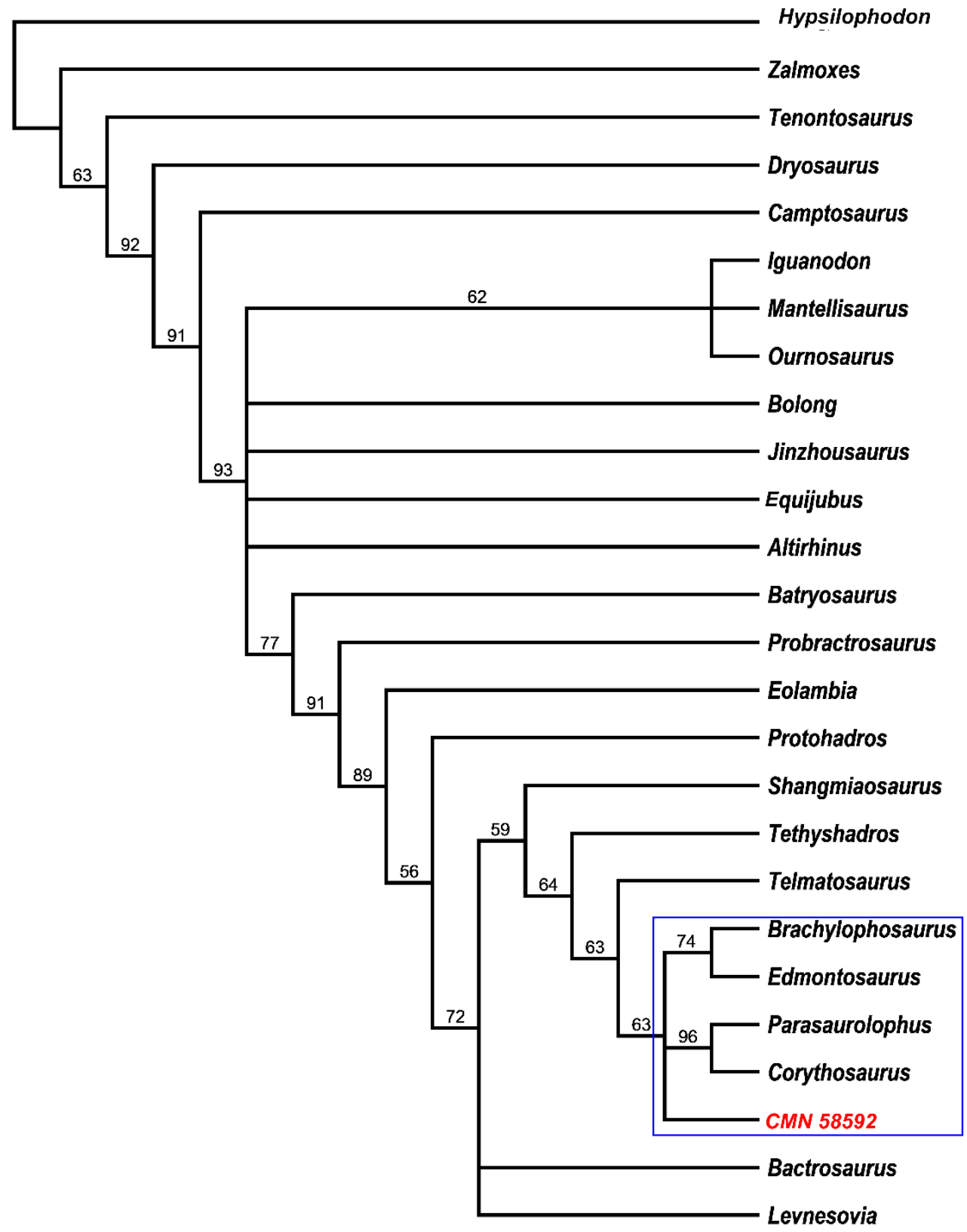

Figure 6.30: Strict Consensus tree of 42 trees from the matrix of $\mathrm{Wu}$ and Godefroit, 2012. CMN 58592 is shown to be allied within the clade Hadrosauridae. Bootstrap values are displayed above nodes. This analysis recovered 42 best trees of 191 steps each, a Consistency Index $=0.63$; Retention Index $=0.82$ and Rescaled Consistency Index of 0.51. The blue box encompasses Hadrosauridae. 


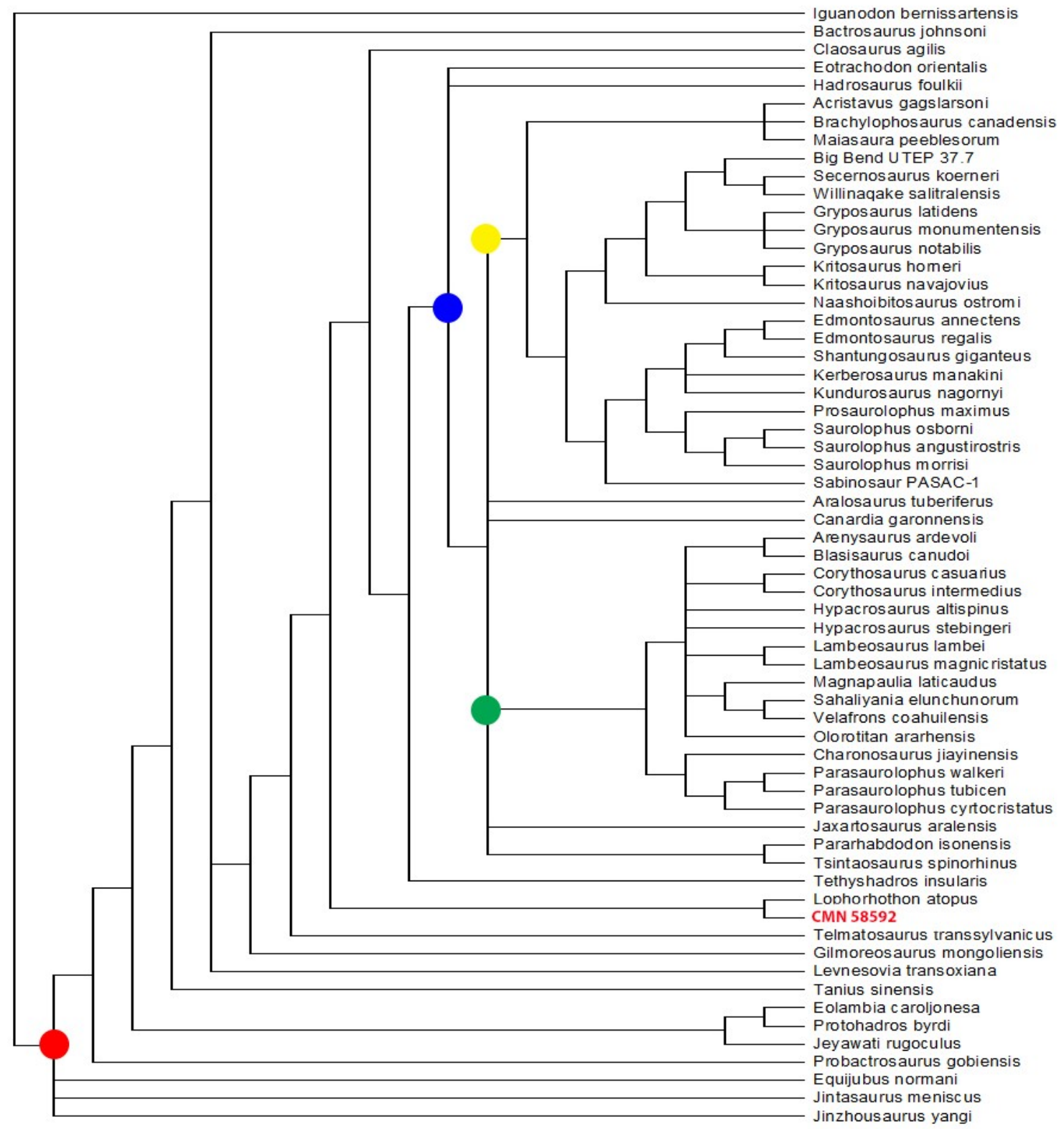

Figure 6.31: Consensus tree based on 56 most parsimonious trees from the matrix of

Prieto- Márquez et al., 2016. CMN 58592 is shown here to ally most closely with

Lophorhothon atopus. The analysis returned 56 trees 900 steps, a Consistency Index of

0.42, Retention Index of 0.77 and a Rescaled Consistency Index of 0.33 . Red Node=

Hadrosauroidea, Blue Node $=$ Hadrosauridae, Yellow Node $=$ Saurolophinae, Green

Node $=$ Lambeosaurinae 


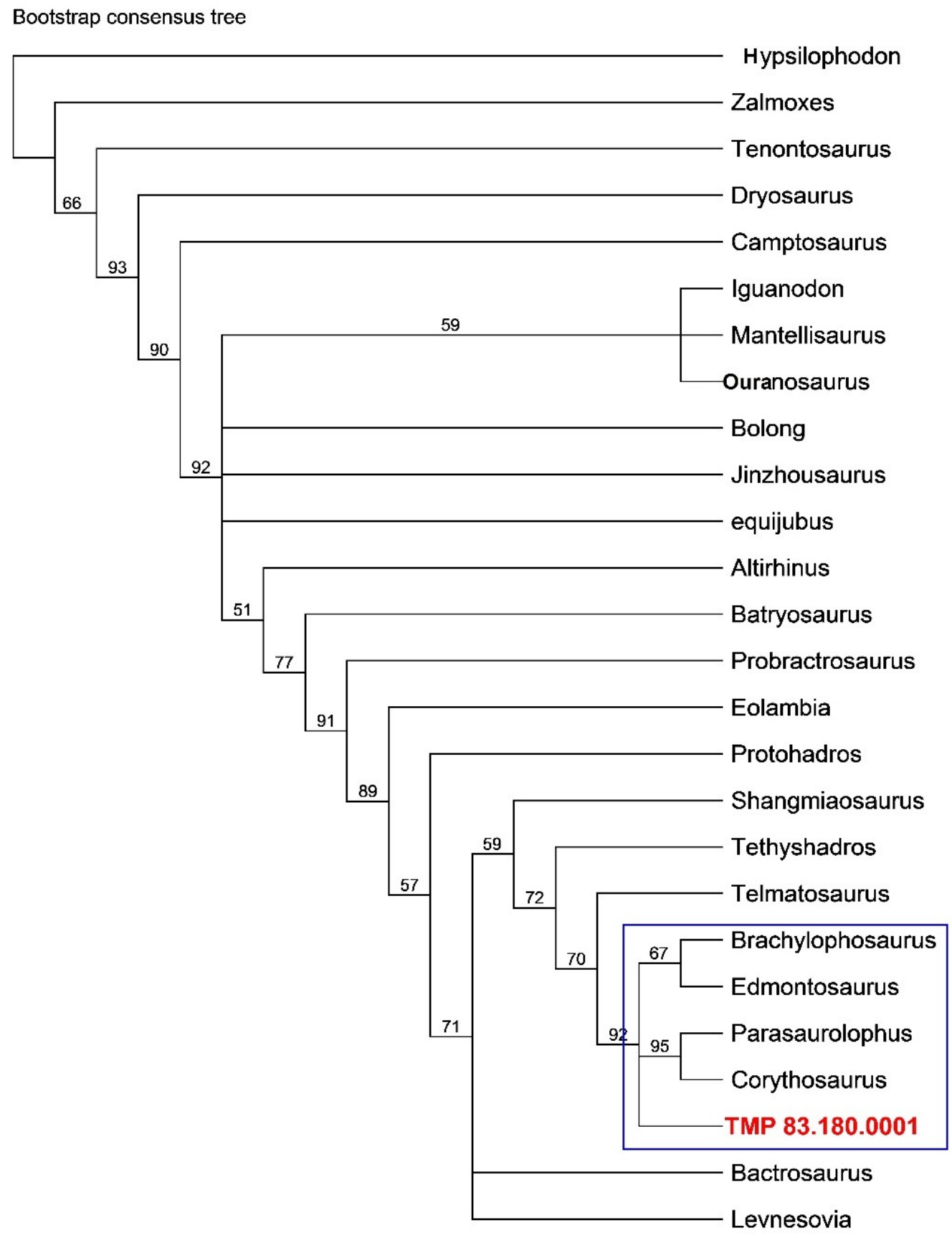

Figure 6.32: Strict Consensus tree of 6 trees from the matrix of Wu and Godefroit, 2012. TMP 83.120.0001 is shown to be allied within the clade Hadrosauridae. Bootstrap values are displayed above nodes. The strict consensus tree has a Consistency Index of 0.70, a Rescaled Consistency Index of 0.61, and Retention Index of 0.87 . The blue box encompasses Hadrosauridae. 


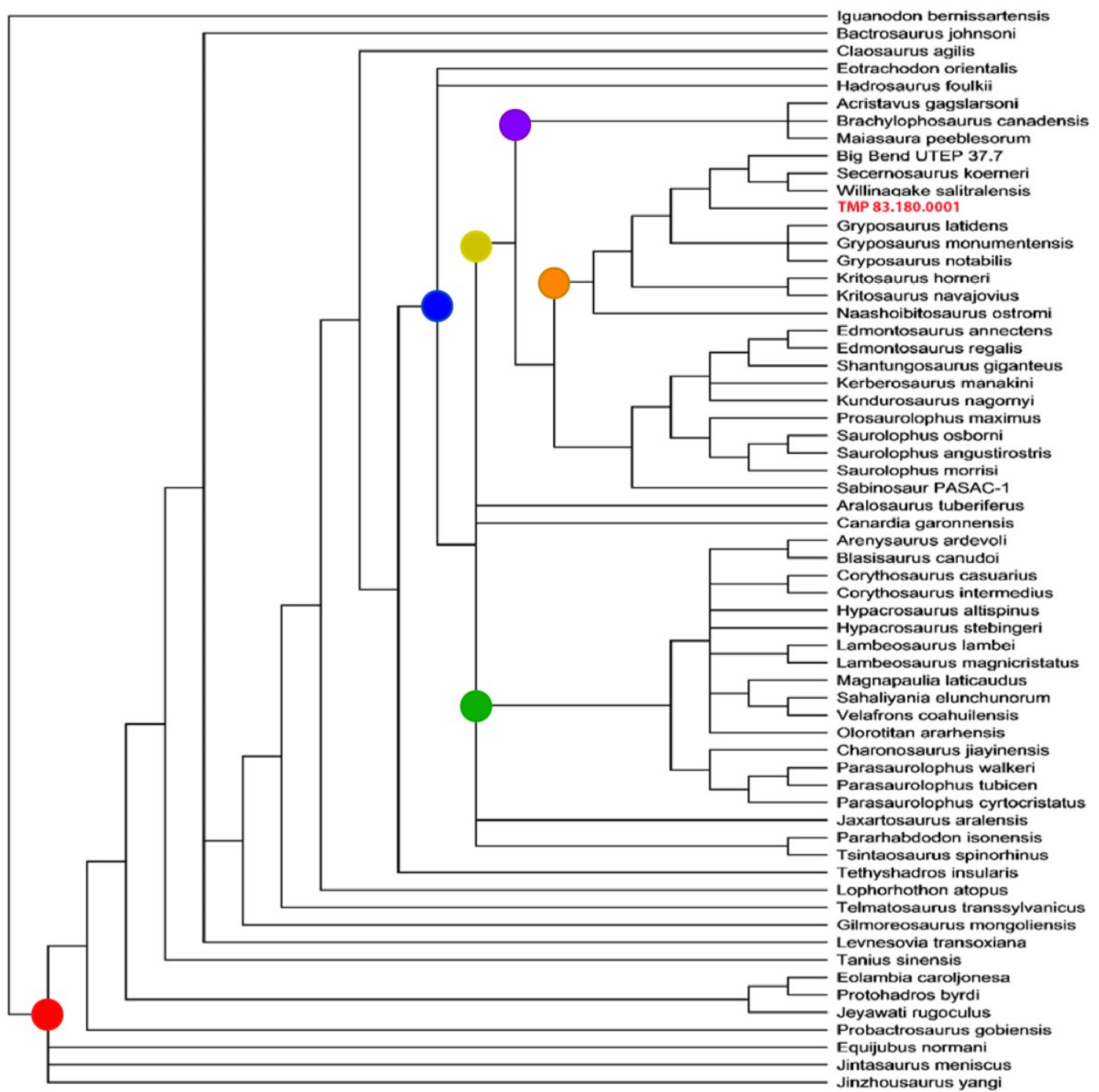

Figure 6.33: Consensus tree based on 56 most parsimonious trees from the matrix of

Prieto- Márquez et al., 2016. TMP83.180.0001 is shown here grouped with UTEP 37.7,

Secernosaurus koeneri and Willinaqake salitralensis. The analysis yielded 56 best trees

of 900 steps, a Consistency Index of 0.420, Retention Index of 0.774, and a Rescaled

Consistency Index of 0.327. Red Node $=$ Hadrosauroidea, Blue Node= Hadrosauridae,

Yellow Node $=$ Saurolophinae, Green Node $=$ Lambeosaurinae, Purple Node $=$

Brachylophosaurini, Orange Node $=$ Kritosaurini. 
$(1 \rightarrow 0)$, depth of the central plate of the ilium and the distance between the pubic peduncle and the caudodorsal prominence of the ischiadic peduncle has a ratio $<0.80$ ); and Ch. $227(1 \rightarrow 2)$, position of the ventral-most margin of the supraacetabular crest is located cranioventrally to the caudoventral margin of the lateral ridge of caudal protuberance of the ischiadic peduncle of the ilium.

\section{5: Discussion}

\section{Phylogenetic placement of CMN 58592}

CMN 58592 is recovered as a hadrosaurid, but not distinguishable as a saurolophine or lambeosaurine, using the data matrix of $\mathrm{Wu}$ and Godefroit (2012). This result likely reflects the fact that, of the 108 characters within the matrix, only ten postcranial characters were available for coding. Therefore, a more inclusive diagnosis from this data matrix may be recovered when cranial information becomes available for analysis.

Conversely, CMN 58592 was recovered as a basal hadrosauroid when using the data matrix of Prieto- Márquez et al., (2016), and is positioned as the sister taxon of Lophorhothon atopus. Beyond the synapomorphies listed in the results supporting this classification in the matrix, CMN 58592 also displays an underived distal ischial knoblike morphology, which does not match known saurolophine ischial morphology. Instead, the small distal ischial process is more reminiscent of basal hadrosauroid taxa, i.e., Eotrachodon orientalis, one of the least derived hadrosaurid taxa (Prieto- Márquez, et al., 2016). 
However, the ischia and ilia of CMN 58592 exhibit derived saurolophine affinities. For the ilia, these include: ventral deflection of the preacetabular process of the ilium less than $150^{\circ}$ (Prieto-Márquez et al., 2016, Ch. 224, State 1); craniodorsal displacement of the ventral apex of the supra-acetabular relative to the caudodorsal portion of the ischiac peduncle (Prieto-Márquez et al., 2016, Ch. 227, State 2); and the lack of an obturator foramen and postpubic process of the pubis (Prieto- Márquez, 2011, not coded). The derived ischial traits include a curved dorsal articular surface of the iliac process of the ischium (Prieto-Márquez et al., 2016 Ch. 224, State 1). Iliac peduncles of basal hadrosauroids typically deflect more craniodorsally and both those of basal hadrosauroids and lambeosaurines typically display a more "thumb-like", curved lateral profile (Prieto- Márquez, 2010). As well, the acetabular and caudodorsal margins of the iliac peduncle are angled slightly convergent towards the dorsal articular surface (PrietoMárquez et al., 2016, Ch. 256, State 1), another feature common to saurolophine ischia (Prieto- Márquez, 2010). Overall, the CMN 58592 material resembles the postcrania of hadrosaurids more than it does early diverging hadrosauroid taxa.

If the phylogenetic placement of the taxon represented by CMN 58592 is correct, it could reflect the presence of a taxon related to the basal hadrosauroid in the older Santonian Milk River Formation of Southern Alberta reported by Larson et al. (2014). However, the stratigraphic position of CMN 58592 near the base of the Taber Coal Zone gives it an inferred intermediate age between two recently described brachylophosaurin saurolophines; Acristavus gagslarsoni from the Two Medicine and Wahweap formations of Montana and Utah, respectively (Gates et al., 2011), and Probrachylophosaurus bergei from the Judith River Formation of Montana (Freedman-Fowler and Horner, 2015) 
(Table 6.3; Fig. 35). The type locality for P. bergei is located $9 \mathrm{~m}$ above the Marker A coal zone of the Taber Coal Zone, placing it within the Herronton sandstone unit that immediately overlies the Foremost Formation (Freedman-Fowler and Horner, 2015). Regardless of the classification of this unit, P. bergei and the CMN 58592 taxon are in relatively close spatiotemporal proximity, although without further material allowing comparison between $P$. bergei and CMN 58592, any purported relationship between these taxa remains speculative.

It should also be noted that the phylogenetic position of L. atopus, the purported sister taxa of CMN 58592, from the analysis using the data matrix of Prieto- Márquez et al. (2016), has been considered problematic and it has been recovered in vastly different positions both within and outside of Hadrosauridae (e.g., Horner et al., 2004; Sues and Averianov 2009; Prieto Márquez, 2010; Larson et al., 2014). A direct comparison of the CMN 58592 material to that of L. atopus is difficult because the only pelvic elements (ischium and pubis) possessed by L. atopus are highly fragmentary (Langston, 1960). Beyond the single ischial character allying these taxa, the general morphology of the ischium of L. atopus does not resemble those of CMN 58592, but, rather, has an iliac peduncle that has a more pronounced cranial deflection and a thinner shaft, suggesting that there is a lack of data allowing for comparison between these two taxa. Although the thinner shaft of CMN 58592 can be attributed to its putatively younger age, the pronounced cranial deflection appears to be a valid character. L. atopus also lacks the terminal shaft process that is present on CMN 58592.

Additional difficulty regarding phylogenetic classification of CMN 58592 is encountered due to coding of juvenile individuals in the matrix (a problem for the TMP 
83.180.0001 ilium since it is likely also from a juvenile-sized individual).

Problematically, L. atopus is also recognized as a juvenile (Langston, 1960; Schwimmer, 1997) and juvenile taxa are known to be recovered in more basal positions than taxa based on adult-sized specimens due to their retention of more plesiomorphic characters (Evans et al., 2013). This this would help explain, in part, the basal position for L. atopus within the analysis of Prieto- Márquez et al. (2016). As well, a lack of cranial characters for both organisms likely contributes to their basal recovery. Indeed, the positions of many of the basal hadrosauroid taxa are problematic, with many exhibiting polytomies and vastly different occurring between the $\mathrm{Wu}$ and Godefroit (2012) and the PrietoMárquez et al. (2016) analyses. This has been attributed to the fact that many basal hadrosauroids are highly fragmentary in nature, leading to vastly different topologies between different studies due to lack of information (Xing et al., 2014).

The lack of cranial material for CMN 58592 and other hadrosauroid taxa, and the lack of data related to diversity of hadrosauroids and hadrosaurids in the early Campanian adds to our ability to confidently assign CMN 58592 a robustly supported phylogenetic placement. Therefore, CMN 58592 can only be referred to as Hadrosauridae indet. at this time. This highlights the potential need to reassess which (especially postcranial) characters are truly informative between taxa (Brady et al., 2015) and for greater sampling overall of hadrosauroids from the early Campanian of North America.

\section{Phylogenetic placement of TMP 83.180.0001.}

TMP 83.180.001 represents multiple juvenile individuals, probably derived from a bonebed. The two left dentaries indicate a minimum two individuals. TMP 83.180.0001 material was previously referred to cf. Kritosaurus sp. by Brett-Surman (1989) based on 
the close resemblance of the scapula and ilium to that of Kritosaurus (now Gryposaurus, Horner and Weishampel, 1990), including specific ilial features such as a strongly ventrally deflected preacetabular process, relatively tall central plate, a pronounced sacral ridge running along the medial side of the central plate and supraacetabular, an overall strongly sigmoidal lateral profile, strong dorsally directed deflection of the postacetabular, and an ischiac peduncle with a considerably larger anterior process.

TMP 83.180.0001 was recovered as a hadrosaurid in the analysis derived from the Wu and Godefroit (2012) data set, with Hadrosauridae being similarly unresolved as for the previous analysis of CMN 58592 (Fig 6.32). The analysis using the data matrix of Prieto- Márquez et al. (2016) recovered TMP 83.180.0001 as a derived saurolophine hadrosaurid and the sister taxon to the clade containing UTEP 37.7 (Big Bend OUT) of Texas, and the South American hadrosaurs Willinaqake salitralensis and Secernosaurus koeneri. These South American hadrosaurids and TMP 83.180.0001 are all within Kritosaurini, which is the most exclusive saurolophine clade containing Kritosaurus navajovius, Gryposaurus notabilis and Naashoibitosaurus ostromi sensu Prieto- Márquez (2014) (Fig 6.33). Thus, the suggestion of Brett-Surman (1989) for a kritosaur-like morphology of TMP 83.180.0001 is supported in this research.

If the recovery of TMP 83.180.0001 as the sister taxon to the clade containing UTEP 37.7 and the South American hadrosaurs is supported when more complete specimens can be analyzed, it has interesting implications for the evolution of hadrosaurs and their dispersal from North America to South America. Based on a phylobiogeographic analysis of all kritosaur taxa, Prieto- Márquez (2014) suggested a southern Laramidian origin for the South American kritosaur clade, supported by the 
basalmost kritosaur (the taxon represented by UTEP 37.7 from Texas), and the basally positioned Kritosaurus and Naashoibitosaurus, all being from the Campanian of southern Laramidia (Prieto- Márquez, 2014) (Table 6.4). However, since the TMP 83.180.0001 taxon is the stratigraphically oldest member of the clade including the South American kritosaurs, my results instead suggests an alternative interpretation of the South American group originating in northern Laramidia in the early Campanian. Based on the results of my study, the Gryposaurus clade shares a common ancestor with the clade that includes TMP 83.180.0001 and South American hadrosaur taxa (Fig 6.33). This is significant as Gryposaurus latidens from the lower Two Medicine Formation of Montana falls within the age range of the Foremost Formation (Fig 6.1) (Prieto- Márquez, 2012), giving it a similar age to TMP 83.180.0001. With both the oldest member of the Gryposaurus clade and the clade containing TMP 83.180.0001 being present in Northern Laramidia during the same early Campanian timeframe, the origination of the South American and Gryposaurus-like hadrosaurids is likely to have occurred in northern Laramidia, not southern Laramidia, by at least $79 \mathrm{Ma}$ (based on the age of the Taber Coal Zone (Freedman-Fowler and Horner, 2015)). Further support for the divergence and origin of these clades occurring in northern Laramidia comes from a bonebed of a yet unpublished new species of Gryposaurus has been reported from the lower Judith River Formation in northern Montana, which is similar in age to the upper Foremost Formation that TMP 83.80.0001 derives from (Freedman-Fowler and Horner, 2016). It is possible that TMP 83.180.0001 may eventually be referable to Gryposaurus, or a related taxon, which would make this the earliest occurrence of such a taxon in Canada thus far (Weishampel et al., 2004; Gates and Sampson, 2007). 
The suggestion that TMP 83.180.0001 also has South American affinities is undercut by the fact that all of the material analyzed here, and the South American kritosaurs (Willinaqake and Secernosaurus) and the Big Bend OUT (UTEP 37.7) are all highly fragmentary in nature, and have, for this reason, been excluded from most recent phylogenetic analyses (e.g.,Valieri et al., 2010; Freedman-Fowler and Horner, 2015). Thus, its close association with its sister taxa may be a factor of their shared fragmentary, postcranial nature, which is more similar to each other than to other, better sampled hadrosaur species. Therefore, as with CMN 58592, a confident generic level classification cannot be made, but it can stated to be a hadrosaurid with kritosaur affinities. With greater sampling, any other remains recovered from the Foremost Formation may provide insight with greater resolution regarding the relationships of these taxa and the specific group of kritosaurs that may be present.

\section{6: Conclusion}

CMN 58592 is classified as a basal hadrosauroid and placed as sister taxa to Lophorhothon atopus, suggesting a previously unknown presence of hadrosauroids in the Foremost Formation. This would extend the last appearance of basal hadrosauroids in Laramidia until $80.5 \mathrm{Ma}$ at least, though a younger date is likely considering CMN 58592 was found in the upper portion of the Foremost Formation. However, due to the problematic nature of hadrosauroid phylogeny, the relatively derived appearance of many features of CMN 58592 and its overall fragmentary nature, more material is needed to determine whether basal hadrosauroids were present to confirm CMN 58592's initial classification, which may be more plesiomorphic within the analyses presented here due to lack of material and unknown ontogenetic status. 
The recovery of the taxon represented by TMP 83.180 .0001 as the basal member of the clade (TMP 83.180.0001+(UTEP 37.7+(Williniqake+Secernosaurus))) alongside early occurrences of other kritosaurs such as Gryposaurus in the early Campanian of northern North America supports a hypothesis for the _possible origin of South American Hadrosaurs in Northern North America (Valieri et al., 2010). If TMP 83.180.0001's classification allying it with South American hadrosaurs remains valid, it supports the hypothesis of a faunal interchange between North and South America occurring either within or before the Campanian that introduced hadrosaurs to South America, where they are not known for the majority of the Cretaceous (Bonaparte, 1996; Valieri et al., 2010). Further sampling will be needed determine the possible presence and affinities of kritosaurin hadrosaurs in the Foremost Formation.

If the results presented here hold true, the suggestion that CMN 58592 represents a possible previously unknown hadrosauroid taxon, and that the TMP 83. 180.0001 represents a saurolophine hadrosaurid (possibly a kritosaur) within the Foremost Formation supports the hypothesis of Ryan et al. (2012) who proposed that the dinosaur assemblages in the Foremost and lower Oldman formations likely resembled those assemblages from the upper Oldman and Dinosaur Park Formations, but were comprised of more basal members of the clades making up the assemblages in the younger formations. The results presented here indicate that saurolophines and centrosaurines (i.e., Xenoceratops foremostensis Ryan, Evans and Shepherd 2012 from the Foremost Formation) are now both known to be members of faunal assemblages throughout the entirety of the Campanian as represented in the Belly River Group. It is also possible that based on the interpretation of the classification of CMN 58592, that basal hadrosauroids 
may have coexisted alongside kritosaurs, and were eventually fully replaced later in the Campanian by derived hadrosaurids. Future prospecting and description of material from the Foremost Formation outcrops is needed to discriminate whether the results presented here are valid or not. 


\section{Chapter 7: Interpretations and Discussion}

\section{1: Sequence Stratigraphy of the Foremost Formation in the Pinhorn Ranch Area}

The exposed Foremost Formation in the Pinhorn Ranch area of the Milk River valley can be divided into two depositional regimes (Fig. 7.1). The stratigraphically older regime encompassing Units I and II of this study as distinguished as an aggradational series of two either estuary mouth barrier-central bay or barrier island-lagoon facies successions truncated by flooding surface discontinuities. The younger depositional regime encompasses the overlying Unit III and the Herronton Sandstone of the Oldman Formation represents an overall prograding facies succession of primarily coastal plain marsh and fluvial deposits.

\section{Unit I and Unit II (Aggradational Successions of Shoreline Progradation)}

Unit I and Unit II are aggradational, displaying two depositional periods of prograding estuary mouth barrier-central bay or barrier island-lagoon shoreline complexes (Fig 7.1). Both Unit I and Unit II are capped by discontinuities, identified in outcrop by sharp boundaries associated with siderite concretions and shell fossil hashes. These discontinuities are located between central bay/lagoonal facies and the overlying basal barrier sandstone facies in both Unit I and Unit II (Fig. 7.1). The discontinuities are interpreted as representing flooding surfaces created during rapid transgressive events that allowed for the erosion and/or non-deposition (MacEachern et al., 1992; Cattaneo and Steel, 2003). These transgressive events were likely related to localized tectonic subsidence linked to mountain building events within the western Rocky Mountain orogeny, which were active at the time (Hamblin and Abrahamson, 1996; Eberth, 2005). 
Figure 7.1: (see page 232): Comparison of palaeoenvironmental proxies within the outcrops of the Foremost Formation observed in this study including facies, depositional units, foraminiferal abundance per sample, infaunal:epifaunal morphogroup ratio (epifaunal=grey, infaunal=white), palaeoenvironmental interpretations, and vertebrate microsites of the Foremost Formation. Note, unlike the other sites, PK and SPS are not located in the Pinhorn Ranch area, therefore their stratigraphic relationships are based solely on the descriptions provided by Cullen et al. (2016) and Peng et al., (2001) respectively and where those horizons may fall within the classification presented in my study. The sea level curve on the far right displays only regressive trends as transgressive events are represented by flooding surfaces (blue dotted line) that created discontinuous surfaces. In general, all proxies presented suggest increased terretrial influence up section and highly variable oxygen and salinity conditions. 


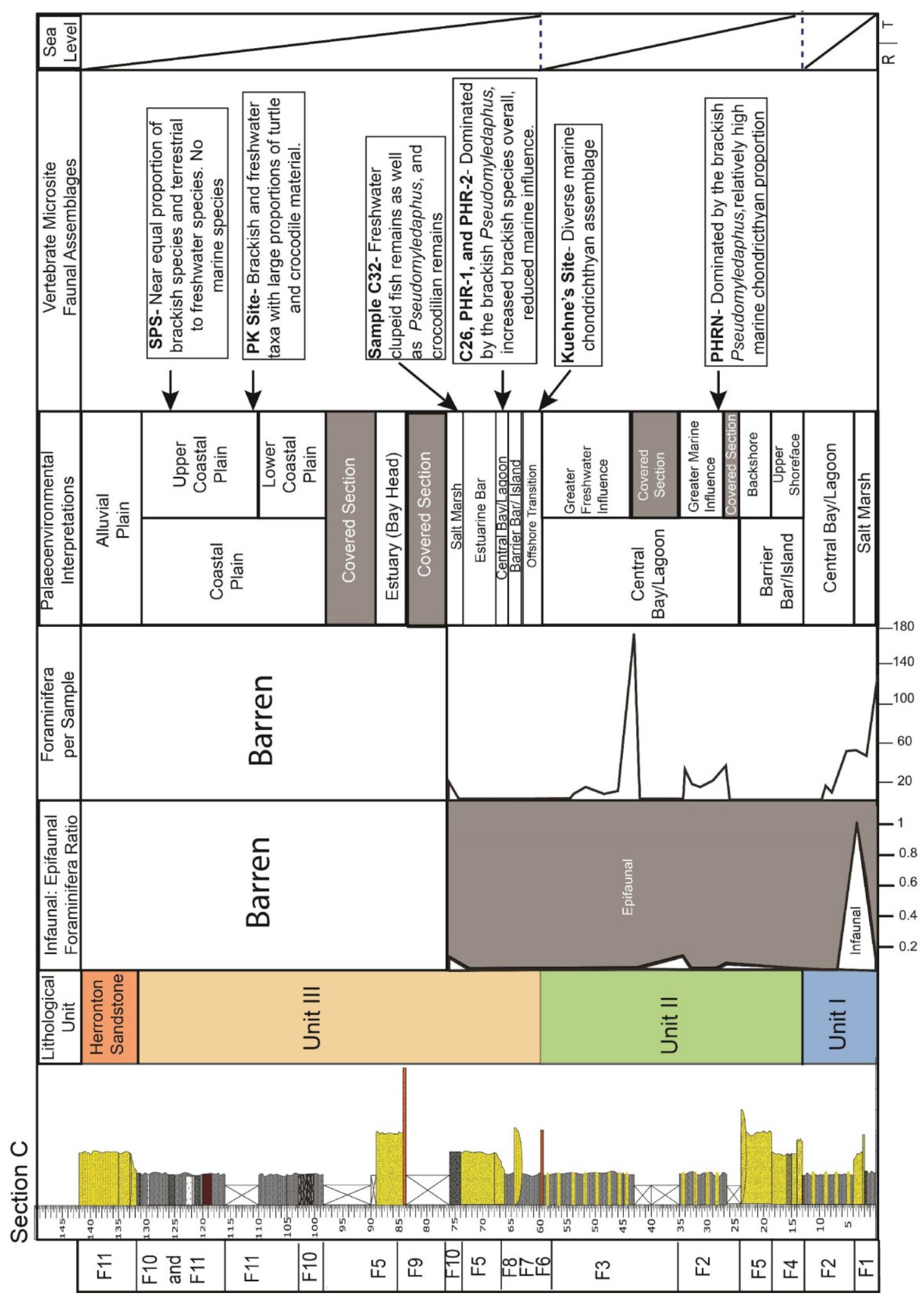


This interpretation is supported by the relative enrichment of the montmorillonitic clay mineral smectite (a type of clay mineral recognized by $\mathrm{Na}$ levels in this study) that forms through weathering of bentonite derived from volcanic ash deposition, a frequent phenomenon that is well documented for the Late Cretaceous of Alberta and entire WIS (Cadrin et al., 1996; Eberth and Hamblin, 1993; Hamblin and Abrahamson, 1996; Fanti, 2009). The largest spikes in $\mathrm{Na}$ (indicative for bentonite) concentrations are seen in samples directly preceding the flooding surfaces, suggesting increased deposition of smectite at the beginning of minor transgressions (Fig 7.1).

Further evidence of rapid transgressive events in this area comes from the iron calcite rich concretionary horizons associated with an offshore transition to lower shoreface environment and found bounding the discontinuities, with the most notable being the firmground surface that terminates Unit II (Fig 7.1). Firmground (and hardground) surfaces form in the lower shoreface to offshore zones during times of sediment starvation under subaqueous conditions, which leads to the early formation of diagenetic cement (commonly carbonate minerals such as siderite and calcite) between deposited grains at the sediment water interface (Laenen and De Craen, 2004). These surfaces are associated with rapid transgressive events with associated shoreline ravinement via wave action (Cattaneo and Steel, 2003). Ravinement causes eroded sediments that would normally be deposited at the shoreline to instead be jettisoned into the deeper basin away from the offshore portion of the shelf. As well, increased sea level would prevent fluvially introduced sediments from entering the lower shoreface, thus starving the shoreface and offshore environments of new sediment (Swift, 1968; Cattaneo and Steel, 2003). Sediment starvation during the formation of these concretionary 
horizons is supported by significant drops in $\mathrm{Al}$ and other terrestrially linked elements (excluding Fe that is locked into the siderite content of the firmground) (Fig. 4.1-4.2). Transgressive firmgrounds are often accompanied by an overlying shell and fossil hashes, accumulated as a regressive lag directly on top of the flooding surface and marking the return of fluvial progradation to the basin (Kidwell, 1986; Rogers and Kidwell, 2000; Leckie and Olson 2003). The firmground outcrops observed here are no different, displaying an overlying bivalve-rich shell hash, thus marking the return of deposition to the lower shoreface and offshore transition.

Based on these lines of evidence, Unit I and Unit II represent aggradational successions of shoreline progradation that were truncated by rapid transgressional events causing net erosional and/or nondepositional in the lower shoreface to offshore transitional environment settings, likely induced by sudden base level subsidence related to tectonism.

\section{Unit III (Regressional)}

Unit III represents a shift from the subsidence interrupted barrier island facies successions in Unit I and Unit II to a regressional phase. This progradational succession transitions from a marine barrier and central bay/lagoonal complex into terrestrial coastal plain and alluvial plain deposits that immediately follow the firmground flooding surface of Unit II. (Fig 7.1). The regressional character of Unit III is supported by the almost complete lack of Foraminifera (excluding the salt marsh associated Assemblage 3), reduced overall $\mathrm{B}$ and $\mathrm{S}$ content in all units except for marsh deposits, increased terrestrial elements such as $\mathrm{Al}$ and especially $\mathrm{K}$, and increasing content of freshwater exclusive unionid bivalve fossil material (Figs 4.2, 4.3 and 7.1). There is also a relative 
increase in terrestrial microvertebrate material in comparison to material from Unit II (PHRN site) and between sites within Unit III in the Pinhorn Area (Figs 5.13 and 7.1). Additional evidence stems from the overall reduction of $\mathrm{Na}$ throughout, suggesting a relative increase in freshwater influence which alters smectite to illite (Cadrin et al., 1995) and may suggest relative reduction in tectonic activity interpreted in connection with studies addressing the Oldman Formation (Eberth and Hamblin, 1993; Eberth, 2005). The overlying Herronton sandstone is gradational with the Taber Coal Zone without evidence for a depositional hiatus between Unit 2 and 3.

The observations and interpretations presented here are consistent with previous studies suggesting that the Foremost Formation represents several aggradational to increasingly progradational parasequences deposited during the Claggett marine regression (Hamblin and Abrahamson, 1996; Eberth, 2005). As well, flooding surfaces identified in this study agree with the observations of previous studies suggesting periods of shoreface and offshore sediment starvation during subsidence driven transgressive events (Kwasniowski and Eberth, 1993; Beavan, 1995; Frampton, 2006). A major difference between this study and previous studies regarding sequence stratigraphic surfaces is that previous studies have subdivided what is referred to here as Unit II into two separate depositional cycles truncated by a wave ravinement surface (Kwasniowski and Eberth, 1993; Beavan, 1995; Frampton, 2006). However, these cycles in my study appeared gradational in outcrop, not sharply divided. Additionally, previous studies have suggested another transgressive interval between the salt marsh facies (Facies 10) and the Crassostrea conglomerate (Facies 9) in Unit III of this study (Ogunyomi and Hills, 1977; Kwasniowski and Eberth, 1993; Beavan, 1995; Frampton, 2006); unfortunately, this 
interval could not be identified here due to a covered section (Fig 7.1). A relative depletion in $\mathrm{Al}$ and other terrestrially linked elements does occur at the shell conglomerate (Fig. 7.1), however, this is almost certainly due to the fact that shell material dominates the rock, and has altered the chemistry to such a degree as to produce signals suggesting low terrestrial influence due to the overabundance of $\mathrm{Ca}$ (Appendix Table A-1, Sample C33).

\section{2: Palaeoenvironmental Interpretations}

Unit I and Unit II share nearly identical palaeoenvironmental settings, representing deposits of a central bay or back barrier lagoonal environment, ranging from a basal upper shoreface barrier (Facies 4 and/or 5) fining upward into brackish marsh and central bay/lagoonal deposits (Facies 1, 2 and 3) (Fig 7.1). However, several key differences are noted. Facies 1 type marsh deposits are exclusive to Unit I, representing a laterally continuous back barrier salt marsh environment with a diverse Foraminifera fauna dominated by Verneuilinoides and Trochammina (Fig 7.1; Appendix Table B-1). Such foraminiferal assemblages are associated with dysoxic bottom water as these genera thrive in oxygen stressed conditions and are commonly encountered in organic rich coastal deposits (Morris, 1971, Johnson et al., 2005; Nagy et al., 2009; Murray et al., 2011). Further support for the interpretation of a dysoxic setting is provided by increases in redox sensitive elements including Mo and S (Tribovillard et al. 2004) and abundant large sized plant fossil content, likely associated with peat accumulation processes (Fig 4.1; Fig. 4.3; Fig. 7.1; Appendix Table A-1). The absence of a salt marsh facies associated with the barrier island of Unit II may indicate a relatively higher sea level than what was present in Unit I. Such back barrier salt marshes require barrier islands that 
protect marshes from frequent wave and storm washover events in order to allow for gradual colonization and stabilization by plant species and production of in situ peat (Prothero and Schwab, 2014). A greater relative sea level in Unit II would increase wave action and in turn inhibit the production of widespread marsh environments (Prothero and Schwab, 2014). However, the overall facies successions and geochemical fingerprints of Unit I and Unit II are almost equivalent and do not suggest a large difference in sea level between the two units (Fig. 7.1). It should also be noted that the stratigraphically equivalent marsh horizons in Section A approximately $1.3 \mathrm{~km}$ south of the Sections C, D and $\mathrm{E}$, were only 20 to $30 \mathrm{~cm}$ in thickness, whereas northern sections had beds up to $1 \mathrm{~m}$ in thickness, showing lateral variability in the deposition of this environment (Compare Section A and Section D Fig 2.1 and Fig 2.5). Therefore, it seems probable that the exclusion of this facies in Unit II is simply due to local variability of the environment and not due to relatively higher sea level. In general, Unit I contains the majority of infaunal Foraminifera in this study, and suggests that its waters were more dysoxic than those encountered in Unit II (Nagy et al., 2009; Murray et al., 2011). Such infaunal faunas are common to marsh settings as marsh sediments are often dysoxic to anoxic at the sediment interface due to large accumulations of peat (Johnson et al., 2005)). The central bay/lagoonal environment was relatively more oxic in comparison, with greater abundance of Morphogroup D-2 Foraminifera and reduced numbers of infaunal and Morphogroup D-1 types. This likely reflects the increasing sediment supply and reduction in nutrients (supported by relative increases in $\mathrm{Al}$ and $\mathrm{K}$ ) in a more near shore, brackish environment, allowing for more oxic bottom waters (Jorissen et al., 1995; Murray et al., 2011). 
Unit II contains thicker central bay/lagoonal deposits with a clear division between outer more marine influenced and inner more terrestrial influenced central bay/lagoon facies (Facies 2 and 3 respectively), a foraminiferal fauna almost exclusively dominated by Haplophragmoides rota and a greater enrichment in terrestrial indicators such as $\mathrm{Al}$ and K relative to Unit I (Fig. 7.1). The Foraminifera represented by morphogroup D-2, (almost exclusively H. rota in Unit II) are known to be found where there is increased terrestrial sediment and therefore dilution of nutrients in deeper infaunal sediments (supported by increased $\mathrm{Al}$ content) which leads to relatively oxic benthic conditions and precludes the diversity and abundance of infaunal types seen in Unit I (Jorissen et al., 1995; Murray et al., 2011). This suggests that the central bays/lagoons of Unit II were oxic compared to the marshes and central bays/lagoons of Unit I. Haplophragmoides rota is also known to tolerate variable salinity conditions and relatively high freshwater input quite well (Nauss, 1947; Tappan, 1962), providing further evidence for a relatively more freshwater influenced central bay/lagoonal setting compared to Unit I. A lagoonal or estuarine setting is equally plausible for Unit I and Unit II based on the facies observed. Further observation of large scale structures or more complete facies successions in the Foremost Formation in the Pinhorn Ranch area may provide further evidence for one setting or the other.

A gradational progression from central bay/lagoonal to beach and shoreline marsh facies to estuarine bay head facies occurs in Unit III, and continues into the deposition of the coastal plain facies of the Taber Coal Zone (Fig 7.1). Freshwater influence is determined to be a major factor in the central bay/lagoonal deposits of Unit III based on the prevalence of brackish water taxa in the $\mathrm{C} 26$ microsite, large plant fossil and amber 
content and complete lack of Foraminifera (Fig. 7.1). Salt marshes shoreward from this central bay/lagoon are deemed to have been relatively anoxic and hypersaline similar to those in Unit I based on the foraminiferal assemblage of Trochammina and H. rota with the addition of the infaunal genus Pseudoclavulina (Figs 3.2 and 7.1). However, these marshes were likely even more stressed based on the diminutive test size of all Foraminifera preserved, which is considered a sign of extreme dysoxia to anoxia and hypersalinity (Reolid et al., 2014). Significant positive excursions in S, which is often linked to organic peat decomposition and dysoxia/anoxia, are also encountered in these marsh deposits (Murray, 1991; Saffert and Thomas, 1998). Although the Taber Coal Zone is here interpreted to be a primarily freshwater setting, B levels become significantly enriched within lower coal bearing beds, which may suggest that they, too, were saline (Figs 4.3 and 7.1). There are two possibilities for this enrichment: 1) B from these samples is enriched due to being deposited in restricted, hyper saline environments (Hofer, 2011; Hofer et al., 2013); or 2) B preferentially adsorbs to clays that are rich in organic material, which is enriched in the Taber Coal Zone (Hofer, 2011; Hofer et al., 2013). Marsh deposits represented in Unit I have less B in their samples, even though their organic content percentage is similar (Fig 7.1). As well, increases in S are also apparent in the lower coal beds, are correlated with hypersaline marshes due to their often dysoxic nature (Sachsenhofer, 1987; Bannerjee and Goodarzi, 1990). Therefore, marsh deposits below the $105 \mathrm{~m}$ mark in Unit III are deemed to be saline (Fig 7.1). A shift to freshwater marsh deposits occurred afterwards as regressional progradation continued, further evidenced by the relative increase in freshwater unionid bivalve fossils following these beds (Johnson and Hendy, 2005). The fluvial sands of the Herronton Sandstone are 
identical to those seen interbedding with the coal beds of the Taber Coal Zone (Facies 11) based on both outcrop appearance and similar enrichments in $\mathrm{Al}$ and $\mathrm{K}$ and depletion in $\mathrm{B}$ and S (Figs 4.1, 4.2 and 4.3). These lithological similarities suggest a gradational boundary between the Taber Coal Zone and the Herronton Sandstone.

The palaeoenvironmental interpretation of the Foremost Formation in the Pinhorn Ranch area of Southern Alberta is that of a brackish water estuarine complex or barrier islands and lagoons displaying varying levels of dysoxia coupled with organic plant matter, transitioning into a coastal plain with shore proximal salt marshes and landward freshwater marshes and streams. Depositional and palaeoenvironmental interpretations from this study are in accordance with those previously observed (Ogunyomi and Hills, 1977; Kwasniowski and Eberth, 1993; Beavan, 1995; Eberth, 2005; Frampton, 2006). Distinction between lagoonal/barrier or estuarine environment is not possible without further observation of large scale stratigraphic structures that can be used to distinguish the two, and therefore require further study. Small differences regarding the presence of fresh water marsh facies in Unit I and Unit II from these studies can be attributed to local differences in depositional environments, which are known to be highly variable in marginal marine environments and already shown to be quite variable within this study alone. However, novel information regarding oxygen conditions has been made via the more robust foraminiferal and geochemical data of this study, further highlighting the environmentally variable nature of the Foremost Formation. 


\section{3: Foraminiferal Assemblages of the Foremost Formation and their Biostratigraphic Correlations}

\subsection{1: Taphonomy of Foraminifera}

It has been demonstrated in previous studies that shallow water, near shore depositional environments preferentially dissolve Foraminifera tests, especially calcareous ones, thus creating a potential taphonomic bias (Murray, 2006). As calcareous Foraminifera are absent and typical brackish water marker species such as Miliammina and Ammotium are rare in this study, taphonomic processes must be considered to determine if they had a role in dissolution or disaggregation of foraminiferal tests. Similar low diversity faunas were also noted by Ogunyomi and Hills (1977) and McNeil et al. (1995) who noted a dominance of Haplophragmoides in the Pinhorn Ranch area and an absence of calcareous species.

Destruction of some Foraminifera via either pre- or post-depositional processes that can involve the breakdown of organic content at the sediment-water interface, which adds $\mathrm{CO}_{2}$ to the water column and increases its acidity, therefore dissolving calcareous tests (Wall, 1983; Murray 2006). This effect is likely prevalent in the portion of the Foremost Formation studied here based on the large plant fossil content encountered in the marsh and central bay/lagoonal facies of each section (Fig 7.1). Up section through the central bay/lagoonal facies, there is a drop in Foraminifera and increase in organic content, thus suggesting a possible link between organic content and preservation of Foraminifera. Additional preservation bias occurs in nearshore marine environments where influx of freshwater, which has a lower $\mathrm{pH}$ than sea water, can cause dissolution of calcareous forms (Schröder-Adams, 2006). As the Foremost Formation represents a coastal 
environment with various freshwater flux, the absence of calcareous forms can also be explained by the corrosive influence of freshwater influence.

Post-burial diagenetic taphonomic modifiers can include thermal alteration via sediment compression that can lead to silicification and colour alteration in agglutinated forms (McNeil, 1997; Schröder- Adams, 2006). Indeed, agglutinated taxa within this study show colour variation between pure white, yellow and ruby red within the central bay/lagoonal facies that they are preserved in, possibly suggesting that burial diagenetic taphonomic bias could have contributed to faunal loss. Finally, hydrostatic pore pressure early in post-burial diagenesis has been shown to increase silicification, suggesting another method for high quality preservation of agglutinated taxa (Schröder-Adams, 2006). A combination of pre-burial high organic content and freshwater influence and compression and thermal alteration post burial were the likely candidates influencing the preservation of Foraminifera in the Foremost Formation.

\subsection{2: Foraminifera Biostratigraphic Zonation and Faunal Comparison of the Foremost Formation}

The biostratigraphic foraminiferal zonations of the Western Interior seaway are most often named and recognized by marker taxa with calcareous tests (Caldwell et al., 1978). Calcareous Foraminifera, however, are completely absent within samples of the Foremost Formation in this study, and were also noted as being absent by Ogunyomi and Hills (1977) and McNeil et al. (1995), making placement of this study into the current biostratigraphic classification problematic. The foraminiferal faunas observed in this study do, however, share agglutinated taxa with both the early to middle Campanian Lenticulina sp. and Eoeponidella linki biozones that the Foremost has been suggested to 
be a part of, allowing for some broad correlations (Caldwell et al., 1978).

Haplophragmoides rota and Verneuilinoides bearpawensis are common species in this study and are present in both of the Lenticulina sp. and Eoeponidella linki zones (Caldwell et al., 1978). The E. linki Zone further shares Haplophragmoides kirki, Reophax texanus and Trochammina albertensis (Caldwell et al., 1978) that are present in samples of the Foremost Formation. This species composition is also quite similar to the assemblages recorded from the underlying Lea Park Formation by North and Caldwell (1964), which contained H. rota, V. bearpawensis. T. diagonis and H. collyra, of which the last has a similar test morphology to H. fraseri. Unfortunately, all of these species listed here and the others encountered in this study have long biostratigraphic ranges in the Late Cretaceous (Caldwell et al., 1978; Johnson, 2005), so deriving a unique characterization for the Foremost Formation remains difficult. In fact, the assemblages observed in this study have the strongest similarities with the assemblage encountered in the late Campanian Gaudryina bearpawensis Subzone of the Haplophragmoides fraseri Zone, which contains the same species listed above in addition to H. fraseri, H. glabra. H. calcula, Saccammina alexanderi and Ammobaculites sp., also found in this study (Caldwell et al., 1978). However, this zone is well constrained to the late Campanian in the WIS, always corresponding to the Bearpaw transgression, which occurred approximately $3 \mathrm{Ma}$ after the deposition of the Foremost Formation (Caldwell et al., 1978; Caldwell, 1993). Additionally, these species similarly show large stratigraphic ranges, provided little resolution regarding age correlation (Caldwell et al., 1978; Caldwell et al., 1993). Therefore, it is unlikely that the Foremost Formation is associated with the $H$. fraseri Zone. 
The relatively low abundance and species richness of agglutinated Foraminifera, the presence of agglutinated taxa with long biostratigraphic ranges in the WIS and the lack of calcareous marker species present in these samples, inhibit a clear zonal designation for the Foremost Formation. However, the taxa that are found within this study area are complementary to the hypothesis that the Foremost is part of the E. linki Zone as suggested by Caldwell et al. (1978). The E. linki fauna has been sampled from marine tongues of the Claggett/Pakowki sea that interfinger with the lower Belly River Group (Foremost Formation) in Western Saskatchewan. Therefore, the E. linki Zone is still the most plausible zonal choice for the Foremost Formation of Southern Alberta thus far (Caldwell et al., 1978).

\section{4: Microvertebrate Faunas of the Foremost Formation and the Belly River Group}

The Foremost Formation shows an overall increase in vertebrate diversity up section, with an approximately $50 \%$ greater diversity between the lowest, most marine influenced PHRN site versus the highest, most terrestrial SPS site (Fig 5.13; Appendix Table D-2). Similarly, vertebrate diversity increases moving up section through the Belly River Group (Figs 5.17 and 5.18; Appendix Table D-7). An analysis of multiple data sets from the Campanian of the Western Interior of North America by Eaton and Kirkland (2008) noted that in general, marine faunas of the Western Interior are less diverse than terrestrial faunas. Cullen et al. (2016) noted that in Alberta, microvertebrate faunas were most sensitive to changes in sea level, with different depositional types contributing very little to these differences. The data recorded here is in accordance with these statements, with clear changes in faunal abundance relative to depositional environment and 
shoreline position and increases in diversity from the most marine sites to the most terrestrial sites.

\section{5: Dinosaur Palaeoecology of the Foremost and Comparisons to the Belly River Group based on Vertebrate Microsite Localities}

Although the Foremost Formation shows relatively similar dinosaurian faunas to the other Belly River Group formations, the macrovertebrate data (only two named taxa, Xenoceratops foremostensis and Colepiocephale lambei, based on non-tooth fossils) is too sparse for detailed comparison to other formations. The microvertebrate record, although still limited, is much more robust. As with the Oldman and Dinosaur Park formations, the Foremost Formation is dominated by hadrosaurs $(78 \%)$ and ceratopsians (9\%), with other ornithischians and theropods comprising less than $13 \%$ of the total fauna (Figs 5.25 and 5.26). It has been suggested by several previous studies based on microfossil and macrofossil material that ceratopsians preferred more coastal proximal lowland environments than other dinosaur groups (Brinkman, 1990; Brinkman et al., 1998; Brinkman et al., 2004). In contrast, more recent studies by Cullen et al. (2016) and Cullen and Evans (2016) found that ceratopsians showed no specific association to any one particular habitat, and that their abundance differences seem be due to latitudinal differences, rather than proximity to the Western Interior Seaway, with the majority of ceratopsian microvertebrate remains in the Belly River Group coming from localities in the southern Milk River area. The analysis of the vertebrate microfossil material at the family level presented here confirms the findings of Cullen and Evans (2016), with the largest difference in their abundance between the Dinosaur Park and Milk River areas as opposed to stratigraphic differences. 
Dinosaur diversity is relatively stable between each of the Belly River Group formations in the Dinosaur Park region (an $8 \%$ overall increase), with an initial decrease in the lower unit and increase back to similar levels in the Comrey and upper units of the Oldman Formation in the Milk River area (Appendix Table D-8). Similar stable diversity trends at the family level in vertebrates have been noted for other deposits from Utah and New Mexico along the shores of the Campanian Western Interior Seaway (Eaton and Kirkland, 2008). The relatively high dinosaur diversity in the Comrey Sandstone (middle unit) of the Oldman Formation in Dinosaur Provincial Park (DPP) is probably due to the large amount of exposure for this unit in this region that has been intensely studied for more than 100 years (Eberth, 2005). The lower unit of the Oldman Formation is not present in DPP, and has limited exposure in the Milk River region, with similar limited exposure of the Comrey and upper units in that area as well (Eberth, 2005). Therefore, drops in dinosaur diversity in the two lower Oldman Units may be explained by the reduced relative exposure and therefore lower amount of sampling. However, diversity and faunal assemblage in the upper unit of the Oldman Formation in the Milk River area is similar to the Comrey sandstone in the Dinosaur Park region and not the time equivalent Dinosaur Park Formation, thus suggesting they did not share similar environments.

Horner et al. (1992) suggested that a marine transgression during the latter part of the Belly River Group (Dinosaur Park Formation) and the equivalent portions of the Judith River and Two Medicine formations in Montana was the primary driver of dinosaur diversity with new taxa forming as regions of varying size were isolated by embayments that assisted in both allopatric and anagenetic speciation events. The data 
from the Foremost Formation is not appropriate for testing this hypothesis, but it supports the intuitive suggestion that increasing the available land area for habitation leads to an increase in dinosaur diversity, whether by migration or speciation. Testing the hypothesis using the data presented here for the Oldman and Dinosaur Park formations is beyond the scope of this project. 


\section{Chapter 8: Conclusions}

1. The Foremost Formation outcrops exposed in the Pinhorn Ranch area of the Milk River valley display an overall shift from more aggradational to regressive progradational parasequences. At least two rapid transgressive events driven by local subsidence interrupted the overall regressive phase of the Claggett marine cycle, creating the aggrading profile in the lower portion of the sections measured here. This suggests that orogenic buildup in the Rocky Mountains and its associated basin subsidence was a controlling factor of local deposition in the WIS.

2. Identified facies successions within the Foremost Formation represent marine to terrestrial transitional environments. Specifically, the Foremost Formation in southern Alberta is suggested to represent a brackish estuarine or barrier island lagoon complex situated on the edge of a coastal plain containing abundant coal swamps and fluvial channels. Distinction between one or the other setting is difficult due to lack of knowledge regarding large scale structures such as valley incision or barrier islands, therefore more work in other areas is needed to distinguish one environment over the other. The abundance of infaunal Foraminifera and the reported geochemistry of the outer central bay/lagoon and marsh deposits suggest relatively dysoxic conditions dominated these environments. Epifaunal dominance within the inner central bay/lagoonal facies is associated with increased nutrient supply and benthic oxic conditions within this environment, with a shoreward loss of Foraminifera coinciding with possible increased freshwater influence. 
3. The Foraminifera biozonation of the Foremost Formation is difficult to determine due to the lack of calcareous marker species and abundance of taxa with large stratigraphic ranges. However, existing taxa share close affinities to the underlying Lea Park Formation, lower Belly River Formation of Saskatchewan and other Campanian aged marine transitional formations from the WIS that are assigned to the E.linki Zone, making this zone the most plausible choice (North and Caldwell, 1964; Morris, 1971; Johnson et al., 2005).

4. The $\mathrm{C} 26$ microsite occurs at the same stratigraphic horizon as the PHR-1 and PHR-2 sites of Peng et al. (2001). Its depositional environment may be interpreted as a quiet water lagoon or estuarine central bay setting based on the abundance of brackish fossil material being concentrated by slow accumulation rather than short lived, high energy events such as storms. The C26 locality is notable for having a greater percentage of large material (e.g., turtles and crocodiles), suggesting a potential taphonomic difference between vertebrate microsites in the Foremost Formation. Further sampling may elucidate this issue.

5. Microfossil and macrofossil data suggests that vertebrate diversity increases upsection in the Foremost Formation. As well upsection diversity increases are seen from the Foremost Formation to the Dinosaur Park Formation in the Dinosaur Park area and from the Foremost Formation to the upper Oldman Formation in the Milk River region. This increase in vertebrate diversity relative to increased terrestrial deposition suggests that sea level fall and increased terrestrial habitat was the greatest driver of diversity increases in vertebrate communities. This diversity difference is likely related to the lower overall number of marine and brackish species versus terrestrial species recorded 
from Cretaceous microsites to date (Eaton and Kirkland 2008), suggesting that marine communities as a whole are less diverse in the WIS during the portion of the Campanian represented by the Foremost Formation.

6. Dinosaur diversity at the family level in the Belly River Group increases only slightly from the Foremost to the Dinosaur Park Formation and upper Oldman Formation, suggesting that similar dinosaur communities were present throughout the Belly River Group at the family level. These observations support previous observations that species level dinosaur diversity increases may have been relatively constant and not be related to speciation events driven by sea level fluctuations leading to reduction or addition of available land area (Horner et al., 1992; Mallon et al., 2012). The Milk River area of Southern Alberta contains a less diverse dinosaur fauna than the rest of the Belly River group and increased percentages of ceratopsian material, suggesting the possibility of a latitudinal difference in dinosaur diversity already reported as existing between Northern Alberta and the rest of the province in the late Campanian (Fanti and Miyashita, 2009). As sampling has been low in the Milk River area due to less outcrop exposure, further work on these deposits are needed to determine the cause of this diversity difference.

7. Hadrosaur macrofossil remains described here confirm the presence of saurolophines and suggest the previously unknown presence of kritosaurs and basal hadrosauroids being present in the Foremost Formation alongside other groups of dinosaurs from the upper Belly River Group formations. This classification strengthens the support that dinosaur communities in the Belly River Group maintained a relatively similar diversity at a more inclusive taxonomic level in each of its formations. These results show that some of the dinosaur clades from younger Belly River members were 
represented in the Foremost Formation as well, albeit by earlier diverging members of those clades (Ryan et al., 2012). 


\section{References}

Abdel-Aziz, S.H., Khalil, A.N. and S.A. Abdel-Maguid. 1993. Food and feeding habits of the common guitarflsh, Rhinobatos rhinobatos in the Egyptian Mediterranean waters. Indian Journal of Marine Sciences 22:287-290.

Archibald, J.D. 1996. Dinosaur Extinction and the End of an Era: What the Fossils Say.

Columbia University Press, New York. 240 pp.

Alexandrowicz, S.W. 1976. Foraminifera from the brackish Santonian deposits in the North Sudetic Basin (Western Poland). Annales de la Societe Geologique de Pologne 46:183195.

Bannerjee, I. and F. Goodarzi. 1990. Paleoenvironment and sulfur-boron contents of the Mannville (Lower Cretaceous) coals of southern Alberta, Canada. Sedimentary Geology 67(3-4):297-310.

Beavan, N.R. 1995. A marine fossil assemblage from the Foremost Formation (Cretaceous, Campanian), southern Alberta, and evaluation of North American Cretaceous elasmobranch biostratigraphy. Unpublished MSc Thesis, University of Calgary, Alberta $163 \mathrm{pp}$.

Beavan, N.R. and A.P. Russell. 1999. An elasmobranch assemblage from the terrestrial-marine transitional Lethbridge Coal Zone (Dinosaur Park Formation: upper Campanian), Alberta. Journal of Paleontology 73:494-503. 
Bell, P. R., and N. E. Campione. 2014. Taphonomy of the Danek Bonebed: a monodominant Edmontosaurus (Hadrosauridae) bonebed from the Horseshoe Canyon Formation, Alberta. Canadian Journal of Earth Sciences 51(11):992-1006.

Bhattacharya, J.P. and H.W. Posamentier. 1994. Sequence stratigraphic and allostratigraphic applications in the Alberta foreland basin. Geological Atlas of the Western Canada Sedimentary Basin. Canadian Society of Petroleum Geologists and Alberta Research Council, Calgary, Alberta 407-412.

Bice, K.L., Birgel, D., Meyers, P.A., Dahl, K.A., Hinrichs, K.U., and R.D. Norris. 2006. A multiple proxy and model study of Cretaceous upper ocean temperatures and atmospheric CO2 concentrations: Paleoceanography 21(2):1-17.

Blakey, R.C., 2014. Paleogeography and paleotectonics of the Western Interior Seaway. Jurassic-Cretaceous of North America: American Association of Petroleum Geologists, Search and Discovery Article 30392: 72.

Blob, R. W., and A. R. Fiorillo. 1996. The significance of vertebrate microfossil size and shape distributions for faunal abundance reconstructions: A Late Cretaceous example. Paleobiology 22:422-435.

Boggs Jr, S. 2006. Sedimentology and Stratigraphy. Pearson Education. London, UK. 676 pp.

Bohor, B.F. and D.M., Triplehorn. 1993. Tonsteins: altered volcanic ash layers in coal-bearing sequences. Geological Society of America Special Paper 285. 44pp.

Boltovskoy, E. and R.C. Wright. 2013. Recent foraminifera. Springer Science \& Business Media. New York, USA. 414 pp. 
Bonaparte, J.F. 1996. Cretaceous tetrapods of Argentina. Münchner Geowiss. Abh. (A) 30:73130.

Brett, C.E. and G.C. Baird. 1986. Comparative taphonomy: a key to paleoenvironmental interpretation based on fossil preservation. Palaios 1:207-227.

Brett-Surman, M. K. 1979. Phylogeny and palaeobiogeography of hadrosaurian dinosaurs. Nature 277(5697):560.

Brett-Surman, M.K. 1989. A revision of the Hadrosauridae (Reptilia: Ornithischia) and their evolution during the Campanian and Maastrichtian. Ph. D. Dissertation, Faculty of the Graduate School of Arts and Sciences of The George Washington University, Washington, D.C.

Brett-Surman, M.K. and J.R. Wagner. 2007. Horns and beaks: ceratopsian and ornithopod dinosaurs. Indiana Press, Bloomington, IN, 384 pp.

Brinkman, D. B. 1990. Paleoecology of the Judith River Formation (Campanian) of Dinosaur Provincial Park, Alberta, Canada: evidence from vertebrate microfossil localities. Palaeogeography, Palaeoclimatology, Palaeoecology 78(1-2):37-54.

Brinkman, D. B., M.J. Ryan, and D. A. Eberth. 1998. The paleogeographic and stratigraphic distribution of ceratopsids (Ornithischia) in the upper Judith River Group of western Canada. Palaios 13(2):160-169.

Brinkman, D.B. 2003. Review of nonmarine turtles from the Late Cretaceous of Alberta. Canadian Journal of Earth Sciences 40(4):557. 
Brinkman, D.B., Russell., A. P., Eberth, D. A., and J. Peng. 2004. Vertebrate palaeocommunities of the lower Judith River Group (Campanian) of southeastern Alberta, Canada, as interpreted from vertebrate microfossil assemblages. Palaeogeography, Palaeoclimatology, Palaeoecology 213(3-4): 295-313.

Brinkman, D.B. 2017. An Illustrated Guide to the Vertebrate Microfossils from the Dinosaur Park Formation. Royal Tyrrell Museum of Palaeontology. 162 pp.

Brown, B. and G.H. Pepper. 1910. The Cretaceous Ojo Alamo Beds of New Mexico: With Description of the New Dinosaur Genus Kritosaurus. Order of the Trustees, American Museum of Natural History 28(24): 267-274.

Brown, B. 1914. Corythosaurus casuarius, a new crested dinosaur from the Belly River Cretaceous, with provisional classification of the family Trachodontidae. Bulletin of the AMNH 33(35): 559-564

Brown, B. and E.M. Schlaikjer. 1943. A study of the troodont dinosaurs with the description of a new genus and four new species. Bulletin of the American Museum of Natural History 82:121-149.

Brown, C. M., N. E. Campione, H. C. Giacomini, L. J. O’Brien, M. J. Vavrek, and D. C. Evans. 2012. Ecological modelling, size distributions, and taphonomic size bias in dinosaur faunas: a comment on Codron et al. 2012. Biology Letters

Brumsack, H.J. 2006. The trace metal content of recent organic carbon-rich sediments: Implications for Cretaceous black shale formation. Palaeogeography, Palaeoclimatology, Palaeoecology 232(2-4):344-361. 
Cadrin, A.A.J., Kyser, T.K., Caldwell, W.G.E., and F.J. Longstaffe. 1996. Isotopic and chemical compositions of bentonites as paleoenvironmental indicators of the Cretaceous Western Interior Seaway. Palaeogeography, Palaeoclimatology, Palaeoecology 119(3-4):301-320.

Caldwell, W. G. E., ed. 1975. The Cretaceous System in the Western Interior of North America: Proceedings. Geological Association of Canada 13. Waterloo, Ont. 666 pp.

Caldwell, W.G.E. North B. R., Stelck C. R., and J.H. Wall. 1978. A foraminiferal zonal scheme for the Cretaceous System in the Interior Plains of Canada. Western and Arctic biostratigraphy Special Paper 18:495-576

Caldwell, W.G.E. 1983. The Cretaceous System in the Williston Basin, a modern appraisal. In: Fourth International Williston Basin Symposium. Christopher, J.E. and Kaldi, J. (eds.). Saskatchewan Geological Society, Special Publication 6:295-312.

Caldwell, W.G.E., Diner, R., Eicher, D. L., Fowler, S.P., North, B.R., Stelck, C.R. and L. von Holdt Wilhelm. 1993. Foraminiferal biostratigraphy of Cretaceous marine cyclothems in Caldwell, W.G.E. and Kauffman, E.G. (eds.), Evolution of the Western Interior Basin: Geological Association of Canada Special Paper 39:477-520.

Carman, K. 1929. Some Foraminifera from the Niobrara and Benton formations of Wyoming. Journal of Paleontology 3(3):309-315.

Carsey, D.O., 1926. Foraminifera of the Cretaceous of central Texas. University of Texas

Case, G. R. 1987. A new selachian fauna from the Late Campanian of Wyoming (Teapot Sandstone Member, Mesaverde Formation, Big Horn Basin). Palaeontographica, Abteilung A 197:1-37. 
Catuneanu, O., Sweet, A.R. and A.D. Miall. 2000. Reciprocal stratigraphy of the CampanianPaleocene Western Interior of North America. Sedimentary Geology 134(3):235-255.

Cattaneo, A. and R.J. Steel. 2003. Transgressive deposits: a review of their variability. EarthScience Reviews 62(3):187-228.

Chamney, T.P. 1976. Foraminiferal morphogroup symbol for paleoenvironmental interpretation of drill cutting samples: Arctic America, Albian continental margin. Maritime Sediments, Special Publication 18:585-624.

Chiba, K., M.J. Ryan, D. R. Braman, D. A. Eberth, E. E. Scott, C. M. Brown, Y. Kobayashi, and D.C. Evans 2015. Taphonomy of a monodominant Centrosaurus apertus (Dinosauria: Ceratopsia) bonebed from the upper Oldman Formation of southeastern Alberta. Palaios 30(9):655-667

Cook, E. 1995. Taphonomy of two non-marine lower Cretaceous bone accumulations from southeastern England. Palaeogeography, Palaeoclimatology, Palaeoecology 116(34):263-270.

Cumbaa, S. L., Shimada, K., and T. D. Cook. 2010. Mid-Cenomanian vertebrate faunas of the Western Interior Seaway of North America and their evolutionary, paleobiogeographical, and paleoecological implications. Palaeogeography, Palaeoclimatology, Palaeoecology 295(1):199-214.

Currie, P. J. and E. B. Koppelhus. 2005. Dinosaur Provincial Park: a spectacular ancient ecosystem revealed. Volume 1. Indiana University Press. Bloomington, IN. 672 pp. 
Cushman, J.A. 1948. Foraminifera, their classification and economic use 4. Cushman Laboratory for Foraminiferal Research. Sharon, Mass. 392 pp.

Cushman, J.A. and J.A. Waters. 1927. Some arenaceous foraminifera from the Upper Cretaceous of Texas. Contributions from the Cushman Laboratory for Foraminiferal Research 2:8185.

Cushman, J.A. and C. I. Alexander. 1930. Some Vaginulina and other foraminifera from the Lower Cretaceous of Texas. Contributions from the Cushman Laboratory for Foraminiferal Research 6(8):1-8.

Cushman, J. A., and E. R. Applin. 1946. Some Foraminifera of Woodbine age from Texas, Mississippi, Alabama, and Georgia. Contributions from the Cushman Laboratory of Foraminiferal Research 22:1-75.

Dawson, G.M. 1883. Preliminary report on the geology of the Bow and Belly River region, Northwest Territory, with special reference to the coal deposits. Geological Survey of Canada, Report of Progress B: 1-23.

Dawson, F.M., Kalkreuth, W.D. and A.R. Sweet. 1994. Stratigraphy and coal resource potential of the Upper Cretaceous to Tertiary strata of northwestern Alberta. Geological Survey of Canada Bulletin 1994. 466 pp.

DeCelles, P.G. 2004. Late Jurassic to Eocene evolution of the Cordilleran thrust belt and foreland basin system, western U.S.A. American Journal of Science 304:105-168.

Dodd, J.R. and R.J. Stanton. 1990. Paleoecology: concepts and applications. John Wiley \& Sons. Hoboken, NJ. 502 pp. 
Dodson, P. 1987. Microfossil studies of dinosaur palaeoecology, Judith River Formation of southern Alberta. In: Currie, P.J., Ecosystems, Short Papers. Royal Tyrrell Museum, Drumheller, Canada Occasional Papers 3:70- 75.

Dowling, D.B. 1915. Southern Alberta Geological Survey of Canada, Summary Report Part L:43-51

Dowling, D.B. 1917. The southern plains of Alberta. Geological Survey of Canada Memoir 93:200.

Eaton, J.G., and J.I. Kirkland. 2008. Diversity patterns of nonmarine Cretaceous vertebrates of the Western Interior Basin; pp. 263-313 in P. J. Harries (Ed.) High-Resolution Approaches in Stratigraphic Paleontology. Springer, Dordrecht.

Eberth, D. A., and A.L. Deino. 1992. A geochronology of the non-marine Judith River Formation of southern Alberta. In Mesozoic of the Western Interior: Abstracts for the Society of Economic Paleontologists and Mineralogists Theme Meeting, Fort Collins, Colorado. Society for Sedimentary Geology, Tulsa, Oklahoma, United States of America $24-25$.

Eberth, D. A., and A. P. Hamblin. 1993. Tectonic, stratigraphic, and sedimentological significance of a regional discontinuity in the upper Judith River Group (Belly River wedge) of southern Alberta, Saskatchewan, and northern Montana. Canadian Journal of Earth Sciences 30(1):174-200.

Eberth, D. A. 2002. Review and comparison of Belly River Group and Edmonton Group stratigraphy and stratigraphic architecture in the southern Alberta Plains. In Conference of the Canadian Society of Petroleum Geology, Calgary, Alberta, abstracts 54. 
Eberth, D.A. and M. A. Getty. 2005. Ceratopsian bonebeds: occurrences, origins and significance. In Dinosaur Provincial Park: A Spectacular Ancient Ecosystem Revealed, P.J. Currie and E.B. Koppelhus (eds.), Indiana University Press 46 (11):501-536.

Eberth, D.A., Rogers, R.R. and A.R. Fiorillo. 2007. A practical approach to the study of bonebeds; pp. 265-331 in R. Rogers, D. Eberth and A. Fiorillo (eds.) Bonebeds: genesis, analysis, and paleobiological significance.

Eberth, D.A., Evans, D.C. and D.W.H. Lloyd. 2014. Occurrence and taphonomy of the first documented hadrosaurid bonebed from the Dinosaur Park Formation (Belly River Group, Campanian) at Dinosaur Provincial Park, Alberta, Canada; pp.502-523 in D.A. Eberth and D.C. Evans (eds.) Hadrosaurs. Indiana University Press, Bloomington, IN.

Eberth, D.A. 2015. Origins of dinosaur bonebeds in the Cretaceous of Alberta, Canada. Canadian Journal of Earth Sciences, 52(8):655-681.

Eicher, D.L., 1960. Stratigraphy and micropaleontology of the Thermopolis Shale 15. Yale University. 123 pp.

Estes, R. 1964. Fossil vertebrates from the late Cretaceous Lance Formation, eastern Wyoming. Berkeley: University of California Press 49. 186 pp.

Estes, R. and P. Berberian. 1970. Paleoecology of a Late Cretaceous vertebrate community from Montana. Breviora 343:1-35.

Evans, D.C., P. J. Currie, D.A. Eberth, and M. J. Ryan. 2006. High-resolution lambeosaurine dinosaur biostratigirphy, Dinosaur Park Formation, Alberta: Sexual dimorphism reconsidered. In Journal of Vertebrate Paleontology 26(3):59A-59A. 
Evans, D.C. 2007a. Phylogeny of lambeosaurine dinosaurs using parsimony and Bayesian likelihood approaches. Journal of Vertebrate Paleontology 27(3):72A.

Evans, D.C. 2007b. Ontogeny and evolution of lambeosaurine dinosaurs (Ornithischia: Hadrosauridae). PhD dissertation, University of Toronto, Toronto, Ontario. 497 pp.

Evans, D. C., R. Bavington., and N. E. Campione. 2009. An unusual hadrosaurid braincase from the Dinosaur Park Formation, and the biostratigraphy of Parasaurolophus (Ornithischia: Lambeosaurinae) from southern Alberta. Canadian Journal of Earth Sciences 46(11):791800.

Fanti, F. and O. Catuneanu. 2009. Stratigraphy of the Upper Cretaceous Wapiti Formation, westcentral Alberta, Canada. Canadian Journal of Earth Sciences 46(4):263-286.

Fanti, F. and T. Miyashita. 2009. A high latitude vertebrate fossil assemblage from the Late Cretaceous of west-central Alberta, Canada: evidence for dinosaur nesting and vertebrate latitudinal gradient. Palaeogeography, Palaeoclimatology, Palaeoecology 275(1):37-53.

Fiorillo, A.R. 1988. Taphonomy of Hazard Homestead Quarry (Ogallala Group), Hitchcock County, Nebraska. Rocky Mountain Geology 26(2):57-97.

Frampton, E. K. 2006. Taphonomy and palaeoecology of mixed invertebrate-vertebrate fossil assemblage in the Foremost Formation (Cretaceous, Campanian), Milk River Valley, Alberta. Unpublished MSc Thesis, The University of Calgary, Alberta. 307 pp.

Freedman-Fowler, E. A., and J.R. Horner. 2015 A New Brachylophosaurin Hadrosaur (Dinosauria: Ornithischia) with an Intermediate Nasal Crest from the Campanian Judith River Formation of Northcentral Montana. PLOS One 10(11). 
Fricke, H.C. and B.Z. Foreman, J.O. 2010. Integrated climate model-oxygen isotope evidence for a North American monsoon during the Late Cretaceous. Earth Planet. Science Letters 289:11-21.

Friedrich, O. 2010. Benthic foraminifera and their role to decipher paleoenvironment during mid-Cretaceous Oceanic Anoxic Events-the "anoxic benthic foraminifera" paradox. Revue de micropaléontologie 53(3):175-192.

Gates, T.A. and S.D. Sampson. 2007. A new species of Gryposaurus (Dinosauria: Hadrosauridae) from the late Campanian Kaiparowits Formation, southern Utah, USA. Zoological Journal of the Linnean Society 151(2):351-376.

Gates, T. A., Horner, J. R., Hanna, R. R., and C.R. Nelson. 2011. New unadorned hadrosaurine hadrosaurid (Dinosauria, Ornithopoda) from the Campanian of North America. Journal of Vertebrate Paleontology 31(4):798-811.

Gates, T. A., Jinnah, Z., Levitt, C., and M.A. Getty, M. A. 2014. New hadrosaurid (Dinosauria, Ornithopoda) specimens from the lower-middle Campanian Wahweap Formation of southern Utah; pp. 156-173 in D.A. Eberth and D. C. Evans (eds.) Hadrosaurs. Indiana University Press, Bloomington, IN.

Gates, T. A., and R. Scheetz. 2015. A new saurolophine hadrosaurid (Dinosauria: Ornithopoda) from the Campanian of Utah, North America. Journal of Systematic Palaeontology 13(8):711-725.

Gale, A.S., Voigt, S., Sageman, B.B. and W.J. Kennedy. 2008. Eustatic sea-level record for the Cenomanian (Late Cretaceous) — extension to the Western Interior Basin, USA Geology 36(11):859-862 . 
Given, M.M. and J.H. Wall. 1971. Microfauna from the upper Cretaceous Bearpaw Formation of south-central Alberta. Bulletin of Canadian Petroleum Geology 19(2):502-544.

Glass, D.J. 1997. Lexicon of Canadian Stratigraphy, vol. 4, Western Canada including eastern British Columbia, Alberta, Saskatchewan and southern Manitoba. Canadian Society of Petroleum Geologists, Calgary. 772 pp.

Goloboff, P. A., Farris J. S., and K. C. Nixon. 2008. TNT, a free program for phylogenetic analysis.

Gradstein, F.M., Ogg, J.G., Schmitz, M. and G. Ogg. 2012. The Geologic Time Scale 2012. Elsevier. $1144 \mathrm{pp}$.

Gordon, J. 2002. Stratigraphy and Sedimentology of the Foremost Formation in Southeastern Alberta and Southwestern Saskatchewan. M. Sc. Dissertation, University of Regina, Regina, Saskatoon. 186 pp.

Goldschmidt, V.M., Peters, C.L. and H.,Hauptmann. 1932. Zur Geochemie des Bors. Nachrichten von der Gesellschaft der Wissenschaften zu Göttingen, MathematischPhysikalische Klasse 402-407.

Guenther, M. F. 2009. Influence of sequence heterochrony on hadrosaurid dinosaur postcranial development. The Anatomical Record 292(9):1427-1441.

Hamblin, A.P. and B. W. Abrahamson. 1996. Stratigraphic architecture of "Basal Belly River" cycles, Foremost Formation Belly River Group, subsurface of southern Alberta and southwestern Saskatchewan. Bulletin of Canadian Petroleum Geology 44:654-673. 
Hammer, Ø., Harper, D.A.T., and P.D. Ryan. 2001. PAST: Paleontological statistics software package for education and data analysis. Palaeontologia Electronica 4(1). http://palaeoelectronica.org/2001_1/past/issue1_01.htm

Haq, B.U. 1998. Natural gas hydrates: searching for the long-term climatic and slope-stability records. Geological Society, London, Special Publications 137(1):303-318.

Hathway, B., C.J. Banks, D.C. Hay and G.J. Prior. 2011. Measured Outcrop Sections T2-R6W401 and T2-R6W4-02 of the Foremost and Oldman Formations (Belly River Group), Pinhorn Provincial Grazing Reserve, Milk River Valley, Southeastern Alberta (NTS 72E/02). ERCB/AGS Open File Report 2011-03.

Hay, W.W. 2011. Can humans force a return to a 'Cretaceous 'climate: Sedimentary Geology 235(1-2):5-26.

He, S., Kyser, T.K. and W.G.E. Caldwell. 2005. Paleoenvironment of the Western Interior Seaway inferred from $\delta 18 \mathrm{O}$ and $\delta 13 \mathrm{C}$ values of molluscs from the Cretaceous Bearpaw marine cyclothem. Palaeogeography, Palaeoclimatology, Palaeoecology 217(1):67-85.

Henderson, L. J., Gordon, R, G., and D. C. Engebretson. 1984. Mesozoic aseismic ridges on the Farallon plate and southward migration of shallow subduction during the Laramide orogeny. Tectonics 3(2):121-132.

Hills L.V. and A.A. Levinson. 1975. Boron content and paleoecologic interpretation of Bearpaw and contiguous Upper Cretaceous strata in the Strathmore well of Southern Alberta. Geological Association of Canada Special Paper 13:411-415 
Hofer, G., Draganits, E., Wagreich, M., Hofmann, C.C., Reischenbacher, D., Grundtner, M.L. and M. Bottig. 2011. Stratigraphy and Geochemical Characterization of Upper Cretaceous Non-Marine-Marine Cycles (Grünbach Formation, Gosau Group, Austria). Austrian Journal of Earth Sciences 104(2):90-107.

Hofer, G., Wagreich, M., and S. Neuhuber. 2013. Geochemistry of fine-grained sediments of the upper Cretaceous to Paleogene Gosau Group (Austria, Slovakia): Implications for paleoenvironmental and provenance studies. Geoescience Frontiers 4(4):449-468

Horner, J. R., D. J. Varricchio and M.B. Goodwin. 1992. Marine transgressions and the evolution of Cretaceous dinosaurs. Nature 358:59-61.

Horner, J. R., De Ricqlès, A., and K. Padian. 2000. Long bone histology of the hadrosaurid dinosaur Maiasaura peeblesorum: growth dynamics and physiology based on an ontogenetic series of skeletal elements. Journal of Vertebrate Paleontology 20(1):115129.

Hsieh, H.L., Kao, W.Y., Chen, C.P. and P.J. Liu. 2000. Detrital flows through the feeding pathway of the oyster (Crassostrea gigas) in a tropical shallow lagoon: $\delta 13 \mathrm{C}$ signals. Marine biology 136(4):677-684.

Jerzykiewicz, T. and D.K. Norris. 1994. Stratigraphy, structure and syntectonic sedimentation of the Campanian "Belly River" clastic wedge in the southern Canadian Cordillera. Cretaceous Research 15:367-399.

Johnson, K.A., Culver, S.J. and D.L. Kamola. 2005. Marginal marine Foraminifera of the Blackhawk Formation (Late Cretaceous, Utah). Journal of Foraminiferal Research 35(1):50-64. 
Johnston, P. A. and A. J. W. Hendy. 2005. Paleoecology of Mollusks from the Upper Cretaceous Belly River Group; pp. 139-162 in P. J. Currie and E. Koppelhus (eds.) Dinosaur Provincial Park: A Spectacular Ancient Ecosystem Revealed.

Jones, R.W. and M.A. Charnock. 1985. "Morphogroups" of agglutinating foraminifera. Their life positions and feeding habits and potential applicability in (paleo) ecological studies. Revue de Paléobiologie 4(2):311-320.

Jorissen, F.J., de Stigter, H.C. and J.G. Widmark. 1995. A conceptual model explaining benthic foraminiferal microhabitats. Marine micropaleontology 26(1-4):3-15.

Jost, L. 2006. Entropy and diversity. Oikos 113(2):363-375.

Kauffman, E.G. 1977. Geological and biological overview: Western Interior Cretaceous basin. The Mountain Geologist. 265 pp.

Kauffman, E.G. and W.G.E. Caldwell. 1993. The Western Interior Basin in space and time; pp. 1-30 in W.G.E Caldwell and E. G. Kauffman. (eds.) Evolution of the Western Interior Basin: Geological Association of Canada, Special Paper 39.

Kauffman, G.B. 1997. Victor Moritz Goldschmidt (1888-1947): A tribute to the founder of modern geochemistry on the fiftieth anniversary of his death. The Chemical Educator 2(5):1-26.

Kidwell, S.M., 1986. Models for fossil concentrations: paleobiologic implications. Paleobiology 12:6-24.

Kirkland, J.I., Eaton, J.G. and D.B. Brinkman. 2013. Elasmobranchs from Upper Cretaceous freshwater facies in southern Utah; pp. 153-194 in A. L. Titus and M. A. Loewen (eds.) 
At the top of the grand staircase: The Late Cretaceous of Southern Utah. Indiana University Press, Bloomington, IN.

Kraishan, G.M. and N.M. Lemont. 1998. Siderite as a constraint on depositional and early diagenetic history: Examples from Barrow Sub-basin, North West Shelf, Western Australia. The APPEA Journal 38(1):238-253.

Kwasniowski, S. and D.A. Eberth. 1993. The Judith River Group (Belly River equivalent) of southern Alberta. Field Trip Guide Book, Pan Canadian, Sept. 29,30 and Oct 1,1993. $64 \mathrm{pp}$.

Laenen, B., and M. De Craen. (2004). Eogenetic siderite as an indicator for fluctuations in sedimentation rate in the Oligocene Boom Clay Formation (Belgium). Sedimentary Geology 163(3-4):165-174.

Langston, Wann, Jr. 1960. The Vertebrate Fauna of the Selma Formation in Alabama The Dinosaurs. Fieldiana, Geology Memoirs 3(6): 315-361.

LaRock J. W. 2000. Sedimentology and taphonomy of a dinosaur bonebed from the Upper Cretaceous (Campanian) Judith River Formation of North Central Montana. Unpublished Master's thesis, Montana State University, Bozeman. 61 pp.

Larson, D.W., Campione, N.E., Brown, C.M., Evans, D.C., and M.J. Ryan. 2014 Hadrosauroid material from the Santonian Milk River Formation of southern Alberta, Canada; pp. 136153 in D. A. Eberth and D. C. Evans (eds.) The Hadrosaurs (D.C. Evans and D.E. Eberth, eds.). Indiana University Press, Bloomington, IN. 
Lawton, T.F. 2008. Laramide sedimentary basins; pp. 429-450 in A.D. Miall (ed.) The Sedimentary Basins of the United States and Canada. Sedimentary Basins of the World 5. Elsevier.

Leckie, R.M. 1985. Foraminifera of the Cenomanian-Turonian Boundary Interval, Greenhorn Formation, Rock Canyon Anticline, Pueblo, Colorado.

Leckie, D.A. and D.G. Smith. 1993. Regional setting, evolution, and depositional cycles of the Western Canada Foreland Basin; in R.W. Macqueen and D.A. Leckie (eds.) Foreland Basins and Fold Belts. 487 pp.

Leckie, R.M., and H.C. Olson. 2003, Foraminifera as proxies for sea-level change on siliciclastic margins. SEPM Special Publication 75:5-19.

Leidy, J. 1856. Notice of remains of extinct reptiles and fishes, discovered by Dr. FV Hayden in the Bad Lands of the Judith River, Nebraska Territory. Proceedings of the Academy of Natural Sciences of Philadelphia 8:72-73.

Loeblich Jr, A.R. and H. Tappan 1950. North American Jurassic Foraminifera: I. The Type Redwater Shale (Oxfordian) of South Dakota. Journal of Paleontology 24(1):39-60.

Liu, S., and C.A Currie. 2015. Farallon plate dynamics prior to the Laramide orogeny: Numerical models of flat subduction. Tectonophysics 666:33-47.

Lund, E.K., and T.A. Gates. 2006. A historical and biogeographical examination of hadrosaurian dinosaurs. In: Lucas SG, Sullivan RM, eds. Late Cretaceous vertebrates from the Western Interior. New Mexico Museum of Natural History and Science Bulletin 35:263-276. 
MacEachern, J.A., Raychaudhuri, I. and S.G., Pemberton. 1992. Stratigraphic applications of the Glossifungites ichnofacies: delineating discontinuities in the rock record. AAPG Search and Discovery Article 90929.

MacEachern, J.A., Pemberton, S.G., Gingras, M.K., Bann, K.L., James, N.P. and R..W Dalrymple. 2010. Ichnology and facies models; pp.19-58 in N.P. James and R. W. Dalrymple (eds.) Facies models 4, Geological Association of Canada.

Maddison, W. P. and D.R. Maddison. 2001. Mesquite: a modular system for evolutionary analysis. Version 3.04.

Mallon, J. C., Evans, D.C., Ryan M.J., and J.S. Anderson. 2012. Megaherbivorous dinosaur turnover in the Dinosaur Park Formation (upper Campanian) of Alberta, Canada. Palaeogeography, Palaeoclimatology, Palaeoecology 350-352:124-138.

McLean, J. R. 1971. Stratigraphy of the Upper Cretaceous Judith River Formation in the Canadian Great Plains. Saskatchewan Research Council Geology Division Report 11. 96 pp.

McNeil, D.H. and W.G.E. Caldwell. 1981. Cretaceous rocks and their foraminifera in the Manitoba Escarpment. Geological Association of Canada Special Paper Series Special Paper 21. Geological Association of Canada. 439 pp.

McNeil, D.H., Wall, J.H., and D.A. Eberth. 1995. Parasequences and foraminiferal distributions in the Campanian Foremost Formation of southern Alberta. 10: Proceedings of the Oil and Gas Forum '95: Geological Survey of Canada Open File 3058:93-97. 
McNeil, D.H. 1997. Diagenetic regimes and the foraminiferal record in the Beaufort-Mackenzie Basin and adjacent cratonic areas. Annales Societatis Geologorum Poloniae 67:271-286

McLennan, S.M., Hemming, S., McDaniel, D.K. and, G.N. Hanson. 1993. Geochemical approaches to sedimentation, provenance, and tectonics. Geological Society of America Special Papers 284:21-40.

Meylan, P.A. and E.S. Gaffney. 1989. The skeletal morphology of the Cretaceous cryptodiran turtle, Adocus, and the relationships of the Trionychoidea. American Museum Novitates $2941.56 \mathrm{pp}$.

Miall, Andrew D., et al. 2009 The Western interior basin. Sedimentary basins of the world 5:329-362.

Miller, K.G., Sugarman, P.J., Browning, J.V., Kominz, M.A., Hernández, J.C., Olsson, R.K., Wright, J.D., Feigenson, M.D. and W. Van Sickel. 2003. Late Cretaceous chronology of large, rapid sea-level changes: Glacioeustasy during the greenhouse world. Geology 31(7):585-588.

Monger, J. W. H. 1993. Cretaceous tectonics of the North American cordillera. Evolution of the Western Interior basin: Geological Association of Canada Special Paper 39: 31-47.

Mori, H., Druckenmiller, P. S., and G.M. Erickson. (2015). A new Arctic hadrosaurid from the Prince Creek Formation (lower Maastrichtian) of northern Alaska. Acta Palaeontologica Polonica 61(1):15-32. 
Morris, R.W. 1971. Upper Cretaceous foraminifera from the upper Mancos Formation, the Mesaverde Group, and the basal Lewis Formation, northwestern Colorado. Micropaleontology 17(3):257-296.

Murray, J. W. 1991. Ecology and distribution of benthic foraminifera; pp. 221-254 in J.J. Lee and O.R. Anderson (eds.) Biology of foraminifera, Academic Press.

Murray, J. 2006. Ecology and Applications of Benthic Foraminifera: Cambridge, New York, NY, Cambridge University Press. 426 pp.

Murray, J.W., Alve, E., and B.W. Jones. 2011. A new look at modern agglutinated benthic foraminiferal morphogroups: their value in palaeoecological interpretation. Palaeogeography, Palaeoclimatology, Palaeoecology 309(3-4):229-241.

Nagy, J., F.M. Gradstein, M.A. Kaminski, and A.E Holbourn. 1995. Foraminiferal morphogroups, paleoenvironments and new taxa from Jurassic to Cretaceous strata of Thakkhola, Nepal. In Proceedings of the Fourth International Workshop on Agglutinated Foraminifera. Grzybowski Foundation Special Publication 3:181-209.

Nagy, J and S.H. Berge. 2008. Micropalaeontological evidence of brackish water conditions during deposition of the Knorringfjellet Formation, Late Triassic-Early Jurassic, Spitsbergen. Polar Research 27:413-427.

Nagy, J., Reolid, M. and F.J. Rodríguez-Tovar. 2009. Foraminiferal morphogroups in dysoxic shelf deposits from the Jurassic of Spitsbergen. Polar Research 28(2):214-221.

Nauss, A.W. 1947. Cretaceous microfossils of the Vermilion area, Alberta. Journal of Paleontology 21(4): 329-343. 
Nesbitt, H. and G.M. Young. 1982. Early Proterozoic climates and plate motions inferred from major element chemistry of lutites. Nature 299(5885):715-717.

Nesbitt, H.W. and G.M. Young. 1989. Formation and diagenesis of weathering profiles. The Journal of Geology 97(2):129-147.

Nicholls, E. L. and A.P. Russell. 1990. Paleobiogeography of the Cretaceous Western Interior Seaway of North America: the vertebrate evidence. Palaeogeography, Palaeoclimatology, Palaeoecology 79(1):149-169.

North, B.R. and W.G.E. Caldwell. 1964. Foraminifera from the Cretaceous Lea Park Formation in south-central Saskatchewan. Saskatchewan Research Council, Geology Division. 43 pp.

North, B.R. and W.G.E. Caldwell. 1970. Foraminifera from the Late Cretaceous Bearpaw Formation in the South Saskatchewan River Valley. Saskatchewan Research Council, Geology Division. 117 pp.

North, B.R. and W.G.E. Caldwell. 1975. Foraminiferal Faunas in the Cretaceous System of Saskatchewan. Geological Association of Canada Special Paper 13:303-331.

Ogunyomi, O. and L.V. Hills. 1977. Depositional environments, Foremost Formation (Late Cretaceous), Milk River area, southern Alberta. Bulletin of Canadian Petroleum Geology 25:929-968.

Oji, T., Ogaya, C. and T. Sato. 2003. Increase of shell-crushing predation recorded in fossil shell fragmentation. Paleobiology 29(4):520-526. 
Oksanen, J., Blanchet, F.G., Kindt, R., Legendre, P., Minchin, P.R., Ohara, R.B., Simpson, G.L., Solymos, P., Stevens, M.H.H., Wagner, H. and M.J. Oksanen. 2013. Package 'vegan'. Community ecology package 2(9).

Peng J., Russel A.P., and D. Brinkman. 2001 Vertebrate microsite assemblages (exclusive of mammals) from the Foremost and Oldman Formations of the Judith River Group (Campanian) of southeastern Alberta: an illustrated guide. Provincial Museum of Alberta Occasional Paper 25.

Phillips, A. 2009. A Late Cretaceous (Cenomanian) Marine Vertebrate- Rich Bioclastic Horizon from the Northeastern Margin of the Western Interior Seaway, Canada. Unpublished MSc Thesis. Carleton University. 254 pp.

Plint, A.G., James, N.P. and R.W. Dalrymple. 2010. Wave-and storm-dominated shoreline and shallow-marine systems pp. 167-200 in N.P. James and R. W. Dalrymple (eds.) Facies models 4, Geological Association of Canada.

Price L. L. and N.L. Ball. 1971. Stratigraphy of Duval Corporation potash shaft No. 1, Saskatoon, Saskatchewan. Geological Survey of Canada Paper 70-71. 107 pp.

Prothero, D.R. and F. Schwab. 2014. Sedimentary Geology Third Edition. W.H. Freeman and Company. 500 pp.

Prieto-Márquez, A., Weishampel D.B., and J.R. Horner. 2006b. The hadrosaurid dinosaur Hadrosaurus foulkii from the Campanian of the East coast of North America, with a review of the genus. Acta Palaeontologica Polonica 51:77-98. 
Prieto- Márquez, A. 2010. Global historical biogeography of hadrosaurid dinosaurs. Zoological Journal of the Linnean Society 159(2):503-525.

Prieto-Márquez, A., and C.I. Serrano Brañas. 2012. Latirhinus uitstlani, a 'broad-nosed' saurolophine hadrosaurid (Dinosauria, Ornithopoda) from the late Campanian (Cretaceous) of northern Mexico. Historical Biology 24(6):607-619.

Prieto-Márquez, A. 2014. Skeletal morphology of Kritosaurus navajovius (Dinosauria: Hadrosauridae) from the Late Cretaceous of the North American south-west, with an evaluation of the phylogenetic systematics and biogeography of Kritosaurini. Journal of Systematic Palaeontology 12(2):133-175.

Prieto- Márquez, A., Gregory, M.E., and J. A. Ebersole. 2016. A primitive hadrosaurid from southeastern North America and the origin and early evolution of 'duck-billed' dinosaurs. Journal of Vertebrate Paleontology 36 (2):e1054495.

Renne P.R., Mundil R., Balco G., Min K., and K. Ludwig. 2010. Joint determination of 40K decay constants and 40Ar*/40K for the Fish Canyon sanidine standard, and improved accuracy for 40Ar/39Ar geochronology. Geochimica et Cosmochimica Acta 74:53495367.

Reolid, M., Nikitenko, B.L., and L. Glinskikh. 2014. Trochammina as opportunist foraminifera in the Lower Jurassic from north Siberia: Polar Research 33:21653.

Rogers, R.R. 1998. Sequence analysis of the Upper Cretaceous Two Medicine and Judith River formations, Montana: nonmarine response to the Claggett and Bearpaw marine cycles. Journal of Sedimentary Research 68(4):615-631. 
Rogers, R. R., and S. M. Kidwell, S. M. 2000. Associations of vertebrate skeletal concentrations and discontinuity surfaces in terrestrial and shallow marine records: a test in the Cretaceous of Montana. The Journal of Geology 108(2):131-154.

Rogers, R.R. and M.E. Brady. 2010. Origins of microfossil bonebeds: insights from the Upper Cretaceous Judith River Formation of north-central Montana. Paleobiology 36(1):80-112.

Rogers, R.R., Kidwell, S.M., Deino, A.L., Mitchell, J.P., Nelson, K. and J.T. Thole. 2016. Age, correlation, and lithostratigraphic revision of the Upper Cretaceous (Campanian) Judith River Formation in its type area (north-central Montana), with a comparison of low-and high-accommodation alluvial records. The Journal of Geology 124(1):99-135.

Russell, L. S., and R.W. Landes. 1940. Geology of the southern Alberta Plains. Canada. Dept. of Mines and Resources. Geological Survey Memoir 221.

Russell, L.S. 1966. Dinosaur hunting in western Canada. Royal Ontario Museum Life Science Contributions 70:1-37.

Ryan, M.J., and A.P. Russell. 2005. A new centrosaurine ceratopsid from the Oldman Formation of Alberta and its implications for centrosaurine taxonomy and systematics. Canadian Journal of Earth Sciences 42(7):1369-1387.

Ryan M.J., Evans, D.C., and K.M. Shepherd. 2012. A new ceratopsid from the Foremost Formation (middle Campanian) of Alberta. Canadian Journal of Earth Sciences 49(10):1251-1262. 
Saffert, H., and E. Thomas. 1998. Living foraminifera and total populations in salt marsh peat cores: Kelsey Marsh (Clinton, CT) and the Great Marshes (Barnstable, MA). Marine Micropaleontology 33(3-4):175-202.

Sageman, B. B., and M. A. Arthur. 1994. Early Turonian paleogeographic/paleobathymetric map, western interior, US; pp. 457-470 in M.V. Caputo, J.A. Peterson and K.J. Franczyk (eds.) Mesozoic Systems of the Rocky Mountain Region, USA. The Rocky Mountain Section SEPM, Denver, Colorado.

Sageman, B.B. and T.W. Lyons. 2004. Geochemistry of fine-grained sediments and sedimentary rocks. Treatise on Geochemistry 7:115-158.

Sankey, J. T. 2000. Late Campanian southern dinosaurs, Aguja Formation, Big Bend, Texas. Journal of Paleontology 75(1):208-215.

Schott, R. K. et al. 2009. The Anatomy and Systematics of Colepiocephale Lambei (Dinosauria: Pachycephalosauridae. Journal of Vertebrate Paleontology 29(3):771-786.

Schröder-Adams, C. 2006. Estuaries of the past and present: a biofacies perspective. Sedimentary Geology 190(1-4):289-298.

Schröder-Adams, C. 2014. The Cretaceous Polar and Western Interior seas: paleoenvironmental history and paleoceanographic linkages. Sedimentary Geology 301:26-40.

Schultze, H. P. 1996. The scales of Mesozoic actinopterygians; pp. 83-93 in G. Arratia and G. Viohl (eds.) Mesozoic Fishes - Systematics and Paleoecology. Museum für Naturkunde in Berlin, Deutsche Forschungsgemeinschaft. 
Severin, K.P. 1983. Test morphology of benthic foraminifera as a discriminator of biofacies. Marine Micropaleontology 8(1):65-76.

Shimada, K and M.J. Everhart. 2003. Ptychodus mammillaris (Elasmobranchii) and Enchodus cf. E. shumardi (Teleostei) from the Fort Hays Limestone Member of the Niobrara Chalk (Upper Cretaceous) in Ellis County, Kansas. Transactions of the Kansas Academy of Science 106(3):171-176.

Shotwell, J.A.1955. An approach to the paleoecology of mammals. Ecology 36(2):327-337.

Shotwell, J.A. 1958. Inter-Community Relationships in Hemphillian (Mid-Pliocene) Mammals. Ecology 39(2):271-282.

Sternberg, C. M. 1945. Pachycephalosauridae proposed for dome-headed dinosaurs, Stegoceras lambei, n. sp., described. Journal of Paleontology 19:534-538.

Sternberg, C. M. 1953. A new hadrosaur from the Oldman Formation of Alberta: discussion of nomenclature. Edmond Cloutier, Queen's Printer. Natl Mus Canada Bull 128: 275-286

Sues, H. D. and A. Averianov. 2009. A new basal hadrosauroid dinosaur from the Late Cretaceous of Uzbekistan and the early radiation of duck-billed dinosaurs. Proceedings of the Royal Society of London B: Biological Sciences 276(1667): 2549-2555.

Sullivan, R.M. 1999. Nodocephalosaurus kirtlandiensis gen. et sp. nov., a new ankylosaurid dinosaur (Ornithischia: Ankylosauria) from the Upper Cretaceous (Late Campanian) Kirtland Formation of New Mexico. Journal of Vertebrate Paleontology 19:126-139.

Swift, D. J. (1968). Coastal erosion and transgressive stratigraphy. Journal of Geology 76(4):444-456. 
Swofford, D. L. 2002. PAUP*. Phylogenetic Analysis Using Parsimony (*and Other Methods). Version 4.0b10 Sinauer Associates, Sunderland, Massachusetts.

Tappan, H. 1962. Cretaceous Foraminifera, Part 3 of Foraminifera from the Arctic slope of Alaska. US Geological Survey, Professional Paper 236:91-209.

Tribovillard, N., Riboulleau, A., Lyons, T. and F. Baudin 2004. Enhanced trapping of molybdenum by sulfurized marine organic matter of marine origin in Mesozoic limestones and shales. Chemical Geology 213(4):385-401.

Valieri, R. D., Haro, J. A., Fiorelli, L. E., and J. O. Calvo 2010. A new hadrosauroid (Dinosauria: Ornithopoda) from the Allen Formation (Late Cretaceous) of Patagonia, Argentina. Revista del Museo Argentino de Ciencias Naturales 12(2):217-231.

Vaughn, C.C., Gido, K.B. and D.E. Spooner. 2004. Ecosystem processes performed by unionid mussels in stream mesocosms: species roles and effects of abundance. Hydrobiologia. 527(1):35-47.

Wagner, J. R. (2001). The hadrosaurian dinosaurs (Ornithiscia: Hadrosauria) of Big Bend National Park, Brewster County, Texas, with implications for late Cretaceous paleozoogeography (Ph. D. dissertation, Texas Tech University, Lubbock, Texas.

Wagner, J. R., and T.M. Lehman. 2009. An enigmatic new lambeosaurine hadrosaur (Reptilia: Dinosauria) from the upper shale member of the Campanian Aguja Formation of TransPecos Texas. Journal of Vertebrate Paleontology 29(2):605-611.

Wall, J.H., 1960. Upper Cretaceous foraminifera from the Smoky River Area, Alberta. Research Council of Alberta 6. 42 pp. 
Wall, J.H., Sweet, A.R. and L.V. Hills. 1971. Paleoecology of the Bearpaw and contiguous Upper Cretaceous formations in the CPOG Strathmore well, southern Alberta. Bulletin of Canadian Petroleum Geology 19(3):691-702.

Wall, J. H. 1983. Jurassic and Cretaceous foraminiferal biostratigraphy in the eastern Sverdrup Basin, Canadian Arctic Archipelago. Bulletin of Canadian Petroleum Geology 31(4):246281.

Weishampel, D.B., Barrett, P.M., Coria, R.A., LeLoeuff, J., Xu, X., and Z. Xijin. 2004. Dinosaur distribution; pp. 517-606 in D.B. Weishampel, P. Dodson, and H. Osmólska (eds.) The Dinosauria. University of California Press. Berkeley, California.

Wickenden, R. T.1932. New species of foraminifera from the upper Cretaceous of the Prairie Provinces. Proceedings and Transactions of the Royal Society of Canada 26(4):85-92.

Williams, G. D., and C. R. Stelck. 1975 Speculations on the Cretaceous paleogeography of North America. The Cretaceous System in the Western Interior of North America: Geological Association of Canada Special Paper 13:1-20.

Wu, W., and P. Godefroit. 2012. Anatomy and relationships of Bolong yixianensis, an Early Cretaceous iguanodontid dinosaur from western Liaoning, China; pp. 293-334 in P. Godefroit (ed.) Bernissart Dinosaurs and Early Cretaceous Terrestrial Ecosystems.

Xing, H., Wang, D., Han, F., Sullivan, C., Ma, Q., He, Y., Hone, D.W., Yan, R., Du, F. and X. Xu. 2014. A new basal hadrosauroid dinosaur (Dinosauria: Ornithopoda) with transitional features from the Late Cretaceous of Henan Province, China. PLoS One 9(6):p.e98821. 
Yandoka, B.M.S., Abdullah, W.H., Abubakar, M.B., Hakimi, M.H. and A.K. Adegoke. 2015. Geochemistry of the Cretaceous coals from Lamja Formation, Yola Sub-basin, Northern Benue Trough, NE Nigeria: Implications for paleoenvironment, paleoclimate and tectonic setting. Journal of African Earth Sciences 104:56-70. 


\section{Appendices}

\section{Appendix A: Sample List}

\begin{tabular}{|l|l|}
\hline Section A Sample \# & Section Height $(\mathbf{m})$ \\
\hline $\mathbf{1}$ & Base Level \\
\hline $\mathbf{2}$ & 1 \\
\hline $\mathbf{3}$ & 2 \\
\hline $\mathbf{4}$ & 3.5 \\
\hline $\mathbf{5}$ & 5 \\
\hline $\mathbf{6}$ & 6.5 \\
\hline $\mathbf{7}$ & 8 \\
\hline $\mathbf{8}$ & 9 \\
\hline $\mathbf{9}$ & 11.5 \\
\hline
\end{tabular}

Table A-1: Section A Sample list

\begin{tabular}{|l|l}
\hline Section B Sample \# & Section Height (m) \\
\hline $\mathbf{1}$ & Base level
\end{tabular}

Table A-2: Section B Sample list 


\begin{tabular}{|c|c|}
\hline Section C Sample \# & Section Height (m) \\
\hline 1 & Base level \\
\hline 2 & 0.5 \\
\hline 3 & 1.8 \\
\hline 4 & 3.2 \\
\hline 5 & 4.7 \\
\hline 6 & 7 \\
\hline 7 & 9 \\
\hline 8 & 11 \\
\hline 9 & 13.2 \\
\hline 10 & 15.5 \\
\hline 11 & 16.5 \\
\hline 12 & 18.6 \\
\hline 13 & 26.6 \\
\hline 14 & 28.6 \\
\hline 15 & 31 \\
\hline 16 & 33 \\
\hline 17 & 35 \\
\hline 18 & 44 \\
\hline 19 & 46 \\
\hline 20 & 49 \\
\hline 21 & 52 \\
\hline 22 & 55 \\
\hline 23 & 58 \\
\hline 24 & 59 \\
\hline
\end{tabular}

Table A-3: Section C Sample List 


\begin{tabular}{|c|c|}
\hline Section C Sample \# & Section Height (m) \\
\hline 25 & 62 \\
\hline \multicolumn{2}{|l|}{26} \\
\hline 27 & 66 \\
\hline 28 & 68 \\
\hline 29 & 70 \\
\hline 30 & 72 \\
\hline 31 & 73 \\
\hline 32 & 76 \\
\hline 33 & 84 \\
\hline 34 & 85 \\
\hline 35 & 86.5 \\
\hline 36 & 88 \\
\hline 37 & 99 \\
\hline 38 & 102.5 \\
\hline 39 & 106 \\
\hline 40 & 109 \\
\hline 41 & 116 \\
\hline 42 & 118 \\
\hline 43 & 121 \\
\hline 44 & 122.2 \\
\hline 45 & 125.6 \\
\hline 46 & 128 \\
\hline 47 & 131.5 \\
\hline 48 & 133.5 \\
\hline 49 & 136 \\
\hline 50 & 139 \\
\hline
\end{tabular}

Table A-3 continued 


\begin{tabular}{|l|l|}
\hline Section D Sample \# & Section Height $(\mathbf{m})$ \\
\hline $\mathbf{1}$ & 1.5 \\
\hline $\mathbf{2}$ & 4 \\
\hline $\mathbf{3}$ & 9 \\
\hline $\mathbf{4}$ & 11.5 \\
\hline $\mathbf{5}$ & 12 \\
\hline $\mathbf{6}$ & 12.5 \\
\hline
\end{tabular}

Table A-4: Section D Sample list

\begin{tabular}{|l|l|}
\hline Section E Sample \# & Section Height $(\mathbf{m})$ \\
\hline $\mathbf{1}$ & 22 \\
\hline $\mathbf{2}$ & 69 \\
\hline $\mathbf{3}$ & 75 \\
\hline
\end{tabular}

Table A-5: Section E Sample list 


\title{
Appendix B: Foraminifera Taxonomy and Data
}

\author{
Family SACCAMMINIDAE (Brady, 1884) \\ Genus Saccammina (Sars, 1869) \\ Saccammina alexanderi (Loeblich and Tappan, 1950) \\ 1950 Proteonia alexanderi Loeblich and Tappan, p. 5, Pl. 1, Fig. 6 \\ Family RZEHAKINIDAE (Cushman, 1933) \\ Genus Miliammina (Heron-Allen and Earland, 1930) \\ Miliammina sproulei (Nauss, 1947) \\ 1947 Miliammina sproulei Naus, p. 339, Pl. 48, Figs. 13a and 13b
}

Family TELAMMINIDAE (Loeblich and Tappan, 1985)

Genus Reophax (de Montfort, 1808)

Reophax texanus (Cushman and Waters, 1927)

1927 Reophax texanus Cushman and Waters, p. 82, P1. 10, Fig. 2 
Family HAPLOPHRAGMOIDIDAE (Maync, 1952)

Genus Haplophragmoides (Cushman, 1910)

Haplophragmoides calcula, (Cushman and Waters, 1927)

1927 Haplophragmoides calcula Cushman and Water, p. 83, Pl. 10, Figs. 5a and 5b

Haplophragmoides fraseri, (Wickenden, 1932)

1932 Haplophragmoides fraseri Wickenden, p. 86, Pl.1, Fig 2a

Haplophragmoides glabra (Cushman and Waters, 1927)

1927 Haplophragmoides glabra Cushman and Waters, p. 83, Pl. 10, Fig.6

Haplophragmoides linki (Nauss, 1947),

1947 Haplophragmoides linki Nauss, p. 339, Pl. 49, Figs. 7a and 7b

Haplophragmoides rota (Nauss, 1947)

1947 Haplophragmoides rota Nauss, p. 339, Pl. 49, Figs. 1-3 
Family TROCHAMMINIDAE (Schwager, 1877)

Genus Trochammina (Parker and Jones, 1859)

Trochammina albertensis (Wickenden, 1932)

1932 Trochammina albertensis Wickenden, p. 90, Pl. 1, Figs. 9a-9c

Trochammina diagonis (Carsey, 1926)

1926 Trochammina diagonis Carey, p. 22, P1. 3, Fig. 1

Trochammina rainwateri (Cushman and Applin, 1946)

1946 Trochammina rainwateri Cushman and Applin, p. 75, P1. 13, Fig. 9

Trochammina sp.

Family VERNEUILINIDAE (Cushman, 1911)

Genus Gaudryina (d'Orbigny, 1839)

Gaudryina bentonensis, (Carman, 1929)

1929 Gaudryina bentonensis Carman, p. 311, Pl. 34, Figs. 8 and 9 
Genus Verneuilinoides (Loeblich and Tappan, 1949)

Verneuilinoides bearpawensis (Wickenden, 1932)

1932 Verneuilinoides bearpawensis Wickenden, p. 87, P1. 1, Fig. 8

Family TEXTULARIIDAE (Ehrenberg,1838)

Genus Textularia (Defrance, 1824)

Textularia sp.

Family PSEUDOGAUDRYINIDAE (Loeblich and Tappan, 1985)

Genus Pseudoclavulina (Cushman, 1936)

Pseudoclavulina sp

Family LITUOLIDAE (Blainville, 1827)

Genus Ammobaculites (Cushman, 1910)

Ammobaculites fragmentarius (Cushman, 1927)

1927 Ammobaculites fragmentarius Cushman, p. 130, Pl. 1, Fig. 8 
Ammobaculites petilus (Eicher, 1960)

1960 Ammobaculites petilus Eicher, p. 62-63, Pl. 4, Figs. 2 and 4

Genus Ammotium (Loeblich and Tappan, 1953)

Ammotium sp.

Family SPIROPLECTAMMINIDAE (Cushman, 1927)

Genus Ammobaculoides (Plummer, 1932)

Ammobaculoides sp.

Genus Spiroplectammina (Cushman, 1927)

Spiroplectammina whitneyi (Cushman and Alexander, 1930)

1930 Spiroplectammina whitneyi Cushman and Alexander, p. 8, Pl. 2, Figs. 12a and 12b

Family EGGERELLIDAE (Cushman, 1937)

Genus Dorothia (Plummer, 1931)

Dorothia smokyensis (Wall, 1960)

1960 Dorothia smokyensis Wall, p. 23-25, Pl. 4, Figs. 22-28 


\section{Appendix C: Geochemical Data}

\begin{tabular}{|c|c|c|c|c|c|c|c|c|c|c|c|c|}
\hline Element & Mo & $\mathbf{C u}$ & $\mathbf{P b}$ & Zn & Ag & $\mathbf{N i}$ & Co & Mn & $\mathbf{F e}$ & As & Au & Th \\
\hline Unit & PPM & PPM & PPM & PPM & PPM & PPM & PPM & PPM & $\%$ & PPM & PPB & PPM \\
\hline LDL & 0.1 & 0.1 & 0.1 & 1 & 0.1 & 0.1 & 0.1 & 1 & 0.01 & 0.5 & 0.5 & 0.1 \\
\hline \multicolumn{13}{|l|}{$\begin{array}{l}\text { Sample } \\
\#\end{array}$} \\
\hline A1 & 0.6 & 35.6 & 15.4 & 96 & 0.1 & 30.5 & 11 & 1257 & 3.75 & 7.1 & 2.5 & 6.7 \\
\hline A2 & 0.7 & 42.1 & 17 & 116 & 0.2 & 39.1 & 13.8 & 767 & 3.08 & 10.2 & 2.4 & 6.8 \\
\hline A3 & 0.6 & 41.1 & 16.7 & 110 & 0.2 & 39.7 & 13.8 & 1230 & 3.69 & 7.1 & 2.7 & 6.6 \\
\hline A4 & 0.6 & 39.8 & 16.2 & 108 & 0.2 & 36.3 & 13.1 & 1782 & 4.6 & 7.6 & 2 & 6.4 \\
\hline A5 & 0.7 & 38.5 & 13.6 & 96 & 0.2 & 38 & 14.4 & 804 & 3.14 & 12.1 & 1.2 & 5.5 \\
\hline A6 & 0.6 & 37.1 & 13.1 & 92 & 0.1 & 34.6 & 13.1 & 340 & 2.74 & 18.2 & 2.4 & 5.5 \\
\hline A7 & 0.9 & 32.1 & 13.1 & 94 & 0.1 & 28.3 & 10.9 & 87 & 1.66 & 10 & 2.1 & 5.4 \\
\hline A8 & 0.5 & 24.2 & 9.5 & 69 & 0.1 & 23.3 & 9.4 & 532 & 2.05 & 4.5 & 1.3 & 5.2 \\
\hline A9 & 1.2 & 24.8 & 6.9 & 28 & 0.2 & 13.4 & 2.9 & 36 & 1.46 & 22.9 & 3 & 5.5 \\
\hline $\mathrm{C} 2$ & 0.5 & 23.1 & 11.6 & 82 & 0.1 & 19.1 & 8.9 & 95 & 2.17 & 12.9 & 1.1 & 7.2 \\
\hline $\mathrm{C3}$ & 1 & 41 & 12.2 & 124 & 0.2 & 45.8 & 15.2 & 311 & 2.41 & 10.2 & 1.6 & 6.1 \\
\hline $\mathrm{C} 4$ & 0.6 & 29.3 & 10.6 & 88 & $<0.1$ & 34.5 & 14.1 & 523 & 2.68 & 11.6 & 3.6 & 4.7 \\
\hline C5 & 0.5 & 37.4 & 13 & 98 & 0.1 & 35.4 & 12.9 & 419 & 2.63 & 7.4 & 1.6 & 5.7 \\
\hline C6 & 0.5 & 32.9 & 12 & 92 & 0.1 & 36.1 & 13 & 726 & 2.84 & 4.4 & 1.5 & 5.5 \\
\hline C7 & 0.6 & 43.6 & 12.9 & 89 & 0.2 & 36.1 & 12.9 & 652 & 2.69 & 5.6 & 0.9 & 5.5 \\
\hline C8 & 0.5 & 29.2 & 10.6 & 86 & 0.1 & 32.3 & 11.8 & 525 & 2.51 & 6.2 & 1.7 & 4.8 \\
\hline C9 & 0.2 & 12.8 & 6.2 & 59 & $<0.1$ & 18.9 & 7.6 & 262 & 1.67 & 4.2 & 1.8 & 3.2 \\
\hline $\mathrm{C} 10$ & 0.5 & 12 & 5.7 & 59 & $<0.1$ & 30.1 & 10.7 & 244 & 1.55 & 4.9 & 1.3 & 3.1 \\
\hline C11 & 0.7 & 42.7 & 15.1 & 93 & 0.2 & 42.4 & 14.9 & 1127 & 3.9 & 6.7 & 1.7 & 5.5 \\
\hline
\end{tabular}

Table C-1: Geochemical data from Sections A and C in this study of the Foremost Formation of the Pinhorn Ranch Area 


\begin{tabular}{|c|c|c|c|c|c|c|c|c|c|c|c|c|}
\hline Element & Mo & $\mathrm{Cu}$ & $\mathbf{P b}$ & Zn & Ag & $\mathbf{N i}$ & Co & Mn & $\mathrm{Fe}$ & As & $\mathbf{A u}$ & Th \\
\hline Unit & PPM & PPM & PPM & PPM & PPM & PPM & PPM & PPM & $\%$ & PPM & PPB & PPM \\
\hline LDL & 0.1 & 0.1 & 0.1 & 1 & 0.1 & 0.1 & 0.1 & 1 & 0.01 & 0.5 & 0.5 & 0.1 \\
\hline \multicolumn{13}{|l|}{$\begin{array}{l}\text { Sample } \\
\#\end{array}$} \\
\hline C12 & 0.5 & 11 & 6.7 & 51 & $<0.1$ & 26 & 9.4 & 205 & 1.43 & 8.8 & 0.7 & 2.7 \\
\hline C13 & 0.7 & 46.9 & 14.6 & 109 & 0.2 & 45.4 & 16.6 & 1004 & 3.78 & 4 & 2.6 & 6 \\
\hline C14 & 0.9 & 48.9 & 14.8 & 105 & 0.2 & 45.4 & 13.8 & 420 & 2.63 & 9.4 & 3.2 & 5.9 \\
\hline C15 & 0.6 & 42.2 & 12.6 & 95 & 0.2 & 42.9 & 15.3 & 956 & 3.61 & 4.9 & 1.1 & 5.6 \\
\hline C16 & 0.9 & 40.3 & 12.5 & 90 & 0.1 & 38.4 & 13 & 455 & 2.3 & 10.6 & 2.1 & 5.2 \\
\hline C17 & 0.7 & 36.4 & 13.4 & 95 & 0.2 & 34.7 & 13.3 & 1109 & 3.33 & 5.1 & 1.2 & 5.9 \\
\hline C18 & 0.5 & 39.4 & 14.4 & 92 & 0.1 & 34.6 & 13 & 509 & 2.53 & 9.1 & 1.6 & 6.3 \\
\hline C19 & 0.6 & 31.3 & 11.5 & 85 & 0.1 & 28.7 & 11.5 & 872 & 3.18 & 12.1 & 2 & 5.5 \\
\hline C20 & 0.5 & 30.3 & 12.6 & 82 & 0.1 & 28.4 & 11.1 & 280 & 2.07 & 11.3 & 0.9 & 5.5 \\
\hline C21 & 0.5 & 34.7 & 14.4 & 86 & 0.1 & 29.9 & 12.4 & 483 & 2.52 & 13.2 & 2.3 & 6.6 \\
\hline $\mathrm{C} 22$ & 0.5 & 38.9 & 14.4 & 91 & 0.1 & 30.2 & 12.1 & 907 & 3.07 & 5.4 & 2.6 & 6.3 \\
\hline $\mathrm{C} 23$ & 0.6 & 18.2 & 9.5 & 70 & 0.1 & 26.6 & 10.7 & 581 & 2.54 & 12 & 2 & 4.5 \\
\hline C24 & 0.4 & 5.9 & 4.7 & 42 & $<0.1$ & 18.9 & 8.3 & 853 & 4.45 & 4.6 & 1 & 2.7 \\
\hline $\mathrm{C} 25$ & 0.4 & 36.4 & 12.4 & 79 & 0.1 & 27.3 & 10.8 & 879 & 3.06 & 4.6 & 0.7 & 5.9 \\
\hline C27 & 0.5 & 42.4 & 16.4 & 98 & 0.1 & 38.3 & 13.4 & 1369 & 2.94 & 13.5 & 1.7 & 6.7 \\
\hline $\mathrm{C} 28$ & 0.6 & 27.7 & 12.1 & 65 & 0.1 & 28.5 & 11.9 & 449 & 1.8 & 12.3 & 2.2 & 5.4 \\
\hline C29 & 0.5 & 17.8 & 8.8 & 60 & $<0.1$ & 25.6 & 11.2 & 1048 & 2.92 & 8.9 & 2.1 & 4.4 \\
\hline C30 & 0.4 & 16.1 & 9.4 & 59 & $<0.1$ & 22.6 & 10.2 & 577 & 1.74 & 11.9 & 2.1 & 4.4 \\
\hline C31 & 0.8 & 36.1 & 13.5 & 79 & 0.2 & 33.6 & 13.7 & 805 & 2.58 & 9.7 & 2.1 & 6 \\
\hline C32 & 1 & 24.6 & 19 & 65 & 0.2 & 28.7 & 11.2 & 252 & 2.17 & 26.7 & 1.1 & 6.8 \\
\hline C33 & 0.3 & 4 & 3.3 & 17 & $<0.1$ & 5.6 & 4 & 639 & 1.94 & 6 & $<0.5$ & 1.7 \\
\hline
\end{tabular}

Table $\mathbf{C}-1$ continued 


\begin{tabular}{|c|c|c|c|c|c|c|c|c|c|c|c|c|}
\hline Element & Mo & $\mathbf{C u}$ & $\mathbf{P b}$ & Zn & Ag & $\mathbf{N i}$ & Co & Mn & $\mathrm{Fe}$ & As & $\mathbf{A u}$ & Th \\
\hline Unit & PPM & PPM & PPM & PPM & PPM & PPM & PPM & PPM & $\%$ & PPM & PPB & PPM \\
\hline LDL & 0.1 & 0.1 & 0.1 & 1 & 0.1 & 0.1 & 0.1 & 1 & 0.01 & 0.5 & 0.5 & 0.1 \\
\hline \multicolumn{13}{|l|}{$\begin{array}{l}\text { Sample } \\
\#\end{array}$} \\
\hline C34 & 0.3 & 6.3 & 4.7 & 31 & $<0.1$ & 9.1 & 4.6 & 145 & 1.01 & 7.8 & $<0.5$ & 3.7 \\
\hline C35 & 0.2 & 3.6 & 4.6 & 29 & $<0.1$ & 6.9 & 3.5 & 230 & 1.13 & 5.1 & $<0.5$ & 3.9 \\
\hline C36 & 0.4 & 3.4 & 4.3 & 24 & $<0.1$ & 6.7 & 3.4 & 832 & 2.66 & 5.2 & $<0.5$ & 3.6 \\
\hline $\mathrm{C} 37$ & 1 & 42.4 & 14.2 & 121 & 0.2 & 21.9 & 11.5 & 62 & 1.79 & 7.5 & 1.2 & 8.5 \\
\hline C38 & 2 & 14.7 & 7.2 & 33 & $<0.1$ & 7.1 & 2.7 & 11 & 0.48 & 3.8 & 0.5 & 3 \\
\hline C39 & 1.6 & 40 & 13.6 & 70 & 0.2 & 21.9 & 8.7 & 65 & 2.26 & 11.5 & 1.4 & 8.2 \\
\hline $\mathrm{C} 40$ & 1.9 & 27.3 & 17.9 & 74 & 0.1 & 19.1 & 8 & 279 & 2.03 & 14.7 & 1.9 & 9.2 \\
\hline $\mathrm{C} 41$ & 2.7 & 42.1 & 12.5 & 71 & 0.2 & 63.3 & 14.4 & 161 & 2.01 & 10.3 & 1.4 & 7.4 \\
\hline $\mathrm{C} 42$ & 2.1 & 29.5 & 16.6 & 113 & 0.2 & 18.5 & 9.9 & 162 & 2.25 & 11.4 & 1.6 & 8.9 \\
\hline $\mathrm{C} 43$ & 5.9 & 23.3 & 12.1 & 25 & 0.1 & 6.2 & 2.8 & 35 & 1.53 & 10.6 & 1 & 12.3 \\
\hline $\mathrm{C} 44$ & 0.9 & 21.8 & 15.1 & 77 & 0.1 & 12.5 & 7.2 & 194 & 1.64 & 8.1 & 1.5 & 9.7 \\
\hline $\mathrm{C} 45$ & 4.3 & 30.1 & 20.3 & 62 & 0.1 & 13.9 & 5.6 & 79 & 2.09 & 17.5 & 1.4 & 10 \\
\hline $\mathrm{C} 46$ & 0.4 & 24.7 & 18.2 & 82 & 0.1 & 15.4 & 7.4 & 321 & 1.85 & 4.8 & 2.9 & 10 \\
\hline $\mathrm{C} 47$ & 1.3 & 20.5 & 14.7 & 68 & $<0.1$ & 14.6 & 7.9 & 341 & 1.86 & 5.1 & 1.2 & 9 \\
\hline $\mathrm{C} 48$ & 1.2 & 12.2 & 11.6 & 49 & $<0.1$ & 13.4 & 6.9 & 484 & 1.62 & 3.9 & 1.7 & 8.9 \\
\hline C49 & 1.2 & 17.4 & 14.4 & 60 & $<0.1$ & 16.2 & 9.2 & 349 & 1.74 & 6.3 & $<0.5$ & 9 \\
\hline C50 & 0.9 & 22.4 & 16.2 & 65 & 0.1 & 14 & 7.7 & 373 & 1.96 & 3.9 & 2.2 & 10.2 \\
\hline
\end{tabular}

Table $\mathbf{C}-1$ continued 


\begin{tabular}{|c|c|c|c|c|c|c|c|c|c|c|c|c|}
\hline Element & $\mathrm{Sr}$ & Cd & Sb & $\mathbf{B i}$ & V & $\mathbf{C a}$ & $\mathbf{P}$ & La & $\mathrm{Cr}$ & Mg & $\mathbf{B a}$ & $\mathbf{T i}$ \\
\hline Unit & PPM & PPM & PPM & PPM & PPM & $\%$ & $\%$ & PPM & PPM & $\%$ & PPM & $\%$ \\
\hline LDL & 1 & 0.1 & 0.1 & 0.1 & 2 & 0.01 & 0.001 & 1 & 1 & 0.01 & 1 & 0.001 \\
\hline \multicolumn{13}{|l|}{$\begin{array}{l}\text { Sample } \\
\#\end{array}$} \\
\hline A1 & 145 & 0.1 & 0.3 & 0.5 & 43 & 1.93 & 0.138 & 23 & 26 & 1.23 & 109 & 0.005 \\
\hline A2 & 134 & 0.2 & 0.4 & 0.4 & 48 & 1.17 & 0.068 & 19 & 31 & 1.03 & 162 & 0.005 \\
\hline A3 & 221 & 0.2 & 0.4 & 0.4 & 54 & 1.52 & 0.253 & 29 & 34 & 0.93 & 917 & 0.005 \\
\hline A4 & 141 & 0.3 & 0.4 & 0.4 & 49 & 1.64 & 0.088 & 20 & 29 & 1.14 & 97 & 0.005 \\
\hline A5 & 107 & 0.2 & 0.4 & 0.3 & 50 & 0.88 & 0.057 & 18 & 31 & 0.86 & 112 & 0.008 \\
\hline A6 & 116 & 0.2 & 0.4 & 0.3 & 41 & 0.97 & 0.054 & 16 & 27 & 0.85 & 216 & 0.007 \\
\hline A7 & 205 & 0.3 & 0.9 & 0.4 & 55 & 0.27 & 0.014 & 15 & 26 & 0.41 & 462 & 0.021 \\
\hline A8 & 85 & 0.4 & 0.3 & 0.2 & 35 & 1.89 & 0.06 & 17 & 22 & 1.19 & 163 & 0.012 \\
\hline A9 & 83 & 0.2 & 0.4 & 0.3 & 29 & 0.12 & 0.02 & 16 & 17 & 0.3 & 90 & 0.01 \\
\hline $\mathrm{C} 2$ & 77 & 0.1 & 0.2 & 0.3 & 33 & 1.29 & 0.034 & 17 & 21 & 0.61 & 119 & 0.007 \\
\hline C3 & 66 & 0.6 & 0.4 & 0.3 & 41 & 0.27 & 0.044 & 16 & 27 & 0.7 & 140 & 0.01 \\
\hline C4 & 94 & $<0.1$ & 0.2 & 0.2 & 51 & 0.5 & 0.061 & 13 & 31 & 0.82 & 215 & 0.005 \\
\hline C5 & 91 & $<0.1$ & 0.3 & 0.3 & 57 & 0.66 & 0.05 & 14 & 35 & 0.89 & 123 & 0.004 \\
\hline C6 & 141 & 0.3 & 0.3 & 0.2 & 49 & 1.1 & 0.064 & 15 & 30 & 1.01 & 255 & 0.005 \\
\hline C7 & 105 & 0.2 & 0.4 & 0.3 & 48 & 1.1 & 0.056 & 15 & 31 & 1.03 & 79 & 0.006 \\
\hline C8 & 81 & $<0.1$ & 0.4 & 0.2 & 47 & 0.93 & 0.056 & 14 & 31 & 0.98 & 176 & 0.006 \\
\hline C9 & 109 & 0.1 & 0.2 & $<0.1$ & 29 & 1.14 & 0.048 & 11 & 21 & 0.89 & 122 & 0.004 \\
\hline $\mathrm{C} 10$ & 97 & $<0.1$ & 0.2 & $<0.1$ & 27 & 1.11 & 0.054 & 11 & 21 & 0.98 & 84 & 0.004 \\
\hline C11 & 303 & 0.5 & 0.5 & 0.3 & 61 & 1.5 & 0.067 & 17 & 35 & 1.01 & 127 & 0.005 \\
\hline $\mathrm{C} 12$ & 64 & 0.1 & 0.2 & $<0.1$ & 27 & 0.52 & 0.04 & 11 & 19 & 0.69 & 124 & 0.003 \\
\hline C13 & 80 & 0.2 & 0.5 & 0.3 & 64 & 0.89 & 0.06 & 18 & 37 & 0.99 & 274 & 0.005 \\
\hline
\end{tabular}

Table $\mathbf{C}-1$ continued 


\begin{tabular}{|c|c|c|c|c|c|c|c|c|c|c|c|c|}
\hline Element & Sr & Cd & Sb & $\mathbf{B i}$ & $\mathbf{V}$ & $\mathbf{C a}$ & $\mathbf{P}$ & La & $\mathrm{Cr}$ & Mg & $\mathbf{B a}$ & $\mathbf{T i}$ \\
\hline Unit & PPM & PPM & PPM & PPM & PPM & $\%$ & $\%$ & PPM & PPM & $\%$ & PPM & $\%$ \\
\hline LDL & 1 & 0.1 & 0.1 & 0.1 & 2 & 0.01 & 0.001 & 1 & 1 & 0.01 & 1 & 0.001 \\
\hline \multicolumn{13}{|l|}{$\begin{array}{l}\text { Sample } \\
\#\end{array}$} \\
\hline C14 & 57 & 0.2 & 0.5 & 0.3 & 58 & 0.69 & 0.045 & 16 & 35 & 0.98 & 128 & 0.005 \\
\hline C15 & 108 & 0.2 & 0.4 & 0.3 & 56 & 1.06 & 0.065 & 17 & 34 & 0.94 & 110 & 0.004 \\
\hline C16 & 70 & 0.1 & 0.5 & 0.2 & 49 & 1.13 & 0.047 & 13 & 31 & 0.99 & 153 & 0.005 \\
\hline $\mathrm{C} 17$ & 102 & 0.2 & 0.4 & 0.3 & 52 & 1.1 & 0.062 & 16 & 30 & 1.03 & 174 & 0.005 \\
\hline C18 & 93 & $<0.1$ & 0.3 & 0.3 & 55 & 0.47 & 0.041 & 14 & 31 & 0.82 & 179 & 0.004 \\
\hline C19 & 178 & $<0.1$ & 0.3 & 0.2 & 45 & 0.61 & 0.047 & 15 & 27 & 0.69 & 245 & 0.005 \\
\hline C20 & 80 & $<0.1$ & 0.3 & 0.2 & 42 & 0.56 & 0.039 & 13 & 26 & 0.7 & 180 & 0.004 \\
\hline C21 & 66 & $<0.1$ & 0.3 & 0.3 & 45 & 0.68 & 0.054 & 15 & 27 & 0.84 & 124 & 0.004 \\
\hline $\mathrm{C} 22$ & 167 & 0.1 & 0.4 & 0.3 & 47 & 1.14 & 0.139 & 24 & 27 & 0.79 & 116 & 0.004 \\
\hline $\mathrm{C} 23$ & 149 & $<0.1$ & 0.3 & $<0.1$ & 32 & 0.78 & 0.058 & 14 & 20 & 0.66 & 212 & 0.008 \\
\hline C24 & 125 & $<0.1$ & $<0.1$ & $<0.1$ & 23 & 3.99 & 0.043 & 17 & 15 & 0.54 & 114 & 0.003 \\
\hline $\mathrm{C} 25$ & 75 & 0.1 & 0.2 & 0.3 & 45 & 0.62 & 0.053 & 17 & 27 & 0.75 & 116 & 0.004 \\
\hline C27 & 133 & 0.2 & 0.3 & 0.3 & 46 & 0.73 & 0.045 & 17 & 26 & 0.74 & 125 & 0.003 \\
\hline C28 & 123 & 0.5 & 0.3 & 0.4 & 30 & 1.75 & 0.066 & 18 & 19 & 1.17 & 180 & 0.017 \\
\hline C29 & 116 & 0.4 & 0.2 & 0.3 & 30 & 2.12 & 0.072 & 16 & 17 & 1.21 & 163 & 0.007 \\
\hline C30 & 65 & 0.3 & 0.2 & 0.2 & 27 & 1.63 & 0.061 & 16 & 17 & 1.15 & 120 & 0.007 \\
\hline C31 & 97 & 0.6 & 0.3 & 0.3 & 40 & 1.95 & 0.065 & 18 & 24 & 1.31 & 195 & 0.011 \\
\hline C32 & 239 & 0.8 & 0.4 & 0.5 & 29 & 4.21 & 0.083 & 19 & 14 & 1.19 & 80 & 0.016 \\
\hline C33 & 359 & $<0.1$ & $<0.1$ & $<0.1$ & 16 & 23.06 & 0.059 & 5 & 7 & 0.42 & 183 & 0.012 \\
\hline
\end{tabular}

Table C-1 continued 


\begin{tabular}{|c|c|c|c|c|c|c|c|c|c|c|c|c|}
\hline Element & $\mathrm{Sr}$ & Cd & Sb & Bi & $\mathbf{V}$ & $\mathbf{C a}$ & $\mathbf{P}$ & La & $\mathrm{Cr}$ & Mg & $\mathbf{B a}$ & $\mathbf{T i}$ \\
\hline Unit & PPM & PPM & PPM & PPM & PPM & $\%$ & $\%$ & PPM & PPM & $\%$ & PPM & $\%$ \\
\hline LDL & 1 & 0.1 & 0.1 & 0.1 & 2 & 0.01 & 0.001 & 1 & 1 & 0.01 & 1 & 0.001 \\
\hline \multicolumn{13}{|l|}{$\begin{array}{l}\text { Sample } \\
\#\end{array}$} \\
\hline C34 & 37 & $<0.1$ & $<0.1$ & $<0.1$ & 18 & 0.58 & 0.032 & 14 & 11 & 0.55 & 79 & 0.005 \\
\hline C35 & 35 & $<0.1$ & 0.1 & $<0.1$ & 18 & 0.58 & 0.032 & 13 & 8 & 0.52 & 83 & 0.009 \\
\hline C36 & 50 & $<0.1$ & $<0.1$ & $<0.1$ & 23 & 0.71 & 0.033 & 13 & 10 & 0.37 & 114 & 0.01 \\
\hline C37 & 61 & 0.4 & 0.4 & 0.6 & 43 & 0.07 & 0.029 & 18 & 27 & 0.47 & 212 & 0.017 \\
\hline C38 & 212 & 0.2 & 0.3 & 0.3 & 24 & 0.59 & 0.012 & 7 & 8 & 0.22 & 389 & 0.062 \\
\hline C39 & 148 & 0.3 & 0.7 & 0.5 & 47 & 0.61 & 0.038 & 16 & 28 & 0.48 & 137 & 0.021 \\
\hline C40 & 153 & 0.3 & 1 & 0.5 & 35 & 1.53 & 0.047 & 19 & 17 & 0.83 & 185 & 0.012 \\
\hline C41 & 121 & 1.1 & 1.4 & 0.4 & 63 & 1.1 & 0.027 & 21 & 27 & 0.64 & 246 & 0.021 \\
\hline $\mathrm{C42}$ & 141 & 0.2 & 0.4 & 0.5 & 27 & 0.9 & 0.041 & 18 & 17 & 0.54 & 244 & 0.009 \\
\hline $\mathrm{C43}$ & 212 & $<0.1$ & 1.3 & 0.8 & 25 & 0.27 & 0.019 & 26 & 12 & 0.35 & 257 & 0.016 \\
\hline $\mathrm{C44}$ & 82 & 0.5 & 0.4 & 0.5 & 24 & 1.29 & 0.06 & 26 & 13 & 1.04 & 188 & 0.013 \\
\hline $\mathrm{C45}$ & 152 & 0.2 & 1.4 & 0.6 & 35 & 0.34 & 0.044 & 22 & 15 & 0.44 & 157 & 0.022 \\
\hline $\mathrm{C} 46$ & 94 & 0.4 & 0.4 & 0.6 & 25 & 1.64 & 0.049 & 25 & 16 & 1.34 & 136 & 0.009 \\
\hline $\mathrm{C47}$ & 70 & 0.4 & 0.4 & 0.5 & 31 & 2.67 & 0.055 & 23 & 18 & 1.94 & 100 & 0.019 \\
\hline $\mathrm{C} 48$ & 54 & 0.2 & 0.2 & 0.3 & 19 & 3.59 & 0.053 & 22 & 14 & 2.05 & 218 & 0.017 \\
\hline C49 & 69 & 0.3 & 0.4 & 0.5 & 21 & 3.39 & 0.049 & 21 & 15 & 2.09 & 134 & 0.019 \\
\hline C50 & 63 & 0.3 & 0.5 & 0.5 & 25 & 1.64 & 0.044 & 22 & 16 & 1.35 & 93 & 0.018 \\
\hline
\end{tabular}

Table $\mathbf{C}-1$ continued 


\begin{tabular}{|c|c|c|c|c|c|c|c|c|c|c|c|c|}
\hline Element & B & Al & $\mathbf{N a}$ & $\mathbf{K}$ & $\mathbf{W}$ & Hg & Sc & Tl & $\mathbf{S}$ & Ga & Se & Te \\
\hline Unit & PPM & $\%$ & $\%$ & $\%$ & PPM & PPM & PPM & PPM & $\%$ & PPM & PPM & PPM \\
\hline LDL & 1 & 0.01 & 0.001 & 0.01 & 0.1 & 0.01 & 0.1 & 0.1 & 0.05 & 1 & 0.5 & 0.2 \\
\hline \multicolumn{13}{|l|}{$\begin{array}{l}\text { Sample } \\
\#\end{array}$} \\
\hline A1 & 13 & 1.9 & 0.36 & 0.3 & $<0.1$ & 0.05 & 9.1 & 0.1 & 0.06 & 6 & $<0.5$ & $<0.2$ \\
\hline A2 & 13 & 2.09 & 0.364 & 0.33 & $<0.1$ & 0.08 & 8 & 0.1 & 0.09 & 7 & 0.6 & $<0.2$ \\
\hline A3 & 14 & 2.29 & 0.442 & 0.32 & $<0.1$ & 0.08 & 11.4 & 0.1 & 0.08 & 7 & 0.7 & $<0.2$ \\
\hline A4 & 11 & 2 & 0.477 & 0.3 & $<0.1$ & 0.06 & 10.9 & 0.1 & 0.11 & 6 & 0.8 & $<0.2$ \\
\hline A5 & 12 & 2.12 & 0.402 & 0.28 & $<0.1$ & 0.06 & 8 & 0.2 & 0.13 & 7 & $<0.5$ & $<0.2$ \\
\hline A6 & 11 & 1.82 & 0.358 & 0.27 & $<0.1$ & 0.15 & 6.7 & 0.2 & 0.47 & 6 & $<0.5$ & $<0.2$ \\
\hline A7 & 24 & 1.37 & 0.581 & 0.21 & $<0.1$ & 0.08 & 7.1 & 0.2 & 0.21 & 5 & 0.6 & $<0.2$ \\
\hline A8 & 11 & 1.52 & 0.34 & 0.25 & $<0.1$ & 0.03 & 5.6 & 0.1 & $<0.05$ & 5 & $<0.5$ & $<0.2$ \\
\hline A9 & 12 & 1.05 & 0.437 & 0.23 & $<0.1$ & 0.14 & 3.9 & 0.2 & 0.18 & 4 & $<0.5$ & $<0.2$ \\
\hline $\mathrm{C} 2$ & 11 & 2.06 & 0.632 & 0.32 & $<0.1$ & 0.06 & 5.8 & 0.3 & 1.15 & 6 & $<0.5$ & $<0.2$ \\
\hline C3 & 14 & 1.9 & 0.67 & 0.27 & $<0.1$ & 0.07 & 6 & 0.2 & 0.18 & 6 & $<0.5$ & $<0.2$ \\
\hline C4 & 10 & 2.07 & 0.77 & 0.29 & $<0.1$ & 0.06 & 7 & 0.1 & 0.15 & 7 & 0.8 & $<0.2$ \\
\hline C5 & 11 & 2.51 & 0.806 & 0.39 & $<0.1$ & 0.07 & 7.7 & 0.2 & 0.18 & 7 & 0.8 & $<0.2$ \\
\hline C6 & 9 & 2.14 & 0.713 & 0.33 & $<0.1$ & 0.08 & 6.9 & 0.2 & $<0.05$ & 6 & 1.1 & $<0.2$ \\
\hline C7 & 10 & 1.97 & 0.949 & 0.32 & $<0.1$ & 0.07 & 6.4 & 0.2 & 0.1 & 7 & 1.7 & $<0.2$ \\
\hline C8 & 10 & 2 & 0.553 & 0.29 & $<0.1$ & 0.07 & 6.2 & 0.1 & $<0.05$ & 6 & $<0.5$ & $<0.2$ \\
\hline C9 & 4 & 1.34 & 0.649 & 0.16 & $<0.1$ & 0.03 & 3.6 & $<0.1$ & $<0.05$ & 4 & 1.4 & $<0.2$ \\
\hline $\mathrm{C} 10$ & 4 & 1.19 & 0.791 & 0.14 & $<0.1$ & 0.03 & 3.4 & $<0.1$ & 0.1 & 4 & 1.1 & $<0.2$ \\
\hline C11 & 12 & 2.09 & 0.925 & 0.31 & $<0.1$ & 0.03 & 10.3 & 0.2 & $<0.05$ & 7 & 1.7 & $<0.2$ \\
\hline $\mathrm{C} 12$ & 5 & 1.44 & 0.675 & 0.17 & $<0.1$ & 0.02 & 2.9 & $<0.1$ & 0.11 & 4 & $<0.5$ & $<0.2$ \\
\hline C13 & 13 & 2.38 & 0.645 & 0.39 & $<0.1$ & 0.06 & 10.2 & 0.2 & 0.16 & 7 & 0.6 & $<0.2$ \\
\hline
\end{tabular}

Table $\mathbf{C}-1$ continued 


\begin{tabular}{|c|c|c|c|c|c|c|c|c|c|c|c|c|}
\hline Element & B & Al & $\mathbf{N a}$ & $\mathbf{K}$ & $\mathbf{W}$ & Hg & Sc & Tl & $\mathbf{S}$ & Ga & Se & Te \\
\hline Unit & PPM & $\%$ & $\%$ & $\%$ & PPM & PPM & PPM & PPM & $\%$ & PPM & PPM & PPM \\
\hline LDL & 1 & 0.01 & 0.001 & 0.01 & 0.1 & 0.01 & 0.1 & 0.1 & 0.05 & 1 & 0.5 & 0.2 \\
\hline \multicolumn{13}{|l|}{$\begin{array}{l}\text { Sample } \\
\#\end{array}$} \\
\hline C14 & 11 & 2.25 & 0.716 & 0.36 & $<0.1$ & 0.09 & 7.1 & 0.2 & 0.08 & 7 & 0.8 & $<0.2$ \\
\hline C15 & 9 & 2.11 & 0.67 & 0.34 & $<0.1$ & 0.08 & 8.9 & 0.2 & 0.08 & 6 & 0.9 & $<0.2$ \\
\hline C16 & 9 & 2.05 & 0.798 & 0.3 & $<0.1$ & 0.06 & 6.2 & 0.2 & 0.48 & 6 & 0.6 & $<0.2$ \\
\hline $\mathrm{C} 17$ & 10 & 1.99 & 0.675 & 0.34 & $<0.1$ & 0.06 & 7.7 & 0.1 & 0.12 & 6 & 0.6 & $<0.2$ \\
\hline C18 & 9 & 2.24 & 0.855 & 0.36 & $<0.1$ & 0.07 & 6.9 & 0.2 & 0.16 & 6 & 0.5 & $<0.2$ \\
\hline C19 & 9 & 1.92 & 0.699 & 0.3 & $<0.1$ & 0.06 & 7.2 & 0.1 & $<0.05$ & 6 & 1.1 & $<0.2$ \\
\hline $\mathrm{C20}$ & 7 & 1.89 & 0.799 & 0.27 & $<0.1$ & 0.06 & 5.3 & 0.1 & 0.12 & 6 & 1.4 & $<0.2$ \\
\hline $\mathrm{C} 21$ & 8 & 2.07 & 0.735 & 0.34 & $<0.1$ & 0.08 & 5.8 & 0.2 & $<0.05$ & 6 & $<0.5$ & $<0.2$ \\
\hline $\mathrm{C} 22$ & 9 & 2.03 & 0.951 & 0.31 & $<0.1$ & 0.09 & 8.4 & 0.2 & 0.08 & 6 & 0.7 & $<0.2$ \\
\hline $\mathrm{C} 23$ & 7 & 1.57 & 1.073 & 0.21 & $<0.1$ & 0.08 & 4.8 & $<0.1$ & 0.32 & 5 & 0.8 & $<0.2$ \\
\hline $\mathrm{C} 24$ & 3 & 1.1 & 0.735 & 0.14 & $<0.1$ & 0.02 & 5.3 & $<0.1$ & 0.12 & 3 & 1.3 & $<0.2$ \\
\hline $\mathrm{C} 25$ & 8 & 1.85 & 0.878 & 0.3 & $<0.1$ & 0.05 & 7.2 & 0.2 & 0.06 & 6 & 0.6 & $<0.2$ \\
\hline $\mathrm{C} 27$ & 9 & 1.98 & 0.73 & 0.32 & $<0.1$ & 0.16 & 6.9 & 0.2 & $<0.05$ & 5 & $<0.5$ & $<0.2$ \\
\hline $\mathrm{C} 28$ & 9 & 1.31 & 1.087 & 0.24 & $<0.1$ & 0.06 & 4.3 & 0.2 & 0.12 & 5 & 2.4 & $<0.2$ \\
\hline $\mathrm{C29}$ & 7 & 1.2 & 0.938 & 0.18 & $<0.1$ & 0.04 & 6.1 & 0.1 & 0.35 & 4 & 1.7 & $<0.2$ \\
\hline C30 & 6 & 1.38 & 0.766 & 0.2 & $<0.1$ & 0.04 & 4.1 & 0.2 & 0.22 & 5 & $<0.5$ & $<0.2$ \\
\hline C31 & 11 & 1.82 & 0.941 & 0.31 & $<0.1$ & 0.05 & 6 & 0.2 & 0.38 & 6 & $<0.5$ & $<0.2$ \\
\hline C32 & 25 & 1.2 & 0.715 & 0.25 & $<0.1$ & 0.16 & 4 & 0.4 & 1.73 & 4 & 0.6 & $<0.2$ \\
\hline C33 & 10 & 0.54 & 0.07 & 0.15 & $<0.1$ & 0.01 & 1.6 & $<0.1$ & 0.06 & 2 & $<0.5$ & $<0.2$ \\
\hline C34 & 21 & 0.83 & 0.498 & 0.19 & $<0.1$ & $<0.01$ & 1.8 & $<0.1$ & 0.25 & 4 & $<0.5$ & $<0.2$ \\
\hline C35 & 13 & 0.75 & 0.332 & 0.19 & $<0.1$ & $<0.01$ & 2 & $<0.1$ & 0.17 & 3 & $<0.5$ & $<0.2$ \\
\hline
\end{tabular}

Table $\mathbf{C}-1$ continued 


\begin{tabular}{|c|c|c|c|c|c|c|c|c|c|c|c|c|}
\hline Element & B & Al & $\mathbf{N a}$ & $\mathbf{K}$ & $\mathbf{W}$ & Hg & Sc & Tl & $\mathbf{S}$ & Ga & Se & Te \\
\hline Unit & PPM & $\%$ & $\%$ & $\%$ & PPM & PPM & PPM & PPM & $\%$ & PPM & PPM & PPM \\
\hline LDL & 1 & 0.01 & 0.001 & 0.01 & 0.1 & 0.01 & 0.1 & 0.1 & 0.05 & 1 & 0.5 & 0.2 \\
\hline \multicolumn{13}{|l|}{$\begin{array}{l}\text { Sample } \\
\#\end{array}$} \\
\hline C36 & 51 & 0.84 & 0.316 & 0.21 & $<0.1$ & $<0.01$ & 3.5 & $<0.1$ & 0.19 & 3 & $<0.5$ & $<0.2$ \\
\hline C37 & 48 & 1.81 & 0.491 & 0.23 & $<0.1$ & 0.06 & 5.5 & 0.2 & 0.29 & 6 & 1.2 & $<0.2$ \\
\hline C38 & 89 & 0.63 & 0.862 & 0.03 & 1.3 & 0.04 & 3.8 & $<0.1$ & 0.77 & 3 & 2.2 & $<0.2$ \\
\hline C39 & 18 & 1.62 & 0.663 & 0.27 & $<0.1$ & 0.11 & 5.9 & 0.3 & 0.62 & 6 & 1.4 & $<0.2$ \\
\hline $\mathrm{C} 40$ & 13 & 1.46 & 0.698 & 0.3 & $<0.1$ & 0.06 & 4.3 & 0.3 & 0.7 & 6 & 0.7 & $<0.2$ \\
\hline C41 & 21 & 1.57 & 0.569 & 0.25 & $<0.1$ & 0.07 & 7.6 & 0.3 & 0.32 & 6 & 1.2 & $<0.2$ \\
\hline $\mathrm{C} 42$ & 9 & 1.59 & 0.649 & 0.3 & $<0.1$ & 0.07 & 5.1 & 1.5 & 0.75 & 6 & 0.6 & $<0.2$ \\
\hline $\mathrm{C} 43$ & 12 & 1.1 & 0.815 & 0.24 & 0.3 & 0.1 & 3.5 & 0.3 & 0.19 & 5 & 1.3 & $<0.2$ \\
\hline C44 & 12 & 1.49 & 0.773 & 0.33 & $<0.1$ & 0.08 & 3.6 & 0.4 & 0.16 & 5 & $<0.5$ & $<0.2$ \\
\hline $\mathrm{C} 45$ & 11 & 1.33 & 0.765 & 0.28 & 0.2 & 0.14 & 4.3 & 0.2 & 0.26 & 5 & 1.6 & $<0.2$ \\
\hline $\mathrm{C} 46$ & 7 & 1.54 & 0.503 & 0.36 & $<0.1$ & 0.07 & 4.5 & 0.4 & 0.08 & 6 & $<0.5$ & $<0.2$ \\
\hline C47 & 8 & 1.47 & 0.614 & 0.35 & $<0.1$ & 0.02 & 3.9 & 0.3 & $<0.05$ & 6 & 0.6 & $<0.2$ \\
\hline $\mathrm{C} 48$ & 5 & 1.26 & 0.528 & 0.34 & $<0.1$ & 0.03 & 2.9 & 0.3 & 0.08 & 5 & $<0.5$ & $<0.2$ \\
\hline C49 & 6 & 1.42 & 0.675 & 0.41 & $<0.1$ & 0.03 & 3.7 & 0.4 & 0.16 & 6 & 1.5 & $<0.2$ \\
\hline C50 & 8 & 1.73 & 0.571 & 0.45 & $<0.1$ & 0.03 & 4.2 & 0.4 & 0.12 & 6 & $<0.5$ & $<0.2$ \\
\hline
\end{tabular}

Table $\mathbf{C}-1$ continued 


\section{Appendix D: Foraminifera Counts}

\begin{tabular}{|c|c|c|c|c|c|c|c|c|c|c|c|}
\hline 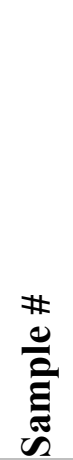 & 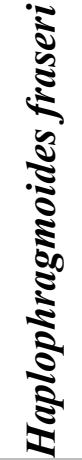 & 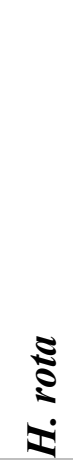 & $\stackrel{ \pm}{\Xi}$ & 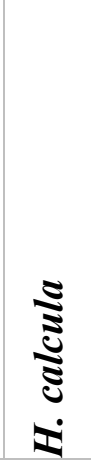 & 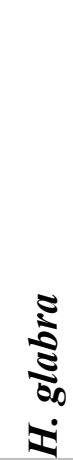 & 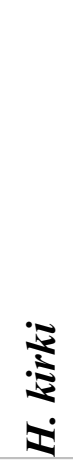 & 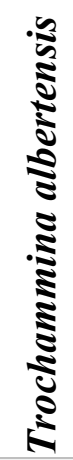 & 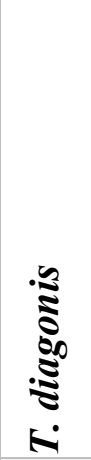 & 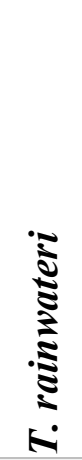 & 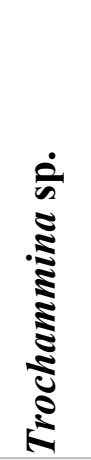 & 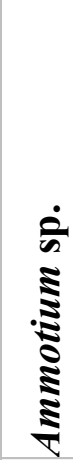 \\
\hline D4 & 2 & 5 & 0 & 0 & 0 & 0 & 0 & 0 & 0 & 0 & 0 \\
\hline D5 & 39 & 5 & 12 & 0 & 0 & 0 & 5 & 0 & 0 & 0 & 0 \\
\hline D6 & 41 & 1 & 1 & 0 & 0 & 0 & 6 & 1 & 0 & 0 & 0 \\
\hline A9 & 14 & 0 & 2 & 0 & 0 & 0 & 3 & 0 & 0 & 0 & 0 \\
\hline C2 & 25 & 14 & 28 & 12 & 0 & 0 & 18 & 12 & 0 & 0 & 0 \\
\hline C3 & 4 & 1 & 6 & 0 & 0 & 0 & 1 & 11 & 1 & 0 & 0 \\
\hline C4 & 3 & 7 & 2 & 5 & 0 & 0 & 0 & 4 & 0 & 1 & 0 \\
\hline C5 & 0 & 12 & 3 & 12 & 0 & 0 & 0 & 0 & 0 & 0 & 0 \\
\hline C6 & 0 & & 1 & 0 & 0 & 1 & 0 & 0 & 0 & 0 & 0 \\
\hline
\end{tabular}

Table D-1: Counts of Foraminifera from outcrop sections of the Foremost Formation in the Pinhorn Ranch 


\begin{tabular}{|c|c|c|c|c|c|c|c|c|c|c|c|c|}
\hline 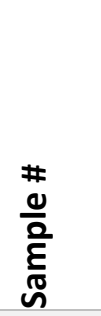 & 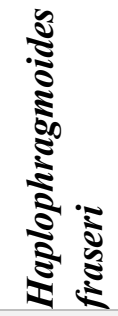 & $\frac{\mathbb{s}}{\mathbf{s}}$ & 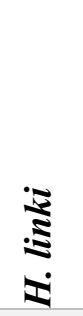 & 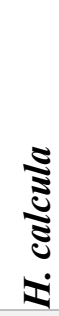 & 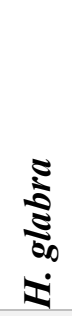 & i & 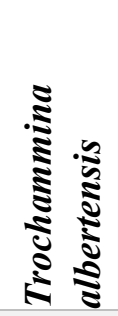 & 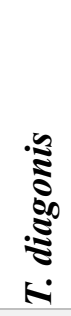 & 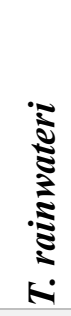 & 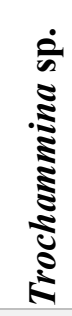 & 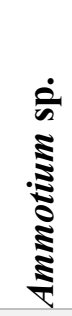 & 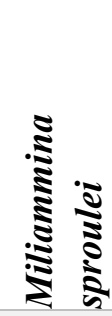 \\
\hline C7 & 0 & 1 & 0 & 1 & 0 & 0 & 0 & 5 & 0 & 2 & 0 & 0 \\
\hline C13 & 2 & 25 & 1 & 0 & 0 & 0 & 0 & 0 & 0 & 0 & 0 & 0 \\
\hline C14 & 0 & 13 & 1 & 0 & 0 & 0 & 0 & 0 & 0 & 0 & 0 & 0 \\
\hline C15 & 0 & 6 & 2 & 0 & 0 & 0 & 0 & 0 & 0 & 0 & 0 & 0 \\
\hline C16 & 0 & 8 & 2 & 0 & 0 & 0 & 1 & 0 & 0 & 0 & 0 & 0 \\
\hline C17 & 0 & 11 & 5 & 6 & 0 & 1 & & 0 & 0 & 0 & 0 & 0 \\
\hline C18 & 0 & 89 & 32 & 0 & 31 & 0 & 1 & 1 & 0 & 0 & 1 & 0 \\
\hline C19 & 0 & 3 & 0 & 1 & 0 & 0 & 0 & 0 & 0 & 0 & 0 & 0 \\
\hline C2O & 0 & 1 & 0 & 0 & 0 & 0 & 0 & 0 & 0 & 0 & 0 & 0 \\
\hline C21 & 0 & 6 & 2 & 0 & 0 & 0 & 0 & 0 & 0 & 0 & 0 & 0 \\
\hline C22 & 0 & 1 & & 0 & 0 & 0 & 0 & 0 & 0 & 0 & 0 & 0 \\
\hline C32 & 0 & 4 & 0 & 4 & 0 & 0 & 3 & 0 & 0 & 1 & 0 & 0 \\
\hline Total & 130 & 213 & 100 & 41 & 31 & 2 & 38 & 34 & 1 & 4 & 1 & 2 \\
\hline
\end{tabular}

Table D-1 continued 


\begin{tabular}{|c|c|c|c|c|c|c|c|c|c|c|c|c|}
\hline $\begin{array}{l}\frac{\#}{0} \\
\frac{0}{\frac{0}{\varepsilon}} \\
\text { J }\end{array}$ & 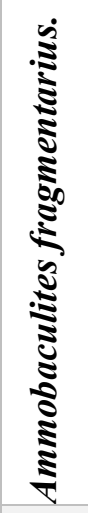 & 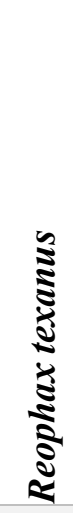 & 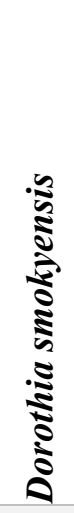 & 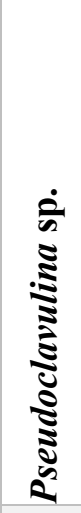 & 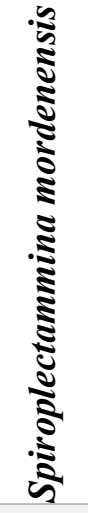 & 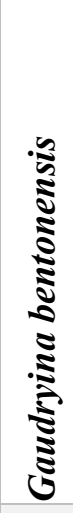 & 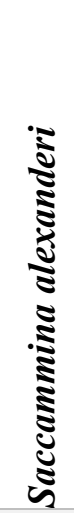 & 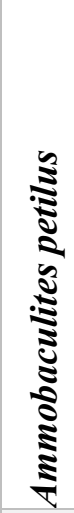 & 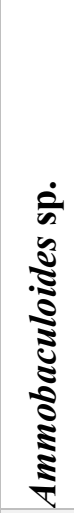 & 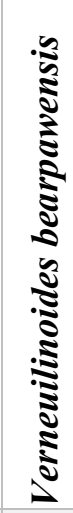 & 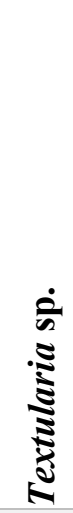 & $\stackrel{\bar{\sigma}}{\stackrel{\pi}{\theta}}$ \\
\hline D4 & 0 & 0 & 0 & 0 & 0 & 0 & 0 & 0 & 0 & 15 & 0 & 22 \\
\hline D5 & 0 & 0 & 0 & 1 & 0 & 0 & 0 & 0 & 0 & 13 & 0 & 75 \\
\hline D6 & 0 & 0 & 0 & 0 & 0 & 0 & 0 & 0 & 0 & 31 & 1 & 83 \\
\hline A9 & 0 & 0 & 0 & 0 & 0 & 0 & 0 & 0 & 0 & 9 & 2 & 30 \\
\hline C2 & 0 & 0 & 8 & 0 & 0 & 0 & 0 & 0 & 0 & 0 & 0 & 117 \\
\hline C3 & 0 & 0 & 3 & 0 & 1 & 0 & 0 & 0 & 0 & 6 & 3 & 38 \\
\hline C4 & 8 & 2 & 2 & 0 & 0 & 0 & 0 & 7 & 3 & 0 & 0 & 44 \\
\hline C5 & 7 & 2 & 1 & 1 & 1 & 3 & 0 & 1 & 0 & 0 & 0 & 43 \\
\hline C6 & 0 & 0 & 0 & 0 & 0 & 0 & 0 & 0 & 0 & 0 & 0 & 2 \\
\hline
\end{tabular}

Table D-1 continued 


\begin{tabular}{|c|c|c|c|c|c|c|c|c|c|c|c|c|}
\hline$\frac{\#}{\frac{\omega}{0}}$ & 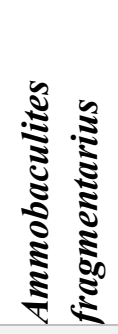 & 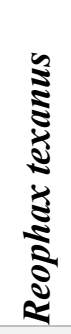 & 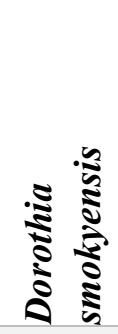 & 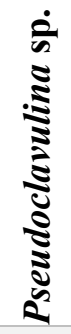 & 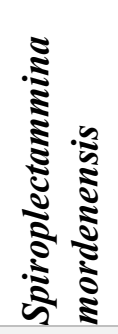 & 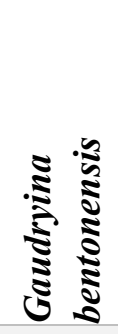 & 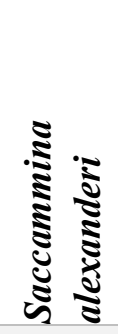 & 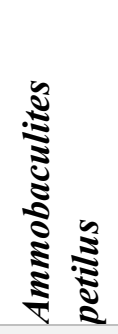 & 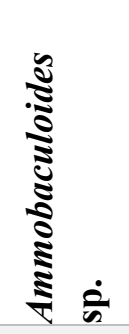 & 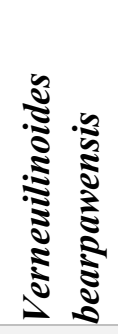 & 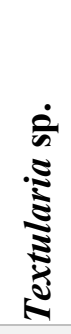 & $\stackrel{\bar{\pi}}{\tilde{\theta}}$ \\
\hline C7 & 0 & 0 & 0 & 0 & 0 & 0 & 0 & 0 & 0 & 0 & 0 & 9 \\
\hline C13 & 0 & 0 & 0 & 1 & 0 & 0 & 0 & 0 & 0 & 0 & 0 & 29 \\
\hline C14 & 0 & 0 & 0 & 0 & 0 & 0 & 0 & 0 & 0 & 0 & 0 & 14 \\
\hline C15 & 0 & 0 & 0 & 0 & 0 & 0 & 0 & 0 & 0 & 0 & 0 & 8 \\
\hline C16 & 0 & 0 & 0 & 0 & 0 & 0 & 0 & 0 & 0 & 0 & 0 & 11 \\
\hline C17 & 0 & 0 & 2 & 0 & 0 & 0 & 0 & 0 & 0 & 0 & 0 & 25 \\
\hline C18 & 0 & 0 & 0 & 0 & 0 & 0 & 1 & 0 & 0 & 0 & 0 & 156 \\
\hline C19 & 0 & 0 & 0 & 0 & 0 & 0 & 0 & 0 & 0 & 0 & 0 & 4 \\
\hline C2O & 0 & 0 & 0 & 0 & 0 & 0 & 0 & 0 & 0 & 0 & 0 & 1 \\
\hline C21 & 0 & 0 & 0 & 0 & 0 & 0 & 0 & 0 & 0 & 0 & 0 & 8 \\
\hline C22 & 0 & 0 & 0 & 0 & 0 & 0 & 0 & 0 & 0 & 0 & 0 & 1 \\
\hline C32 & 0 & 0 & 0 & 1 & 0 & 0 & 0 & 0 & 0 & 0 & 0 & 13 \\
\hline Total & 15 & 4 & 16 & 4 & 2 & 3 & 1 & 8 & 3 & 74 & 6 & 733 \\
\hline
\end{tabular}

Table D-1 continued 


\section{Appendix E: Microsite Data}

\begin{tabular}{|c|c|c|c|c|c|c|c|c|c|c|c|c|c|}
\hline Taxon & 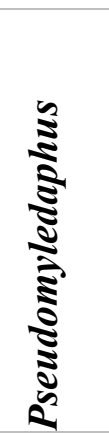 & 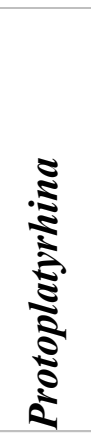 & 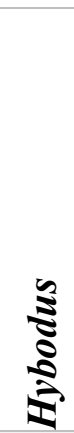 & 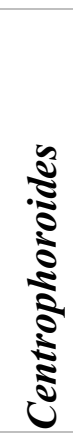 & 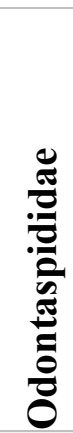 & $\frac{\Xi}{5}$ & 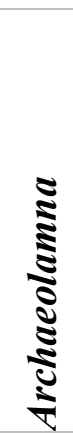 & 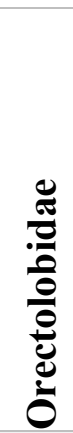 & 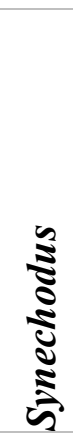 & 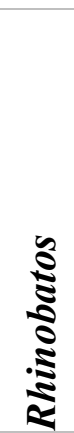 & 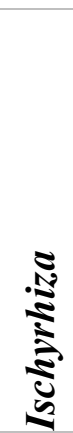 & 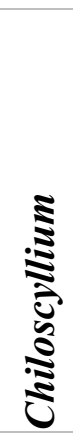 & 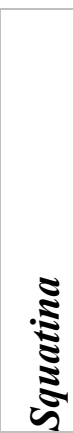 \\
\hline SPS & 235 & 0 & 0 & 0 & 0 & 0 & 0 & 0 & 0 & 0 & 0 & 5 & 0 \\
\hline PK & 29 & 0 & 1 & 0 & 2 & 0 & 3 & 0 & 0 & 0 & 0 & 0 & 0 \\
\hline PHR-1 & 1952 & 0 & 10 & 0 & 23 & 0 & 0 & 0 & 0 & 0 & 8 & 0 & 1 \\
\hline PHR-2 & 2164 & 0 & 15 & 0 & 79 & 0 & 10 & 1 & 1 & 9 & 16 & 6 & 8 \\
\hline PHRN & 3780 & 382 & 18 & 15 & 50 & 4 & 27 & 5 & 10 & 3 & 20 & 0 & 34 \\
\hline C26 & 56 & 0 & 0 & 0 & 0 & 0 & 1 & 1 & 0 & 0 & 0 & 0 & 0 \\
\hline
\end{tabular}

Table E-1: Counts of identifiable fossil elements from vertebrate microsites of the Foremost Formation. Left most column contains site names. Data compiled from this study (Site C26) and Cullen and Evans (2016). 


\begin{tabular}{|c|c|c|c|c|c|c|c|c|c|c|c|c|c|}
\hline Taxon & 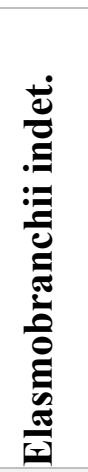 & 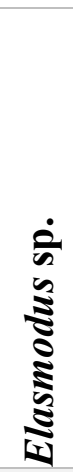 & 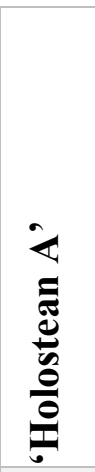 & 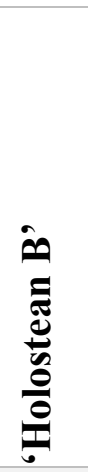 & 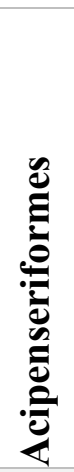 & 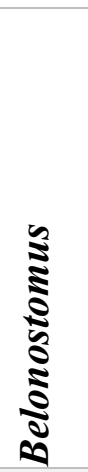 & 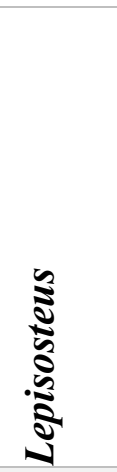 & : & 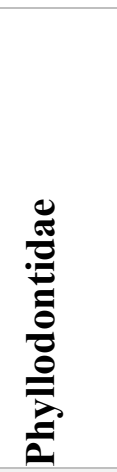 & 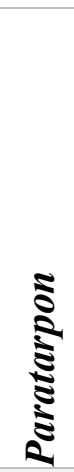 & 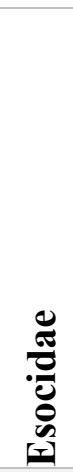 & 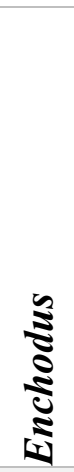 & : \\
\hline SPS & 0 & 0 & 229 & 45 & 14 & 0 & 204 & 5 & 139 & 29 & 0 & 22 & 46 \\
\hline PK & 2 & 4 & 0 & 6 & 0 & 0 & 43 & 0 & 0 & 0 & 0 & 0 & 1 \\
\hline PHR-1 & 0 & 0 & 94 & 355 & 90 & 185 & 2463 & 9 & 1156 & 4 & 0 & 10 & 89 \\
\hline PHR-2 & 0 & 0 & 22 & 166 & 25 & 160 & 834 & 17 & 2016 & 7 & 0 & 30 & 265 \\
\hline PHRN & 690 & 0 & 8 & 56 & 2 & 0 & 143 & 0 & 2281 & 0 & 0 & 0 & 305 \\
\hline $\mathrm{C} 26$ & 0 & 0 & 0 & 10 & 0 & 0 & 21 & 2 & 24 & 0 & 0 & 1 & 0 \\
\hline
\end{tabular}

Table E-1 continued 


\begin{tabular}{|c|c|c|c|c|c|c|c|c|c|c|c|c|c|}
\hline Taxon & $\begin{array}{l}\frac{\bar{d}}{\sigma o} \\
\frac{0}{0} \\
\frac{d}{0}\end{array}$ & 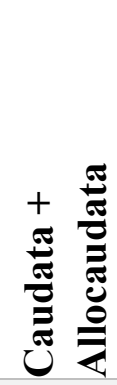 & 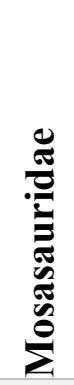 & 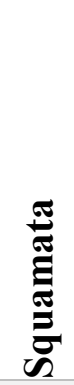 & 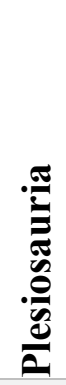 & 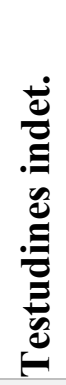 & 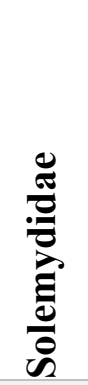 & 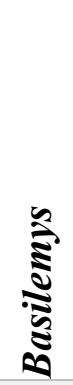 & 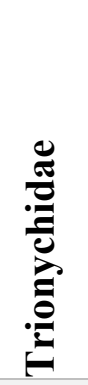 & $\begin{array}{l}\tilde{E} \\
\mathbb{E} \\
\mathbb{E}\end{array}$ & 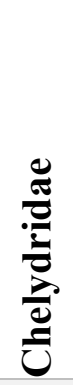 & 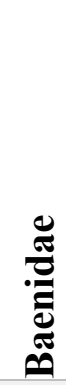 & 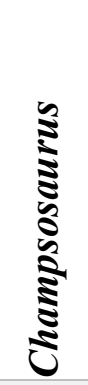 \\
\hline SPS & 24 & 409 & 0 & 7 & 0 & 0 & 0 & 0 & 1 & 0 & 4 & 18 & 50 \\
\hline PK & 1 & 1 & 1 & 5 & 0 & 3 & 35 & 2 & 24 & 9 & 1 & 8 & 28 \\
\hline PHR-1 & 33 & 41 & 0 & 12 & 0 & 0 & 1 & 0 & 106 & 129 & 21 & 93 & 97 \\
\hline PHR-2 & 31 & 103 & 0 & 11 & 0 & 0 & 0 & 0 & 7 & 3 & 1 & 2 & 213 \\
\hline PHRN & 10 & 24 & 0 & 0 & 0 & 0 & 272 & 0 & 21 & 15 & 0 & 2 & 64 \\
\hline C26 & 4 & 1 & 0 & & 0 & 0 & 11 & 0 & 1 & 20 & 0 & 0 & 0 \\
\hline
\end{tabular}

Table E-1 continued 


\begin{tabular}{|c|c|c|c|c|c|c|c|c|c|c|c|c|c|c|}
\hline Taxon & 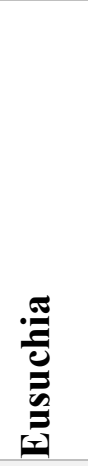 & 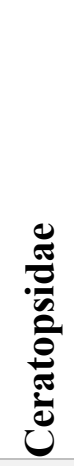 & 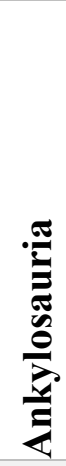 & 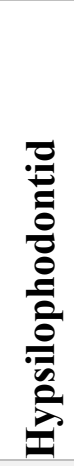 & 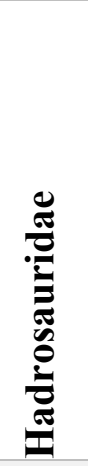 & 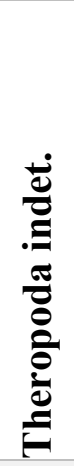 & 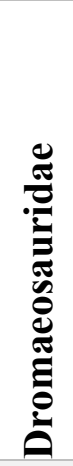 & 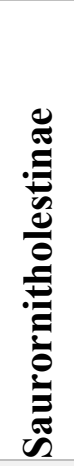 & 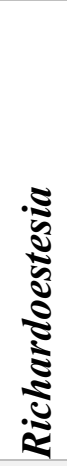 & 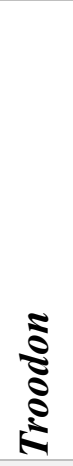 & 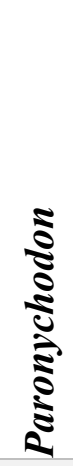 & 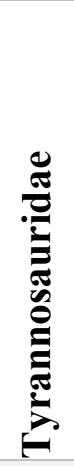 & $\frac{8}{2}$ & 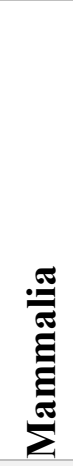 \\
\hline SPS & 38 & 2 & 2 & 2 & 162 & 0 & 0 & 2 & 0 & 0 & 2 & 1 & 3 & 38 \\
\hline PK & 51 & 2 & 6 & 1 & 6 & 0 & 0 & 4 & 0 & 0 & 0 & 1 & 0 & 0 \\
\hline PHR-1 & 122 & 52 & 8 & 2 & 178 & 0 & 0 & 7 & 3 & 0 & 0 & 7 & 3 & 11 \\
\hline PHR-2 & 205 & 12 & 8 & 0 & 263 & 0 & 0 & 18 & 3 & 0 & 1 & 9 & 0 & 9 \\
\hline PHRN & 151 & 4 & 8 & 0 & 6 & 5 & 0 & 0 & 1 & 0 & 0 & 1 & 1 & 2 \\
\hline C26 & 20 & 0 & 1 & 0 & 2 & 1 & 0 & 1 & 0 & 0 & 0 & 1 & 0 & 0 \\
\hline
\end{tabular}

Table E-1 continued 


\begin{tabular}{|l|l|l|l|l|l|l|}
\hline Site & $\begin{array}{l}\text { Shannon } \\
\text { H }\end{array}$ & Equitability & $\begin{array}{l}\text { Simpson's } \\
\text { Index }\end{array}$ & $\begin{array}{l}\text { Simpson's } \\
\text { Diversity }\end{array}$ & $\begin{array}{l}\text { Berger } \\
\text { Parker }\end{array}$ & $\begin{array}{l}\text { Hill } \\
\text { Number }\end{array}$ \\
\hline SPS & 2.396005 & 0.321159 & 0.123384 & 0.876616 & 0.235328 & 10.97923 \\
\hline PK & 2.585307 & 0.458812 & 0.101741 & 0.898259 & 0.182143 & 13.26736 \\
\hline PHR-1 & 2.023345 & 0.227193 & 0.211287 & 0.788713 & 0.333966 & 7.563585 \\
\hline PHR-2 & 2.004194 & 0.227303 & 0.213754 & 0.786246 & 0.320593 & 7.420114 \\
\hline PHRN & 1.716795 & 0.189945 & 0.286783 & 0.713217 & 0.448931 & 5.566659 \\
\hline C26 & 2.152873 & 0.415021 & 0.157806 & 0.842194 & 0.312849 & 8.609562 \\
\hline
\end{tabular}

Table E-2: Diversity indices for microsites of the Foremost Formation of Alberta based on data from Table E-1.

\begin{tabular}{|l|l|l|l|l|l|}
\hline $\begin{array}{l}\text { Abrasion Stage } \\
\text { Stage 0 }\end{array}$ & Stage 1 & Stage 2 & Stage 3 & Stage 4 \\
\hline $\begin{array}{l}\text { Number of } \\
\text { Elements }\end{array}$ & 296 & 559 & 180 & 53 & 0 \\
\hline
\end{tabular}

Table E-3: Abrasion stages of material from C26. Total number of elements is 1088. 


\begin{tabular}{|l|l|l|l|}
\hline & Inland & Mixed & Coastal \\
\hline SPS & 713 & 558 & 419 \\
\hline PK & 3 & 190 & 82 \\
\hline PHR-1 & 266 & 3411 & 3691 \\
\hline PHR-2 & 438 & 1647 & 4645 \\
\hline PHRN & 347 & 421 & 7647 \\
\hline C26 & 7 & 69 & 103 \\
\hline
\end{tabular}

Table E-4: Relative distribution of palaeocommunities of Cullen et al. (2016) within Foremost Formation microsites based on the data from Table E-1.

\begin{tabular}{|l|l|l|l|}
\hline & Inland & Mixed & Coastal \\
\hline DPF & 35.9703 & 37.59369 & 26.25839 \\
\hline OM & 55.95316 & 39.41444 & 4.333116 \\
\hline OMMR & 50.04758 & 46.73056 & 2.970364 \\
\hline FF & 7.582249 & 25.31323 & 67.03985 \\
\hline OMMR Upper & 56.13327 & 40.90385 & 2.559373 \\
\hline OMMR Lower & 41.30507 & 55.10103 & 3.560782 \\
\hline DPF Post LCZ & 0.089445 & 0.626118 & 99.04592 \\
\hline DPF Pre LCZ & 40.82349 & 42.59386 & 16.41328 \\
\hline
\end{tabular}

Table E-5: Relative distribution of palaeocommunities of Cullen et al. (2016) in the Belly River Group formations based on the data from Table E-6. 


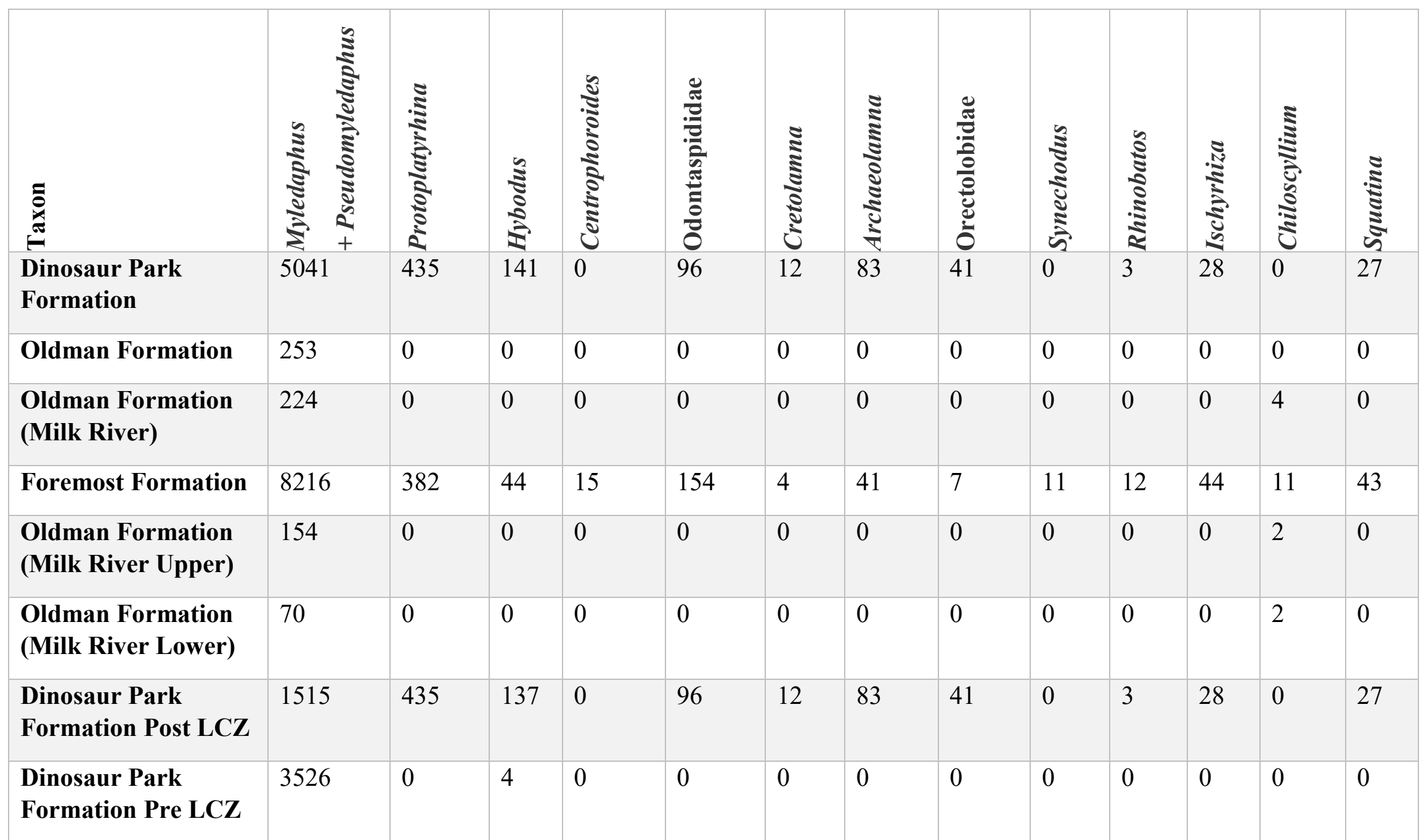

Table E-6: Counts of identifiable fossil elements from vertebrate microsites of the Belly River Group. Left most column contains site names. Data compiled from this study (Site C26) and Cullen and Evans (2016). 


\begin{tabular}{|c|c|c|c|c|c|c|c|c|c|c|c|c|c|}
\hline Taxon & 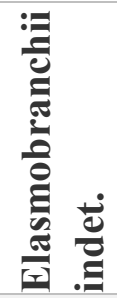 & 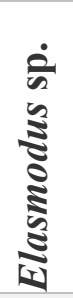 & 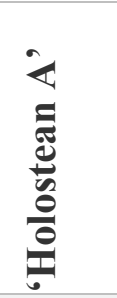 & 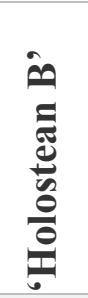 & 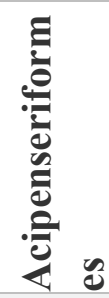 & 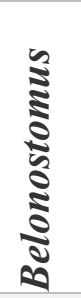 & 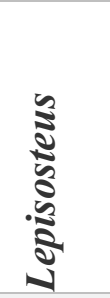 & 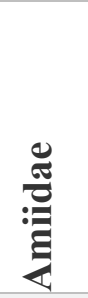 & 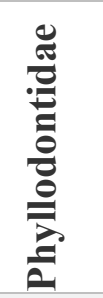 & $\frac{\sqrt{3}}{\sqrt[3]{2}}$ & 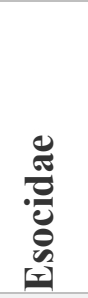 & 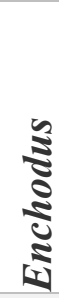 & $\frac{\sqrt[3]{2}}{3}$ \\
\hline $\begin{array}{l}\text { Dinosaur Park } \\
\text { Formation }\end{array}$ & 6 & 45 & 4011 & 226 & 124 & 115 & 4688 & 377 & 1093 & 2 & 138 & 4 & 495 \\
\hline Oldman Formation & 0 & 0 & 1376 & 0 & 20 & 21 & 687 & 80 & 59 & 0 & 65 & 0 & 293 \\
\hline $\begin{array}{l}\text { Oldman Formation } \\
\text { (Milk River) }\end{array}$ & 0 & 0 & 592 & 34 & 16 & 17 & 2642 & 127 & 162 & 0 & 145 & 0 & 470 \\
\hline $\begin{array}{l}\text { Foremost } \\
\text { Formation }\end{array}$ & 692 & 4 & 353 & 638 & 131 & 345 & 3708 & 33 & 5616 & 0 & 40 & 1 & 62 \\
\hline $\begin{array}{l}\text { Oldman Formation } \\
\text { (Milk River } \\
\text { Upper) }\end{array}$ & 0 & 0 & 367 & 0 & 0 & 6 & 625 & 74 & 62 & 0 & 112 & 0 & 220 \\
\hline $\begin{array}{l}\text { Oldman Formation } \\
\text { (Milk River } \\
\text { Lower) }\end{array}$ & 0 & 0 & 225 & 34 & 16 & 11 & 2017 & 53 & 100 & 0 & 33 & 0 & 250 \\
\hline $\begin{array}{l}\text { Dinosaur Park } \\
\text { Formation Post } \\
\text { LCZ }\end{array}$ & 6 & 45 & 0 & 0 & 15 & 0 & 0 & 0 & 894 & 0 & 0 & 4 & 0 \\
\hline $\begin{array}{l}\text { Dinosaur Park } \\
\text { Formation Pre } \\
\text { LCZ }\end{array}$ & 0 & 0 & 4011 & 226 & 109 & 115 & 4688 & 377 & 199 & 2 & 138 & 0 & 495 \\
\hline
\end{tabular}

Table E-6 continued 


\begin{tabular}{|c|c|c|c|c|c|c|c|c|c|c|c|c|c|c|}
\hline Taxon & 预 & 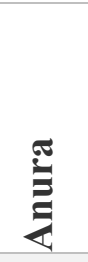 & 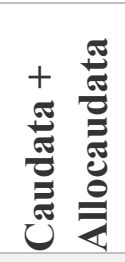 & 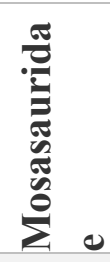 & 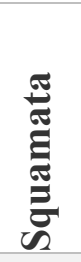 & 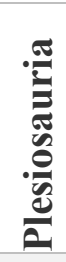 & : & 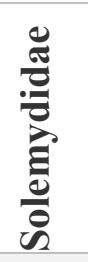 & 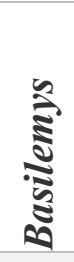 & 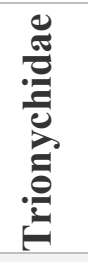 & 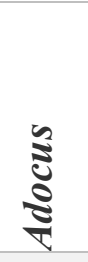 & 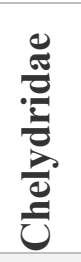 & 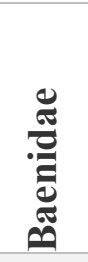 & 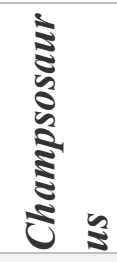 \\
\hline $\begin{array}{l}\text { Dinosaur Park } \\
\text { Formation }\end{array}$ & 1263 & 605 & 3237 & 1 & 312 & 3 & 0 & 0 & 7 & 346 & 0 & 83 & 172 & 623 \\
\hline Oldman Formation & 610 & 306 & 1570 & 0 & 127 & 0 & 0 & 0 & 0 & 84 & 0 & 17 & 38 & 102 \\
\hline $\begin{array}{l}\text { Oldman Formation } \\
\text { (Milk River) }\end{array}$ & 1644 & 961 & 3424 & 0 & 271 & 0 & 0 & 0 & 0 & 146 & 47 & 117 & 109 & 374 \\
\hline $\begin{array}{l}\text { Foremost } \\
\text { Formation }\end{array}$ & 710 & 100 & 578 & 1 & 35 & 0 & 3 & 319 & 2 & 160 & 176 & 27 & 123 & 452 \\
\hline $\begin{array}{l}\text { Oldman Formation } \\
\text { (Milk River Upper) }\end{array}$ & 920 & 697 & 2479 & 0 & 122 & 0 & 0 & 0 & 0 & 98 & 7 & 96 & 78 & 92 \\
\hline $\begin{array}{l}\text { Oldman Formation } \\
\text { (Milk River Lower) }\end{array}$ & 724 & 264 & 945 & 0 & 149 & 0 & 0 & 0 & 0 & 48 & 40 & 21 & 31 & 282 \\
\hline $\begin{array}{l}\text { Dinosaur Park } \\
\text { Formation Post } \\
\text { LCZ }\end{array}$ & 3 & 0 & 0 & 1 & 0 & 3 & 0 & 0 & 0 & 0 & 0 & 0 & 0 & 1 \\
\hline $\begin{array}{l}\text { Dinosaur Park } \\
\text { Formation Pre } \\
\text { LCZ }\end{array}$ & 1260 & 605 & 3237 & 0 & 312 & 0 & 0 & 0 & 7 & 346 & 0 & 83 & 172 & 622 \\
\hline
\end{tabular}

Table E-6 continued 


\begin{tabular}{|c|c|c|c|c|c|c|c|c|c|c|c|c|c|c|}
\hline Taxon & 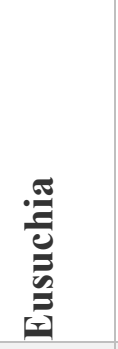 & 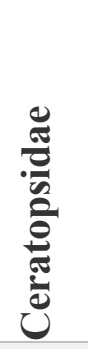 & 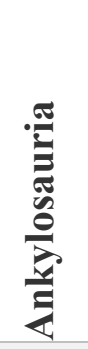 & 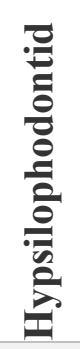 & 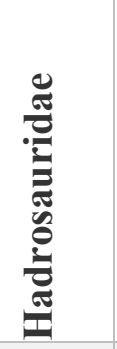 & 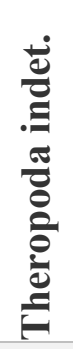 & 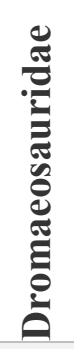 & 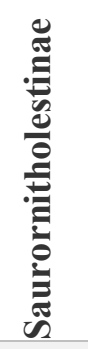 & 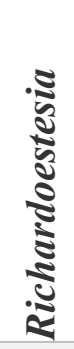 & 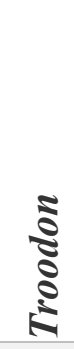 & 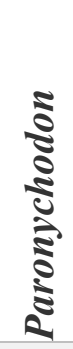 & 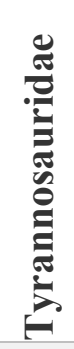 & $\sum_{\ddot{U}}^{\infty}$ & \\
\hline $\begin{array}{l}\text { Dinosaur Park } \\
\text { Formation }\end{array}$ & 1073 & 159 & 351 & 12 & 2234 & 0 & 16 & 231 & 0 & 12 & 0 & 31 & 1 & 148 \\
\hline Oldman Formation & 196 & 14 & 521 & 8 & 1087 & 0 & 4 & 65 & 0 & 11 & 0 & 14 & 0 & 57 \\
\hline $\begin{array}{l}\text { Oldman Formation } \\
\text { (Milk River) }\end{array}$ & 603 & 153 & 42 & 11 & 1979 & 0 & 4 & 144 & 23 & 22 & 16 & 37 & 22 & 130 \\
\hline Foremost Formation & 587 & 72 & 33 & 5 & 617 & 6 & 0 & 32 & 7 & 0 & 3 & 20 & 7 & 60 \\
\hline $\begin{array}{l}\text { Oldman Formation } \\
\text { (Milk River Upper) }\end{array}$ & 406 & 119 & 37 & 9 & 1576 & 0 & 4 & 112 & 21 & 22 & 12 & 29 & 17 & 99 \\
\hline $\begin{array}{l}\text { Oldman Formation } \\
\text { (Milk River Lower) }\end{array}$ & 197 & 34 & 5 & 2 & 403 & 0 & 0 & 32 & 2 & 0 & 4 & 8 & 5 & 31 \\
\hline $\begin{array}{l}\text { Dinosaur Park } \\
\text { Formation Post LCZ }\end{array}$ & 2 & 1 & 0 & 0 & 0 & 0 & 0 & 0 & 0 & 0 & 0 & 0 & 1 & 1 \\
\hline $\begin{array}{l}\text { Dinosaur Park } \\
\text { Formation Pre LCZ }\end{array}$ & 1071 & 158 & 351 & 12 & 2234 & 0 & 16 & 231 & 0 & 12 & 0 & 31 & 0 & 147 \\
\hline
\end{tabular}

Table E-6 continued 


\begin{tabular}{|l|l|l|l|l|l|l|}
\hline Formation & $\begin{array}{l}\text { Shannon- } \\
\text { Wiener }\end{array}$ & Equitability & $\begin{array}{l}\text { Simpson's } \\
\text { Index }\end{array}$ & $\begin{array}{l}\text { Simpson's } \\
\text { Diversity }\end{array}$ & $\begin{array}{l}\text { Berger } \\
\text { Parker }\end{array}$ & $\begin{array}{l}\text { Hill } \\
\text { Number }\end{array}$ \\
\hline $\begin{array}{l}\text { Foremost } \\
\text { Formation }\end{array}$ & 2.223786 & 0.219823 & 0.1896 & 0.8104 & 0.332067 & 9.242258 \\
\hline Oldman Formation & 2.45874 & 0.274811 & 0.118336 & 0.881664 & 0.204294 & 11.69007 \\
\hline $\begin{array}{l}\text { Dinosaur Park } \\
\text { Formation }\end{array}$ & 2.624925 & 0.256207 & 0.107021 & 0.892979 & 0.17907 & 13.80354 \\
\hline $\begin{array}{l}\text { Dinosaur Park } \\
\text { Formation Pre LCZ }\end{array}$ & 2.500328 & 0.247105 & 0.114545 & 0.885455 & 0.189055 & 12.1865 \\
\hline $\begin{array}{l}\text { Dinosaur Park } \\
\text { Formation Post LCZ }\end{array}$ & 1.589712 & 0.195828 & 0.295296 & 0.704704 & 0.451699 & 4.902336 \\
\hline $\begin{array}{l}\text { Oldman Formation } \\
\text { (Milk River) }\end{array}$ & 2.459048 & 0.256246 & 0.127574 & 0.872426 & 0.232735 & 11.69368 \\
\hline $\begin{array}{l}\text { Oldman Formation } \\
\text { (Milk River Lower) }\end{array}$ & 2.31072 & 0.265422 & 0.164442 & 0.835558 & 0.334051 & 10.08168 \\
\hline $\begin{array}{l}\text { Oldman Formation } \\
\text { (Milk River Upper) }\end{array}$ & 2.349676 & 0.259115 & 0.143898 & 0.856102 & 0.285797 & 10.48217 \\
\hline
\end{tabular}

Table E-7: Diversity indices for microsites of the Belly River Group of Alberta based on data from Table E-6. 


\begin{tabular}{|l|l|l|l|l|l|l|}
\hline Formation & $\begin{array}{l}\text { Shannon- } \\
\text { Wiener }\end{array}$ & Equitability & $\begin{array}{l}\text { Simpson's } \\
\text { Index }\end{array}$ & $\begin{array}{l}\text { Simpson's } \\
\text { Diversity }\end{array}$ & $\begin{array}{l}\text { Berger } \\
\text { Parker }\end{array}$ & $\begin{array}{l}\text { Hill } \\
\text { Number }\end{array}$ \\
\hline $\begin{array}{l}\text { Foremost } \\
\text { Formation }\end{array}$ & 0.899748 & 0.134726 & 0.614214 & 0.385786 & 0.776101 & 2.458984 \\
\hline Oldman Formation & 0.925464 & 0.124183 & 0.490196 & 0.509804 & 0.63051 & 2.523039 \\
\hline $\begin{array}{l}\text { Dinosaur Park } \\
\text { Formation }\end{array}$ & 0.943993 & 0.117682 & 0.559679 & 0.440321 & 0.733421 & 2.570224 \\
\hline $\begin{array}{l}\text { Oldman Formation } \\
\text { (Milk River) }\end{array}$ & 0.797458 & 0.10229 & 0.67081 & 0.32919 & 0.814068 & 2.219892 \\
\hline $\begin{array}{l}\text { Oldman Formation } \\
\text { (Milk River Lower) }\end{array}$ & 0.722218 & 0.116592 & 0.68533 & 0.31467 & 0.822449 & 2.058995 \\
\hline $\begin{array}{l}\text { Oldman Formation } \\
\text { (Milk River Upper) }\end{array}$ & 0.812046 & 0.107258 & 0.66708 & 0.33292 & 0.811953 & 2.252512 \\
\hline $\begin{array}{l}\text { Dinosaur Park } \\
\text { Formation Post LCZ }\end{array}$ & 0 & 0 & 0 & 0 & 0 & 0 \\
\hline $\begin{array}{l}\text { Dinosaur Park } \\
\text { Formation Pre LCZ }\end{array}$ & 0.943332 & 0.117604 & 0.560012 & 0.439988 & 0.733662 & 2.568527 \\
\hline
\end{tabular}

Table E-8: Diversity indices for dinosaur microsite material of the Belly River Group of Alberta based on data from Table E-6. 


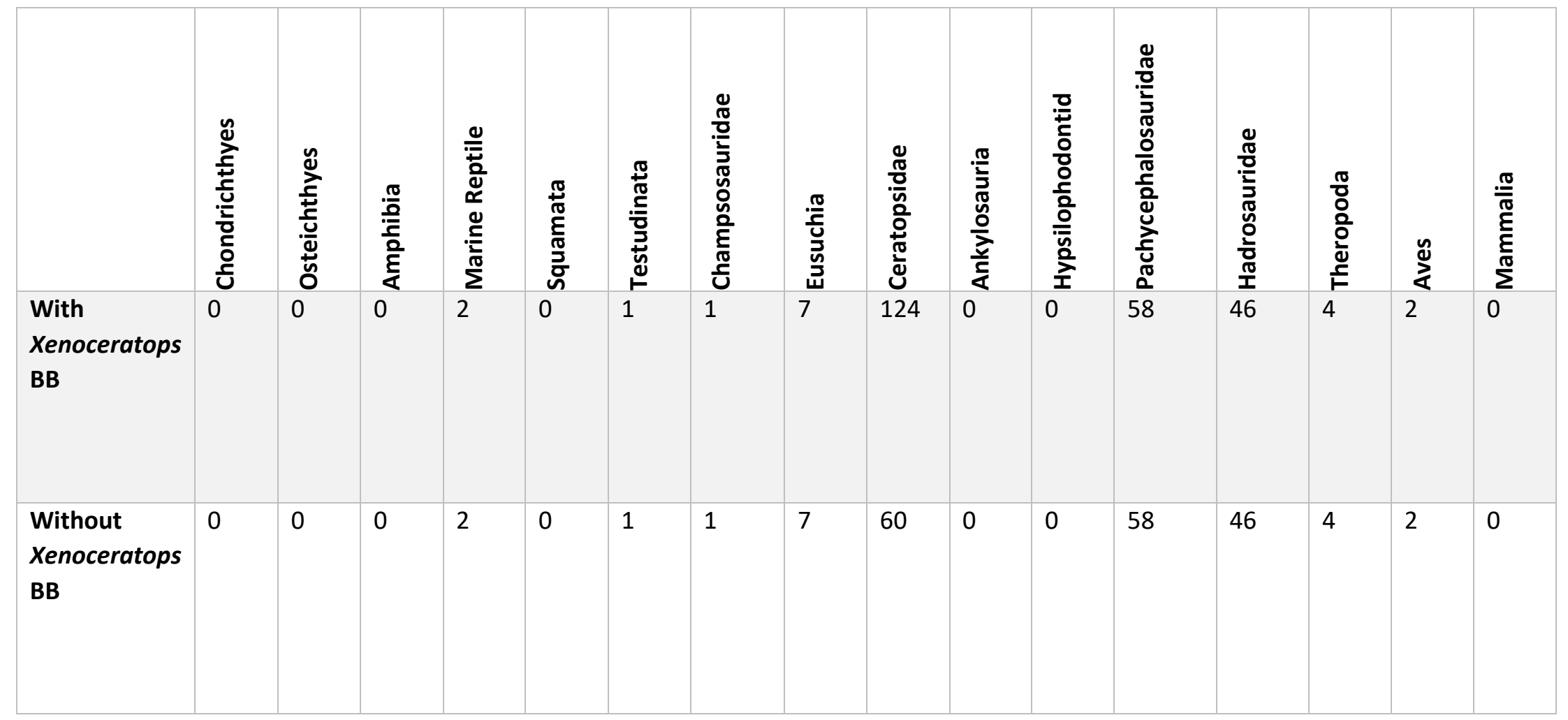

Table E-9: Macrofossil material counts from the Foremost Formation of Alberta based on the databases from the Canadian Museum of Nature, Royal Ontario Museum and Royal Tyrrell Museum. 


\begin{tabular}{|l|l|l|}
\hline Catalogue Number & Element & Locality Name \\
\hline TMP1977.010.0002 & JAW & Grassy Lake \\
\hline TMP1978.009.0015 & TARSAL & Lost River \\
\hline TMP1988.060.0018 & VERTEBRA-CERVICAL & White Rock Coulee \\
\hline TMP1990.155.0006 & JAW & Grassy Lake \\
\hline TMP1998.068.0175 & VERTEBRA & \\
\hline TMP1999.063.0013 & VERTEBRA-CAUDAL, & Milk River Canyon-Calib Coulee \\
\hline TMP2005.061.0030 & TENDON, RIB & \\
\hline TMP2007.035.0022 & CALCANEUM & Wendy's Site \\
\hline
\end{tabular}

Table E-10: Undescribed hadrosaur macrofossil material from the Foremost Formation. Information provided by the Royal Tyrrell Museum of Palaeontology in Drumheller, Alberta, Canada. 


\begin{tabular}{|l|l|l|}
\hline Catalogue Number & Element & Locality Name \\
\hline TMP2007.035.0023 & VERTEBRA-CAUDAL & Chin Coulee \\
\hline TMP2007.035.0063 & ASTRAGALUS & Chin Lake \\
\hline TMP2009.060.0001 & VERTEBRA-CAUDAL & Bow River - Torkelson Site \\
\hline TMP2010.120.0007 & METATARSAL & Hays \\
\hline TMP2010.120.0009 & VERTEBRA & Hays \\
\hline TMP2012.011.0002 & VERTEBRA-CAUDAL & Stantec - Bow Island Reclamation Site BI1 \\
\hline TMP2012.039.0047 & PROOTIC & Milk River Natural Area \\
\hline
\end{tabular}

Table E-10 continued 


\begin{tabular}{|c|c|c|}
\hline Hadrosauroid Taxa & Formation & Age \\
\hline Hadrosaurus foulkii & $\begin{array}{l}\text { Woodbury Fm., } \\
\text { Haddonfield, New } \\
\text { Jersey, USA }\end{array}$ & $\begin{array}{l}\text { Campanian ( 83 Ma) } \\
\text { (Prieto- Márquez et } \\
\text { al., 2006b) }\end{array}$ \\
\hline Lophorhothon atopus & $\begin{array}{l}\text { Mooreville Chalk Fm. } \\
\text { (lower unnamed } \\
\text { member), Alabama, } \\
\text { USA }\end{array}$ & $\begin{array}{l}\text { Santonian- } \\
\text { Campanian } \\
\text { boundary ( 83Ma) } \\
\text { (Prieto- Márquez, } \\
\text { 2010) }\end{array}$ \\
\hline
\end{tabular}

Table E-11: List of Known Campanian Basal Hadrosauroids from North America for age comparisons to the material described in this study. 


\begin{tabular}{|l|l|l|}
\hline Saurolophine Taxon & Formation & Age \\
\hline Gryposaurus latidens & $\begin{array}{l}\text { Lower Two Medicine } \\
\text { Fm., Montana, USA }\end{array}$ & $\begin{array}{l}\text { Late Santonian to early } \\
\text { Campanian ( 84 Ma) (Horner } \\
\text { et al., 1992) }\end{array}$ \\
\hline Acristavus gagslarsoni & $\begin{array}{l}\text { Two Medicine Fm., } \\
\text { Montana, USA; } \\
\text { Wahweap Fm., Utah, } \\
\text { USA. }\end{array}$ & $\begin{array}{l}\text { Early to mid-Campanian ( 81 } \\
\text { Ma) (Gates et al., 2011) }\end{array}$ \\
\hline Probrachylophosaurus bergei & $\begin{array}{l}\text { Judith River Fm., } \\
\text { Montana, USA }\end{array}$ & $\begin{array}{l}\text { Middle Campanian ( 78 Ma) } \\
\text { (Freedman-Fowler and Horner, } \\
\text { 2015) }\end{array}$ \\
\hline Brachylophosaurus canadensis & $\begin{array}{l}\text { Judith River Fm., } \\
\text { Montana, USA; Oldman } \\
\text { Fm., Alberta, Canada }\end{array}$ & $\begin{array}{l}\text { Late Campanian ( 77 Ma) } \\
\text { LaRock, 2000) }\end{array}$ \\
\hline Maiasaura peeblesorum & $\begin{array}{l}\text { Upper Two Medicine } \\
\text { Fm., Montana, USA }\end{array}$ & $\begin{array}{l}\text { Mid to late Campanian ( 76 } \\
\text { Ma) (Horner et al., 2004) }\end{array}$ \\
\hline Prosaurolophus maximus & $\begin{array}{l}\text { Dinosaur Park Fm., } \\
\text { Alberta, Canada }\end{array}$ & $\begin{array}{l}\text { Late Campanian ( 76 to 72 Ma) } \\
\text { (Evans, 2007b) }\end{array}$ \\
\hline Prosaurolophus blackfeetensis & $\begin{array}{l}\text { Upper Two Medicine } \\
\text { Fm., Montana, USA }\end{array}$ & $\begin{array}{l}\text { Mid to late Campanian ( 76 to } \\
\text { 72 Ma) (Horner, 1992) }\end{array}$ \\
\hline Gryposaurus notabilis & $\begin{array}{l}\text { Dinosaur Park Fm., } \\
\text { Alberta, Canada }\end{array}$ & $\begin{array}{l}\text { Late Campanian ( 76-72 Ma) } \\
\text { (Evans, 2007b) }\end{array}$ \\
\hline
\end{tabular}

Table E-12: List of Known Campanian Saurolophine Hadrosaurid taxa from North America for age comparisons to the material described in this study. 


\begin{tabular}{|l|l|l|}
\hline Gryposaurus monumentensis & $\begin{array}{l}\text { Kaiparowits Fm., Utah, } \\
\text { USA }\end{array}$ & $\begin{array}{l}\text { Late Campanian ( 76 to 74 Ma) } \\
\text { (Gates and Sampson, 2007) }\end{array}$ \\
\hline UTEP 37.7 & Aguja Fm., Texas, USA & $\begin{array}{l}\text { Late Campanian ( 76 to 72 Ma) } \\
\text { (Wagner, 2001) }\end{array}$ \\
\hline Rhinorex condrupus & Neslen Fm., Utah, USA & $\begin{array}{l}\text { Late Campanian ( 75 Ma) (Gates } \\
\text { and Sheetz, 2014) }\end{array}$ \\
\hline Kritosaurus horneri & $\begin{array}{l}\text { Kirtland Fm., New Mexico, } \\
\text { USA }\end{array}$ & $\begin{array}{l}\text { Late Campanian ( 74.5 to 73 Ma) } \\
\text { (Lund and Gates, 2006) }\end{array}$ \\
\hline Kritosaurus navajovius & $\begin{array}{l}\text { Kirtland Fm., New Mexico, } \\
\text { USA }\end{array}$ & $\begin{array}{l}\text { Late Campanian ( 74.5 to 73 Ma) } \\
\text { (Sullivan, 1999) }\end{array}$ \\
\hline Naashoibitosaurus ostromi & $\begin{array}{l}\text { Kirtland Fm, New Mexico, } \\
\text { USA }\end{array}$ & $\begin{array}{l}\text { Late Campanian ( 74.5 to 73 Ma) } \\
\text { (Lund and Gates, 2006) }\end{array}$ \\
\hline Latirhinus uitstlani & $\begin{array}{l}\text { Cerro de Pueblo Fm., } \\
\text { Coahuila, Mexico }\end{array}$ & $\begin{array}{l}\text { Late Campanian (72.5 to 71 Ma) } \\
\text { (Prieto-Márquez and Brañas, 2012) }\end{array}$ \\
\hline
\end{tabular}




\begin{tabular}{|l|l|l|}
\hline Lambeosaurine Taxa & Formation & Age \\
\hline Adelolophus hutchisoni & Wahweap Fm., Utah, USA & $\begin{array}{l}\text { Mid Campanian ( 78 Ma) (Gates } \\
\text { et al., 2014) }\end{array}$ \\
\hline Corythosaurus casuarius & $\begin{array}{l}\text { Dinosaur Park Fm., Alberta, } \\
\text { Canada }\end{array}$ & $\begin{array}{l}\text { Late Campanian ( 77 to } 75 \text { Ma) } \\
\text { (Evans, 2007b) }\end{array}$ \\
\hline Corythosaurus intermedius & $\begin{array}{l}\text { Dinosaur Park Fm., Alberta, } \\
\text { Canada }\end{array}$ & $\begin{array}{l}\text { Late Campanian ( 77 to 75 Ma) } \\
\text { (Evans, 2007b) }\end{array}$ \\
\hline Lambeosaurus lambei & $\begin{array}{l}\text { Dinosaur Park Fm., Alberta, } \\
\text { Canada }\end{array}$ & $\begin{array}{l}\text { Late Campanian ( 76 to } 75 \text { Ma) } \\
\text { (Evans, 2007b) }\end{array}$ \\
\hline Lambeosaurus magnicristatus & $\begin{array}{l}\text { Dinosaur Park Fm., Alberta, } \\
\text { Canada }\end{array}$ & $\begin{array}{l}\text { Late Campanian ( 76 to 75 Ma) } \\
\text { (Evans, 2007b) }\end{array}$ \\
\hline Parasaurolophus walkeri & $\begin{array}{l}\text { Dinosaur Park Fm., Alberta, } \\
\text { Canada }\end{array}$ & $\begin{array}{l}\text { Late Campanian ( 76 to 74 Ma) } \\
\text { (Evans, 2007b) }\end{array}$ \\
\hline Parasaurolophus tubicen & $\begin{array}{l}\text { Lower Kirtland Fm., New Mexico, } \\
\text { USA }\end{array}$ & $\begin{array}{l}\text { Late Campanian ( 76 to 74 Ma) } \\
\text { (Horner et al., 2004) }\end{array}$ \\
\hline Parasaurolphus cyrtocristatus & $\begin{array}{l}\text { Fruitland Fm., New Mexico, USA; } \\
\text { Kaiparowits Fm., Utah, USA }\end{array}$ & $\begin{array}{l}\text { Late Campanian ( 76 to 74 Ma) } \\
\text { (Horner et al., 2004) }\end{array}$ \\
\hline Angulomastacator daviesi & \begin{tabular}{l} 
Aguja Fm., Texas, USA \\
\hline
\end{tabular} & $\begin{array}{l}\text { Late Campanian ( 76 to 72 Ma) } \\
\text { (Wagner \& Lehman, 2009) }\end{array}$ \\
\hline
\end{tabular}

Table E-13: List of Known Campanian Lambeosaurine Hadrosaurid taxa from North America for age comparisons to the material described in this study. 